UNIVERSIDADE DE SÃO PAULO

FFCLRP - DEPARTAMENTO DE BIOLOGIA

PROGRAMA DE PÓS-GRADUAÇÃO EM ENTOMOLOGIA

\title{
Revisão taxonômica e análise cladística de Acrochaeta \\ Wiedemann, 1830 (Diptera: Stratiomyidae: Sarginae), com considerações sobre a monofilia de Merosargus
} Loew, 1855

\author{
DIEGO AGUILAR FACHIN
}

Dissertação apresentada à Faculdade de Filosofia, Ciências e Letras de Ribeirão Preto da USP, como parte das exigências para a obtenção do título de Mestre em Ciências, Área: Entomologia

RIBEIRÃO PRETO-SP 
UNIVERSIDADE DE SÃO PAULO

FFCLRP - DEPARTAMENTO DE BIOLOGIA

PROGRAMA DE PÓS-GRADUAÇÃO EM ENTOMOLOGIA

\section{Revisão taxonômica e análise cladística de Acrochaeta \\ Wiedemann, 1830 (Diptera: Stratiomyidae: Sarginae), com considerações sobre a monofilia de Merosargus} Loew, 1855

\section{DIEGO AGUILAR FACHIN}

Orientador: Dalton de Souza Amorim

Dissertação apresentada à Faculdade de Filosofia, Ciências e Letras de Ribeirão Preto da USP, como parte das exigências para a obtenção do título de Mestre em Ciências, Área: Entomologia

RIBEIRÃO PRETO-SP 
Autorizo a reprodução total ou parcial deste trabalho para fins de estudo didático e científico, desde que citada a fonte.

FICHA CATALOGRÁFICA

Fachin, Diego Aguilar

Revisão taxonômica e análise cladística de Acrochaeta Wiedemann, 1830 (Diptera: Stratiomyidae: Sarginae), com considerações sobre a monofilia de Merosargus Loew, 1855 / Diego Aguilar Fachin. - 2014.

173 f.: il.

Orientador: Dalton de Souza Amorim.

Dissertação de Mestrado, apresentada à Faculdade de Filosofia, Ciências e Letras de Ribeirão Preto - USP, área de concentração: Entomologia.

1. Taxonomia. 2. Sistemática Filogenética. 3. Diptera. 4. Stratiomyidae. 5. Acrochaeta. 
Dedico aos meus pais que me ajudaram muito, mas que não tiveram as mesmas oportunidades que eu tive. 


\section{AGRADECIMENTOS}

Agradeço ao meu orientador, Dalton de Souza Amorim, não apenas pela orientação ao longo desses dois anos, mas também pela oportunidade, confiança e pela amizade. Já são cinco anos de muitos ensinamentos, tanto no âmbito acadêmico quanto no profissional.

Sou muito grato aos meus pais e minha irmã pelo incentivo em continuar com meus estudos, mesmo quando as coisas pareciam tão difíceis. O esforço deles (financeiro, mental etc.) foi fundamental para a conclusão do meu trabalho.

À Bel, por acreditar na minha capacidade e por sempre me "proteger". Você é uma pessoa muito boa, com um coração muito grande, essencial para o bom andamento do laboratório e sempre fundamental na preparação das lâminas e das demais técnicas.

À Rafaela Lopes Falaschi, pelos puxões de orelha estratégicos, pelas boas conversas, por me ajudar a organizar o laboratório e a mesa da Bel, e pelos elogios sinceros.

Ao Mateus Henrique Santos, pela força quando precisei e pela amizade.

Agradeço ao pessoal do laboratório de Morfologia e Evolução de Diptera, Sarah Siqueira de Oliveira, Renato Capellari e Marco Marinho, pela amizade e pela disposição em ajudar sempre. Em especial, agradeço a ala mais jovem do laboratório (Bel, eu já fiz o meu agradecimento a você, mesmo você sendo da parte mais jovem) pela grande amizade além dos limites da vida acadêmica: Caleb Califre Martins, por me ajudar no preparo de armadilhas para a Bel e também por me ajudar a manter tudo na devida ordem; Paula Raile Riccardi pelo papel de irmã mais velha, sempre dando bons conselhos e broncas também; ao Danilo César Ament, por me ajudar em praticamente tudo, pelas boas horas de conversa e por me lembrar sempre dos mais famosos bordões; e à Gabi Pirani pelo papel de irmã mais nova, por me fazer perguntas pertinentes sobre o meu trabalho e pelas boas risadas em todos os momentos.

Agradeço com distinção também ao Diego Sasso Porto (Lester) pela sincera amizade nesses últimos três anos. Obrigado pela força e opinião em todas as coisas que tenho feito (manuscritos, monitorias, palestras etc.).

Ao professor José Roberto Pujol-Luz, por toda ajuda e ensinamentos em sistemática de Stratiomyidae e pela confiança depositada em mim ao longo dos últimos quatro anos. 
À professora Cristiane Vieira de Assis Pujol Luz, por me ajudar como coautora na preparação de alguns manuscritos para o Catálogo de Diptera da Colômbia, e à professora Marta Wolff pela oportunidade.

Ao professor Carlos José Einicker Lamas, por toda sua ajuda com empréstimos de material do Museu de Zoologia e de outras instituições e também pela oportunidade de trabalhar com o material de Sarginae do Sisbiota.

Ao Dr. Norman E. Woodley, do National Museu of Natural, Washington, D.C., por me receber em seu laboratório e por me ajudar com diversas questões e problemas em Stratiomyidae. Sou especialmente grato à Lucrecia Rodriguez e ao Daniel Perez, pessoas com um coração muito grande, que foram fundamentais durante o tempo que passei em Washington, D.C.

Agradeço ao Dr. Martin Hauser, do California State Collection of Arthropods, Sacramento, Califórnia, por me receber em seu laboratório e pelas demais pessoas, Darolyn, Cris Borkent e Brandi, que me receberam e prestaram um enorme auxílio durante minha visita em Sacramento, Califórnia.

Aos curadores e outros pesquisadores que prontamente me atenderam e emprestaram material de Stratiomyidae ao longo desses dois anos: Torsten Dikow (USNM), Erica Maclister (BMNH), Maria Elina Bichuette (UFSCar), Claudio José Barros de Carvalho (DZUP), Márcia Souto Couri (MNRJ), Jeffrey Skevington (CNC), Fabio Siqueira Pitaluga de Godoi (UFAM), Franziska Anderle (NMW) e a Marion Kotrba (ZSBS).

Ao Marcoandré Savaris por me fornecer importante material das suas coletas no Estado do Paraná.

Aos professores Eduardo Almeida, Vera Cristina Silva, Fernando Zucolloto, Flávio Bockmann e Annie Schmaltz Hsiou, pela amizade e pelos ensinamentos.

Aos funcionários da USP que sempre me ajudaram das mais diferentes maneiras: Renata Cavallari, Vera Cassia Cicilini de Lucca, Miriam Osório, Carlos Almada, Caique da Silva Della Motta, Juliano Oliveira Marquetti, Denise Aparecida Silveira, Maria Fabiana Cardoso e Cidinha.

Aos meus amigos queridos da $45^{\circ}$ turma, Vinícius (Gameta), Felipe, (Cenoia), Angelo (Luigi), João (Frango), Ricardo (Zuado), Nielson (Mixi), Luís Roberto (Amau), Gabriel (Fumaça), Guilherme (Úlcera), Mateus (Garçom), Ian (Piau), Danilo (Ghost), Juliana (Pupa), Ana Paula (Tênia), Ana Cristina (Ket), Letícia (Canjica) e Daniele (Loba), por serem grandes amigos, sempre próximos. 
A outras pessoas admiráveis de outras turmas da Biologia, Priscila (Tilápia), Rafael (Mestre), Murilo (Vaca), Robson (Johnny), Pedro (Tomate), Rafael (Sptz), Rafael (Miojo), Daniel do Carmo, Flávia (Sininho), pela enorme amizade ao longo desses anos.

Agradeço também aos outros tantos amigos que de alguma forma contribuíram com o meu trabalho: Lucas Testa, Assyr Neto de Carvalho, Jadson Alex Dantas Costa, Anderson Teixeira, Alana Brunini, Laura Rocha Prado, Gabriel Biffi, João Paulo Basso Alves, Lucas Lecci, Fábio Quinteiros, Denise Alves, Simeão Moraes, Priscila Okano, Lívia Pinheiro, Vanessa Roma, Caio Pires, André Micas, Karla Tepedino e Thiago Macedo.

A minha sogra, Bernadete Montebelli, e a meu sogro, Sisino Motta Neto, pelos bons momentos compartilhados em Ribeirão Preto e Piracicaba.

À FAPESP, pelos auxílios concedidos (Processos: 2011/14472-6 e 2013/02824$0)$.

Ao Departamento de Biologia e ao Programa de Pós-Graduação em Entomologia da Faculdade de Filosofia, Ciências e Letras de Ribeirão Preto.

E, por último, agradeço à Ana Elisa Montebelli Motta, por sempre estar do meu lado nesses últimos três anos. Obrigado por ser forte na minha ausência e por estar sempre presente quando estive preocupado e triste. Obrigado também pela compreensão, paciência e apoio, principalmente nos momentos difíceis. Eu te amo. 


\section{NOTA TAXONÔMICA}

Esta dissertação é parte dos requisitos para obtenção do título de Mestre no programa de pós-graduação em Ciências, área de concentração: Entomologia. Dessa forma, não é considerada uma publicação de acordo com os requisitos do Código Internacional de Nomenclatura Zoológica. Por isso, os nomes de táxons (espécies e grupos de espécies) e novas combinações aqui propostas são provisórios, não publicados de acordo com as regras do Código Internacional de Nomenclatura Zoológica (ICZN, 1999: Artigo 9) e, portanto, sem valor taxonômico perante as regras do Código (ICZN, 1999: Artigo 10), de modo que esses nomes não devem ser citados em nenhuma circunstância, devendo aguardar sua publicação regular em períodicos científicos 


\section{SUMÁRIO}

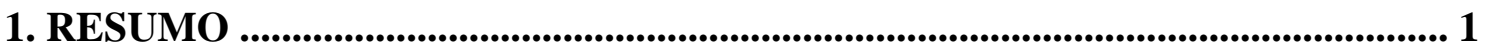

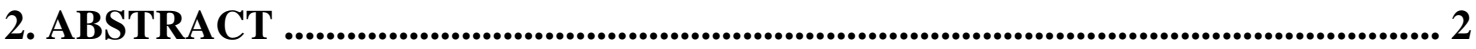

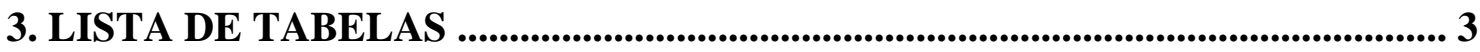

4. LISTA DE FIGURAS ....................................................................................................... 4

5. LISTA DE ACRÔNIMOS DAS INSTITUIÇÕES CITADAS NO TEXTO ........ 7

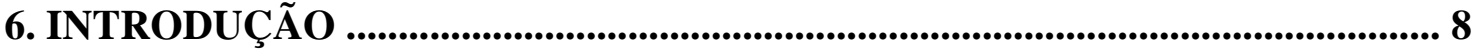

6.1. A família Stratiomyidae .............................................................................. 8

6.2. A subfamília Sarginae ......................................................................... 9

6.3. O gênero Acrochaeta Wiedemann, 1830 .............................................. 15

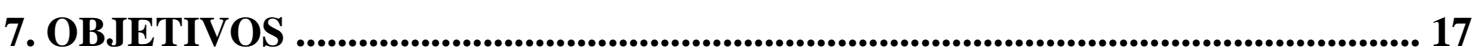

8. MATERIAL E MÉTODOS .......................................................................... 17

8.1. MATERIAL BIOLÓGICO ............................................................... 17

8.2. MÉTODOS _............................................................................................... 18

8.2.1. Identificação do material ........................................................ 18

8.2.2. Preparação e manuseio do material ......................................... 19

8.2.3. Descrição das espécies .............................................................. 19

8.2.4. Terminologia adotada .............................................................. 20

8.3. ANÁLISE CLADÍSTICA ......................................................................... 20

8.3.1. Amostragem taxonômica .................................................................. 20

8.3.2. Estudo dos caracteres ......................................................................... 21

8.3.3. Matriz e análise computacional .............................................. 21

8.4. MAPAS DE DISTRIBUIÇÃO ........................................................... 26

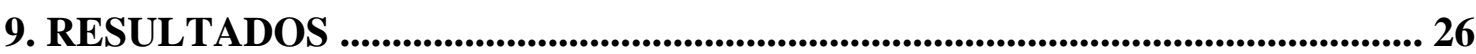

9.1. Revisão taxonômica .............................................................................................. 26

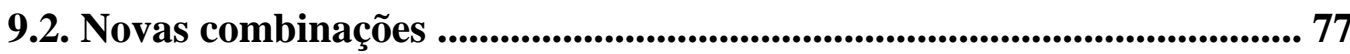

9.3. Chave de identificação para as espécies do gênero Acrochaeta.............. 80

9.4. Lista de caracteres ........................................................................... 102

9.5. Análise cladística ........................................................................ 113

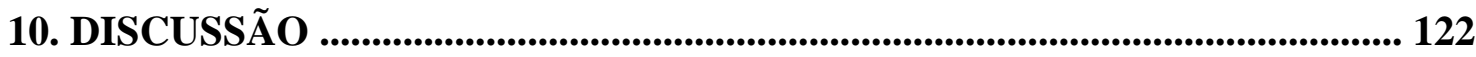

10.1. Relacionamento de Acrochaeta e Merosargus ........................................ 122 
10.2. Novas combinações: Merosargus picta, $M$. chalconota, M. longiventris e

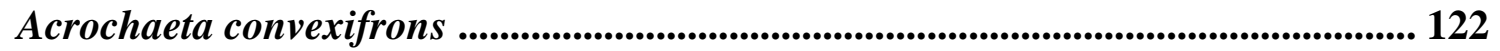

10.3. O posicionamento de Acrochaeta degenerata ..................................... 124

10.4. Grandes clados em Acrochaeta ............................................................... 125

10.5. O relacionamento dentro do grupo-flaveola .......................................... 125

10.6. A não-monofilia de Merosargus ........................................................... 126

10.7. O posicionamento de Merosargus mirabilis ............................................. 128

10.8. Evolução do comprimento do complexo flagelar ................................ 129

10.9. Evolução do padrão de coloração e características associadas .......... 130

10.10. Evolução dos singonocoxitos .............................................................. 130

10.11. Evolução do número de lóbulos do edeago ...................................... 131

10.12. Evolução do formato da parte anterior e do tamanho da abertura

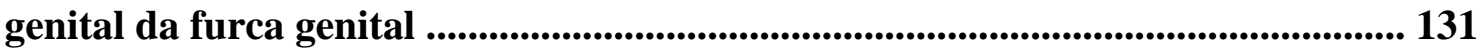

10.13. Considerações sobre as árvores obtidas com pesagem implícita .... 132

11. CONSIDERAÇÕES FINAIS 133

12. REFERÊNCIAS BIBLIOGRÁFICAS ................................................................. 164

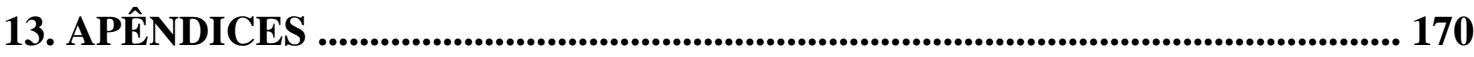

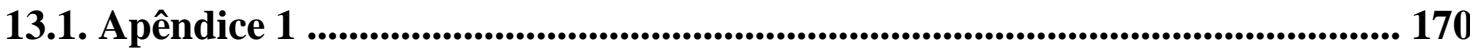




\section{RESUMO}

Dentre as doze subfamílias de Stratiomyidae, Sarginae conta com 22 gêneros e 562 espécies mundiais, sendo 267 destas neotropicais. Não há análise cladística para a subfamília e tão pouco para os gêneros. Boa parte dos gêneros em Sarginae são mal delimitados, com diagnoses baseadas principalmente em plesiomorfias. O gênero Acrochaeta enquadra-se nessa situação, uma vez que muitas espécies de Merosargus têm sido identificadas como pertencentes à Acrochaeta, por conta da presença de antenas longas e mesmo padrão de coloração no escudo entre as espécies de ambos os gêneros. Somam-se a isso, as imprecisões taxonômicas e morfológicas nas descrições das espécies de Acrochaeta e Merosargus, e a ausência de ilustrações de genitálias masculina e feminina, informação muito útil na delimitação dos gêneros. Para tanto, o presente trabalho realizou a revisão taxônomica e uma análise cladística de Acrochaeta com o objetivo de delimitar o gênero sob um ponto de vista filogenético. O gênero Acrochaeta com este estudo passa a ter 15 espécies conhecidas (sete já descritas e oito novas). No presente estudo, três espécies de Acrochaeta foram transferidas para Merosargus: $M$. chalconota comb. nov, $M$. longiventris comb. nov. e $M$. picta comb. nov. Outra foi transferida para Chrysochlorina (Chrysochlorininae): C. elegans comb. nov. Além disso, M. convexifrons foi transferida para Acrochaeta: A. convexifrons comb. nov. O gênero e as sete espécies conhecidas foram redescritas, e as novas espécies descritas. Uma chave dicotômica para espécies do gênero também é apresentada. A análise cladística contou com 45 táxons terminais e 63 caracteres morfológicos, obtendo quatro árvores mais parcimoniosas (pesagem igual). O consenso estrito dessas quatro árvores foi escolhido como referência para a discussão sobre os principais problemas de homologia, posicionamento de espécies, evolução de caracteres e formação de grupos de espécies dentro do gênero. A monofilia de Acrochaeta foi recuperada por caracteres de cabeça, tórax e abdômen. Um clado dentro do gênero foi bem caracterizado, principalmente por caracteres de genitália masculina. Além disso, a ampliação da amostragem fora do gênero permitiu obter resultados preliminares sobre a não-monofilia de Merosargus, uma vez que algumas espécies são mais próximas de Acrochaeta e Himantigera do que da espécie-tipo do gênero, Merosargus obscurus.

Palavras-chave: Acrochaeta, biodiversidade, taxonomia, sistemática filogenética, Stratiomyidae 


\section{ABSTRACT}

Among the twelve subfamilies of Stratiomyidae, the Sarginae include 22 genera and 562 described species worldwide, of which 267 are Neotropical. There is still not a cladistic analysis for the subfamily or to the genera. Most of the Sarginae genera are poorly delimited, with diagnosis based mainly on plesiomorphies. The Acrochaeta falls into this situation, because many species of Merosargus have been identified as Acrochaeta due to the presence of elongated antenna and the similar color pattern of scutum between species of both genera. In addition, there is taxonomic and morphological inaccuracy in descriptions of species of Acrochaeta and Merosargus, and lack of illustrations of male and female genitalias of the species, information that could be useful in the delimitation of the genera. This study, hence, makes a taxonomic revision and a cladistic analysis of the genus Acrochaeta, aiming to define the genus from phylogenetic perspective. The Acrochaeta now includes 15 species (seven described and eigth new species). In this study, three Acrochaeta species were transferred to Merosargus: $M$. chalconota comb. nov, M. longiventris comb. nov. and M. picta comb. nov. Another was moved to Chrysochlorina (Chrysochlorininae): $C$. elegans comb. nov. In addition, M. convexifrons were moved to Acrochaeta: A. convexifrons comb. nov. The genera Acrochaeta and all previously described species were redescribed, and the new species were described. An identification key to species of the genus is provided. A cladistic analysis is performed, 45 terminal taxa and 63 morphological characters, resulting in four most parsimonious trees (equal weighting). Problems of homology, the position of species in the topology, character evolution and robustness of clades are discussed based on the strict consensus phylogeny. The monophyly of Acrochaeta was recovered by characters of head, thorax and abdomen. An inner clade in the genus was recovered, especially based on characters of the male genitalia. Furthermore, a wide selection of outgroups allowed preliminary results on the non-monophyly of Merosargus, because some of its species being closer to Acrochaeta and Himantigera than a clade that includes the type-species of the genus, Merosargus obscurus.

Key words: Acrochaeta, biodiversity, taxonomy, phylogenetic systematics, Stratiomyidae 


\section{LISTA DE TABELAS}

Tabela 1. Números de espécies de Stratiomyidae por região biogeográfica e por subfamília .. 11 Tabela 2. Números de espécies de cada gênero de Sarginae por região biogeográfica e em cada gênero 13

Tabela 3. Lista dos táxons terminais utilizados e sua distribuição geográfica ........................... 24

Tabela 4. Matriz de dados com 63 caracteres e 45 táxons terminais utilizados na análise ..... 114

Tabela 5. Comparação entre número de passos, I.C. e I.R. para diferentes valores de $k$ para a matriz de dados 116

Tabela 6. Lista detalhada do material dissecado e analisado 171 


\section{LISTA DE FIGURAS}

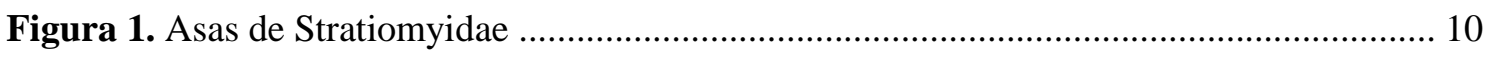

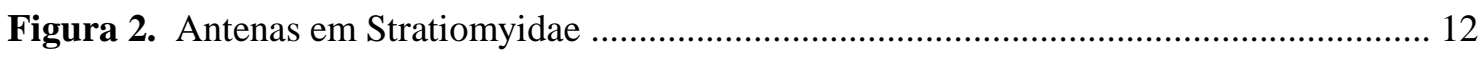

Figuras 3-6. Espécies de Merosargus (Sarginae) em habitus dorsal ...................................... 15

Figuras 7-10. Cabeça e tórax de espécies de Acrochaeta ............................................................ 31

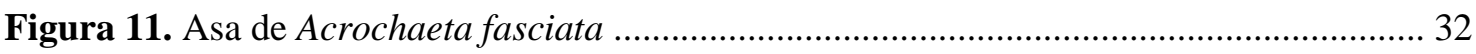

Figuras 12-14. Acrochaeta degenerata, fêmea ......................................................................... 34

Figuras 15-17. Acrochaeta asapha, sp. nov., holótipo fêmea ................................................. 36

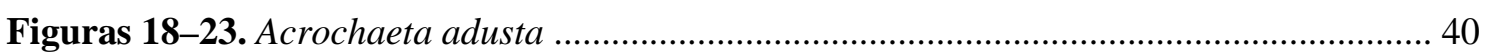

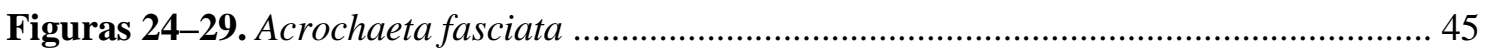

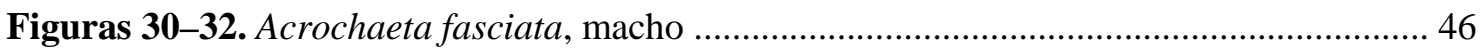

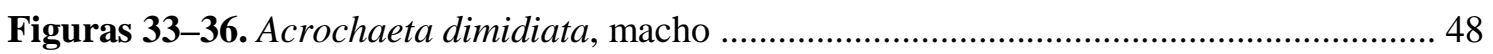

Figuras 37-42. Acrochaeta pseudopolychaeta, sp. nov. ........................................................ 51

Figuras 43-48. Acrochaeta polychaeta, sp. nov ................................................................... 54

Figuras 49-54. Acrochaeta convexifrons, comb. nov. ………............................................... 57

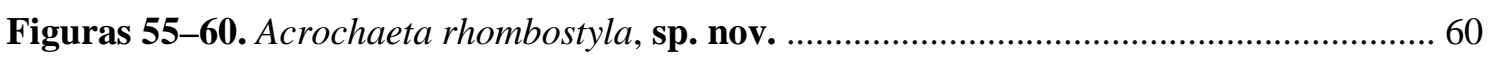

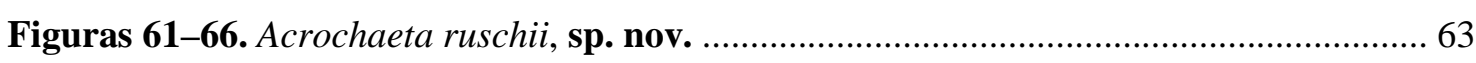

Figuras 67-69. Acrochaeta ruschii, sp. nov., holótipo macho .................................................. 64

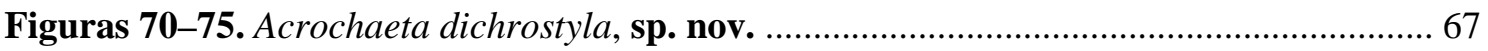

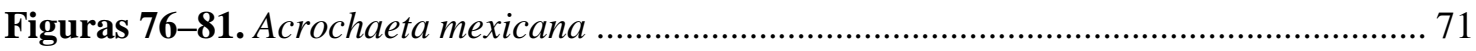

Figuras 82-85. Acrochaeta balbii, sp. nov., holótipo macho ................................................. 74

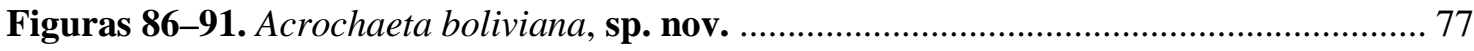

Figuras 92-105. Acrochaeta spp., asa e cabeça em vista dorsal ................................................ 85

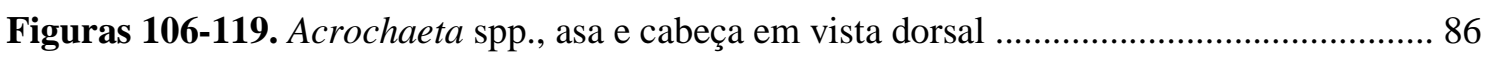

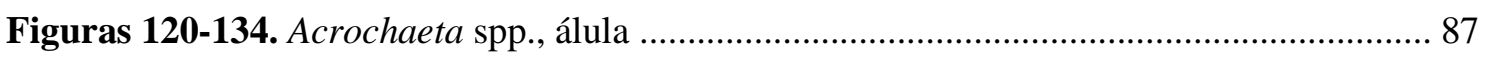

Figuras 135-149. Acrochaeta spp., escudo em vista dorsal .................................................... 88

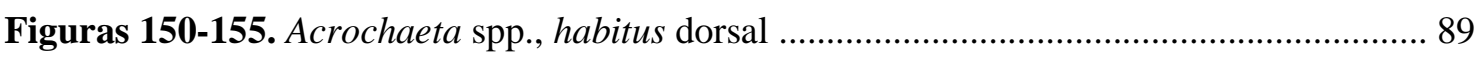

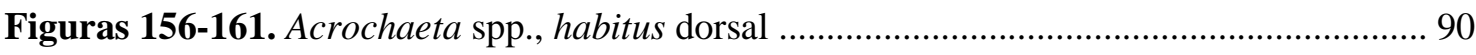

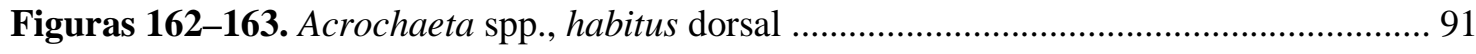

Figuras 164-168. Acrochaeta degenerata, holótipo macho, [BMNH] ..................................... 92

Figuras 169-172. Acrochaeta adusta, holótipo fêmea, [BMNH] ............................................. 93

Figuras 173-177. Acrochaeta fasciata, holótipo macho, [NMW] ............................................. 94

Figuras 178-182. Acrochaeta dimidiata, holótipo macho, [BMNH] ....................................... 95

Figuras 183-188. Acrochaeta mexicana, holótipo macho, [BMNH] ..................................... 96

Figuras 189-193. Acrochaeta flaveola, holótipo macho, [BMNH] ........................................ 97

Figuras 194-202. Merosargus (Acrochaeta) picta, comb. nov., [NMW] ................................ 98 
Figuras 203-207. Merosargus (Acrochaeta) chalconota, comb. nov., holótipo macho, [NMW]

Figuras 208-212. Merosargus (Acrochaeta) longiventris, comb. nov., holótipo macho, [PAN] 100

Figura 213. Mapa de distribuição das espécies exclusivamente sul-americanas de Acrochaeta 101

Figura 214. Mapa de distribuição da espécie Acrochaeta adusta 101

Figura 215. Mapa de distribuição da espécie Acrochaeta fasciata 102

Figura 216. Mapa de distribuição das espécies da América Central e localidades próximas na América do Sul de Acrochaeta 102

Figura 217. Consenso estrito das quatro árvores mais parcimoniosas obtidas na análise cladística de Acrochaeta 117

Figura 218. Consenso estrito das dezesseis árvores mais parcimoniosas obtidas na análise cladística de Acrochaeta desconsiderando os táxons com apenas fêmeas 118

Figura 219. Árvore mais parcimoniosa da análise cladística de Acrochaeta, obtida por meio de pesagem implícita com valor de $k=7.8125$ 119

Figuras 220-223. Árvores mais parcimoniosas da análise cladística de Acrochaeta, obtidas por meio de pesagem implícita com diferentes valores de $k$ 120

Figuras 224-227. Árvores mais parcimoniosas da análise cladística de Acrochaeta, obtidas por meio de pesagem implícita com diferentes valores de $k$ 121

Figuras 228-231. Árvores mais parcimoniosas da análise cladística de Acrochaeta, obtidas por meio de pesagem implícita com diferentes valores de $k$............................................................ 122

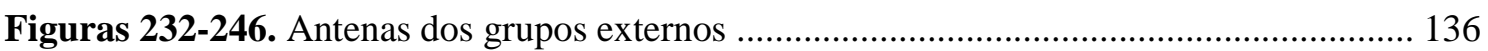

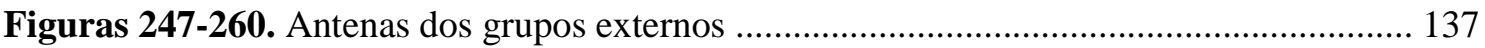

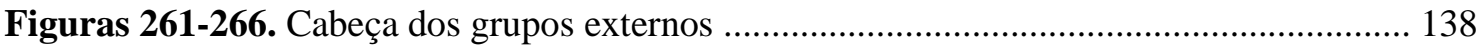

Figuras 267-282. Escudo em vista dorsal dos grupos externos .............................................. 139

Figuras 283-293. Escudo em vista dorsal dos grupos externos .............................................. 140

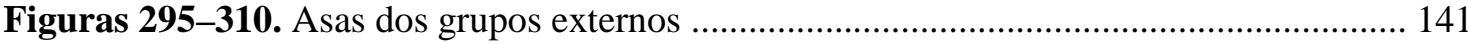

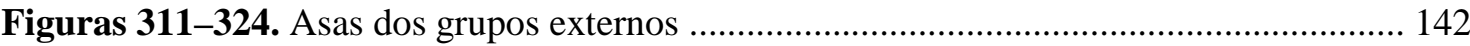

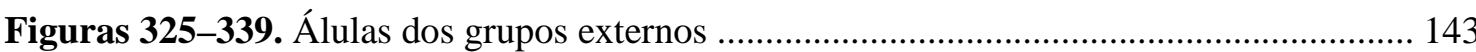

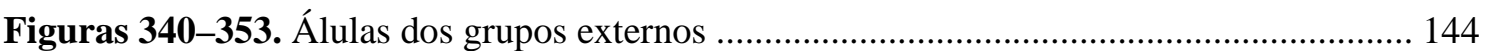

Figuras 354-359. Genitálias masculinas dos grupos externos em vista dorsal ........................ 145

Figuras 360-365. Genitálias masculianas dos grupos externos em vista dorsal ..................... 146

Figuras 366-370. Genitálias masculinas dos grupos externos em vista dorsal ........................ 147

Figuras 372-377. Genitálias masculinas dos grupos externos em vista dorsal ........................ 148

Figuras 378-380. Genitálias masculinas dos grupos externos em vista dorsal ........................ 149

Figuras 381-386. Genitálias masculinas dos grupos externos em vista ventral ...................... 150 
Figuras 387-392. Genitálias masculinas dos grupos externos em vista ventral 151

Figuras 393-398. Genitálias masculinas dos grupos externos em vista ventral 152

Figuras 399-404. Genitálias masculinas dos grupos externos em vista ventral 153

Figuras 405-407. Genitálias masculinas dos grupos externos em vista ventral 154

Figuras 408-417. Edeago+parâmeros dos grupos externos 155

Figuras 418-429. Epândrio, cercômeros e proctiger dos grupos externos 156

Figuras 430-441. Epândrio, cercômeros e proctiger dos grupos externos 157

Figuras 442-444. Epândrio, cercômeros e proctiger dos grupos externos 158

Figuras 445-460. Furca genital (esternito 9) dos grupos externos 159

Figuras 462-470. Furca genital (esternito 9) dos grupos externos 160

Figuras 471-476. Grupos externos em habitus dorsal 161

Figuras 477-482. Grupos externos em habitus dorsal e lateral .............................................. 162

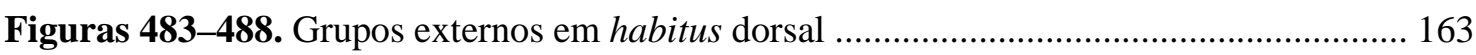

Figuras 489-494. Grupos externos em habitus dorsal e lateral .............................................. 164 


\section{LISTA DE ACRÔNIMOS DAS INSTITUIÇÕES CITADAS NO TEXTO}

AMNH - American Museum of Natural History, Nova Iorque, Estados Unidos

BMNH - The Natural History Museum, Londres, Inglaterra

CAS - California Academy of Sciences, San Francisco, Califórnia, Estados Unidos

CNC - Canadian National Collection of Insects, Ottawa, Canadá

DZUP - Coleção Entomológica Padre Jesus Santiago Moure, Universidade Federal do

Paraná, Brasil

NMW - Naturhistorisches Museum Wien, Viena, Áustria

MNRJ - Museu Nacional do Rio de Janeiro, Universidade Federal do Rio de Janeiro, Brasil

MZUSP - Museu de Zoologia de São Paulo, Universidade de São Paulo, Brasil

PAN - Museum of the Institute of Zoology, Polish Academy of Sciences, Varsóvia, Polônia

SEMC - Snow Entomological Museum, Department of Entomology, University of Kansas, Lawrence, Kansas, Estados Unidos

USNM - National Museum of Natural History, Washington, D.C., Estados Unidos

WSU - Department of Entomology, Washington State University, Pullman, Washington, Estados Unidos

ZSBS - Zoologische Staatssammlung München, Munique, Alemanha 


\section{INTRODUÇÃO}

\subsection{A família Stratiomyidae}

Stratiomyidae é uma família de moscas de tamanho médio a grande (2 a $34 \mathrm{~mm}$ ) e que apresentam coloração e formato do corpo muito variado. A família é irmã de Xylomyidae e pertence à subordem Brachycera, infraordem Stratiomyomorpha (composta pelas famílias Pantophthalmidae, Xylomyidae e Stratiomyidae) (Woodley 1989, 2001; Woodley et al. 2009). Os adultos são facilmente reconhecidos pela venação das asas, com as veias radiais concentradas na porção anterior da asa e uma pequena célula discal da qual se irradiam as nervuras medianas (e.g., Fig. 1). As larvas de Stratiomyidae, assim como as de Xylomyidae, apresentam a cutícula impregnada por carbonato de cálcio (Woodley 1989, 2001, 2009), podendo ser aquáticas ou terrestres, frequentemente associadas a matéria orgânica em decomposição.

É a família mais diversa em termos de números de gêneros e espécies de Stratiomyomorpha, com 2.872 espécies descritas (Tabela 1) em 377 gêneros para o mundo, dos quais 988 espécies em 160 gêneros são conhecidas para a região Neotropical (Woodley 2001, 2011). Desse total, 328 espécies ocorrem no Brasil (Carvalho et al. 2012).

De acordo com o catálogo mundial (Woodley 2001), a família é dividida em 12 subfamílias: Antissinae, Beridinae, Chiromyzinae, Chrysochlorininae, Clitellariinae, Hermetiinae, Nemotelinae, Pachygastrinae, Parhadrestiinae, Raphiocerinae, Sarginae e Stratiomyinae. Dentre essas, Sarginae é a mais rica em espécies na região Neotropical, com 267 espécies (Woodley 2001, 2011) e a terceira em número de espécies no mundo (Tabela 1). Uma grande parte da fauna Neotropical de Stratiomyidae foi incansavelmente estudada por James (e.g., 1941, 1973a, 1973b, 1974, 1975) e James \& McFadden (e.g., 1971, 1979, 1982), inclusive com chaves para subfamílias, gêneros e espécies, bem como um catálogo para a fauna (James 1973a).

No que diz respeito às relações filogenéticas entre as subfamílias, Woodley (2001) publicou a primeira análise cladística para a família, que diferentemente da proposta de Brammer \& von Dohler (2010) aponta que as subfamílias Antissinae, Sarginae e Stratiomyinae formariam grupos monofiléticos. 


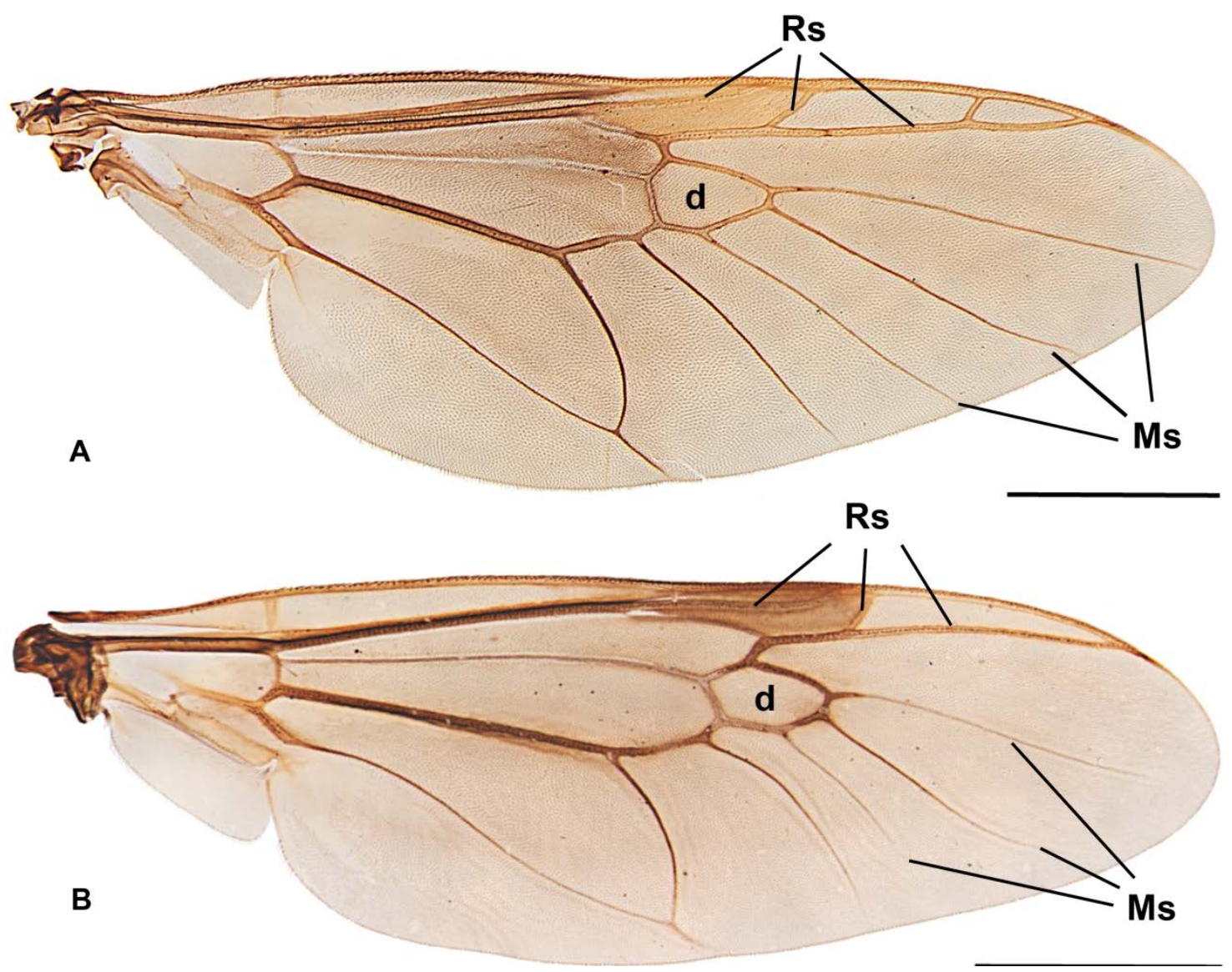

Figura 1. Asas de Stratiomyidae. A: Cyphomyia picta Schiner, 1868 (Clitellariinae). B: Myxosargus sp. Brauer, 1882 (Stratiomyinae). Escala, $1 \mathrm{~mm}$.

\subsection{A subfamília Sarginae}

Sarginae tem distribuição mundial e conta com 562 espécies conhecidas em 22 gêneros (Tabela 2), dos quais 267 espécies em oito gêneros são neotropicais (Woodley 2001, 2011), de modo que mais da metade das espécies do mundo para a subfamília são neotropicais.

Os sargíneos adultos são tradicionalmente caracterizados por apresentarem o último flagelômero da antena modificado em arista (Fig. 2), de cinco a seis flagelômeros no complexo basal contando a arista-formando uma estrutura compacta e globosa (complexo flagelar globoso, bastante característico dos gêneros Merosargus Loew, 1855, Microchrysa Loew, 1855, Ptecticus Loew, 1855 e Sargus Fabricius, 1798) (Fig. 2)—e presença da veia bm-cu nas asas (e.g., Fig. 295) (Woodley 2001, 2009). Na literatura, apesar de não haver nenhuma análise cladística de Stratiomyidae com uma amostragem considerável de Sarginae ou tão pouco uma análise da subfamília, há 
alguma discussão sobre a monofilia do grupo. Woodley (2001) entende que modificações na antena da subfamília (e.g., último flagelômero modicado em arista, número reduzido de flagelômeros) seriam condições sinapomórficas para o grupo, desse modo, indicando que Sarginae seria monofilético, ao passo que, Brammer \& von Dohlen (2010) sugerem que Sarginae formaria um agrupamento parafilético.

Tabela 1. Números de espécies de Stratiomyidae por região biogeográfica e por subfamília. (modificado de Woodley 2001, 2011).

\begin{tabular}{lccccccc}
\hline & Neártica & Neotropical & Paleártica & Afrotropical & Oriental & Australásia \\
Antissinae & 2 & 5 & 1 & & & 11 & 19 \\
Beridinae & 8 & 83 & 67 & 4 & 53 & 30 & 242 \\
Chiromyzinae & 1 & 35 & & & & 21 & 57 \\
Clitellariinae & 18 & 125 & 33 & 11 & 36 & 35 & 258 \\
Chysochlorininae & 1 & 26 & & 4 & 1 & 4 & 36 \\
Hermetiinae & 12 & 59 & 1 & 4 & 16 & 11 & 103 \\
Nemotelinae & 42 & 48 & 92 & 42 & 2 & 4 & 227 \\
Pachygastrinae & 24 & 134 & 52 & 102 & 126 & 184 & 622 \\
Parhadrestiinae & & 2 & & & & & 2 \\
Raphiocerinae & & 39 & & & 1 & 1 & 41 \\
Sarginae & 20 & 267 & 45 & 121 & 76 & 34 & $562^{*}$ \\
Stratiomyinae & 139 & 164 & 162 & 96 & 59 & 72 & 692 \\
Incertae sedis & & 1 & 3 & & 1 & & 5 \\
Total por região & 267 & 988 & 456 & 384 & 371 & 407 & $2872^{*}$ \\
\hline
\end{tabular}

* A soma total não corresponde aos valores na tabela, pois há uma espécie de Merosargus ( $M$. beameri James, 1941) que ocorre nas regiões Neártica e Neotropical.

As formas imaturas de Sarginae apresentam hábitos terrestres. Com relação à alimentação, as larvas podem ser saprófagas, vivendo e alimentando-se, principalmente em ambientes com material orgânico em diferentes níveis de decomposição (Rozkosný 1982) ou alimentando-se das bactérias que se proliferam no material em decomposição. Particularmente, as larvas das espécies do gênero Merosargus são especializadas em se alimentar de diferentes orgãos de plantas, com destaque para os ataques em espécies do gênero Heliconia Linnaeus, no qual os imaturos de diferentes espécies podem se alimentar da mesma espécie de planta, mas de regiões distintas (pseudocaule, inflorescência) (Fontenelle et al. 2012). Os adultos de Sarginae são vistos sobre a 
vegetação e, em particular, sobre folhas e flores. Em alguns casos, também são encontrados próximos às fontes de alimentos das larvas. Particularmente, Merosargus e Ptecticus formam agregados ao redor de frutos caídos (com competição interespecífica pelo local de oviposição), sobre os quais as fêmeas ovipositam (Rozkosný 1982; Woodley 2001).

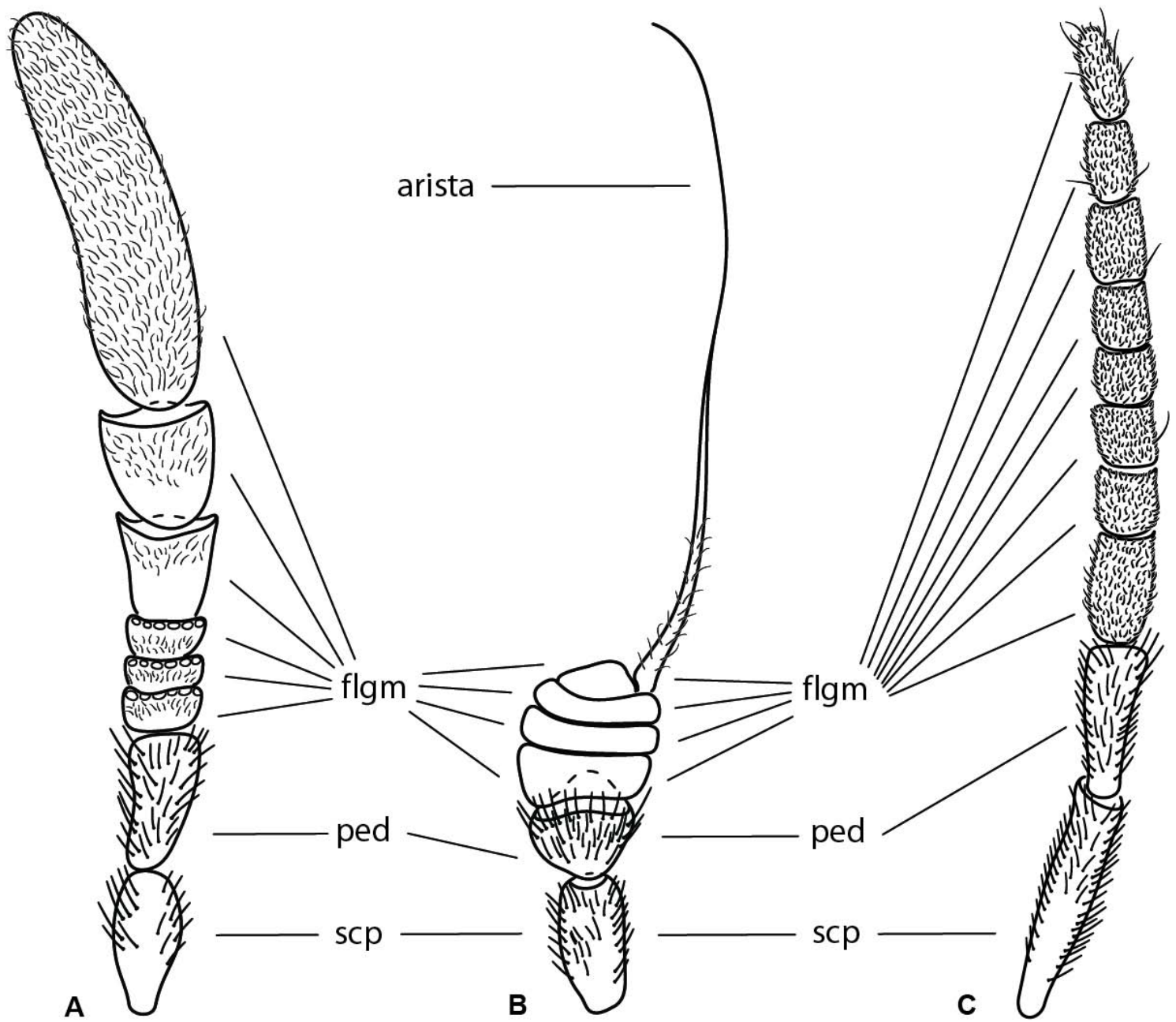

Figura 2. Antenas em Stratiomyidae. A: Myxosargus sp. Brauer, 1882 (Stratiomyinae). B: Merosargus nebulifer James, 1971 (Sarginae). C: Cyphomyia picta Schiner, 1868 (Clitellariinae).

Não há uma análise cladística para a subfamília e tão pouco há trabalhos revisionais com os gêneros. Não há também chaves de identificação globais para as espécies da grande maioria dos gêneros. Limitações às quais têm impedido um melhor entendimento do grupo, tanto taxonomicamente quanto morfologicamente, dificultando especialmente o reconhecimento e a delimitação precisa da grande maioria dos gêneros 
como grupos naturais, e consequentemente estudos biogeográficos e de evolução de comportamentos e hábitos diversos.

Tabela 2. Números de espécies de cada gênero de Sarginae por região biogeográfica e em cada gênero (modificado de Woodley 2001, 2011).

Neártica Neotropical Paleártica Afrotropical Oriental Australásia

Acrochaeta Wiedemann, 1830

Amsaria Adisoemarto, 1974

Cephalochrysa Kertész, 1912

Chloromyia Duncan, 1837

Chrysochromioides Brunetti, 1926

Dinosargus Lindner, 1968

Filiptschenkia Pleske, 1926

Formosargus James, 1939b

Gongrosargus Lindner, 1959

Himantigera James, 1982

Lobisquama James, 1982

Merosargus Loew, 1855

Microchrysa Loew, 1855

Microptecticus Lindner, 1936a

Microsargus Lindner, 1958

Otochrysa Lindner, 1938

Paraptecticus Grünberg, 1915

Ptecticus Loew, 1855

Ptectisargus Lindner, 1968

Sagaricera Grünberg, 1915

Sargus Fabricius, 1798

Stackelbergia Pleske, 1930

Incertae sedis

Total por região
10

10

10

4

1

1

1

2

8

4

1

1

1

$\begin{array}{ccc} & 10 \\ 1 & 1 \\ 8 & 7 & 25\end{array}$

2

9

45
4

8

1

142

6

12

26

20

3

$2 \quad 48$

$1-1$

1

22

$\begin{array}{lllllll}5 & 52 & 6 & 14 & 50 & 17 & 144\end{array}$

(20)

3

$2 \quad 3$

$\begin{array}{lllllll}6 & 47 & 22 & 17 & 13 & 8 & 113\end{array}$

1

35

35

* A soma total não corresponde aos valores na tabela, pois há uma espécie de Merosargus ( $M$. beameri James, 1941) que ocorre nas regiões Neártica e Neotropical.

Dos 22 gêneros de Sarginae, oito são monotípicos e restritos a uma determinada região biogeográfica (quatro na afrotropical, dois na paleártica, um na neotropical e um 
na oriental). Outros cinco gêneros também são restritos a determinadas regiões e representados por poucas espécies (e.g., Acrochaeta Wiedemann, 1830, Formosargus James, 1939b, Gongrosargus Lindner, 1959, Himantigera James, 1982, Microptecticus Lindner, 1936a, Paraptecticus Grünberg, 1915). Esses, assim como os gêneros Merosargus e Sargus, são pouco delimitados, sendo que alguns desses gêneros, como comentado, são monotípicos.

Na região Neotropical, Acrochaeta e Himantigera, apesar de conterem uma baixa riqueza de espécies, são de difícil identificação. Algumas espécies de Merosargus (e.g., M. aurivena James, 1971, M. brunnipes McFadden, 1971, M. flavissimus James, 1971, M. pictithorax Curran, 1933) (Fig. 3) são frequentemente confundidas com espécies de Acrochaeta por conta de semelhanças em características de antenas, cabeça, asa e principalmente padrão de coloração. Espécies de Himantigera, por sua vez, às vezes são identificadas como pertencentes à Sargus. Em Merosargus e Sargus, a dificuldade em identificar as espécies é ainda maior. São gêneros basicamente delimitados por plesiomofias, com elevado número de espécies descritas (143 e 113 espécies, respectivamente) e as chaves de identificação, quando presentes, são apenas regionais (James \& McFadden 1971, 1982). Cabe ressaltar que Sargus é um gênero de distribuição mundial, tornando mais difícil o reconhecimento da identidade do gênero. Espécies paleárticas (Mason \& Rozkosný 2008) e orientais de Sargus formam grupos claramente distintos das espécies neotropicais e mesmo na região Neotropical é possível distinguir dois grupos claramente independentes (James \& McFadden 1982), indicando que talvez Sargus atualmente seja formado por mais de um gênero.

Segundo Woodley (2009), Merosargus apresenta-se provavelmente parafilético em relação a Acrochaeta. Tradicionalmente esses dois gêneros são separados pelo comprimento das antenas-flagelômeros curtos em Merosargus, flagelômeros longos em Acrochaeta. Entretanto, isso não tem se mostrado suficiente, pois há variação do comprimento entre espécies de ambos os gêneros. James \& McFadden (1971, 1982) apontaram para a dificuldade de delimitação de Merosargus, comentando que Merosargus poderia ser um agregado de grupos menores, ou seja, não monofilético ou até mesmo um conjunto de linhagens não diretamente relacionadas dentro da subfamília. Woodley (2009) também comentou sobre a necessidade de revisão desses gêneros, inclusive Acrochaeta.

Em Ptecticus (talvez o gênero melhor delimitado em Sarginae), a situação é um pouco melhor. Ainda assim, há ausência de trabalhos gerais, o que tem impossibilitado 
uma visão consistente da fauna mundial. As chaves para a identificação da fauna, quando presentes, também são apenas regionais (James \& McFadden 1982, Leal 1979).

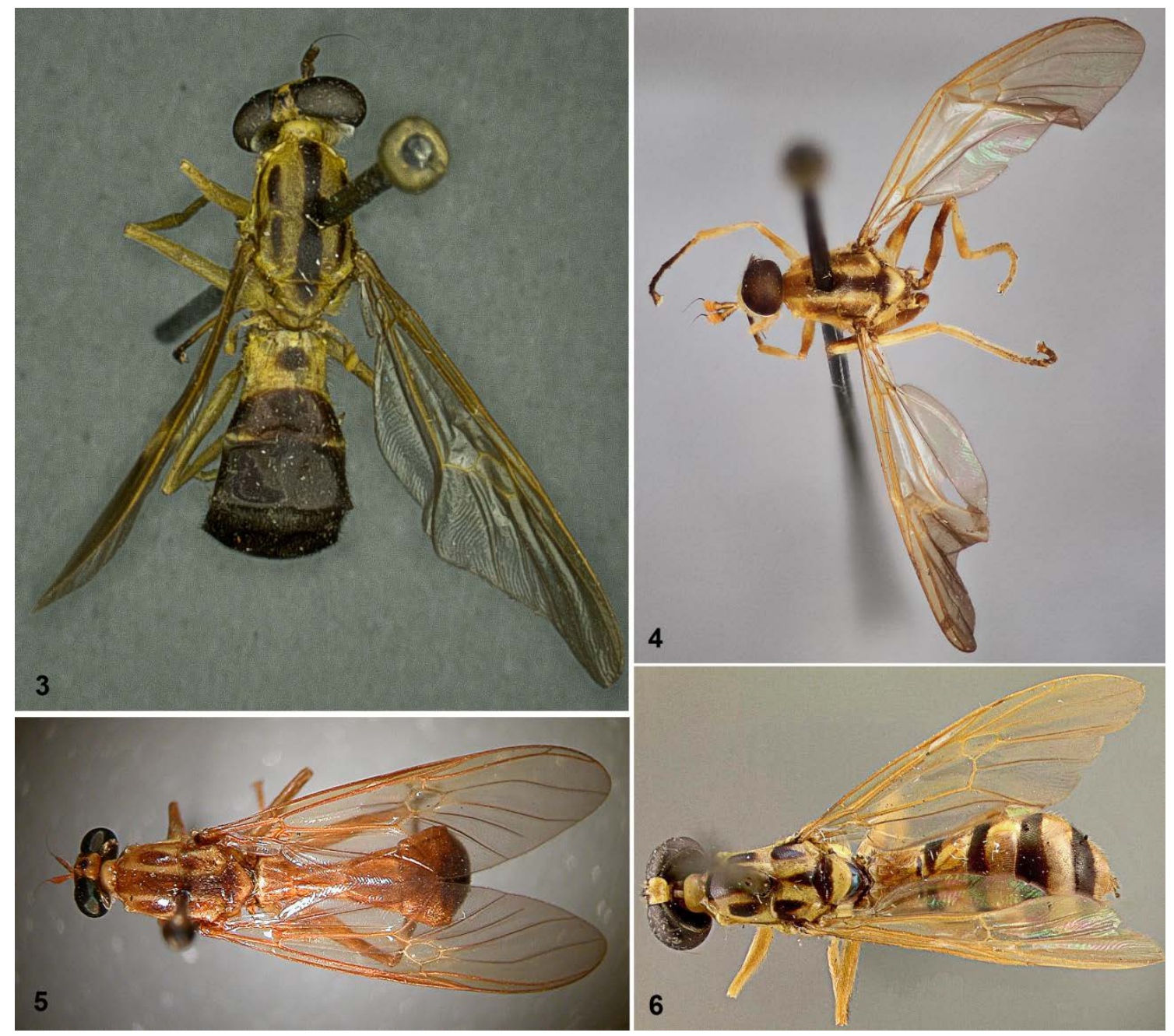

Figuras 3-6. Espécies de Merosargus (Sarginae) em habitus dorsal. 3. M. aurivena James, 1971, holótipo, [SEMC]. 4. M. brunnipes McFadden, 1971, alótipo [WSU]. 5. M. flavissimus James, 1971, holótipo [CAS]. 6. M. pictithorax Curran, 1933, holótipo [AMNH].

Outro desafio importante diz respeito à fauna Afrotropical. Alguns gêneros, como Dinosargus Lindner, 1968 e Ptectisargus Lindner, 1968, são bastante singulares e de difícil comparação e posicionamento em relação aos outros gêneros da subfamília, ao que passo que outros, como Sagaricera Grünberg, 1915 e Paraptecticus aparentam ser subgrupos modificados dentro de gêneros de ampla distribuição (ou seja, sugerindo outros problemas de parafilia). Há ainda a questão de 35 espécies incertae sedis Afrotropicais descritas principalmente para os gêneros disponíveis e não válidos, 
Chrysonotus Loew, 1855 e Chrysochroma Williston, 1896, ambos sinônimos de Sargus em Sarginae.

\subsection{O gênero Acrochaeta Wiedemann, 1830}

O gênero Acrochaeta tem distribuição restrita à Região Neotropical, com atualmente 10 espécies descritas - seis para o Brasil, duas para o México e duas para a Venezuela. A informação taxonômica publicada sobre o gênero pode ser vista no quadro 1, que reproduz o conteúdo relativo à Acrochaeta do catálogo mundial de Stratiomyidae (Woodley 2001, 2011).

Na literatura, não há estudos formais sobre as relações de parentesco entre os gêneros de Sarginae ou sobre as relações entre as espécies de Acrochaeta. As descrições das espécies, em especial as mais antigas, possuem imprecisões taxonômicas e morfológicas. Como é o caso, por exemplo, de A. adusta Lindner, 1949 e A. dimidiata Lindner, 1949, que não é mencionado informação sobre as antenas (ver Lindner 1949). Isso torna necessária uma padronização nas descrições, chaves e ilustrações (além de serem feitas referências às estruturas não estudadas, como a genitália masculina) para que haja uma taxonomia cada vez mais precisa do grupo. Adicionalmente, muito pouco foi publicado sobre a diversidade de Acrochaeta, sendo que os únicos trabalhos, para a maioria das espécies, são as descrições originais_Perty (1833), Wiedemann (1830), Bigot (1879), Brauer (1882), Enderlein (1914) e Lindner (1949). James \& McFadden (1982) em um estudo revisional de Sarginae da América Central, comentaram brevemente sobre a distribução, diagnose e relações de parentesco de A. mexicana Lindner, 1949 com A. fasciata Wiedemann, 1830.

As espécies de Acrochaeta em sua maioria são reconhecidas pelo tamanho do corpo relativamente grande $(7.5-19.0 \mathrm{~mm})$, com o abdômen muito alongado, frequentemente clavado, com os primeiros segmentos abdominais peciolados, algo semelhante a vespas (e.g., Figs. 153 e 156). A coloração também é algo marcante na maioria das espécies do gênero-o corpo variando entre o amarelo e o marrom escuro com padrão característico de bandas escuras longitudinais no escudo e horizontais no abdômen, o que remete novamente à semelhança com os vespídeos (provavelmente Polistinae). Entrentanto, a característica mais marcante, talvez diagnóstica, que tem gerado inúmeras dúvidas sobre a validade do gênero Acrochaeta é a antena: alongada (flagelômeros mais longos que largos) e achatada, na minoria dos casos com uma arista pubescente em toda a sua extensão. Condição que também pode ser vista em algumas 
espécies de Merosargus. Entretanto, o alongamento em espécies de Merosargus não é tão distinto quanto, por exemplo, na espécie-tipo de Acrochaeta (A. fasciata) (Fig. 24), mas em alguns casos é muito próximo à condição de A. degenerata Lindner, 1949 (Fig. 14) e A. mexicana (Fig. 81).

O padrão de coloração do corpo, apesar de característico das espécies do gênero, como já comentado, também pode ser encontrado em espécies de Merosargus (e.g., $M$. brunnipes, M. pictithorax) (Fig. 3) e em espécies do gênero Chrysochlorina James, 1939a, subfamília Chrysochlorininae (Iide 1966). Isso sugere surgimentos independentes dessa característica, provavelmente associados ao comportamento mimético desses grupos. A posição da origem da veia $\mathrm{R}_{2+3}$ também tem sido usada para reconhecer a espécies de Acrochaeta (James \& McFadden 1982). Em Sarginae, essa característica também auxilia na delimitação de gêneros, como em Cephalochrysa Kertész, 1912, Microchrysa, Sargus, Sagaricera, com a origem de $\mathrm{R}_{2+3}$ próxima a parte distal da célula discal ou em Himantigera, com a origem bem próxima a r-m (James \& McFadden 1982; Woodley 2009), bem como na separação de espécies de Merosargus (James \& McFadden 1971). Portanto, é necessário certo cuidado com essa característica, uma vez que a posição de origem da veia varia bastante tanto entre espécies de Acrochaeta quanto de Merosargus, em que $\mathrm{R}_{2+3}$ surge antes de r-m, pouco depois ou mais próxima do ápice da célula discal.

Com base nessas semelhanças principalmente entre espécies de Acrochaeta e Merosargus, Woodley (2001, 2009) fez alguns comentários sobre parentesco em Sarginae, sugerindo que Merosargus poderia ser parafilético em relação a Acrochaeta, o que explicaria as semelhanças compartilhadas entre algumas espécies de Merosargus e de Acrochaeta.

Quadro 1. Conhecimento taxonômico para o gênero Acrochaeta (modificado de Woodley 2001).

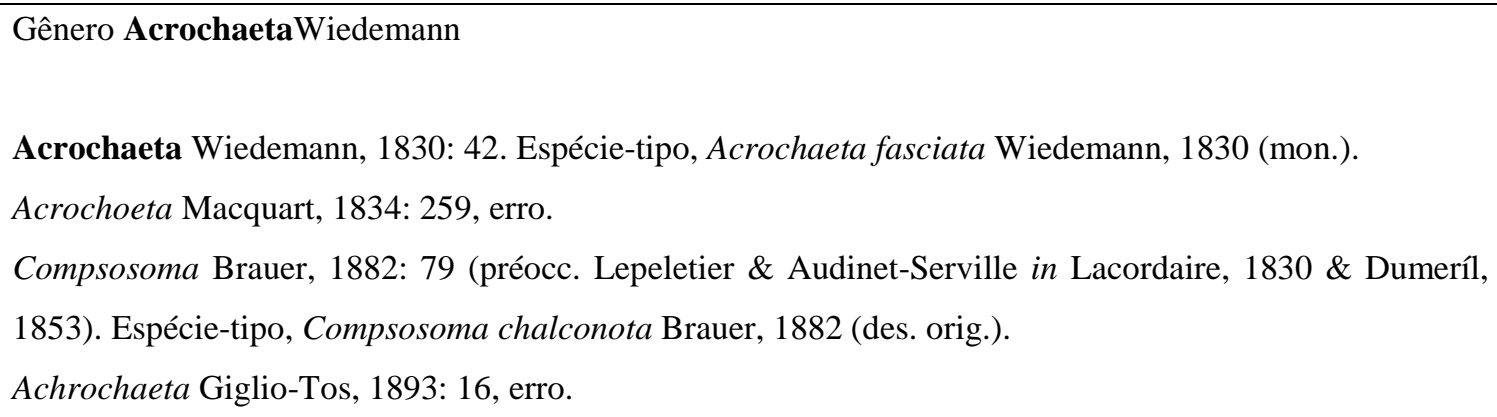


adusta Lindner, 1949a: 813. Localidade-tipo: Brazil, Santa Catarina, Nova Teutonia. Holótipo + , [ВНMH].

chalconota (Brauer), 1882: 79. Localidade-tipo: Venezuela. Holótipo $\widehat{\jmath}$, [NMW].

degenerata Lindner, 1949a: 812. Localidade-tipo: Brazil, Santa Catarina, Nova Teutonia. Holótipo $\widehat{\jmath}$, [ВНMH].

dimidiata Lindner, 1949a: 811. Localidade-tipo: Brazil, Santa Catarina, Nova Teutonia. Síntipos 1 ふ, 1 只, [BHMH].

elegans Perty, 1833a: plate 36, figure 15 (descrição em Perty 1833b: 184). Localidade-tipo: Brazil, “Amazon River”. Síntipos, [ZSBS].

fasciata Wiedemann, 1830: 42. Localidade-tipo: "Brazil”. Holótipo $\curvearrowright$, [NMW].

flaveola (Bigot), 1879b: 205. Localidade-tipo: México. Holótipo $\precsim$ [BHMH].

Acrochaeta flaviola James \& McFadden, 1982: 21, erro.

longiventris Enderlein, 1941b: 595. Localidade-tipo: Brazil, Santa Catarina. Holótipo ${ }_{+}$, [PAN].

mexicana Lindner, 1949a: 814. Localidade-tipo: México. Holótipo ふَ̋, [BHMH].

picta (Brauer), 1882: 80. Localidade-tipo: Venezuela. Síntipos 1ð̊, 2 ๆ, [NMW].

\section{OBJETIVOS}

O objetivo deste trabalho foi realizar uma revisão taxonômica do gênero Acrochaeta e uma análise cladística das relações entre as espécies do gênero, incluindo o estudo da questão da posição do gênero em relação à Merosargus.

\section{MATERIAL E MÉTODOS}

\subsection{Material biológico}

O material biológico utilizado para essa revisão foi proveniente de seis instituições:

- CAS, California Academy of Sciences, São Francisco, Califórnia, Estados Unidos.

- CNC, Canadian National Collection, Arachnids and Nematodes, Ottawa, Canadá.

- CSCA, California State Collection of Arthropods, Sacramento, Califórnia, Estados Unidos. 
- DZUP, Coleção Entomológica Padre Jesus Santiago Moure, Universidade Federal do Paraná.

- MZUSP, Museu de Zoologia de São Paulo, Universidade de São Paulo:

- Biota-Diptera (Proc. FAPESP 2003/10.274-9);

- Hymenoptera Parasitóides da Região Sudeste Brasileira (Proc. FAPESP 2008/57949-4; Proc. CNPQ 573802/2008-4);

- Diversidade e endemismo de Diptera (Insecta) em um fragmento de Floresta Atlântica Semidecídua, em Sertãozinho-SP (Proc. FAPESP 2009/ 54.497-8);

- Fauna Cavernícola de Altamira (Proc. Fapesp 2008/05678-7);

- Diptera dos estados do Mato Grosso, Mato Grosso do Sul e Rondônia: Diversidade, Sistemática e Limites distribucionais (Proc. FAPESP 2010/52.314-0; Proc. CNPQ 563256/2010-9).

- MNRJ, Museu Nacional do Rio de Janeiro, Universidade Federal do Rio de Janeiro.

- USNM, National Museum of Natural History, Washington, D.C., Estados Unidos.

O material-tipo (holótipos e síntipos) de nove das dez espécies descritas foi analisado apenas por fotos (Figs. 164-212), disponibilizadas pelo Natural History Museum, Londres, Inglaterra (BMNH), Naturhistorisches Museum Wien, Viena, Áustria (NMW) e Museum of the Institute of Zoology, Polish Academy of Sciences, Varsóvia, Polônia (PAN). Três espécies (A. chalconota, A. degenerata e A. flaveola Bigot, 1879) não possuem, nas fotos ou em suas descrições originais, informações detalhadas o suficiente de antena e/ou genitália masculina e não foi possível conseguir material adicional das mesmas. Desse modo, não foi possível incluir informação de genitália masculina e, em alguns casos de antena, para essas espécies na análise cladística.

A lista completa (incluindo informação de etiqueta e instituição depositária) dos espécimes examinados encontra-se no apêndice 1 (Tabela 6).

\subsection{MÉTODOS}




\subsubsection{Identificação do material}

O material de Stratiomyidae foi identificado em nível genérico utilizando-se principalmente a chave de Woodley (2009) e em alguns casos recorrendo à literatura primária de cada gênero estudado. Exemplares de outros gêneros de Sarginae utilizados como grupos externos na análise foram identificados em nível específico, utilizando as chaves de James \& McFadden $(1971,1982)$ e com o auxílio de material de referência do MZUSP e do USNM, das descrições originais e de fotos de material-tipo. As espécies do gênero Acrochaeta foram identificadas com o auxílio das descrições originais e fotos de material-tipo——ão há chaves para a identificação das espécies.

\subsubsection{Preparação e manuseio do material}

Genitálias masculinas e femininas de exemplares de cada espécie foram clareadas com a realização da técnica usual com $\mathrm{KOH} 10 \%$ a $60^{\circ} \mathrm{C}$ por $30-40$ minutos, seguido por desidratação alcoólica e, posterior montagem em lâminas temporárias com glicerina para visualização. Na maioria dos casos, para melhor visualização dos processos internos do singonocoxito e a relação dos parâmeros com o edeago, o epândrio era removido com microalfinetes. Em alguns casos, para detalhamento do edeago, este foi retirado do singonocoxito também com o auxílio de microalfinetes.

Outras estruturas com detalhes importantes para a taxonomia do gênero e da subfamília (antena e asa) passaram pelo procedimento de desidratação alcoólica e, foram montadas em lâminas permanentes com balsamo do Canadá (modificado de Huber \& Reis 2011).

O habitus dos espécimes (alfinetados ou em álcool) em vista dorsal e/ou lateral, bem como detalhes de estruturas montadas em lâmina (antenas e asas) foram fotografados utilizando a camera Leica DC 500 acoplada a um estereomicroscópio Leica M16 e as imagens processadas com AutoMontage Pro v5.02.0096 e depois, essas fotos foram editadas com o programa Adobe Photoshop CS4. As estruturas morfológicas relevantes para o estudo taxonômico (e.g., genitália masculina e antena) foram ilustradas com o auxílio de microscópio acoplado a câmara clara, posteriormente escaneadas, digitalizadas e trabalhadas com o programa Adobe Illustrator CS5.

\subsubsection{Descrição das espécies}

Para cada espécie do grupo interno (Acrochaeta), foram feitas fotografias de habitus em vista dorsal, escudo, abdômen e asa, além de ilustrações de antena, cabeça, 
genitália masculina (em vistas dorsal e ventral, epândrio, edeago, parâmero) e genitália feminina (em vista dorsal e furca genital). Procedimento semelhante foi feito para as espécies utilizadas como grupos externos, exceto ilustração de cabeça para algumas espécies e vista dorsal da genitália feminina não ilustrada. As figuras foram organizadas em pranchas em ordem filogenética das espécies, segundo o cladograma da figura 217-exceto ilustrações de genitália e antena das espécies de Acrochaeta, apresentadas logo em seguida às descrições-, para facilitar o reconhecimento de condições homólogas. A descrição das espécies de Acrochaeta também seguiu a ordem filogenética (exceto para $A$. degenerata) e os clados em Acrochaeta indicados nos comentários taxonômicos. As informações em negrito nas diagnoses são àquelas destacadas como sinapomórficas.

Um índice de proporção de comprimento das antenas foi utilizado nas descrições das espécies: relação comprimento/largura dos flagelômeros (complexo flagelar, não incluindo a arista). O comprimento do corpo foi medido sem a inclusão da antena. Todas as medidas estão em milímetros.

A divisão em grupo de espécies foi feita com base em características diagnósticas recuperadas como sinapomorfias para o grupo de espécie em questão.

\subsubsection{Terminologia adotada}

A terminologia utilizada para as descrições segue Cumming \& Wood (2009), exceto para alguns detalhes da fronte (área medial e área lateral) (James \& McFadden 1971, 1982) e para detalhes da furca genital (processo póstero-lateral, margem posterior) (Woodley 1981). As abreviações utilizadas nas estruturas são: A, anal; ab, abertura genital; anepm: anepímero; anepsta: anepisterno anterior; anepstp: anepisterno posterior; apod ej, apódema ejaculatório; apod goncx, apódema gonocoxal; ar, arista; ar lt, área lateral; ar md, área medial; C, costal; catpm: catepímero; cerc, cercômero; cl frnt, calo frontal; CuA, cubital anterior; CuP, cubital posterior; cx: coxa; d, célula discal; ed, edeago; epand, epândrio; esctl: escutelo; espr a: espiráculo anterior; espr p: espiráculo posterior; est: esternito; fc, face; fc gen, furca genital; flgm, flagelômero; frnt inf, fronte inferior; goncx, gonocoxito; gonst, gonóstilos; h, humeral; hlt: hálter; lb pprn: lóbulo póspronotal; lmed, lóbulo medial do edeago; ltg: laterotergito; M, medial; mp, margem posterior; Ms, mediais; mr: mero; mtanepst, metanepisterno; mtcpst: metacatepisterno; mtepm: metepímero; mtg: mediotergito; npl: notopleura; ped, pedicel; plp, palpus; pm dl, parâmero dorsal; pms: processo medial do singonocoxito; pm vl, 
parâmero ventral; pt goncx, ponte gonocoxal; pp, processo posterolateral; pprn: póspronoto; prbs, proboscide; prct, proctiger; prepm: pré-epimero; prepst: pré-episterno; prescd: pré-escudo; R, radial; Rs, radiais; Sc, subcostal; scd: escudo; scp, scape; sut trn: sutura transversal; tbrc oc, tubérculo ocelar; tg: tergito; vrtx, vertex. Área medial e área lateral são subdivisões da parte superior da fronte.

\subsection{ANÁLISE FILOGENÉTICA}

\subsubsection{Amostragem taxonômica}

A amostragem compreende 45 táxons terminais correspondentes a cinco gêneros. O grupo interno é representado por 17 táxons terminais (nove espécies nominalmente inseridas em Acrochaeta e oito espécies novas) e os grupos externos por 28 táxons terminais (26 espécies descritas e três espécies novas) pertencentes a quatro diferentes gêneros de Sarginae (Tabela 3). Como não há uma análise cladística para a subfamília ou para os gêneros internamente, esses foram escolhidos por serem considerados na literatura como os mais próximos a Acrochaeta (James \& McFadden 1971, 1892; Woodley 2009). As dúvidas com relação à monofilia de Merosargus e Acrochaeta, bem como a relação desses com os demais Sarginae, fez com que fosse necessário uma grande amostragem de espécies de Merosargus (17 espécies descritas e três novas), gênero tradicionalmente considerado mais próximamente relacionado a Acrochaeta.

\subsubsection{Estudo dos caracteres}

A codificação de caracteres seguiu o modelo de codificação contingente de Forey \& Kitching (2000), que opta pela separação de caracteres com vários estados em um caráter mais inclusivo de ausência e presença e um mais específico com os diferentes estados, sendo o estado de ausência substituído por missing data. Apesar de criar certa dependência entre os caracteres resultantes da divisão, esse tipo de codificação foi escolhido, pois garante o melhor aproveitamento da informação disponível.

A otimização dos caracteres quase sempre utilizou o algoritmo ACCTRAN (accelerated transformation), que em situações de resolução dúbia opta por interpretar a evolução do caráter como um único surgimento e uma ou mais reversões, em detrimento da interpretação de surgimentos independentes (de Pinna 1991; Amorim 2002). 
A otimização e a análise da evolução dos caracteres foram realizadas no programa Winclada (Nixon 2002).

\subsubsection{Matriz e análise computacional}

A matriz de dados (Tabela 4) foi construída com a nova versão do programa Winclada (Nixon, 2002) e conta com 63 caracteres morfológicos, sendo 60 novos e três retirados da literatura (Tabela 4) e 45 táxons terminais (Tabelas 3 e 4). A ordenação das séries de transformação foi feita a posteriori, por meio da comparação e enraizamento com os grupos-externos (Nixon \& Carpenter 1993). Todos os caracteres foram tratados como não-ordenados. Os dados ausentes (missing data) e inaplicáveis foram tratados como (?) e (-) respectivamente.

A análise de parcimônia consistiu de uma busca heurística feita com o programa TNT (Tree Analysis Using New Technology), versão 1.1 (Goloboff et al. 2008b), com os seguintes parâmetros: random seed $=0$, hold $=20000$, hold/40 em um tbr de 300 replicações. Assim, foram realizados dois tipos de análises: (1) com pesos iguais e (2) com pesagem implícita (Goloboff 1993, 2008a)—valor de $k$ (constante de concavidade) $=7.8125$ obtido a partir do script setk.run, desenvolvido por Salvador Arias (com. pess.) e cada valor inteiro de $k$ no intervalo de 1 a 13 . Esse intervalo de valores de $k$ tem como objetivo verificar a estabilidade da árvore (Tabela 5) obtida a partir do valor de $k$ $=7.8125$.

A análise com pesagem implícita (diferentes valores de $k$, incluindo o valor de obtido por meio do setk.run) foi feita com o objetivo de verificar o comportamento dos dados frente à pesagem diferencial dos caracteres. A ideia por trás da pesagem implícita é dar pesos diferentes aos caracteres em função de seus respectivos índices de consistência (I.C.), uma vez que o grau de homoplasia de cada caráter é utilizado como indicador do peso que este deverá receber na análise. Desse modo, diferentes valores de $k$ terão um impacto distinto na pesagem diferencial dos caracteres homoplásticos, de modo que, quanto menor o valor de $k$ empregado, menor os pesos dos caracteres mais homoplásticos. Por outro lado, para valores de $k$ cada vez maiores, a análise aproximase a uma com pesagem igual (função linear de homoplasia) (Goloboff 1993; Schuh \& Brower 2009). Ainda sim, não existe um critério objetivo para obtenção de um valor ideal de $k$ ou intervalo de valores, o que torna a escolha variável, podendo ser feita inclusive de forma arbitrária. 
Por fim, foi realizada uma busca conforme os parâmetros acima e pesagem igual, mas tornando inativos os táxons representados apenas por fêmeas, a fim de verificar se a quantidade de dados faltantes interferiu no resultado das análises como um todo, uma vez que um terço dos caracteres (22) são exclusivamente baseado em genitália masculina. 
Tabela 3. Lista dos táxons terminais utilizados e sua distribuição geográfica.

\begin{tabular}{|c|c|}
\hline Táxons & Distribuição geográfica \\
\hline \multicolumn{2}{|l|}{ Acrochaeta Wiedemann, 1830} \\
\hline Acrochaeta adusta Lindner, 1949 & Neotropical (Brasil) \\
\hline Acrochaeta chalconota Brauer, 1882 & Neotropical (Venezuela) \\
\hline Acrochaeta degenerata Lindner, 1949 & Neotropical (Brasil) \\
\hline Acrochaeta dimidiata Lindner, 1949 & Neotropical (Brasil) \\
\hline Acrochaeta flaveola Bigot, 1879 & Neotropical (México) \\
\hline Acrochaeta longiventris Enderlein, 1914 & Neotropical (Brasil) \\
\hline Acrochaeta mexicana Lindner, 1949 & Neotropical (México) \\
\hline Acrochaeta picta Brauer, 1882 & Neotropical (Venezuela) \\
\hline Acrochaeta asapha, sp. nov. & Neotropical (Brasil) \\
\hline Acrochaeta boliviana, sp. nov. & Neotropical (Bolívia) \\
\hline Acrochaeta dichrostyla, sp. nov. & Neotropical (Brasil) \\
\hline Acrochaeta polychaeta, sp. nov. & Neotropical (Brasil) \\
\hline Acrochaeta pseudopolychaeta, sp. nov. & Neotropical (Brasil) \\
\hline Acrochaeta rhombostyla, sp. nov. & Neotropical (Brasil) \\
\hline Acrochaeta ruschii, sp. nov. & Neotropical (Brasil) \\
\hline Himantigera James, 1982 & \\
\hline
\end{tabular}




\begin{tabular}{|c|c|}
\hline Himantigera nigrifemorata Macquart, 1847 (Figs. 235, 270, 298, 328, 357, 384, 421, 448, 474) & Neotropical (Costa Rica, El Salvador, Guatemala, México) \\
\hline Himantigera silvestris McFadden, 1982 (Figs. 236, 262, 264, 271, 299, 329, 358, 385, 413-415, 422, 475) & Neotropical (Brasil, Costa Rica, Guatemala, México) \\
\hline \multicolumn{2}{|l|}{ Merosargus Loew, 1805} \\
\hline Merosargus akrei James, 1971 (Figs. 239, 273, 302, 332, 361, 388, 425, 451, 477) & Neotropical (Brasil, Equador, México, Panamá, Peru) \\
\hline Merosargus albopictus James, 1971 (Figs. 253, 287, 316, 346, 374, 401, 438, 463) & Neotropical (Brasil, Equador, Guiana, Peru) \\
\hline Merosargus aurivena James, 1971 (Figs. 241, 276, 304, 334, 363, 390, 427, 453, 479) & Neotropical (Costa Rica, Panamá) \\
\hline Merosargus azureus Enderlein, 1914 (Figs. 240, 266, 275, 303, 333, 362, 389, 426, 452, 478) & $\begin{array}{l}\text { Neotropical (Brasil, Costa Rica, Equador, Guiana, Panamá, } \\
\text { Peru, Venezuela) }\end{array}$ \\
\hline Merosargus barbatus James, 1971 (Figs. 254, 288, 317, 347, 375, 402, 439, 464, 490) & Neotropical (Costa Rica, Guatemala, Panamá) \\
\hline Merosargus beameri James, 1941 (Figs. 255, 289, 319, 348, 403, 440, 465) & Neártica (EUA); Neotropical (México) \\
\hline Merosargus cingulatus Schiner, 1868 (Figs. 256, 290, 320, 349, 377, 404, 441, 466, 491) & $\begin{array}{l}\text { Neotropical (Brasil, Colômbia, Costa Rica, Equador, El } \\
\text { Salvador, Guatemala, Honduras, México, Nicaraguá, Panamá, } \\
\text { Trinidad e Tobago, Venezuela }\end{array}$ \\
\hline Merosargus convexifrons James, 1971 & Neotropical (Costa Rica, Equador, México) \\
\hline Merosargus coriaceus Giglio-Tos, 1891 (Figs. 243, 306, 336, 365, 392, 429, 454) & Neotropical (Costa Rica, Guatemala, México) \\
\hline Merosargus elatus Curran, 1932 (Figs. 252, 286, 315, 373, 400, 437, 462, 489) & Neotropical (Costa Rica, Mexico, Panamá) \\
\hline Merosargus festivus Williston, 1888 (Figs. 247, 281, 310, 340, 369, 396, 433, 458, 484) & Neotropical (Brasil) \\
\hline Merosargus hyalopterus Giglio-Tos, 1891 (Figs. 242, 277, 305, 335, 364, 391, 428, 480) & Neotropical (Equador, México Peru) \\
\hline Merosargus lampronotus James, 1941 (Figs. 257, 291, 321, 350, 352, 405, 442, 467, 492) & Neotropical (Costa Rica, Panamá) \\
\hline
\end{tabular}




\begin{tabular}{|c|c|}
\hline Merosargus mirabilis James, 1971 (Figs. 234, 269, 297, 327, 356, 383, 411-412, 420, 447, 473) & Neotropical (Costa Rica, Guatemala, México) \\
\hline Merosargus nebulifer James, 1971 (Figs. 246, 280, 309, 339, 368, 395, 432, 457, 483) & Neotropical (Brasil, Equador, Panamá, Peru) \\
\hline Merosargus obscurus Wiedemann, 1830 (Figs. 244, 278, 307, 337, 368, 393, 430, 455, 481) & Neotropical (Brasil) \\
\hline Merosargus opaliger Lindner, 1931 (Figs. 258, 292, 322, 351, 379, 406, 443, 468) & Neotropical (Brasil) \\
\hline Merosargus taeniatus Wiedemann, 1830 (Figs. 245, 279, 308, 338, 367, 394, 431, 456, 482) & Neotropical (Brasil) \\
\hline Merosargus, sp. nov. 1 (Figs. 260, 293, 323, 352, 469, 493) & Neotropical (Bolívia) \\
\hline Merosargus, sp. nov. 2 (Figs. 250, 284, 313, 343, 460, 487) & Neotropical (Brasil) \\
\hline Merosargus, sp. nov. 3 (Figs. 251, 295, 314, 344, 372, 399, 436, 461, 488) & Neotropical (Brasil) \\
\hline \multicolumn{2}{|l|}{ Ptecticus } \\
\hline Ptecticus lanei James, 1941 (Figs. 237, 272, 300, 330, 359, 386, 423, 449) & Neotropical (Brasil) \\
\hline \multicolumn{2}{|l|}{ Sargus } \\
\hline Sargus fasciatus Fabricius, 1805 (Figs. 232, 261, 267, 295, 325, 354, 381, 418, 445, 471) & $\begin{array}{l}\text { Neártica (Canadá, EUA); Neotropical (Bahamas, Brasil, Costa } \\
\text { Rica, Cuba, República Dominicana, Equador, El Salvador, } \\
\text { Granada, Guatemala, Honduras, Jamaica, México, Panamá, } \\
\text { Porto Rico) }\end{array}$ \\
\hline Sargus thoracicus Mcquart, 1834 (Figs. 233, 268, 296, 326, 355, 382, 408-410, 419, 446, 472) & $\begin{array}{l}\text { Neotropical (Brasil, Costa Rica, Guatemala, Honduras, } \\
\text { México) }\end{array}$ \\
\hline
\end{tabular}




\subsection{MAPAS DE DISTRIBUIÇÃO}

Os mapas de distribuição das espécies do gênero foram construídos usando o Google Earth 7.1.1.1888, onde foi feita a plotagem dos pontos a partir de coordenadas geográficas e/ou localidades dadas pelas etiquetas e o Quantum Gis 2.0.1-Dufour, utlizado para construção e edição final dos mapas.

\section{RESULTADOS}

\subsection{Revisão taxonômica}

Foram examinadas 18 espécies de Acrochaeta, das quais nove já descritas anteriormente (Quadro 1) e oito novas. Apenas Acrochaeta elegans Perty, 1833 não foi examinada, pois se trata de uma espécie de Chrysochlorina (comunicação pessoal com o Dr. Norman E. Woodley) e, portanto, sua inclusão em Acrochaeta equivocada. Das nove espécies conhecidas de Acrochaeta, apenas seis foram redescritas, uma vez que $A$. chalconota Brauer 1882, A. longiventris Enderlein 1914 e A. picta Brauer 1882 pertencem a outro gênero, como apontado pela análise cladística do presente trabalho. Por outro lado, de acordo com a mesma análise cladística apresentada aqui, $M$. convexifrons McFadden, 1971 corresponde a uma espécie de Acrochaeta, sendo, portanto, também redescrita. Assim, o gênero atualmente conta com 15 espécies—sete já descritas e oito novas.

\section{Acrochaeta Wiedemann, 1830}

(Figs. 7-212)

Acrochaeta Wiedemann, 1830: 42. Espécie-tipo, Acrochaeta fasciata Wiedemann (monótipo).

Compsosoma Brauer, 1882: 79. Espécie-tipo, Compsosoma chalconota Brauer (designação original), comb. nov.

Achrochaeta Giglio-Tos, 1893: 16, erro.

Diagnose. Coloração do corpo amarelo a marrom escuro, nunca metálica, exceto o mediotergito. Tubérculo ocelar projetado (Figs. 8 e 9), marrom escuro a preto, 
contrastando com a coloração amarelada da área medial da parte superior da fronte. Antenas alongadas, com os flagelômeros sempre mais longos que largos (e.g., Figs. 14, 24, 75), arista tão ou mais longa quanto o restante da antena (e.g., Figs. 14, 24, 75). Calo frontal não distinto da parte inferior da fronte. Escudo e abdômen com largas bandas escuras longitudinais e horizontais respectivamente (e.g., Figs. 146 e 153). Asas amarelo avermelhadas (e.g., Fig. 96 e 98), quase tão longa quanto o corpo; $\mathbf{R}_{\mathbf{2}+3}$ sempre surgindo depois de r-m, pelo menos a uma distância equivalente ao comprimento de r-m (e.g., Fig. 11); célula discal alongada (e.g., Fig. 11); CuP alcançando a bifurcação entre $\mathrm{CuA}_{1}$ e $\mathrm{CuA}_{2}$ (e.g., Fig. 11); álula estreita, com pilosidade, quando presente, apenas súpero-distal (e.g., Fig. 122). Abdômen clavado, fortemente peciolado entre os segmentos 1-2 (e.g., Figs. 152 e 153).

Redescrição. Macho. Comprimento: corpo, 7.5-19.0; asa, 8.0-14.0. Cabeça (e.g., Figs. 7-9). Vértex estreito com cerdas; tubérculo ocelar projetado acima da margem dos olhos, marrom escuro a preto, não metálico, constrastando com a coloração amarela da parte superior da fronte. Margens da área medial da parte superior da fronte com coloração mais clara que a margem lateral, não metálica, frequentemente convergindo em direção ao calo frontal; área lateral originando-se posteriormente no vértex. Calo frontal tão proeminente quanto a parte inferior da fronte. Antenas alongadas; escapo mais longo que o pedicelo; complexo flagelar alongado (flagelômeros mais longos que largos); quarto flagelômero pequeno, retangular; arista apical, tão longa quanto o restante da antena, larga e pubescente na base. Tórax (Fig. 10). Amarelo a marrom escuro, bandas longitudinais do escudo marrom escuras; escutelo preto anteriormente; pleura frequentemente com manchas escuras; mediotergito metálico ou não metálico. Pernas amarelo avermelhadas, coxas e fêmures posteriores frequentemente marrom escuros. Asa (e.g., Fig. 11). Coloração das veias amarelo avermelhadas. $\mathrm{R}_{2+3}$ originando-se depois de $\mathrm{r}-\mathrm{m}$, a uma distância equivalente à metade do comprimento de $\mathrm{r}-\mathrm{m}$, paralela a $\mathrm{R}_{1}$ até a margem da asa; $\mathrm{r}-\mathrm{m}$ frequentemente tão longa quanto o terceiro setor da célula discal ou quanto bm-cu. Segundo e quarto setores da célula discal frequentemente mais longos que o primeiro e quinto, respectivamente (célula discal alongada); veia $\mathrm{M}$ distinta apenas apicalmente; $\mathrm{M}_{3}$ convexa, incompleta no seu último quinto distal; veia $\mathrm{CuP}$ alcançando ou bem próxima da bifurcação entre $\mathrm{CuA}_{1}$ e $\mathrm{CuA} 2$. Extremo basal de $\mathrm{A}_{1}$ nua até metade de seu comprimento (e.g., Figs. 11, 123). Álula estreita, frequentemente com pouca pilosidade súpero-distal. Abdômen. Amarelo 
dourado a marrom escuro, com largas bandas horizontais marrons escuras. Clavado, tergitos 3-5 bruscamente mais largos que 1-2; peciolado, tergito 1 com a parte proximal mais larga, tergito 2 com a parte proximal mais estreita. Genitália. Cápsula genital frequentemente arredondada. Gonocoxitos e hipândrio parcialmente fusionados; apódema gonocoxal com comprimento muito variável, muito acima da margem basal da genitália; extensão longitudinal do apódema ultrapassando a metade do singonocoxito; processo medial do singonocoxito digitiforme. Apódema ejaculatório bem desenvolvido, muita acima do limite basal da genitália. Parâmeros projetados ou não, fusionados à base do edeago. Edeago trífido, lóbulos de formato e comprimento semelhantes (e.g., Figs. 30-32). Gonóstilos largos, convexos dorsalmente. Epândrio suavemente mais longo que largo (quadrangular) a distintamente mais longo que largo. Próctiger bem desenvolvido, largura equivalente ao comprimento dos cercômeros; cercomêros em formato de bastão.

Fêmea. Similar ao macho, exceto no que segue. Comprimento: corpo, 8.0-18.0; asa, 7.0-13.5. Genitália. Tergito 8 largo, retangular. Tergito 9 frequemente mais largo posteriormente, conectado lateralmente com a furca. Furca genital em formato de "Y" fortemente estreitando da porção posterior para a anterior; margem posterior frequentemente bilobada; processos póstero-laterais paralelos, muito estreitos no terço basal; abertura genital oval, pequena, ocupando menos que um terço da porção anterior da placa. Cercômero 1 maior em comprimento que o comprimento do cercômero 2.

Distribuição geográfica. Neotropical (Antígua e Barbuda, Bolívia, Brasil, Costa Rica, El Salvador, Equador, Guatemala, México, Panamá, Paraguai) (Fig. 213-216).

Comentários. Em Sarginae, o S9 (hipândrio) sempre aparece fundido aos gonocoxitos, condição modificada em relação ao plano-básico de Diptera e compartilhada com outras famílias de Brachycera (Wood 1991; Sinclair et. al. 1993). Entretanto, como é o caso aqui (clado das espécies metálicas de Merosargus + Acrochaeta), nota-se a presença de uma linha (às vezes mais fraca, às vezes mais forte) entre o que seriam os dois gonocoxitos (e.g., Figs. 27 e 403), indicando que não há uma fusão completa entre eles-a qual seria uma condição apómorfica em relação à fusão completa vista nas espécies utilizadas como grupos externos (e.g., Figs. 381 e 392). Essa estrutura fundida ou às vezes parcialmente fundida tem recebido diferentes nomes na literatura, como “synsternite” (Rozkošný \& Kovac 2000). Entretanto, essa estrutura atualmente é considerada como a fusão da margem posterior dos gonocoxitos e não uma extensão distal do S9. Dessa forma, o termo usado aqui para se referir a ela será “singonocoxito”. 
No que diz respeito às modificações da genitália masculina dentro do gênero, algumas estruturas (gonóstilos, edeago e parâmeros) mostram-se bastante modificadas em algumas espécies com relação ao plano-básico de Acrochaeta: gonóstilos fortemente estreitos no terço apical (e.g., Fig. 58), edeago com uma única abertura e porção dorsal dos parâmeros extremamente projetada em forma de forquilha muito além do ápice do edeago (e.g., Figs. 67-69). Essas modificações, juntamente com outras características, tem suportado a formação de um grupo de espécies dentro do gênero, como é discutido abaixo, no chamado grupo-flaveola. 

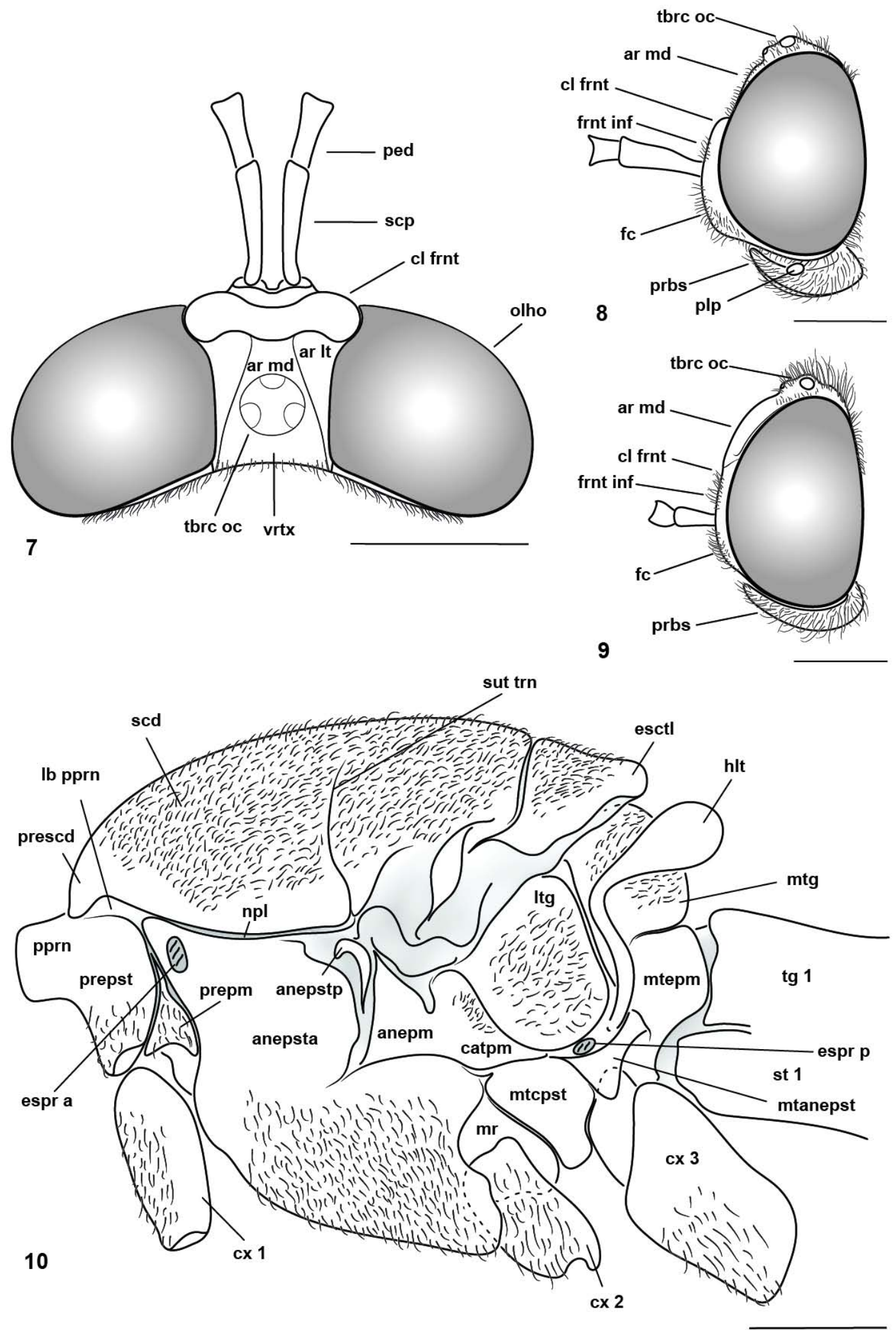

Figuras 7-10. Cabeça e tórax de espécies de Acrochaeta. 7. A. fasciata, cabeça em vista dorsal. 8. A. adusta, cabeça em vista lateral. 9. A. dichrostyla, sp. nov. (holótipo macho), cabeça em vista lateral. 9. A. fasciata, tórax em vista lateral. Escala, 1 mm. 


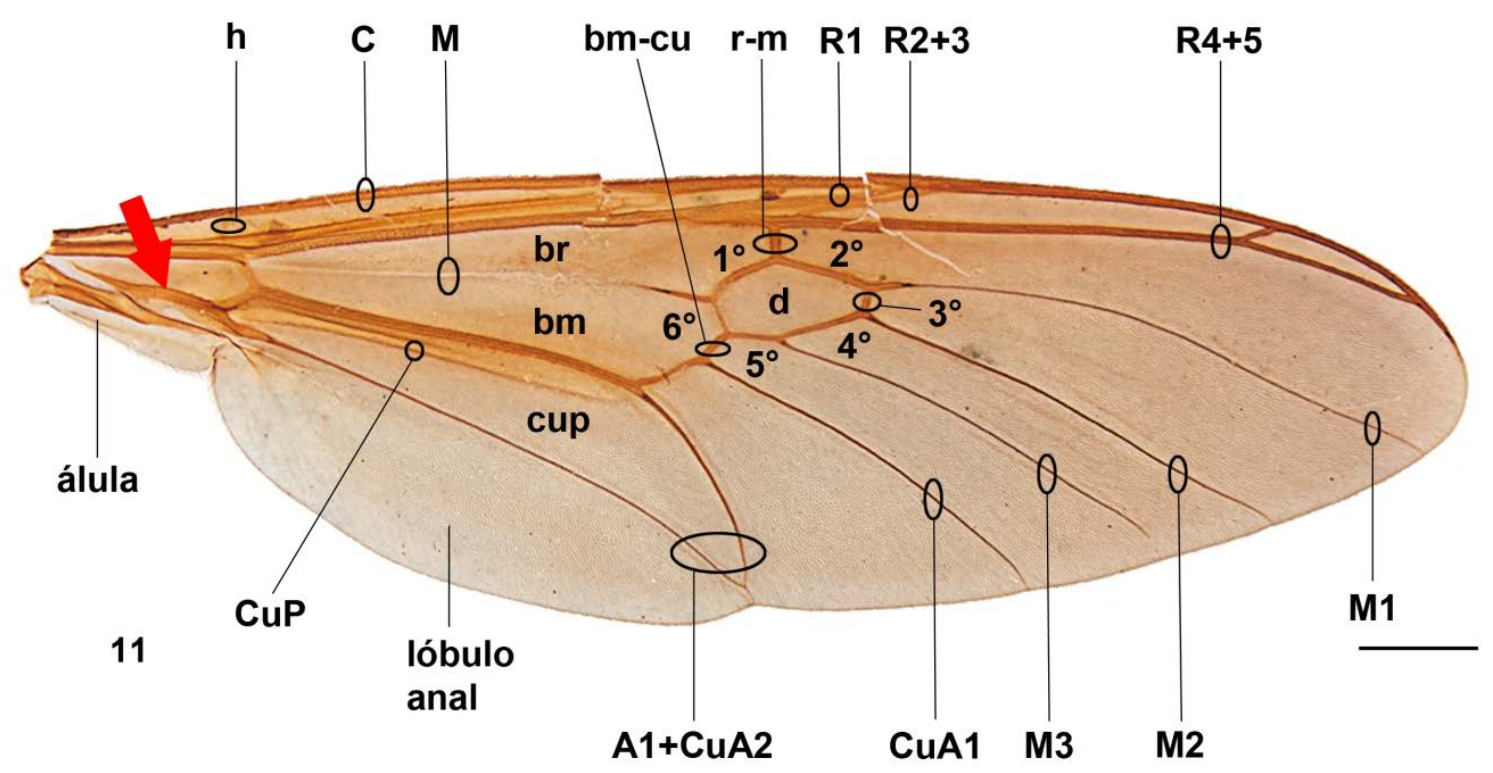

Figura 11. Asa de Acrochaeta fasciata. A seta vermelha indica o que foi considerado como o extremo basal de $\mathrm{A}_{1}$. Escala, $1 \mathrm{~mm}$.

\section{Acrochaeta degenerata Lindner, 1949}

(Figs. 12-14, 92-93, 120, 135, 150, 164-168)

Acrochaeta degenerata Lindner, 1949: 812-813. Localidade-tipo: Brasil, Santa Catarina. Holótipo macho, [BMNH].

Diagnose. Parte superior da fronte larga—claramente mais larga que nas outras espécies (Fig. 93)—, lateralmente marrom escura, marcada de amarelo próximo à margem dos olhos e do calo. $\mathrm{R}_{2+3}$ muito curta, originando antes de $\mathrm{r}-\mathrm{m}$, fusionada com $\mathrm{R}_{1}$ logo em seguida (Fig. 92); célula discal quase retangular, segundo setor duas vezes mais longo que o primeiro (Fig. 92). Abertura genital da furca dividida em três oríficios semicirculares de tamanho similar (Fig. 13).

Material examinado. HOLÓTIPO, 1 \#m, BRASIL, Santa Catarina, Nova Teutônia,

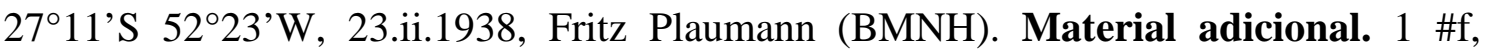
BRASIL, Minas Gerais, Arcelurgo, F. Fortaleza, xii.1946, Barretto col. (MZUSP). 1 \#f, Santa Catarina, Chapecó. Linha Montebelo, 277’11.74”S 52³2’20.22”W, 580m, 1-31.x.2012, M. Savaris, S. Lampert cols.; 2 \#f, 1-30.xi.2012. (MZUSP). 
Redescrição. Fêmea. Comprimento: corpo, 9.0-10.0; asa, 8.0-9.5. Cabeça (Fig. 93). Vértex amarelo a marrom escuro, distalmente marrom escuro; tubérculo com pilosidade negra. Parte superior da fronte variando de amarelo a marrom escuro medialmente; marrom escuro lateralmente, com marcas amarelas próximas à margem dos olhos e do calo; margens mediais paralelas distalmente ao tubérculo; fronte imediatamente acima ao calo suavemente achatada; calo frontal amarelo (em alguns casos com uma larga mancha marrom cobrindo quase toda sua extensão); parte inferior da fronte e face variando entre amarelo e marrom. Antenas marrom escuras; escapo quase duas vezes o comprimento do pedicelo; complexo flagelar extremamente alongado (3-3.5:1) (Fig. 14); quarto flagêlomero tão longo quanto a arista basalmente; arista com muitas cerdas basalmente. Tórax (Fig. 135). Coloração amarela a amarela avermelhada com bandas do escudo bem distintas; banda medial com variação de espessura; escutelo mais escuro anteriormente; anepisterno anterior, catepisterno e anepímero com ou sem manchas escuras; laterotergito e mediotergito totalmente marrom escuros ou com manchas escuras apenas proximalmente. Pernas amarelo avermelhadas, exceto pelos tarsos anteriores, dois terços dos fêmures medianos e posteriores e coxas posteriores, marrom escuras. Asa (Fig. 92). $\mathrm{R}_{2+3}$ reduzida, originando-se antes de $\mathrm{r}-\mathrm{m}$, fundindo-se com $\mathrm{R}_{1}$ logo depois de sua origem, $\mathrm{r}-\mathrm{m}$ tão longa quanto terceiro setor da célula discal ou bmcu. Segundo setor duas vezes o comprimento do primeiro (célula discal retangular), quarto setor mais curto que o quinto; $\mathrm{M}_{3}$ reta. Extremo basal de $\mathrm{A}_{1}$ pilosa em todo seu comprimento (Fig. 120). Álula nua (Fig. 120). Halteres amarelo avermelhados. Abdômen. Amarelo, com largas bandas marrom escuras; mancha do segmento $1 \mathrm{com}$ variação intraespecífica, estreita (menos da metade) ou encobrindo quase todo o segmento. Genitália (Figs. 12-13). Tergito 8 suavemente mais estreito anteriormente. Tergite 9 subdividido em duas placas romboidais. Furca genital muito estreita na porção anterior (Fig. 13); margem posterior convexa, não bilobada; processos póstero-laterais paralelos, estreitos no terço basal e apical; abertura genital dividida em três oríficios semi-circulares de tamanho similar. Cercômero 1 duas vezes o comprimento do cercômero 2.

Distribuição geográfica. Brasil (Minas Gerais, Santa Catarina) (Fig. 213).

Comentários. Apesar dessa espécie não ter sido recuperada como sendo do clado Acrochaeta, optou-se por mantê-la no gênero. A justificativa sobre a sua manutenção em Acrochaeta se apoia na presença das mesmas sinapomorfias do gênero (e.g., escudo fortemente marcado por três faixas longitudinais, abdômen peciolado) e de grupos mais 
inclusivos em Acrochaeta (elevação do tubérculo ocelar) ainda que não haja informação de genitália masculina (para mais detalhes, ver Discussão, pág. 125). Essa é a única espécie de Acrochaeta que apresenta três aberturas na furca genital (Fig. 13). Duas espécies de Merosargus (M. akrei James \& McFadden, 1971 e M. bivittatus James, 1971) também apresentam essa condição (Figs. 451 e 459, respectivamente), entretanto, não há indício de parentesco direto entre essas três espécies, se tratando de uma condição apomórfica que deve ter surgido mais de uma vez na história de Sarginae.

O holótipo macho examinado por fotos (Figs. 164-168) encontra-se em boas condições, mas sem os flagelômeros, e as pernas medianas e posteriores estão danificadas, bem como a asa esquerda em $\mathrm{R}_{1}$.
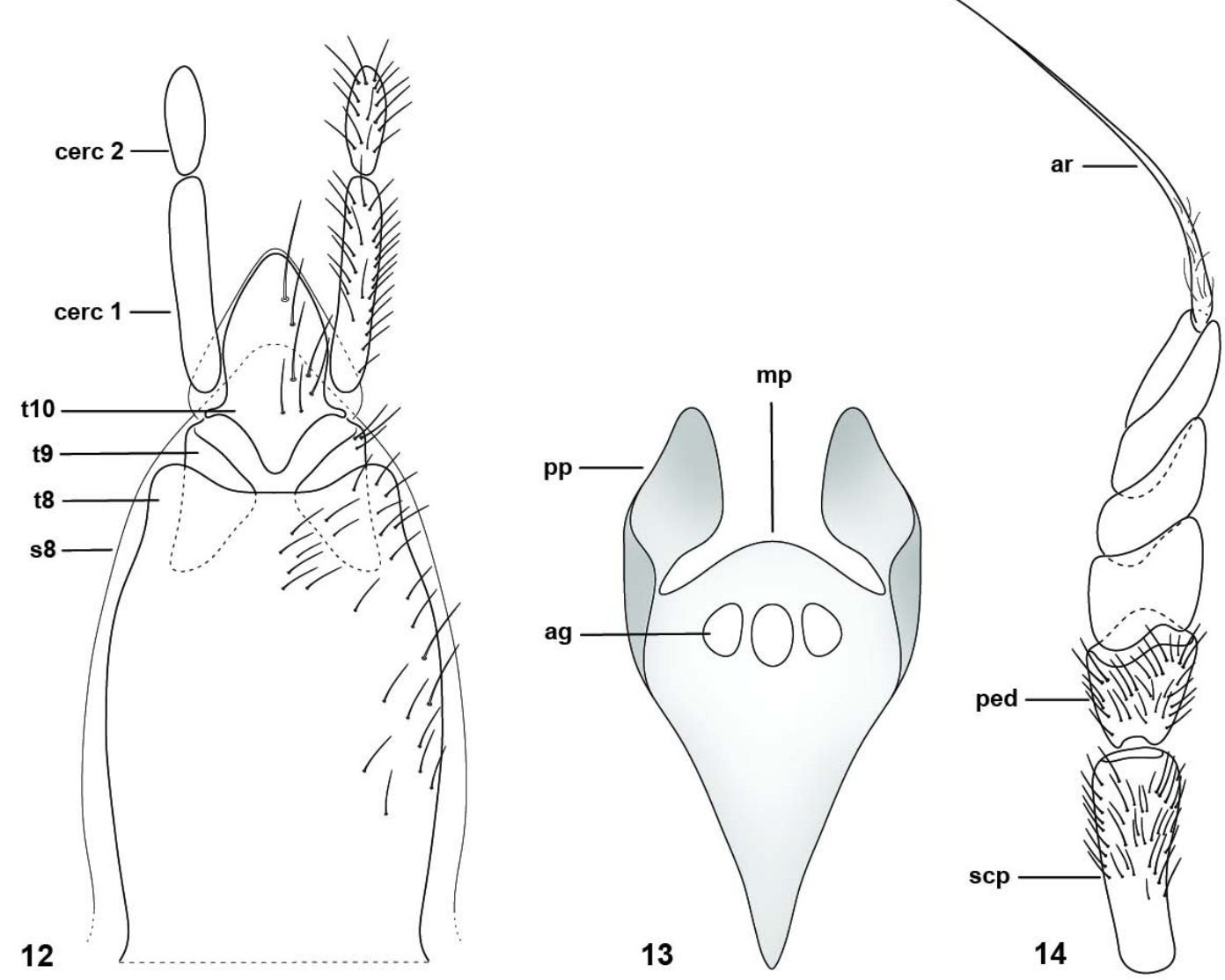

Figuras 12-14. Acrochaeta degenerata, fêmea. 12. Genitália feminina, vista dorsal. 13. Furca genital. 14. Antena. 


\section{Acrochaeta asapha, sp. nov.}

(Figs. 15-17, 94-95, 121, 136, 151)

Diagnose (fêmea). Cabeça e corpo bem escurecidos (marrom escuro) (Fig. 151). Tubérculo ocelar não projetado. Tórax totalmente escuro (Fig. 136), tornando de difícil visualização o padrão de bandas do escudo. $R_{2+3}$ originando-se bem depois de r-m (Fig. 94). Álula nua (Fig. 121).

Material examinado. HOLÓTIPO, \#f (lâmina permanente), BRASIL, São Paulo, Ribeirão Grande, Parque Estadual Intervales-Barra Grande, Malaise, 2405’52.5”S 48²2’17.5”W, 13-16.xii.2000, M. T. Tavares \& eq. cols. (MZUSP).

Descrição. Fêmea. Comprimento: corpo, 12.0; asa, 9.5. Cabeça (Fig. 95). Vértex marrom-avermelhado; tubérculo ocelar não projetado. Parte superior da fronte marrom avermelhada medialmente, margens abaixo do tubérculo estreitando-se ventralmente (mais ou menos triangulares), área lateral preta; parte inferior da fronte e face marrom avermelhada. Antenas marrom escuras; escapo mais longo que o pedicelo; complexo flagelar extremamente alongado (3.2:1) (Fig. 15); quarto flagelômero suavemente menor em tamanho que a parte basal da arista; arista larga e pubescente basalmente. Tórax (Fig. 136). Marrom avermelhado a marrom escuro; faixas do escudo marrom escuras a pretas. Pernas anteriores marrom avermelhadas; medianas e posteriores, marrom escuras, exceto pelas tíbias e tarsômeros, marrom amarelados. Asa (Fig. 94). $\mathrm{R}_{2+3}$ originando-se bem depois de $\mathrm{r}-\mathrm{m}$, próximo do ápice da célula discal; $\mathrm{r}-\mathrm{m}$ mais longa que o terceiro setor da célula discal ou bm-cu. Segundo e quarto setores levemente mais longo que o primeiro e quinto, respectivamente (célula discal não alongada). Álula nua (Fig. 121). Halteres marrom amarelados. Abdômen. Marrom avermelhado. Genitália (Figs. 16-17). Tergito 9 mais largo posteriormente. Furca genital com a porção anterior gradualmente diminuindo de largura em direção à base (Fig. 16); leve incisão medial na margem posterior; processos póstero-laterais paralelos, exceto pelo extremo distal, divergente; abertura genital pequena, oval. Cercômero 1 duas vezes o comprimento do cercômero 2.

Macho. Desconhecido.

Etimologia. O nome da espécie é feminino e o epíteto específico vem do grego asaphes, significando escuro, como referência à coloração marrom escura da espécie, quando comparada com as demais do gênero.

Distribuição geográfica. Brasil (São Paulo) (Fig. 213). 
Comentários. Apesar da ausência de informação de genitália masculina, essa espécie foi recuperada como irmã de todas as outras espécies de Acrochaeta (Fig. 217).
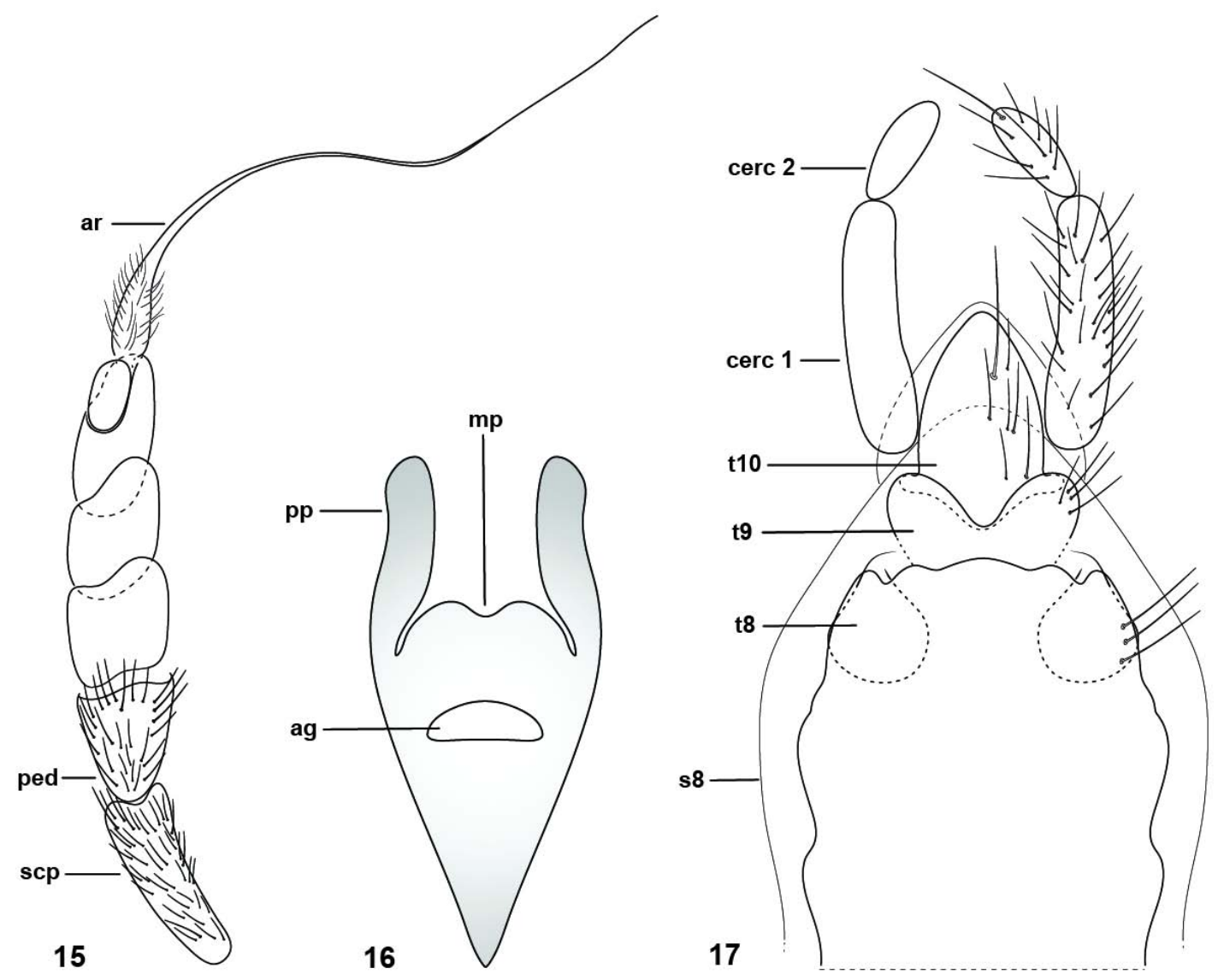

Figuras 15-17. Acrochaeta asapha, sp. nov., holótipo fêmea. 15. Antena. 16. Furca genital. 17. Genitália feminina, vista dorsal.

\section{Acrochaeta adusta Lindner, 1949}

(Figs. 18-23, 96-97, 122, 137, 152, 169-172)

Acrochaeta adusta Lindner, 1949: 813. Localidade-tipo: Brasil, Santa Catarina, Nova Teutônia. Holótipo fêmea, [BMNH].

Diagnose. Corpo marrom a marrom escuro (Fig. 152). Antenas fortemente alongadas, com a arista gradualmente afinando em direção ao ápice, completamente coberta por cerdas nos dois terço basais (Fig. 18). Escudo em alguns casos, com difícil visualização das bandas longitudinais (Fig. 137). 
Material examinado. HOLÓTIPO, 1 \#f, BRASIL, Santa Catarina, Nova Teutônia, 27²1's 52²3’W, ii.1937, Fritz Plaumann (BMNH). Material adicional. 1 \#m, BRASIL, Bahia, Camacan, Serra Bonita, Córrego 1, 15²3’26”S 39³3’58”W, 822m, 31.vii-4.viii.2008, Malaise trap, Calor, Lecci, Pinho, \& Moretto col. 1 \#m, 2 \#f, Espírito Santo, Santa Teresa, Estação Biológica Santa Lucia, 867m, 1958’37.3”S 39³3’58”W, 06-09.iv.2001, Malaise trap, Ponto 1, bosque, Azevedo, C.O. col. 1 \#m, Minas Gerais, Botelhos, Córrego da Onça, 2140’90”S 46²2’05”W, 15.xii.200615.i.2007, Malaise trap, Basso, J. col.; 1 \#m, 4 \#f, 15.i-21.ii.2007; 1 \#m, 21.ii30.iii.2007; 1 \#f (slide-mounted), 07.xii.2008-06.i.2009; 1 \#f, 05-20.xi.2006, Amorim, Falaschi \& Oliveira col. 1 \#f, Cabo Verde, Fazenda da Cata, 21²7’11.04”S 46²0’52.8”W, 07-23.ix.2006, Malaise trap, Amorim, Ribeiro, Falaschi \& Oliveira col.; 1 \#f, 10-23.ix.2006; 1 \#m, 1 \#f, 11.viii-13.x.2007; 1 \#m, 01-04.2010, Amorim col; 1 \#f, 1.iv-10.ix.2010, Amorim, Oliveira \& Capellari col; 1 \#m, 03.xi.2010-19.ii.2011, Amorim \& Oliveira col. 1 \#m, 14.vii.2011-04.2012, Malaise trap, clareira, Amorim \& Oliveira col.; 3 \#m, Malaise trap, barranco. 1 \#m Lavras, ix.1948, Vaiidone R. 1 \#f, Paraná, Morretes, Parque Estadual do Pau Oco, 25³4’27.9”'S 4853’46.7”W, Malaise trap, 10-13.iv.2002, Tavares, M.T \& eq. cols. 1 \#f, Rio de Janeiro, 1 \#f, Itatiaia, Macieiras, 1800m, i.1948, C. d’Andretta; 1 \#f, Maromba, ix.1946, Barretto col. 1 \#m,

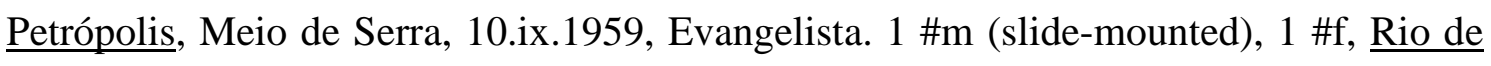
Janeiro, Parque Estadual do Desengano, Trilha, Refugo, Malaise trap 2, 17-20.iv.2002; 1 \#m (slide-mounted), Bosque, Malaise trap 3; 1 \#f, Bosque, Malaise trap, 2023.iv.2002; 1 \#m, 17-20.iv.2002; 1 \#m, Bosque, 17-20.iv.2002. 1 \#m, Distrito Federal, iv.1938. (MZUSP). 1 \#m, 1 \#f, Santa Catarina, Joinville, 26¹8’18.3”S 4850'45.9”W, viii.1940, Shade, F. (USNM). 1 \#f, São Bento do Sul, 26¹4’50.9”S 49²2’52.8”W. 1 \#m, São Paulo, Barueri, 23³0’40.7”S 4652’36.4”W, 6.xii.1965, Lenko, K. col.; 1 \#f, 15.xii.1965. 1 \#m, Boracéia, vi, 1948, Lane, J. col. 4 \#m, 2 \#f, Cajuru, Cássia dos Coqueiros, 21¹6’31”S 47¹8’17.2”W, ii.1947, Barreto, M.P. col. 1 \#m, 2 \#f, Campos do Jordão, Horto Florestal Estadual, 22.xi.2010, Malaise II, Airton \& Marcos col; 1 \#m, Horto Florestal Estadual, 1527m, 22³9’45.7”S 45²7’11.1”W, Malaise II, 14.iii.2011, A.S. Soares col. 1 \#f, Cantareira, Chapadão, viii.1946, Barretto, col.; 1 \#f, viii.1958, Lane, J. col. 1 \#m, Embú, xii, 1952, Lane, J. col. 13 \#m, 11 \#f, Jundiaí, Serra do Japi, Córrego da cachoeira do Paraíso, 23¹4’S 4657’W, 1050m, 19.xii.2007-20.ii.2008, Malaise trap, Lecci, L.S., Moretto, R.A. \& Nascimento, E.A; 3 \#m (1 \#m slide-mounted), 3 \#f, Serra do Japí, Trilha da Cachoeira do Paraíso-Riacho 
Paraíso, 2314”S 4657”W, 25.ii-12.iii.2008, Malaise trap, Lecci, L.S., Moretto, R.A. \& Nascimento, E.A; 1 \#m, Serra do Japí, 23¹4’29.6”S 4656’14.1”W, 29.vi.2009, Armadilha I, A.S. Soares col.; 1 \#m, Serra do Japí, 23¹4’19.1”S 4656’15.3”W, 29.vi.2009, Armadilha II, A.S. Soares col.; 1 \#f, Serra do Japí, 23¹4’2.5”S 4656’18.5”W, 29.vi.2009, Armadilha III, Alt. 1173m, A.S. Soares col.; 1 \#m, Serra do Japí, 23¹3’54.1”S 4656’22.6”W, 29.vi.2009, Armadilha IV, Alt. 1195m, A.S. Soares col.; 2 \#m, 1 \#f, Serra do Japí, 08.v.2010, Malaise I. 1 \#m, Salesópolis, Estação Ecológica de Boracéia, 19.iii.1972, Guimarães, J.H. col.; 1 \#m, 22.ii.1966, Rabello, E. col. 1 \#f, Santo André, REBIO, Paranapiacaba, 2346’46”'S 46¹8'29”'W, 21.vii21.viii2010, Malaise 3, Moll \& Nihei col. 1 \#m, 1 \#f, São Carlos, Córrego Canchim, 220’47.9”S 4753’27.1”W, 20.xii.2007. 3 \#m, 1 \#f, São Luís do Paraitinga, P.E.S.M. Núcleo Sta. Virgínia, 23¹9’27.2”S 4505’38.5”W, 22.x.2010, Malaise - Ponto 2, N.W. Perioto \& eq. cols; 2 \#f, P.E.S.M. - Núcleo Sta. Virgínia, 23¹9’27.1”S 4505’38.4”W, 22.x.2010, Malaise - Ponto 6 (teste), N.W. Perioto \& eq. cols. 1 \#m, 1 \#f, P.E.S.M. Núcleo Sta. Virgínia, 2319’27.2”S 4505’38.5”W, 22.x.2010, Malaise - Ponto 7 (teste), N.W. Perioto \& eq. cols. (MZUSP).

Redescrição. Macho. Comprimento: corpo, 12.5-16.0; asa, 10.5-14.0. Cabeça (Figs. 8 e 97). Vértex marrom escuro, suavemente projetado; tubérculo ocelar marrom escura a preta. Parte superior da fronte marrom avermelhada (em alguns exemplares quase preta) medialmente; área lateral marrom escuro a preto; margens da área medial triangular abaixo do tubérculo; parte inferior da fronte e face marrons. Antenas marrom escuras, longas; escapo mais longo que o pedicelo; complexo flagelar extremamente alongado (5.8:1) (Fig. 18); quarto flagelômero pequeno e retangular; arista com dois terços basais mais largos e cobertos por cerdas. Tórax (Fig. 137). Marrom a marrom escuro (em alguns exemplares, com difícil distinção das bandas no escudo); escutelo mais escuro anteriormente; pleura com uma mancha amarela no anepisterno e catepisterno. Pernas marrons a marrom escuras, exceto tíbias e tarsos medianos e posteriores, marrom avermelhados. Asa (Fig. 96). $\mathrm{R}_{2+3}$ originando-se próximo de $\mathrm{r}-\mathrm{m}$, a uma distância equivalente a metade do comprimento de $\mathrm{r}-\mathrm{m}$; $\mathrm{r}-\mathrm{m}$ mais longa que o terceiro setor da célula discal ou bm-cu. Segundo e quarto setores mais longos que o primeiro e quinto, respectivamente (célula discal alongada). Halteres amarelo avermelhados. Abdômen. Marrom avermelhado, com largas bandas marrom escuras. Genitália (Figs. 19-21). Cápsula genital levemente quadrangular; apódema gonocoxal muito reduzido; extensão longitudinal dos apódemas alcançando o nível do parâmeros; processo medial 
fortemente projetado. Gonóstilos mais largos nos dois terços basais, estreitando levemente em direção ao ápice. Epândrio quadrangular.

Fêmea. Similar ao macho, exceto no que segue. Comprimento: corpo, 10.0-14.0; asa, 8.5-12.0. Genitália (Figs. 22-23). Tergito 9 mais largo posteriormente. Furca genital com a porção anterior estreitando-se em direção à base (Fig. 22); margem posterior suavemente bilobada; processos póstero-laterais paralelos, estreitos no terço basal; abertura genital oval, pequena, ocupando menos que um terço da porção anterior da placa. Cercômero 1 mais que o dobro do comprimento do cercômero 2.

Distribuição geográfica. Brasil (Bahia, Espírito Santo, Minas Gerais, Paraná, Rio de Janeiro, Santa Catarina, São Paulo) (Fig. 214).

Comentários. Essa espécie aparece na análise cladística como irmã de Acrochaeta fasciata apresentando como sinapomorfias: antenas pilosas e mais largas nos dois terços basais. Além disso, é muito similar a $A$. fasciata no que diz respeito à genitália masculina (e.g., processo medial fortemente projetado, gonóstilos largos), mas pode ser diferenciada da mesma por apresentar a coloração do corpo mais escura (marrom escuro) e faixa horizontal do primeiro tergito abdominal não reduzida (Fig. 152).

O holótipo examinado por fotos (Figs. 169-172) encontra-se em boas condições, mas sem a cabeça, tíbias e tarsos medianos. 

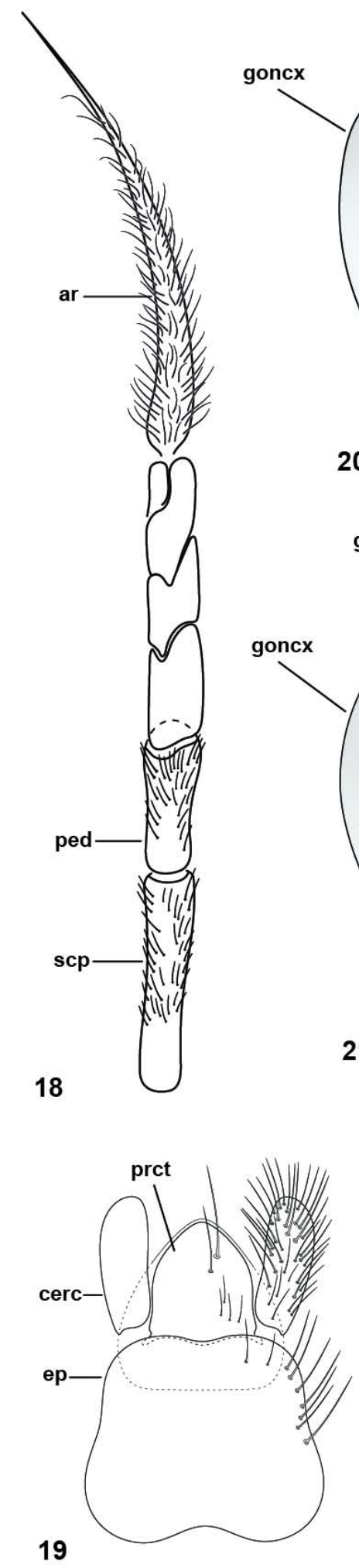
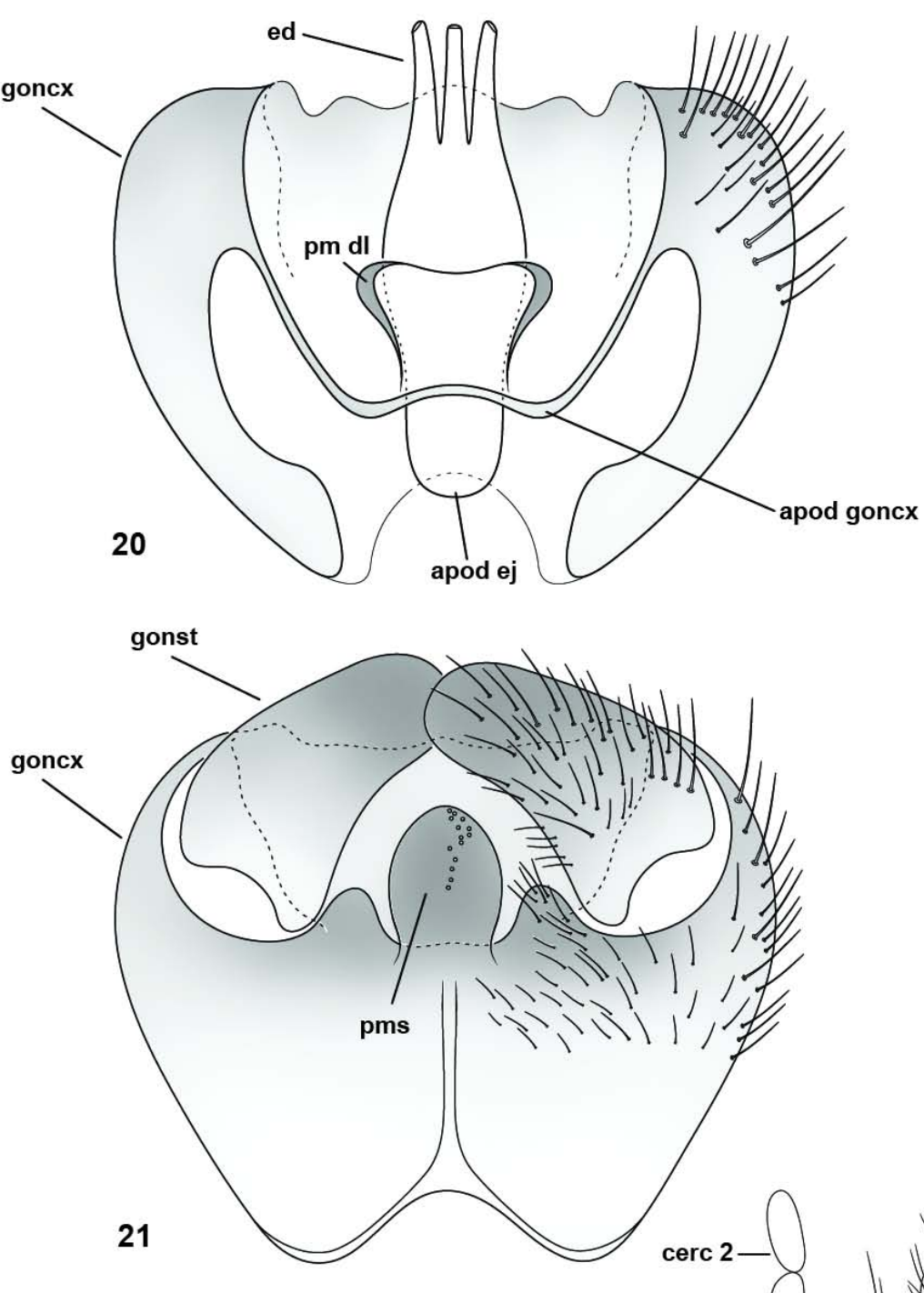

21

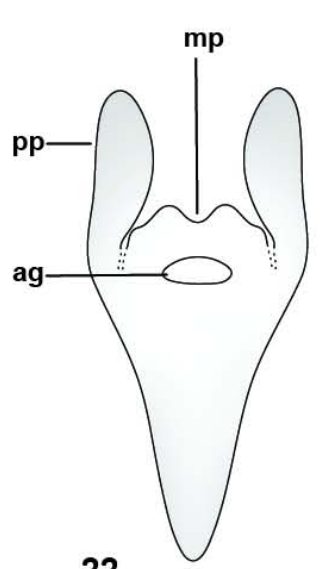

22

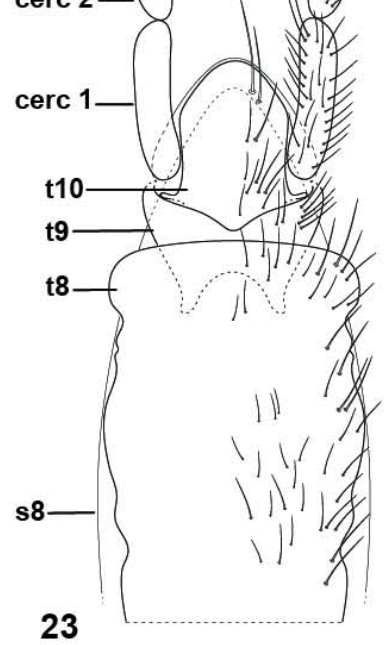

Figuras 18-23. Acrochaeta adusta, (18-21, macho; 22-23, fêmea). 18. Antena. 19. Epandrio, vista dorsal. 20. Cápsula genital, vista dorsal. 21. Cápsula genital, vista ventral. 22. Furca genital. 23. Genitália feminina, vista dorsal. 


\section{Acrochaeta fasciata Wiedemann, 1830}

(Figs. 7, 10, 11, 24-29, 30-32, 123, 138, 153, 173-177)

Acrochaeta fasciata Wiedemann, 1830: 42-43. Localidade-tipo: Brasil. Holótipo macho, [NMW].

Diagnose. Corpo amarelo a amarelo dourado (Fig. 153). Antenas fortemente alongadas, com a arista gradualmente afinando em direção ao ápice, completamente coberta por cerdas nos dois terço basais (Fig. 24), como em A. adusta. Padrão de bandas do escudo bem distinto (Fig. 138). Tergito 1 do abdômen com uma mancha central marrom escura (Fig. 153).

Material examinado. HOLÓTIPO, 1 \#m, BRASIL, Bahia, Coll. Winthem (NMW). Material adicional. 1 \#f, BRASIL, Amapá, Serra do Navio, x.59, Dicelli col. (MNRJ). 1 \#f, Espírito Santo, Santa Teresa, iv.1969, Papavero, N. col.; 1 \#f, Estação Biológica Santa Lucia, 867 m, 1958’37.3”S 40³2’22.5”W, 06-09.iv.2001, Malaise trap, ponto 1, Bosque, Azevedo, C.O. \& eq. col. 1 \#m, ponto 2, Bosque. 5 \#m, 2 \#f, Mato Grosso do Sul, Maracajú, Serviço Febre Amarela, M.E.S., Bras. (MZUSP). 1 \#m, Minas Gerais, Belo Horizonte, 800m, Estação Ecológica, UFMG campus - clear trail 60m in from road near swamp, Malaise trap, 28-30.vi.1993, S.D. Gaimari. (CSCA). 1 \#f, Botelhos, Córrego da Onça, 2140’90”S 46²2’05”W, 20.xi-28.xii.2006, Malaise trap, Basso, J. col.; 1 \#f, 21.ii-30.iii.2007; 1 \#f, 07.xii.2008-06.i.2009. 1 \#f, 16-20.vi.2007, Shannon trap, Amorim, Oliveira, Capellari \& Riccardi col. 3 \#m, Cabo Verde, Fazenda da Cata, 593 m, 2127’08.46”S 46²0’52.8”W, Malaise trap, barranco, 14.vii-04.i.2012, Amorim \& Oliveira col; 1 \#m, clareira; 1 \#f, 21²7’11”S 46²0’52”W, 03.xi19.ii.2011. 2 \#f Itápolis, Fazenda do Pombal, 24.iii.2006, Paula, G.A.R. (MZUSP). 1 \#m, Paraná, Araucária, Larona, S. leg. (MZUSP). 1 \#m, Rio de Janeiro, Itatiaia, Maromba, ix. 1946, Barreto col. 1 \#m, Macieiras, 1800 m, i.1948, d’Andretta, C. 1 \#f, Jardim Botânico, vii.1934, Lopes, M.S. (Coleção Instituto Oswaldo Cruz - nº 9.835); 1 \#m, Embrapa, MNRJ ( ${ }^{\circ}$ 8.016) (MNRJ). 1 \#f, Santa Catarina, Blumenau, Catharina, J. 1 \#f, Chapecó, Linha Monte Belo, 277’74”S 52³2’22”W, 580m, 01-31.x,2012, M. Savaris, S. Lampert cols.; 1 \#m, 1 \#f, Chapecó, Linha Monte Belo, 277’74”S 52³2’22”W, 580m, 01-30.xi,2012, M. Savaris, S. Lampert cols. 1 \#m, Florianópolis, vii.1960, Casemiro, col. 1 \#m, 1 \#f (slide-mounted), Ratones, sobre o afluente do Rio Ratones, Malaise trap I, 27³0’66”S 48²9’22”W, 05.i-07.iii.2010, Pinho, L.C. leg. 1 
\#f, Nova Teutonia, 2711's 52²3’W, 300-500 m, iii.1971, Plaumann, F; 1 \#f, 9.ii.1938; 1 \#m, ix.1952; 1 \#f, vii.1967; 1 \#m, xii, 1969; 1 \#m, x.1970; 1 \#m, xii, 1970; 1 \#m, v.1971. 1 \#m, São Paulo, Barueri, 23³0’40.7”S 4652’36.4”W, 21.iv.1958, Lenko, K; 1 \#m, 5.ii.1966; 1 \#m, 25.ii.1966; 1 \#m, 1 \#f, 18.x.1955. 1 \#f, Cajuru, Cássia dos Coqueiros, ix.1954, Barretto, M.P. col. 1 \#m, Campos do Jordão, Eug. Lefevre, 1200 m, 22.iii.1963, Guimarães, J., Rabello, E., Barroso, A. \& L.T.F; 2 \#f, Horto Florestal Estadual, 22.xi.2010, Malaise II, Airton \& Marcos col. 1 \#m, Embú, 23³8'57”S 4651'9.5”W, xii.1952. Lane, J. 2 \#m, Ferraz de Vasconcelhos, 23³2’32.1”S 46²2’8.3”W, iv.1954, Barreto Reyes. 1 \#f, Iguape, Est. Ecol. JuréiaItatins, 24³1’12”S 47¹2’5.8”W, 19.xi.2010, Malaise Ponto 4, N.W. Perioto \& eq. cols. 2 \#m, 3 \#f (1 \#m, 1 \#f slide-mounted), Jundiaí, Serra do Japí, Trilha da Cachoeira do Paraíso-Riacho Paraíso, Malaise trap, 23¹4”S 4657”W, 25.ii-12.iii.2008, Lecci, L.S., Moretto, R.A. \& Nascimento, E.A.; 4 \#m, 3 \#f, 19.xii.2007-20.ii.2008; 2 \#f, 23¹4'29.6”S 4656’14.1”W, 29.vi.2009, Armadilha I, A.S. Soares col.; 2 \#f, 23¹4’19.1”S 4656’15.13”W, 29.vi.2009, Armadilha II, A.S. Soares col; 1 \#m, 1 \#f, 23¹4’2.5”S 4656’18.5”W, 29.vi.2009, Armadilha III, Alt. 1173m, A.S. Soares col. 1, \#m, 18.iii.2010, Malaise I; 1 \#m, 18.iii.2010, Malaise V; 1 \#m, 1 \#f, 08.v.2010, Malaise I; 2 \#m, 08.v.2010, Malaise IV; 1 \#m, 07.viii.2010, Malaise I. 1 \#f, Juquiá, Lane, J. col. 1 \#m (slide-mounted), Ribeirão Grande, Parque Estadual Intervales-Barra Grande, 245’52.5”S 48²2’17.5”W, 13-16.XII.2000, Tavares, M.T \& eq. cols; 1 \#m, 24¹6’27.7’S 48²5’19.3”W, Malaise - Ponto 3, N.W. Perioto \& eq. cols. 1 \#f, Salesópolis, Reserva Biológica de Boracéia, Trilha dos Pilões 23³9’05.3”S 4553’51.7’W, Malaise trap, ponto 5, mata, 30.iii-02.iv.2001, Amarante, S.T.P. \& eq. cols; 1 \#f, Malaise trap, ponto 6, mata; 1 \#m, 23³9’05.1”S 4553’51.8”W, Malaise trap, 22.ii.2005 (15h00-16h00), Nogueira, L.K. \& Aguiar, A.P.; 1 \#m (slide-mounted), 23³9’S 4553’W, 20-25.xi.2009, Amorim, Ribeiro \& Berbert; 1 \#f, iii.1972, Guimarães, J.H. col. 1 \#f, Carrera, M. ii.1949; 1 \#m, 850 m, 14-16.ii.1950, Trav., Trav. Filho \& Rabello col. 1 \#m, Santo André, REBIO, Paranapiacaba, 2346’46”S 46¹8'29”W, 21.vii-21.viii2010, Malaise 3, Moll \& Nihei col; 1 \#m, 2346’38”S 46¹8’42”W, 21.i-22.ii.2011, Malaise 1, Gudin \& Dios col. 1 \#m, 1 \#f, São Luís do Paraitinga, P.E.S.M - Núcleo Sta. Virgínia, 23¹9’24.8”S 4505’40.1”W, 22.ix.2010, Malaise - Ponto 3, N.W. Perioto \& eq. cols.; 4 \#m, 3 \#f, P.E.S.M - Núcleo Sta. Virgínia, 23¹9’27.2”S 4505’38.5”W, 22.x.2010, Malaise - Ponto 2, N.W. Perioto \& eq. cols.; 2 \#m, 1 \#f, P.E.S.M - Núcleo Sta. Virgínia, 23¹9’16.9”S 4505’46.6”W, 
22.x.2010, Malaise - Ponto 5, N.W. Perioto \& eq. cols.; 5 \#m, 2 \#f, P.E.S.M - Núcleo

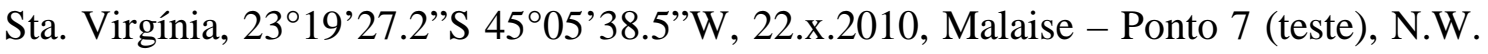
Perioto \& eq. cols.; 3 \#m, P.E.S.M - Núcleo Sta. Virgínia, 23¹9’16.9”S 4505’46.6”W, 21.xii.2010, Malaise - Ponto 5, N.W. Perioto \& eq. cols.; 1 \#m, P.E.S.M - Núcleo Sta. Virgínia, 23¹9’27.1”S 4505’38.4”W, 21.i.2011, Malaise -

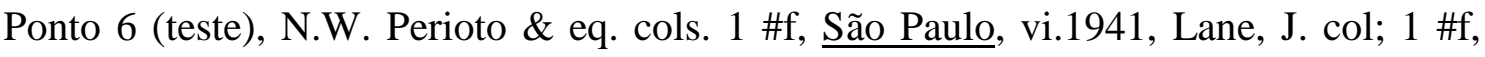
Cantareira, viii.1958, Lane, J. col; 1 \#f, Cidade Jardim, xii.1945, Barretto col. (MZUSP). 1 \#f, PARAGUAI, Canindeyú, Reserva Natura Bosque, Mbaracayú, Jejuímí, Malaise trap 5, bosque médio, 2-10.iv.1996, Costa, A.C.F. col. (DZUP).

Redescrição. Macho. Comprimento: corpo, 10.0-19.0; asa, 8.5-14.0. Cabeça (Fig. 7). Vértex amarelo. Parte superior da fronte amarela medialmente, marrom escura lateralmente; margem da área medial triangular abaixo do tubérculo; parte inferior da fronte e face amarelas. Antenas marrom escuras a pretas, alongadas; escapo mais longo que o pedicelo; complexo flagelar extremamente alongado (4:1) (Fig. 24); quarto flagelômero pequeno, retangular; arista com dois terços basais mais largos, estreitandose em direção ao ápice, cobertos por cerdas. Tórax (Figs. 10 e 138). Amarelo dourado, bandas do escudo marrom escuras; escutelo preto anteriormente; anepisterno anteriormente com pequena mancha escura próximo à sutura notopleural; catepisterno marrom escuro ventralmente. Pernas amarelo avermelhadas, exceto pelos tarsos anteriores, coxas e parte ventral dos fêmures posteriores, marrom escuros. Asa (Fig. 11). $R_{2+3}$ originando-se próximo de $r-m$, a uma distância equivalente à metade do comprimento de r-m; r-m tão longa quanto o terceiro setor de célula discal ou quanto bm-cu. Segundo e quarto setores mais longos que o primeiro e quinto, respectivamente (célula discal alongada). Abdômen. Amarelo dourado com largas bandas horizontais marrom escuras; banda do tergito 1 reduzida ao centro da placa. Genitália (Figs. 25-27, 30-32). Cápsula genital arredondada; apódema gonocoxal muito reduzido; extensão longitudinal dos apódemas alcançando o nível do parâmeros; processo medial fortemente projetado, estreitando-se distalmente. Gonóstilos largos. Epândrio quadrangular, gradualmente estreitando-se em direção ao ápice.

Fêmea. Similar ao macho, exceto no que segue. Comprimento: corpo, 10.0-18.0; asa, 9.0-13.5. Genitália (Figs. 28-29, 30-32). Tergito 9 suavemente mais largo posteriormente, dividido em duas porções mais esclerosadas. Furca genital estreitandose fortemente da porção posterior para a anterior (Fig. 28); margem posterior suavemente bilobada; processos póstero-laterais paralelos, muito estreitos no terço 
basal; abertura genital oval, pequena, ocupando menos que um terço da porção anterior da placa. Cercômero 1 levemente mais longo que o comprimento do cercômero 2.

Distribuição geográfica. Brasil (Amapá, Bahia, Espírito Santo, Mato Grosso do Sul, Minas Gerais, Rio de Janeiro, Santa Catarina, São Paulo), Paraguai. (Fig. 215).

Comentários. A localidade-tipo de Acrochaeta fasciata, espécie-tipo do gênero Acrochaeta, como indicado na descrição original é "Brasil”. A análise das etiquetas do holótipo (Fig. 177), no entanto, indica que a localidade-tipo é “Bahia, Brasil”.

O holótipo macho examinado apenas por fotos (Figs. 173-177) encontra-se em péssimas condições: cabeça bastante danificada (olho esquerdo e fronte), perda dos flagelômeros da antena esquerda, asa direita e pernas posteriores (exceto pelas coxas) abdômen danificado no segmento 1 e a asa rasgada na célula b-m. 


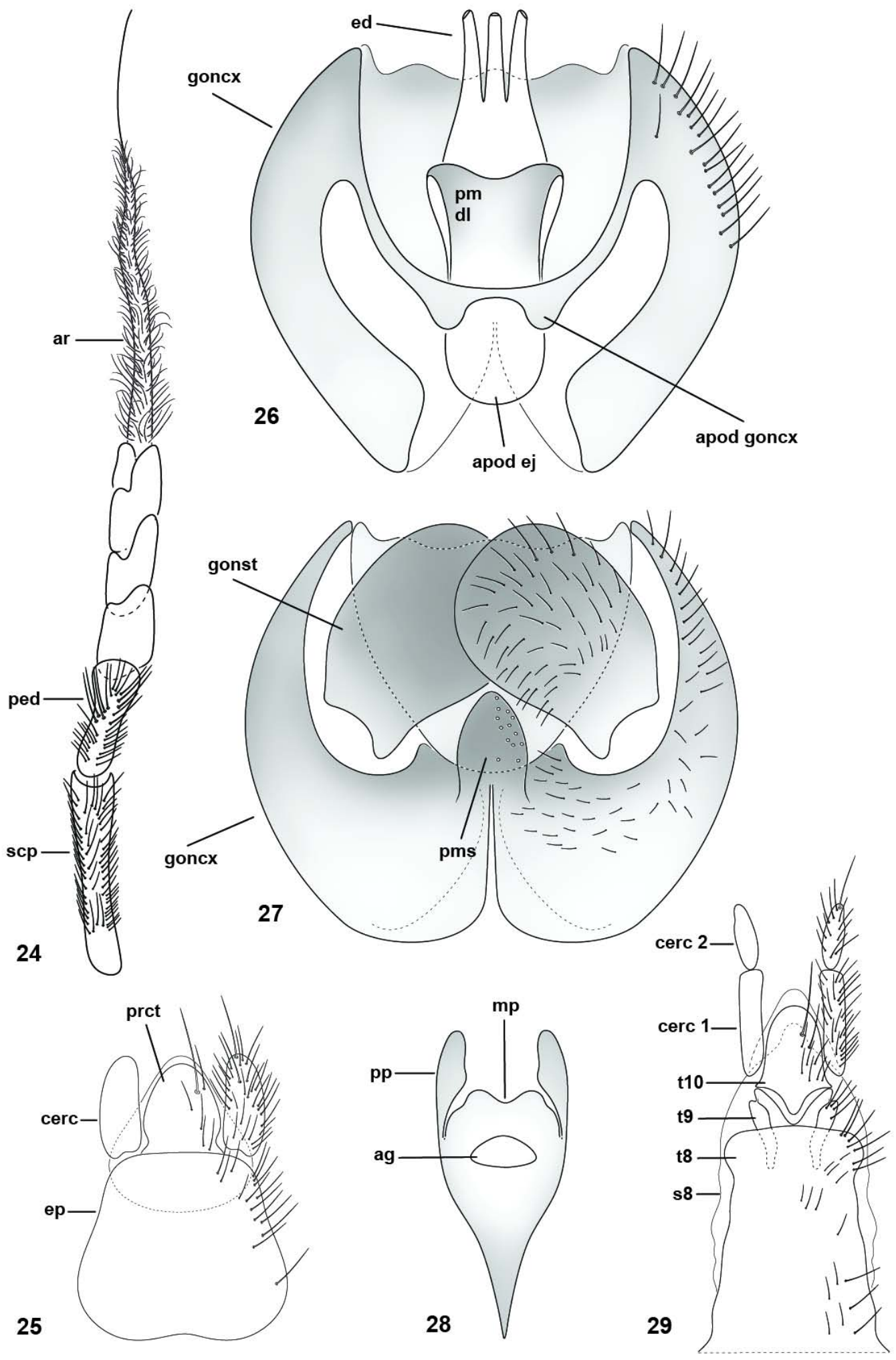

Figuras 24-29. Acrochaeta fasciata (24-27, macho; 28-29, fêmea). 24. Antena. 25. Epândrio, vista dorsal. 26. Cápsula genital, vistal dorsal. 27. Cápsula genital, vista ventral. 28. Furca genital. 29. Genitália feminina, vista dorsal. 

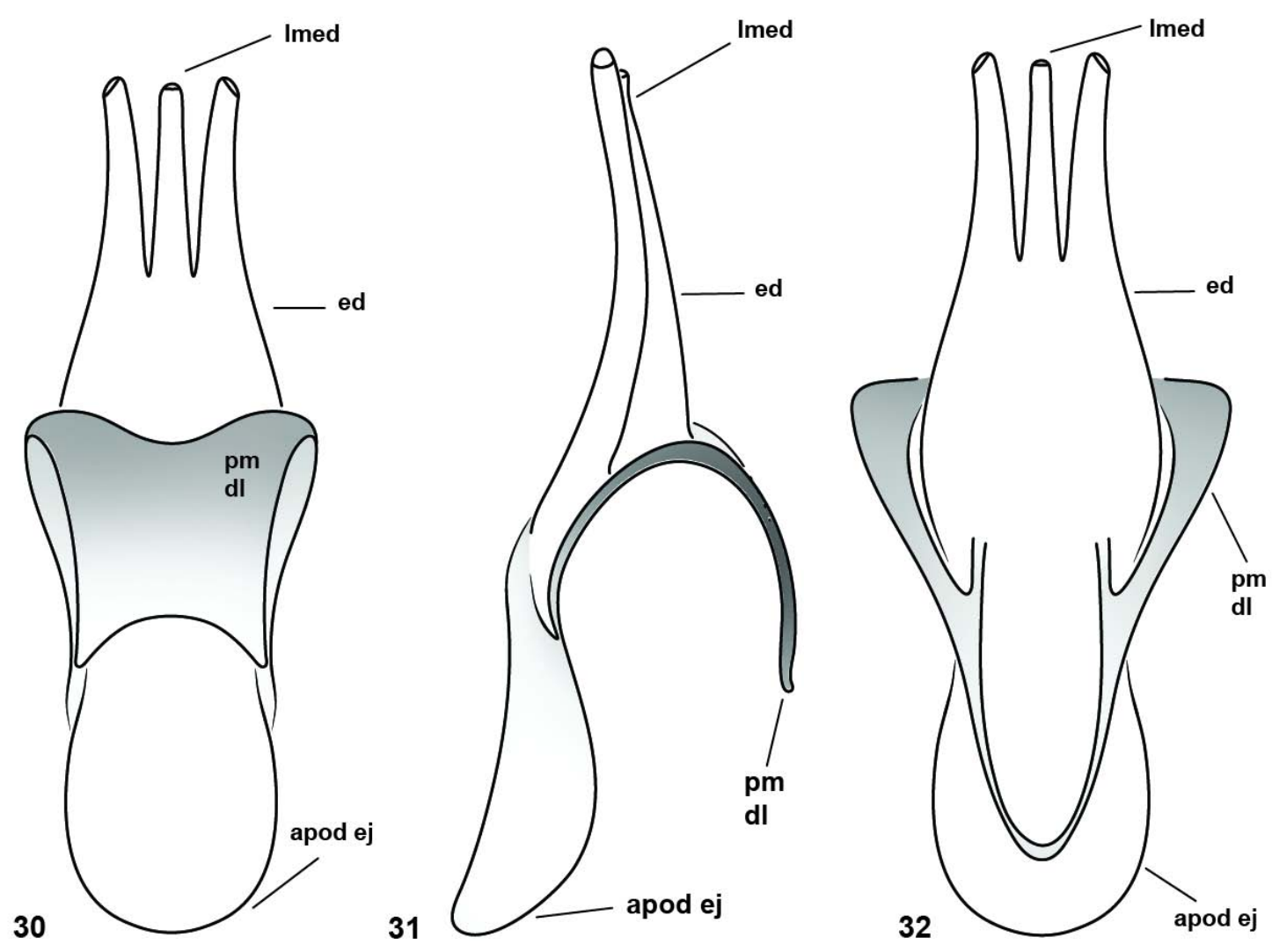

Figuras 30-32. Acrochaeta fasciata, macho. 30. Edeago e parâmeros, vista dorsal. 31. Edeago e parâmeros, vista lateral. 32. Edeago e parâmeros, vista ventral.

\section{Acrochaeta dimidiata Lindner, 1949}

(Figs. 33-36, 98-99, 124, 139, 154, 178-182)

Acrochaeta dimidiata Lindner, 1949: 811-812. Localidade-tipo: Brasil, Santa Catarina, Nova Teutônia. Holótipo macho, [BMNH].

Diagnose (macho). Coloração do corpo amarelo avermelhada (Fig. 154). Pilosidade do vértex concentrada na região do tubérculo ocelar. Parte basal da arista muito mais larga que nas outras espécies (Fig. 33). $\mathrm{R}_{2+3}$ originando-se muito depois de $\mathrm{r}-\mathrm{m}$ (Fig. 98); $\mathrm{M}_{3}$ reta (Fig. 98).

Material examinado. HOLÓTIPO, 1 \#m, BRASIL, Nova Teutônia, 27²11's 52²3’W, 15.iii.1937, Fritz Plaumann (BMNH). Material adicional. 2 \#m, BRASIL, Santa Catarina, Nova Teutônia, x.1967, F. Plaumann col. (MZUSP). 
Redescrição. Macho. Comprimento: corpo, 11.0-12.0; asa, 9.0-12.0. Cabeça (Fig. 99). Vértex amarelo anteriormente e avermelhado posteriomente; tubérculo ocelar preto no centro e avermelhado nas laterais, com distinta pilosidade amarela. Parte superior da fronte amarelo avermelhada medialmente, preta lateralmente; margem da área medial triangular abaixo do tubérculo; parte inferior da fronte e face amarelas. Antenas marrom avermelhadas; escapo mais longo que o pedicelo; complexo flagelar alongado (2.3:1) (Fig. 33); quarto flagelômero muito pequeno em relação à arista basalmente; arista marrom escura, larga e com grande quantidade de cerdas basalmente. Tórax (Fig. 139). Amarelo avermelhado, bandas do escudo marrom escuras; escutelo preto anteriormente; anepisterno anteriormente, catepisterno, laterotergito e mediotergito com manchas marrom escuras. Pernas amarelo avermelhadas, exceto tíbias e tarsos anteriores, parte distal dos fêmures medianos, coxas, trocânteres e dois terços dos fêmures posteriores, marrons. Asa (Fig. 98). $\mathrm{R}_{2+3}$ originando-se muito depois de $\mathrm{r}-\mathrm{m}$, próximo ao ápice da célula discal; r-m mais longa que o terceiro setor da célula discal ou bm-cu. Segundo e quarto setores tão longos quanto o segundo e o quinto, respectivamente; $\mathrm{M}_{3}$ reta. Halteres amarelo avermelhados. Abdômen. Amarelo avermelhado, com largas bandas marrom escuras. Genitália (Figs. 34-36). Cápsula genital levemente quadrangular; apódemas gonocoxais pouco desenvolvidos; extensão longitudinal dos apódemas suavemente ultrapassando o nível do parâmeros; processo medial do singonocoxito fortemente projetado, gradualmente estreitando-se distalmente. Gonóstilos mais largo no terço distal. Epândrio retangular, algo estreito na parte basal.

Fêmea. Desconhecida.

Distribuição geográfica. Brasil (Santa Catarina) (Fig. 213).

Comentários. Essa espécie aparece no cladograma como irmã do clado Acrochaeta polychaeta sp. nov. e A. pseudopolychaeta sp. nov. com base no tamanho equivalente entre o primeiro e segundo setores da célula discal. A. dimidiata é muito semelhante a essas outras espécies no que diz respeito à genitália masculina: forma geral e comprimento dos lóbulos do edeago, largura do gonóstilos e formato geral dos parâmeros. No entanto, $A$. dimidiata pode ser separada dessas duas espécies pela arista mais larga e pubescente apenas na base (Fig. 33).

O holótipo macho examinado por fotos (Figs. 178-182) encontra-se em boas condições. 

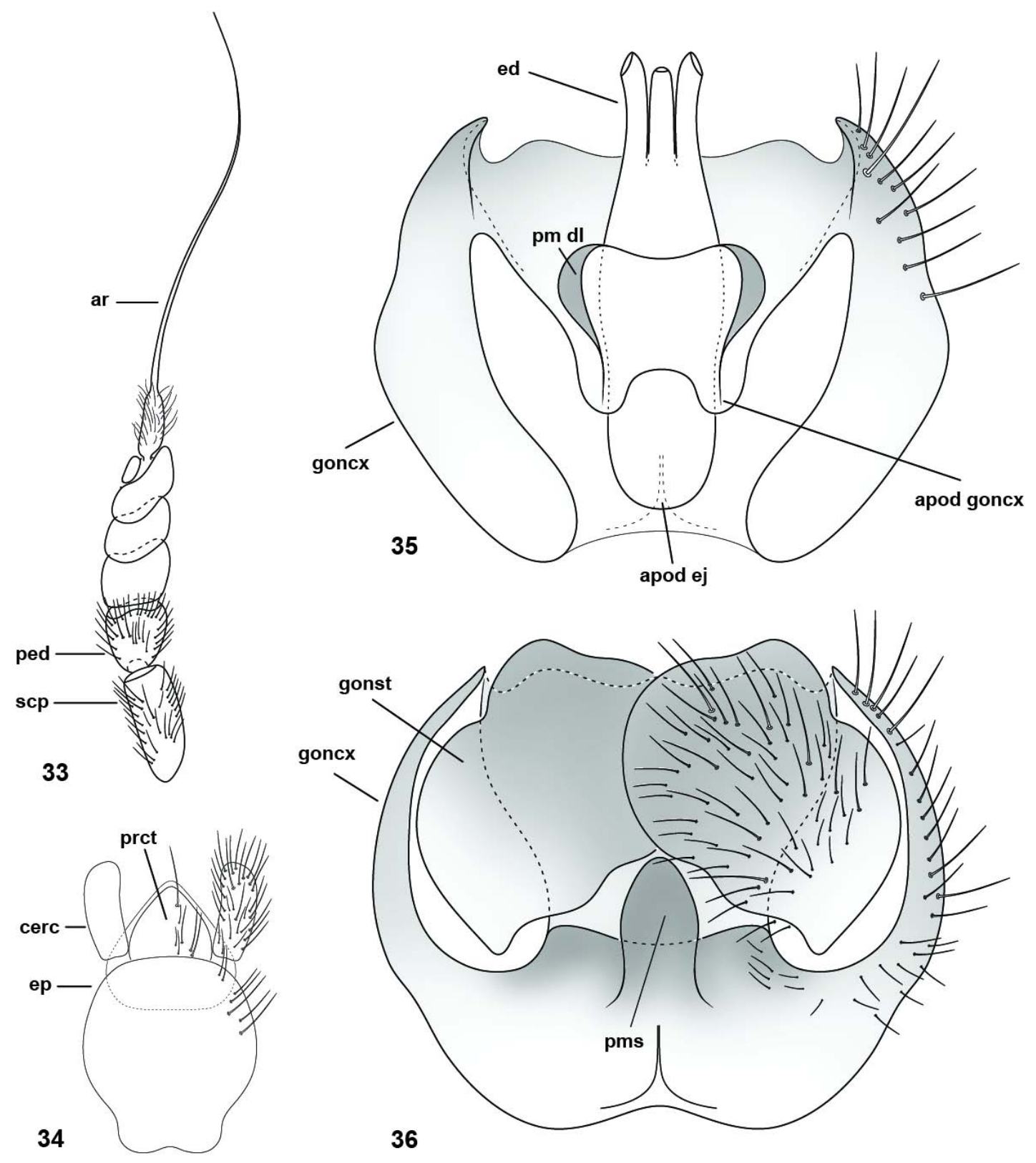

Figuras 33-36. Acrochaeta dimidiata, macho. 33. Antena. 34. Epândrio, vista dorsal. 35. Cápsula genital, vista dorsal. 36. Cápsula genital, vista ventral.

\section{Acrochaeta pseudopolychaeta, sp. nov.}

(Figs. 37-42, 100-101, 125, 140, 155)

Diagnose. Coloração do corpo marrom a marrom escuro (Fig. 155). Arista pubescente em todo seu comprimento (Fig. 37). Mediotergito marrom a marrom escuro, não 
contrastando com a coloração do corpo. Terceiro setor da célula discal tão longo quanto r-m (Fig. 100).

Material examinado. HOLÓTIPO, 1 \#m, BRASIL, São Paulo, Salesópolis, Estação Biológica de Boracéia, 11.xi.1960, Lenko, K. col. (MZUSP). PARÁTIPOS: 1 \#m, BRASIL, São Paulo, Bocaina, iv.1924, Luedw. col.; 1 \#f, iv.1924. 1 \#f, São Paulo, Cantareira, Chapadão, xi.1946, Barretto col; 1 \#f, xi.1951, Carreira, M; 1 \#f, Horto Florestal, Chapadão, xi.1946, Carrera, M. 1 \#f, 29.viii.1977, Val, F. C. col (MZUSP).

Descrição. Macho. Comprimento: corpo, 12.0-16.0; asa, 9.0-11.0. Cabeça (Fig. 101). Vértex marrom a marrom escuro; tubérculo ocelar bastante projetado. Parte superior da fronte marrom medialmente, preta lateralmente; margens da área medial estreitando-se ventralmente; parte inferior da fronte e face marrom avermelhadas a marrom. Antenas marrom escuras a pretas, alongadas; comprimento do escapo duas vezes o do pedicelo; complexo flagelar extremamente alongado (3.3:1) (Fig. 37); quarto flagelômero com um terço do comprimento do terceiro; arista pubescente em toda extensão, gradualmente diminuindo de espessura em direção ao ápice. Tórax (Fig. 140). Marrom avermelhado a marrom escuro, faixas do escudo marrom escuras; escutelo marrom escuro a preto proximalmente. Pernas marrom avermelhadas, exceto pelos tarsos anteriores, coxas, trocânteres e fêmures posteriores marrom escuros. Asa (Fig. 100). $\mathrm{R}_{2+3}$ originando-se bem depois de $\mathrm{r}-\mathrm{m}$, próximo ao ápice da célula discal, a uma distância equivalente ao dobro do comprimento de r-m; r-m tão longa quanto o terceiro setor da célula discal ou bm-cu. Segundo e quarto setores tão longo quanto o primeiro e o quinto, respectivamente. Halteres amarelo avermelhados. Abdômen. Amarelo avermelhado, com largas bandas marrom a marrom escuras. Genitália (Figs. 38-40). Cápsula genital quadrangular; apódema gonocoxal pouco desenvolvido; extensão longitudinal dos apódemas gonocoxais abaixo do nível dos parâmeros; processo medial do singonocoxito cilíndrico, fortemente projetado. Gonóstilos extremamente largos nos dois terços distais. Epândrio quadrangular; cercômeros mais curtos que epândrio.

Fêmea. Similar ao macho, exceto no que segue. Comprimento: corpo, 12.0-15.0; asa, 10.0-11.0. Genitália (Figs. 41-42). Tergito 9 tão longo quanto largo, mais esclerosado lateralmente. Furca genital estreitando-se gradualmente da porção posterior para a anterior (Fig. 41); margem posterior bilobada; processos póstero-laterais paralelos, extremos basal e apical mais estreitos; abertura genital aproximadamente triangular, pequena, ocupando menos que um terço da porção anterior da placa. Comprimento do cercômero 1 levemente mais longo que o do cercômero 2. 
Etimologia. O nome da espécie é feminino e o epíteto específico faz referência a sua semelhança com $A$. polychaeta, ainda que correspondendo a uma espécie distinta, indicado com o acréscimo da raiz grega pseudo, que significa falso.

Distribuição geográfica. Brasil (São Paulo) (Fig. 213).

Comentários. Na análise cladística, essa espécie aparece como irmã de Acrochaeta polychaeta sp. nov. sendo uma sinapomorfia para o clado com ambas as espécies, a arista larga e pubescente em toda a extensão. Essa condição parece tratar-se uma modificação da arista vista em A. adusta e A. fasciata (e.g., Fig. 24). Essa espécie é tão escura quanto A. asapha sp. nov. e A. adusta, mas possui um padrão de faixas do escudo bastante distinto (Fig. 139), diferentemente do que é visto nas outra duas (Figs. 136137). 

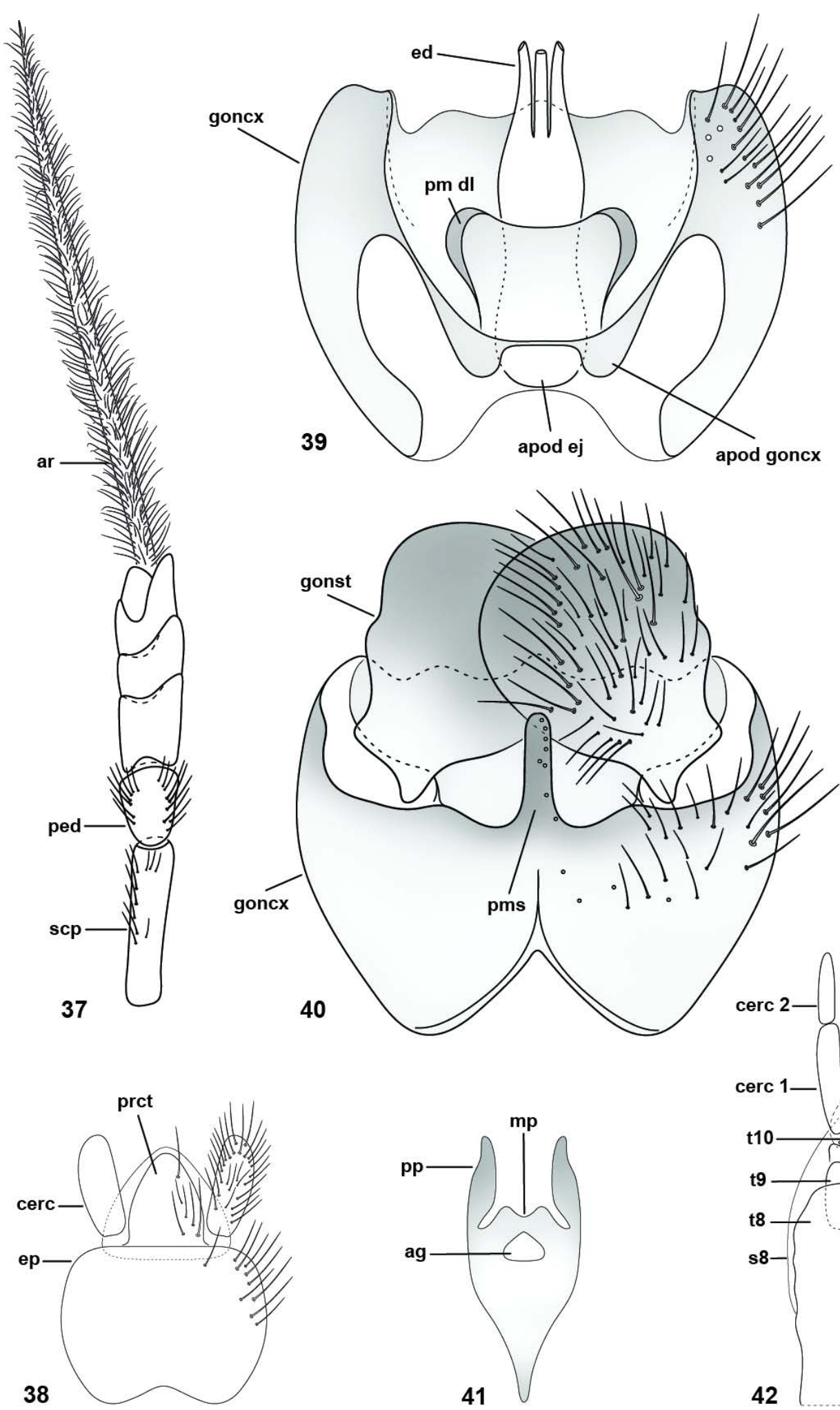

38
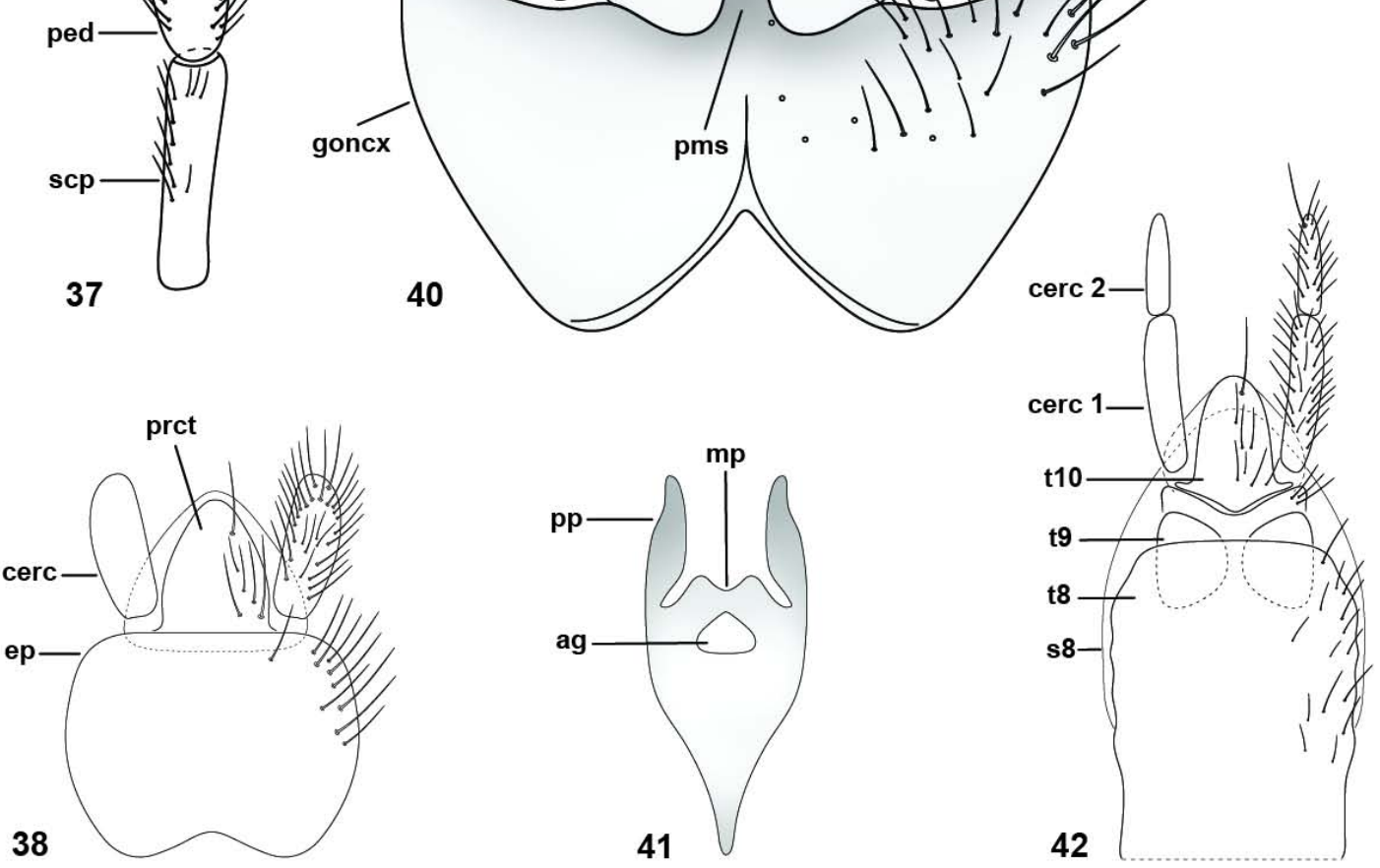

Figuras 37-42. Acrochaeta pseudopolychaeta, sp. nov., (37-40, holótipo macho; 41-42, parátipo fêmea). 37. Antena. 38. Epândrio, vista dorsal. 39. Cápsula genital, vista dorsal. 40. Cápsula genital, vista ventral. 41. Furca genital. 42. Genitália feminina, vista dorsal. 


\section{Acrochaeta polychaeta, sp. nov.}

(Figs. 43-48, 102-103, 126, 141, 156)

Diagnose. Coloração do corpo amarelo claro (Fig. 156). Arista pubescente em todo seu comprimento, gradualmente estreitando-se em direção ao ápice (Fig. 43), como em $A$. pseudopolychaeta. Mediotergito marrom a marrom escuro, contrastando com a coloração amarelada do restante da pleura. Terceiro setor da célula discal evidentemente mais curto que r-m (Fig. 102).

Material examinado. HOLÓTIPO, 1 \#m, BRASIL, Rio de Janeiro, Nova Iguaçu, Reserva Biológica do Tinguá, 22³4’37”S 43²6’05”W, 05-08.iii.2002, Malaise trap, Trilha Ponto 1, Amarante, S. T. P. \& eq. cols. (MZUSP). PARÁTIPOS: 1 \#m, BRASIL, Paraná, Morretes, Parque Estadual do Pau Oco, 25³4’27.9”S 4853’46.7’W, 7-10.iv.2002, Malaise trap, Tavares, M. T \& eq. cols.; 1 \#f, iii.1945, Halschbach col. 1 \#m, São Paulo, Jaraguá, 5.ii.1951, Lane, J. col. 1 \#m, Salesópolis, Estação Biológica de Boracéia, 850 m, xi.1957, Carrera, M.; 1 \#m, 850 m, 30.iii.1951, L.T.F \& H.A.C.; 1 \#f (slide-mounted), Trilha dos Pilões, 2339’05.3”S 4553’51”W, 30.iii-02.iv.2001, Malaise trap, Amarante, S. T. P. \& eq. col.; 1 \#m, 1 \#f, 23³9”S 4553’W, 6-11.xi.2010, Amorim e Riccardi col. (MZUSP). 1 \#m, São Paulo, Cantareira, Chapadão, xi.1946, Barreto col; 1 \#m, Horto Florestal, i.1944, Lamosa. (MZUSP).

Descrição. Macho. Comprimento: corpo, 13.0-16.0; asa, 10.0-11.0. Cabeça (Fig. 103). Vértex amarelo, avermelhado medialmente; tubérculo ocelar bastante projetado. Parte superior da fronte amarela medialmente, preta lateralmente; margens da área medial estreitando-se ventralmente; parte inferior da fronte e face amarelo claras, com duas manchas marrom escuras acima da inserção das antenas. Antenas marrom escuras a pretas, alongadas; comprimento do escapo duas vezes o do pedicelo; complexo flagelar extremamente alongado (4:1) (Fig. 43); quarto flagelômero pequeno, arredondado; arista pubescente em toda a sua extensão, gradualmente diminuindo de espessura em direção ao ápice. Tórax (Fig. 141). Amarelo claro, faixas longitudinais no escudo marrom escuras a pretas; escutelo marrom escuro a preto proximalmente; anepisterno anteriormente com uma larga mancha marrom escura estendendo-se até o catepisterno ventralmente; laterotergito e mediotergito marrom escuros em quase toda a superfície. Pernas amarelas, exceto pelos quatro tarsômeros distais anteriores, terço distal dos fêmures medianos, coxas, trocânteres e fêmures posteriores, marrom a 
marrom escuros. Asa (Fig. 102). $\mathrm{R}_{2+3}$ originando-se depois de $\mathrm{r}-\mathrm{m}$, a uma distância equivalente ao comprimento de $\mathrm{r}-\mathrm{m}$; $\mathrm{r}-\mathrm{m}$ três vezes o comprimento do terceiro setor da célula discal, tão longa quanto bm-cu. Segundo setor tão longo quando o primeiro, quarto setor mais longo que o quinto. Halteres amarelo claros. Abdômen. Amarelo claro, com largas bandas marrom escuras. Genitália (Figs. 44-46). Cápsula genital arredondada; apódema gonocoxal pouco desenvolvido; processo medial do singonocoxito, fortemente projetado, estreitando em direção ao ápice. Gonóstilos largos, metade distal fortemente concâva. Epândrio quadrangular; cercômeros tão longos quanto o epândrio.

Fêmea. Similar ao macho, exceto no que segue. Comprimento: corpo, 14.0-15.0; asa, 11.0-12.5. Genitália (Figs. 47-48). Tergito 8 suavemente projetado distalmente. Tergito 9 levemente mais largo posteriormente, dividido em duas porções quadrangulares mais esclerosadas. Furca genital estreitando-se gradualmente da porção posterior para a anterior (Fig. 47); margem posterior bilobada; processos pósterolaterais paralelos, extremos basal e apical mais estreitos; abertura genital oval, pequena, ocupando menos que um terço da porção anterior da placa. Comprimento do cercômero 1 levemente mais longo que o do cercômero 2.

Etimologia. O nome é feminino, e o epíteto específico do grego poly, significando muitos, e chaeta, significando cerdas, em alusão a quantidade de cerdas da arista.

Distribuição geográfica. Brasil (Paraná, Rio de Janeiro, São Paulo) (Fig. 213).

Comentários. Além das semelhanças na arista (Figs. 37, 43)—sinapomorfias que unem Acrochaeta polychaeta sp. nov. e A. pseudopolychaeta sp. nov.-, essas duas espécies são bastante similares no que diz respeito à genitália masculina: forma geral da cápsula genital, apódemas gonocoxais arrendondados, lóbulos do edeago distalmente separados e parâmeros suavemente bilobados. A. polychaeta sp. nov. apresenta coloração amarelada (Fig. 156) e terceiro setor da célula discal claramente mais curto que r-m (Fig. 102), enquanto que A. pseudopolychaeta sp. nov. apresenta coloração marrom escura (Fig. 155) e terceiro setor da célula discal tão longo quanto r-m (Fig. 100). Outras características que também auxiliam na separação das duas espécies são: o processo medial do singonocoxito cilíndrico na genitália masculina de $A$. pseudopolychaeta sp. nov. (Fig. 40), e a coloração do mediotergito marrom escura em A. polychaeta sp. nov., constrastando com a coloração amarela do corpo. 


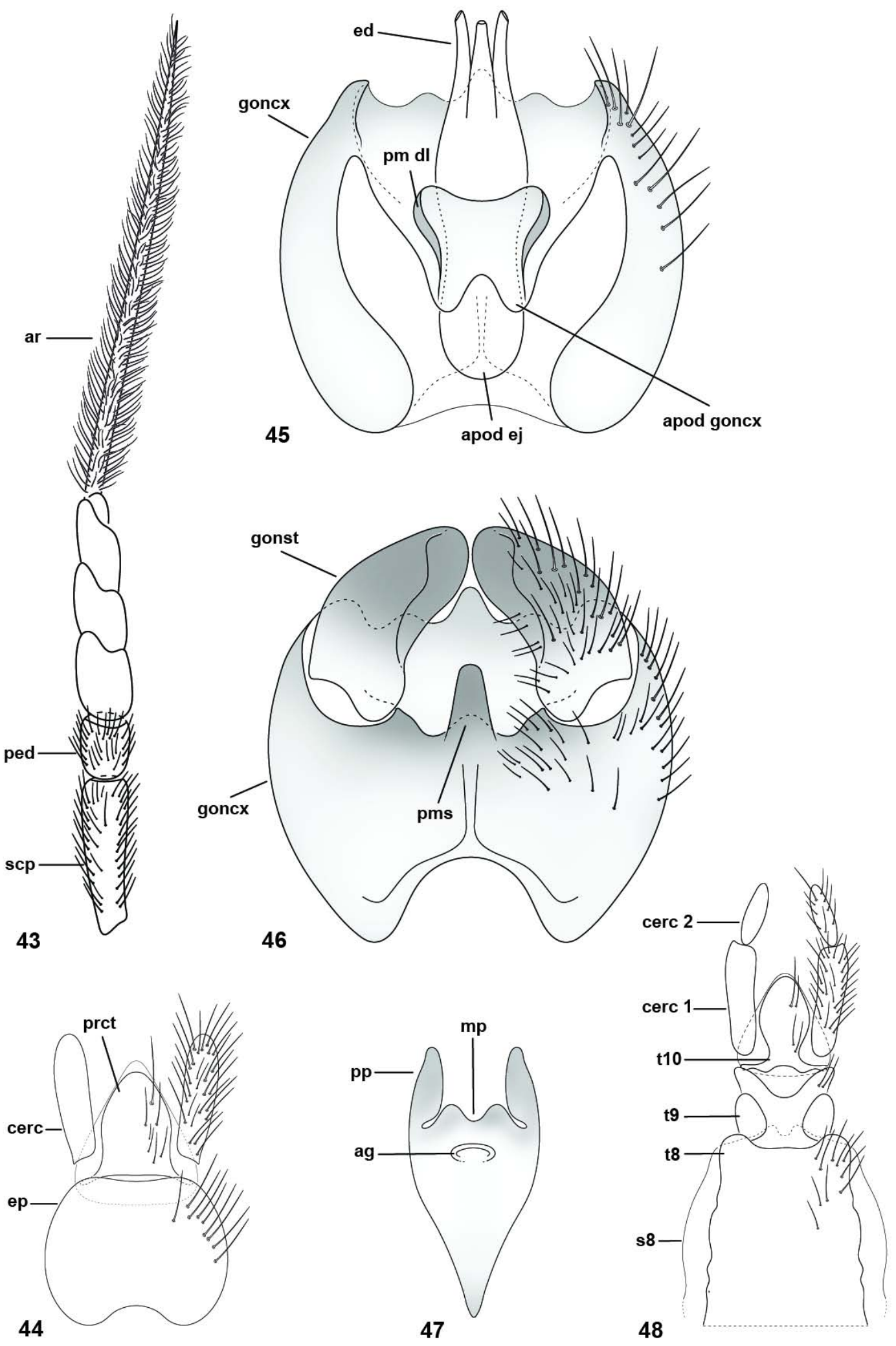

Figuras 43-48. Acrochaeta polychaeta, sp. nov., (43-46, holótipo macho; 47-48, parátipo fêmea). 43. Antena. 44. Epândrio, vista dorsal. 45. Cápsula genital, vista dorsal. 46. Cápsula genital, vista ventral. 47. Furca genital. 48. Genitália feminina, vista dorsal. 
Acrochaeta convexifrons (McFadden, 1971), comb. nov.

(Figs. 49-54, 104-105, 127, 142, 157)

Merosargus convexifrons McFadden, 1971: 37-38, 68 (key to species). Localidade-tipo: México, Puebla, 5 miles NE of Tezuitlan, 5100m. Holótipo macho, [SEMC]; Parátipo macho, [WSU].

Diagnose. Corpo amarelo (Fig. 157). Antena globular (Fig. 49). Escutelo com coloração metálica; mediotergito distintamente verde ou azul metálico. Tergito $1 \mathrm{com}$ duas manchas marrom escuras proximais e uma banda distal marrom escura, coloração amarela entre as manchas. Paramêros não projetados (Fig. 51); edeago simples (único lóbulo) (Fig. 51); gonóstilos com uma projeção basal interna (Fig. 52).

Material examinado. COSTA RICA, 1 \#f, Cartago, La Cangreja, 948’ N 8358’W, 1950m, vi-vii.1992, Malaise, P. Hanson. 1 \#f, Guanacaste, Volcán Cacao, Cerro Pedregal, 1000m, $10^{\circ} 56^{\prime} \mathrm{N}$ 85²8’ W, ii-iv.1989, Malaise trap, P. Hanson. 1 \#f, Heredia Pr, La Selva Biol. Sta. $3 \mathrm{~km} \mathrm{~S} \mathrm{Pto.} \mathrm{Viejo,} 10^{\circ} 26^{\prime} \mathrm{N} 8^{\circ} 01^{\prime} \mathrm{W}, 13 . v .1990$, H.A. Hespenheide. 2 \#m, 1 \#f, Puntarenas, San Vito, Estación Biológica Las Alturas, 1500 meters, 857’ N 8250’W, i.1992, Malaise trap, P. Hanson; 2 \#m, iii.1992; 5 \#m, 15 \#f, iv.1992; 1 \#f, v.1992. 1 \#f, vic. Monte Verde, Cerro Amigos, 1840m, 14.vi.2000, 10¹9’12”N 8447’44”W, N.E. Woodley; 3 km SW Rincon, 10m, 841’ N 83²9’W, ii.1992, Malaise, P. Hanson. 1 \#f, San José, San José, Univ. Costa Rica campus, 27.v.1987, A.L. Norrbom. 1 \#f, Zurqui de Moravia, 1003’N 8401’W, iv.1992, 1600m, Malaise trap, P. Hanson; 1 \#f, v.1992; 1 \#f, vi.1992; 2 \#f, iv-v.1993; 1 \#f, 22.vii08.viii.2010, 840057/100258, Brian Brown col. 1 \#f, 26 km N San Isidro, 9³0’N 8343’W, 2100m, ii-v.1992, Malaise trap, P. Hanson. 1 \#f, San Antonio de Escazu, 954’N 8409’W, 1300m, iv.1989, Malaise, W. Eberhard. GUATEMALA, 1 \#f, Guatemala Prov., Fraijanes, Finca S. Antonio, 1800m, vi.1987, M.J. Sharkey. MÉXICO, 1 \#m, Hidalgo, 2 km S. Chapulhuacán, 920m, 24.vi.1977, E.M. \& J.L. Fisher. (USNM).

Descrição. Macho. Comprimento: corpo, 9.5.0-11.0; asa, 8.0-9.0. Cabeça (Fig. 105). Vértex amarelo avermelhado. Parte superior da fronte amarela, fortemente projetada em toda a sua extensão medial; área lateral preta e sinuosa; parte inferior da fronte e face amarelas. Antenas amarelo avermelhadas; escapo mais longo que o pedicelo; complexo flagelar globular (1.3:1) (Fig. 49); quarto flagelômero tão longo quanto a arista 
basalmente; arista amarelo avermelhada, mais longa que o restante da antena, pubescente e levemente mais larga na base. Tórax (Fig. 142). Amarelo avermelhado, escudo com distintas faixas longitudinais marrom escuras a pretas; escutelo preto proximalmente com coloração azul metálica; mediotergito marrom escuro a preto com coloração metálica azul e verde; anespisterno anteriormente marrom escuro ventralmente, reduzida mancha marrom escura próxima à sutura notopleural. Pernas amarelo avermelhadas, exceto pelos quatro tarsômeros distais anteriores, pretos, coxas posteriores e fêmures posteriores ventralmente marrom escuros. Asa (Fig. 104). $R_{2+3}$ originando-se pouco depois de $\mathrm{r}-\mathrm{m}$; a uma distância equivalente ao comprimento de rm; r-m mais longa que o terceiro setor da célula discal ou bm-cu. Segundo setor mais longo que o quinto; quarto setor de $\mathrm{M}_{1+2}$ equivalente ao quinto. Extremo basal de $\mathrm{A}_{1}$ nua em todo seu comprimento (Fig. 127). Halteres amarelo. Abdômen. Amarelo, com conspícuas bandas proximais marrons avermelhadas; tergito 1 com duas manchas proximais e uma faixa distal reduzida no centro da placa. Genitália (Figs. 50-52). Cápsula genital arredondada; processo medial do singonocoxito muito projetado, estreitando-se bruscamente em direção ao ápice. Parâmeros não projetados. Edeago simples. Gonóstilos largos com uma projeção interna arrendondada. Epândrio aproximadamente retangular, alongado.

Fêmea. Similar ao macho, exceto no que segue. Comprimento: corpo, 8.0-11.0; asa, 7.0-10.0. Tórax. Anepisterno anteriormente com uma larga mancha marrom escura próxima à sutura notopleural. Genitália (Figs. 53-54). Tergito 8 com margens distais projetadas. Tergito 9 mais largo distalmente. Furca genital com formato oval (Fig. 53) margem anterior tão larga quanto a posterior; porção anterior suavemente diminuindo de largura em direção à base; margem posterior bilobada; processos póstero-laterais paralelos, estreitos e arrendondados no ápice. Comprimento do cercômero 1 duas vezes o do cercômero 2.

Distribuição geográfica. Costa Rica (Cartago, Guanacaste, Heredia, Puntarenas, San José), Equador, Guatemala (Guatemala), México (Hidalgo, Puebla) (Fig. 216).

Comentários. Apesar de apresentar condições únicas entre as espécies de Acrochaeta (e.g., antena globular, arista mais longa que o restante da antena, veia Cup não alcançando a bifurcação entre $\mathrm{CuA}_{1}$ e $\mathrm{CuA}_{2}$, apódema ejaculátorio ultrapassando em muito o limite basal dos gonocoxitos), essa espécie pertence a Acrochaeta, como pode ser visto no cladograma da figura 217. Assim, é proposta aqui uma nova combinação transferindo Merosargus convexifrons para o gênero Acrochaeta. 


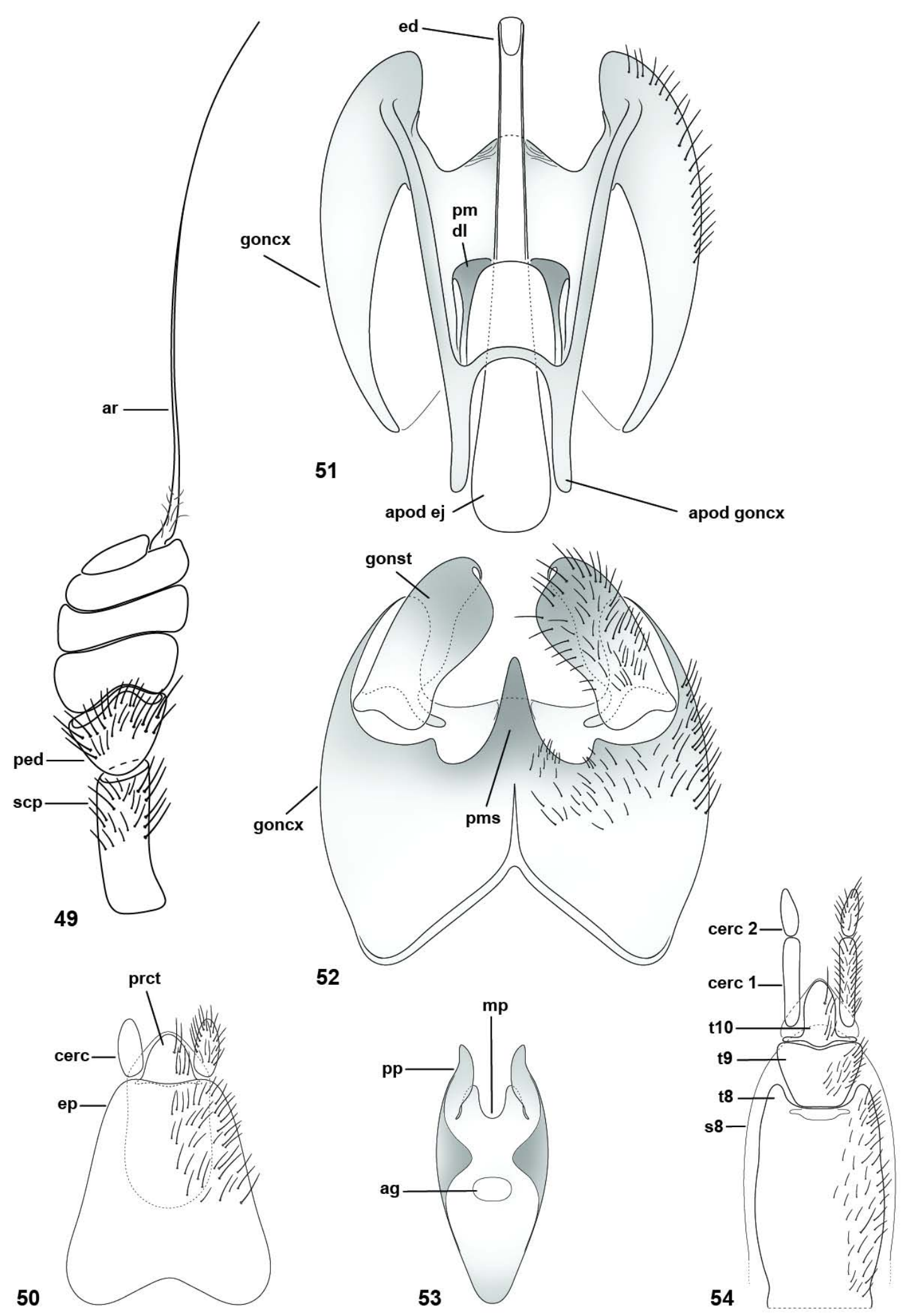

Figuras 49-54. Acrochaeta convexifrons, comb. nov. (49-52, macho; 53-54, fêmea). 49. Antena. 50. Epândrio, vista dorsal. 51. Cápsula genital, vista dorsal. 52. Cápsula genital, vista ventral. 53. Furca genital. 54. Genitália feminina, vista dorsal. 


\section{Grupo-flaveola.}

(Figs. 55-163)

Diagnose. Área medial da parte superior da fronte fortemente projetada em toda sua extensão medial (Fig. 9); área lateral preta e sinuosa. Apódema gonocoxal muito desenvolvido, maior que o lóbulo do edeago (e.g., Fig. 57). Ponte gonocoxal elevada distalmente (e.g., Fig. 62). Edeago simples (único lóbulo), completamente envolvido pelos parâmeros (e.g., Figs. 67-69); parâmeros largos nos dois terços basais, distalmente projetado em forma de forquila, ultrapassando em muito o ápice do edeago (e.g., Figs. 67-69). Gonóstilos arredondados, mais largos basalmente, afilados apicalmente (e.g., Fig. 58). Epândrio distintamente mais longo que largo (e.g., Fig. 56). Porção anterior da furca cilíndrica, com estreitamento não aparente (e.g., Fig. 64); abertura genital da furca muito pequena (e.g., Fig. 64).

Espécies incluídas: Acrochaeta dichrostyla, A. rhombostyla, A. ruschii, A. mexicana, A. flaveola, A. balbii e A. boliviana.

Acrochaeta rhombostyla, sp. nov.

(Figs. 55-60, 106-107, 128, 143, 158)

Diagnose. $\mathrm{M}_{3}$ completa (Fig. 106). Cápsula genital distintamente romboidal dorsalmente; gonóstilos com uma longa projeção na margem dorsal (Fig. 58). Margem posterior da furca genital muito projetada (Fig. 59).

Material examinado. HOLÓTIPO, \#m, BRASIL, Mato Grosso do Sul, Bodoquena, Serra da Bodoquena, Fazenda Califórnia, 2041’55.4”S 5652’49.4”W, Malaise trap 6, 06-21.ix.2011, Lamas, Nihei \& eq. col. (MZUSP). PARÁTIPOS: 1 \#f, BRASIL, Mato Grosso do Sul, Bodoquena, Fazenda Califórnia, 2041’49.9”S 5652’54.0”W, Malaise trap 4, 06-21.ix.2011, Lamas eq. col.; 1 \#m, Mato Grosso do Sul, Bodoquena, Serra da Bodoquena, Fazenda Califórnia - Topo, 2041’55.9”S 5652’59.4”W, Malaise trap 6, 22.viii-06.ix.2011, Lamas, Nihei \& eq. cols. (MZUSP).

Descrição. Macho. Comprimento: corpo, 7.5-14.0; asa 8.0-12.0. Cabeça (Fig. 107). Vértex amarelo avermelhado. Parte superior da fronte superior amarela avermelhada medialmente, fortemente projetada em toda sua extensão; área lateral preta e sinuosa; parte inferior da fronte e face amarelas. Antenas amarelo avermelhadas; comprimento 
do escapo aproximadamente duas vezes o do pedicelo; complexo flagelar alongado (1.9: 1) (Fig. 55); quarto flagelômero mais longo que a arista basalmente; arista amarelo avermelhada na metade basal, marrom distalmente, levemente mais larga, com pouca pilosidade basalmente. Tórax (Fig. 143). Amarelo esbranquiçado, faixas do escudo pretas; escutelo marrom anteriormente; anepisterno anteriormente com uma pequena mancha marrom; mediotergito marrom claro com reflexos metálicos. Pernas amarelo avermelhadas, exceto pelas coxas, trocânteres, terço distal dos fêmures posteriores e tarsos posteriores, marrom escuros. Asa (Fig. 106). $\mathrm{R}_{2+3}$ originando-se depois de $\mathrm{r}-\mathrm{m}$; a uma distância equivalente ao comprimento de $\mathrm{r}-\mathrm{m}$; $\mathrm{r}-\mathrm{m}$ tão longa quanto o terceiro setor da célula discal ou bm-cu. Segundo e quarto setores mais longos que o primeiro e quinto, respectivamente. $\mathrm{M}_{3}$ completa. Halteres amarelo avermelhados. Abdômen. Amarelo, com bandas proximais amarelo avermelhadas nos segmentos 1-3, bandas marrom escuras nos segmentos 4-6. Genitália (Figs. 56-58). Cápsula genital romboidal dorsalmente, margens distais bem próximas; processo medial do singonocoxito largo, pouco projetado. Margens distais dos parâmeros estreitas e projetadas em forma de forquilha. Gonóstilos largos nos dois terços basais (exceto pela base), afilando bruscamente em direção ao ápice, com uma projeção digitiforme adicional na margem dorsal, tão longa quanto a projeção do ápice. Epândrio retangular, alongado. Margem externa dos cercomêros mais baixa que a interna.

Fêmea. Similar ao macho, exceto no que segue. Comprimento: corpo, 8.0; asa, 9.0. Genitália (Figs. 59-60). Tergito 9 suavemente mais largo posteriormente. Furca genital com grande distinção de largura entre parte posterior e anterior (Fig. 59); porção anterior mais ou menos cilíndrica, estreitando-se levemente em direção à base; margem posterior projetada; processos póstero-laterais paralelos, margem distal inclinada; abertura genital circular. Cercômero 1 duas vezes o comprimento do cercômero 2 .

Etimologia. O nome da espécie é feminino, e o epíteto específico do grego rhombos, e stylus, que significa, alongado e pontudo, em referência ao formato romboidal dos gonóstilos.

Distribuição geográfica. Brasil (Mato Grosso do Sul) (Fig. 213).

Comentários. Essa espécie aparece como irmã de Acrochaeta ruschii sp. nov. apresentando como sinapomorfias: $r-m$ posicionada antes de $M_{3}$ na célula discal e a presença de uma projeção na margem dorsal dos gonóstilos. A condição apomórfica da genitália masculina tem origem única no gênero e é mais confiável que a da venação alar como indicação do parentesco entre as duas espécies. 


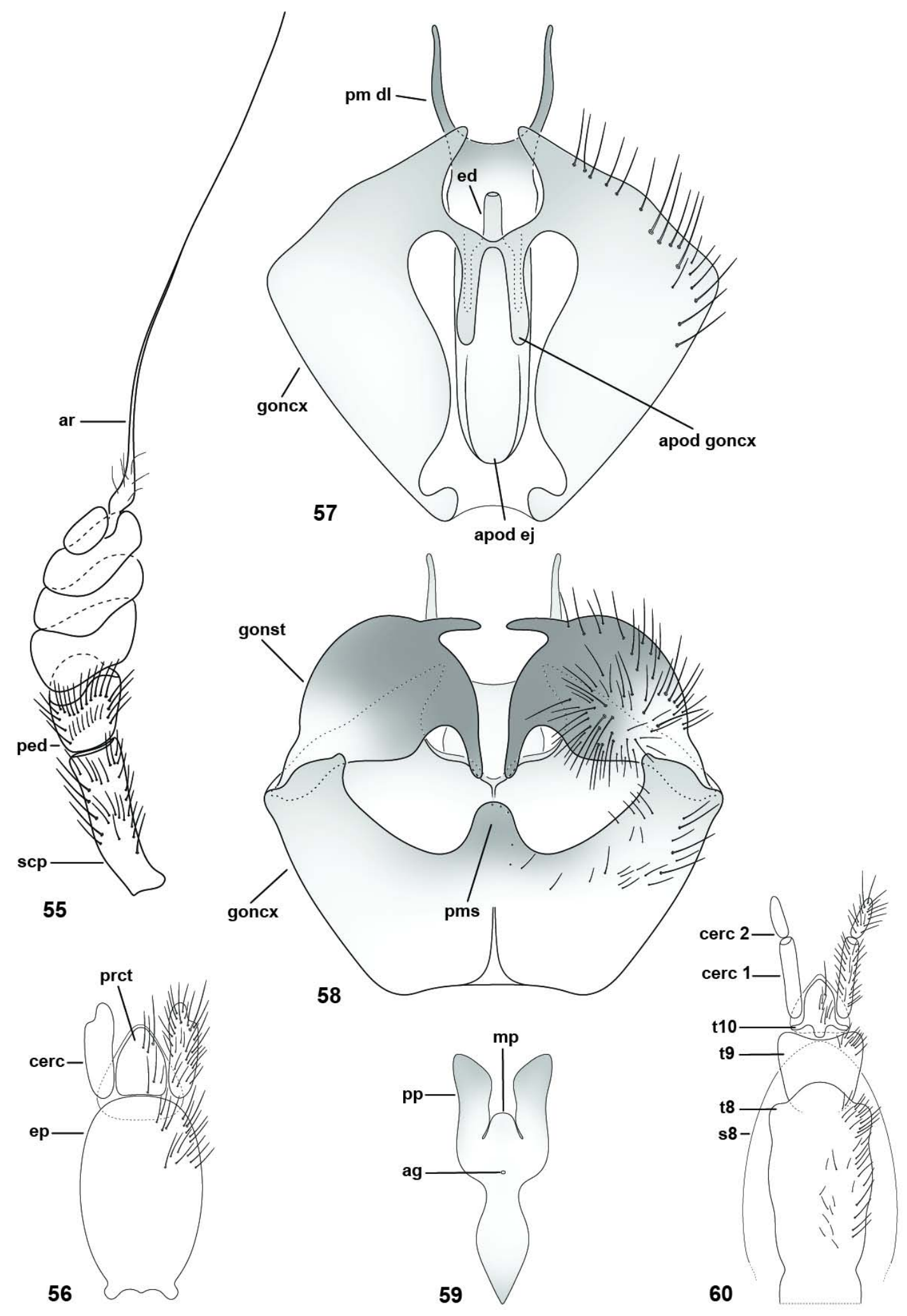

Figuras 55-60. Acrochaeta rhombostyla, sp. nov., (55-58, holótipo macho; 59-60, parátipo fêmea). 55. Antena. 56. Epândrio, vista dorsal. 57. Cápsula genital, vista dorsal. 58. Cápsula genital, vista ventral. 59. Furca genital. 60. Genitália feminina, vista dorsal. 


\section{Acrochaeta ruschii, sp. nov.}

(Figs. 61-66, 67-69, 108-109, 129, 144, 159)

Diagnose. Manchas marrom escuras dos tergitos 1-2 ausentes ou reduzidas (Fig. 159). Gonóstilos com uma pequena projeção na margem dorsal (Fig. 63). Furca genital com a margem posterior muito projetada, conectando-se distalmente com a margem apical dos processos póstero-laterais (Fig. 64).

Material examinado. HOLÓTIPO, \#m, BRASIL, São Paulo, Sertãozinho, Reserva

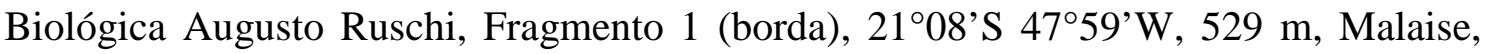
16-30.iii.2011, Silva, V. C., Donda, P. F. \& Ignácio, G. PARÁTIPOS: mesma localidade que o holótipo exceto por: 1 \#f (1 \#f abdômen, antena e asa em lâmina permanente), Fragmento 1 (interior) 13-27.x.2010; 2 \#m (1 \#m abdômen, antena e asa em lâmina permanente), Fragmento 1 (interior) 27.x.-10.xi.2010; 2 \#f, Fragmento 1 (borda), 27.x.-10.xi.2010; 1 \#f, Fragmento 1 (interior), 10-24.xi.2010; 1 \#m (genitália em glicerina junto do espécime), Fragmento 1 (borda) 24.xi-08.xii.2010; 1 \#f, 24.xi08.xii.2010, Brian Brown col.; 1 \#m, Fragmento 1 (borda), 22.xii.2010-05.i.2011; 1 \#f, Fragmento 1 (borda), 05-19.i.2011; 2 \#f, Fragmento 1 (borda), 13-27.iv.2011; 1 \#f, Fragmento 1 (interior), 07-21.xii.2011; 1 \#f, Fragmento 1, Malaise branca, 30.iii13.vi.2011; 1 \#m, Fragmento 1, 17-31.viii.2011; 1 \#f, Fragmento 1, 14-28.ix.2011; 1 \#m, Fragmento 1, 26.x-9.xi.2011; 1 \#m, Fragmento 1, 7-21.xii.2011 (MZUSP).

Descrição. Macho. Comprimento: corpo, 10.0-14.0; asa, 8.5-12.0. Cabeça (Fig. 109). Vértex amarelo claro. Parte superior da fronte amarelo claro medialmente, fortemente projetada em toda sua extensão; área lateral preta e sinuosa. Parte inferior da fronte e face amarelo claras. Antenas amarelo avermelhadas; escapo mais longo que o pedicelo; complexo flagelar alongado (2.6:1) (Fig. 66); quarto flagelômero tão longo quanto a arista basalmente; arista suavemente mais larga, pubescente apenas na base. Tórax (Fig. 144). Amarelo claro, com bandas marrom escuras no escudo; escutelo preto anteriormente; anepisterno anteriormente e catepisterno ventralmente com manchas marrom escuras; mediotergito marrom escuro a preto, com coloração metálica. Pernas amarelas exceto pelos tarsômeros anteriores 2-5, coxas e trocânteres posteriores, marrom escuros, e terço distal dos fêmures medianos e parte ventral dos fêmures posteriores, marrom a marrom escuro. Asa (Fig. 108). $\mathrm{R}_{2+3}$ originando-se depois de $\mathrm{r}-$ m; a uma distância equivalente ao comprimente de r-m; $r-m$ claramente mais longa que o terceiro setor da célula discal, tão longa quanto bm-cu. Segundo e quarto setores mais 
longo que o primeiro e o quinto, respectivamente. $\mathrm{M}_{3}$ completa ou incompleta. Halteres amarelo claros. Abdômen. Amarelo claro (frequentemente esbranquiçado), com bandas proximais marrom escuras; tergitos 1-2 com manchas ausentes ou reduzidas. Genitália (Figs. 61-63, 67-69). Cápsula genital aproximadamente quadrangular, singonocoxito com a margem distal dorsalmente estreitando-se gradualmente em direção ao ápice; processo medial arredondado; apódemas gonocoxais muito desenvolvidos, mais longo que o lóbulo do edeago. Parâmeros com sua metade distal duas vezes mais larga que a basal, projeções distais gradualmente estreitando-se em direção ao ápice. Gonóstilos arredondados, mais largos basalmente, afilados apicalmente, com uma pequena projeção na margem dorsal. Epândrio retangular, muito alongado.

Fêmea. Similar ao macho, exceto no que segue. Comprimento: corpo, 8.0-11.0; asa, 8.0-10.0. Genitália (Figs. 64-65). Tergito 9 duas vezes mais largo que longo. Furca genital com a parte anterior cilíndrica (exceto pela base), levemente aumentando de expessura posteriormente (Fig. 64); margem posterior muito projetada, conectando-se distalmente com o ápice dos processos póstero-laterais; processos postero-laterais paralelos, margem distal inclinada; abertura genital circular. Comprimento do cercômero 1 mais longo que o do cercômero 2.

Etimologia. Essa espécie foi nomeada em homenagem a Augusto Ruschi, ornitólogo brasileiro especialista em beija-flores, cujo nome também foi dado a Reserva Biológica em Sertãozinho (Estado de São Paulo), local de coleta do holótipo dessa espécie.

Distribuição geográfica. Brasil (São Paulo) (Fig. 213).

Comentários. Essa espécie é muito similar a Acrochaeta balbii sp. nov., e A. rhombostyla. sp. nov., compartilhando entre si: flagelômeros suavemente mais longos que largos, parâmeros em formato em forquilha (condição semelhante à de $A$. dichrostyla sp. nov.) e formato geral dos gonóstilos, muito mais largos basalmente que distalmente. Entretanto, A. ruschii, sp. nov. difere de $A$. balbii sp. nov. e de $A$. dichrostyla sp. nov. pela presença de uma projeção na margem dorsal dos gonóstilos (Fig. 63) (sinapomorfia compartilhada com A. rhombostyla sp. nov.) e, de todas, pelo tergito 1 sem as bandas horizontais ou fortemente reduzidas (Fig. 159) e, nas fêmeas, pelo formato da furca genital (Fig. 64), características únicas desta espécie. 


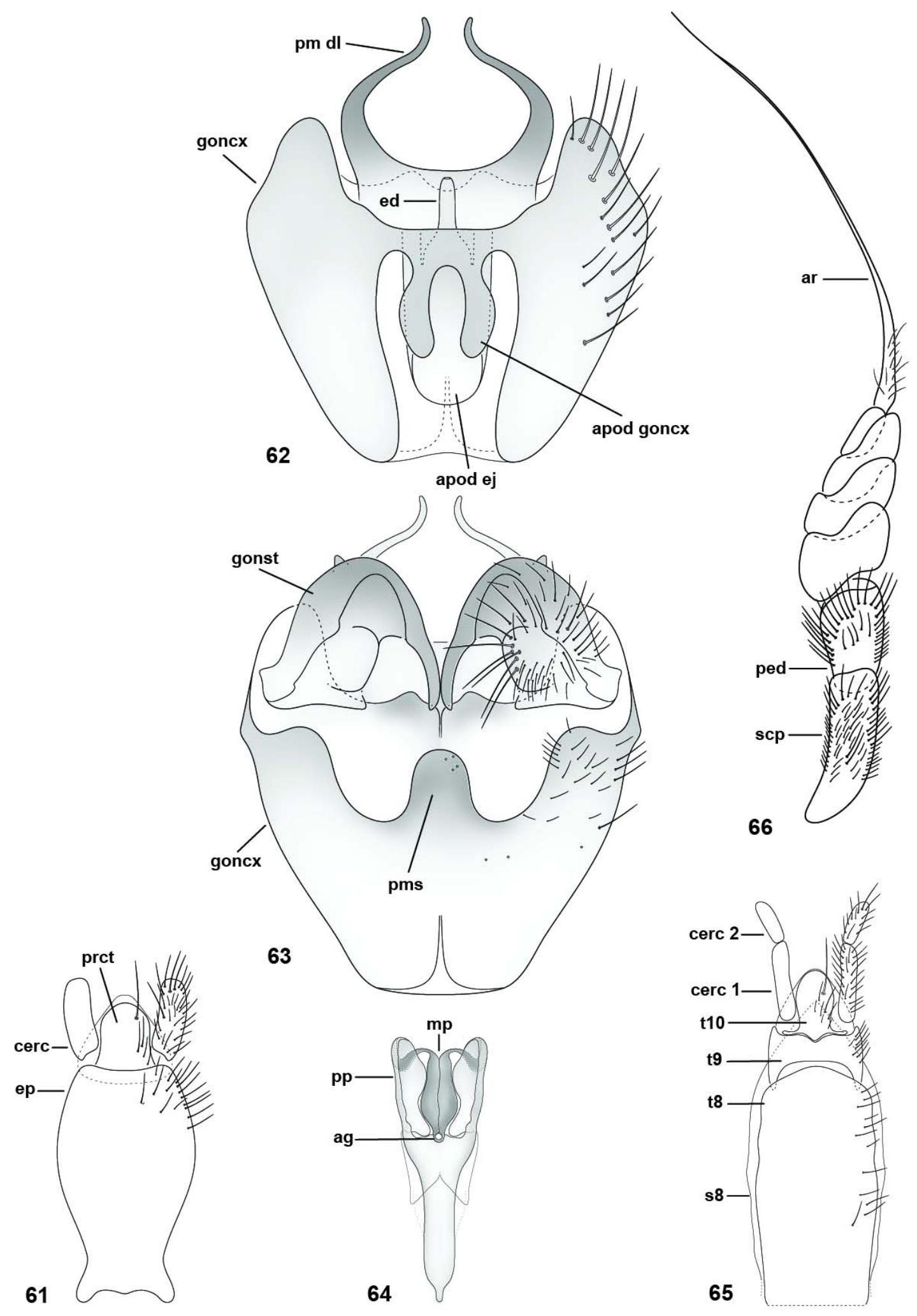

Figuras 61-66. Acrochaeta ruschii, sp. nov., (61-63, 66, holótipo macho; 64-65, parátipo fêmea). 61. Epândrio, vista dorsal. 62. Cápsula genital, vista dorsal. 63. Cápsula genital, vista ventral. 64. Furca genital. 65. Genitália feminina, vista dorsal. 66. Antena. 


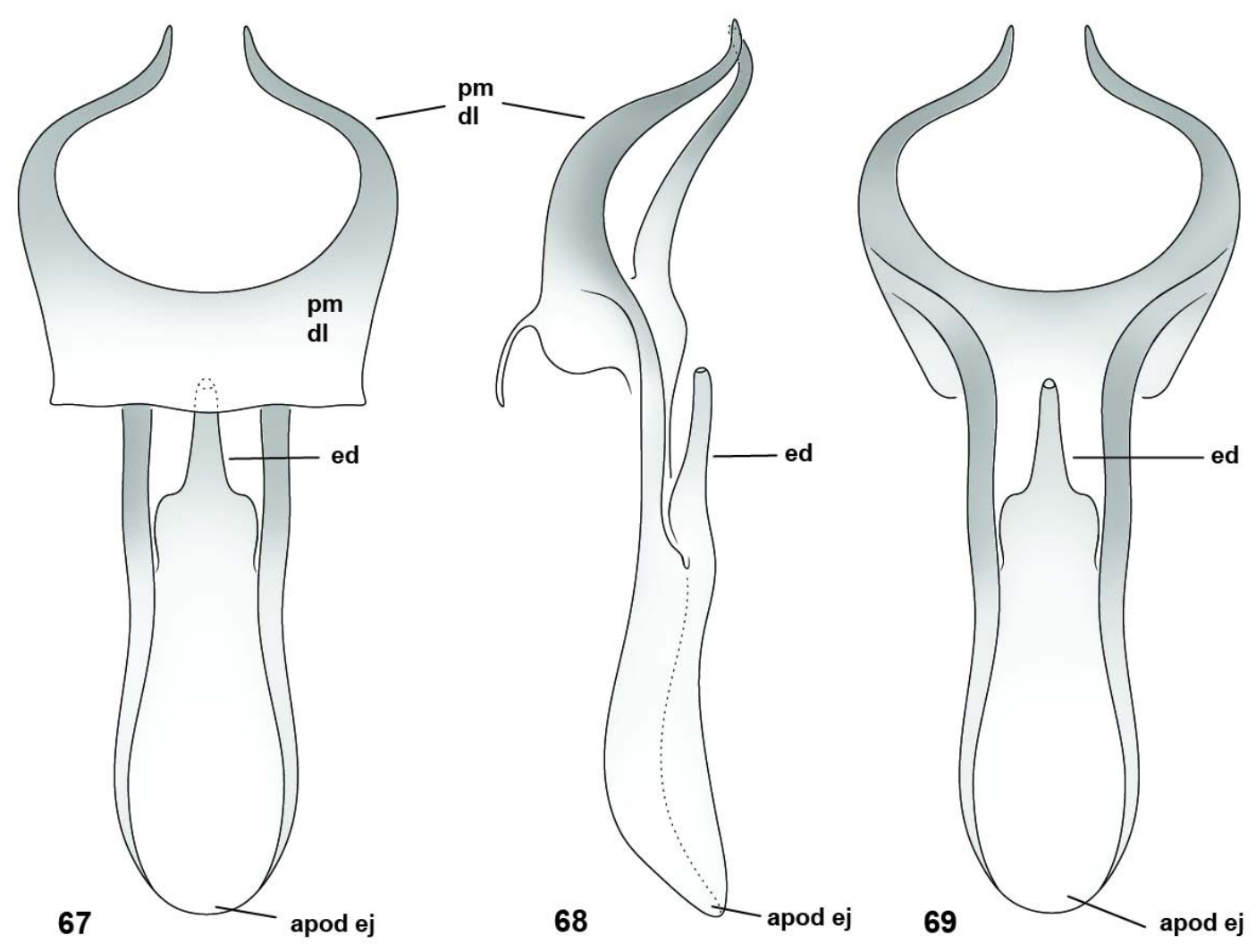

Figuras 67-69. Acrochaeta ruschii, sp. nov., holótipo macho. 67. Edeago e parâmeros, vista dorsal. 68. Edeago e parâmeros, vista lateral. 69. Edeago e parâmeros, vista ventral.

\section{Acrochaeta dichrostyla, sp. nov.}

(Figs. 9, 70-75, 110-111, 130, 145, 160)

Diagnose. Coloração do abdômen amarelo avermelhado, contrastando com o restante do corpo (Fig. 160). Mediotergito verde metálico. Processo medial do singonocoxito fortemente projetado, com pequenas projeções lateralmente em forma espinhos (Fig. 71); gonóstilos bífidos distalmente (Fig. 71).

Material examinado. HOLÓTIPO, 1 \#m, BRASIL, Rondônia, Monte Negro, Linha C25, Setor Chacareiro, 10¹6’21.4”S 63²0’45.4”W, Malaise 29, 10.ii-05.iv.2012, Lamas, Nihei \& eq. cols. (MZUSP). PARÁTIPOS: 1 \#f, Rondônia, Campo Novo, Fazenda Amorim, 1040’6”S 63²9’0”W, Malaise 6 m, 06-10.xii.2011, Amorim, Ament \& Riccardi col. (MZUSP); 1 \#m, Fazenda Rancho Grande 62 km S. Ariquemes, 165m, $10.32^{\circ} 62.48^{\circ} \mathrm{W}, 12-22 . x i .1991$, H.M. Fisher collector (CSCA); 1 \#f, Vilhena, 13.xi.1986, C. Elias leg. Polonoroeste (DZUP). 
Descrição. Macho. Comprimento: corpo, 10.0-14.0; asa, 9.0-12.0. Cabeça (Figs. 9 e 111). Vertex amarelo avermelhado. Parte superior da fronte superior amarela avermelhada, fortemente projetada em toda a sua extensão medial; área lateral preta e sinuosa; parte inferior da fronte e face amarelas. Antenas amarelo avermelhadas; escapo mais longo que o pedicelo; complexo flagelar alongado (2.1:1) (Fig. 75); quarto flagelômero tão longo quanto a arista basalmente; arista amarelo avermelhada na metade basal e marrom escura na metade apical, pubescente, suavemente mais larga na base. Tórax (Fig. 145). Amarelo avermelhado, faixas longitudinais do escudo distintas, marrom escuras a pretas; escutelo preto proximalmente; mediotergito marrom escuro a preto, com coloração metálica azul e verde. Pernas amarelo avermelhadas. Asa (Fig. 110). $R_{2+3}$ originando-se pouco depois de $r-m$; a uma distância equivalente ao comprimento de r-m; r-m tão longa quanto o terceiro setor da célula discal ou bm-cu. Segundo e quarto setores mais longo que o primeiro e o quinto, respectivamente. Halteres amarelo avermelhados. Abdômen. Amarelo avermelhado, com inconspícuas bandas proximais marrom avermelhadas. Genitália (Figs. 70-72). Cápsula genital levemente romboidal (mais estreita na metade basal); margem ventral do singonocoxito com uma incisão profunda, processo medial fortemente projetado, pontiagudo no terço distal, margens laterais com pequenas projeções em forma de espinhos. Porção dorsal dos parâmeros mais larga no último terço distal, fortemente projetada em forma de forquilha. Gonóstilos bífidos no terço distal. Epândrio retangular, muito alongado.

Fêmea. Similar ao macho, exceto no que segue. Comprimento: corpo, 11.0-13.0; asa, 11.0-12.0. Genitália (Figs. 73-74). Tergito 8 suavemente mais largo na metade distal. Tergito 9 tão largo quanto longo. Parte anterior da furca genital tão larga quanto a posterior (Fig. 73); porção anterior cilindríca, arredondada na base, allargando levemente de largura em direção ao ápice; margem posterior reta; processos pósterolaterais divergentes, muito estreitos na base, arrendondados no ápice; abertura genital circular. Comprimento do cercômero 1 mais longo que o do cercômero 2.

Etimologia. O nome da espécie é feminino e o epíteto específico do grego dichrous e stylus, fazendo referência ao gonóstilo bifurcado da genitália masculina dessa espécie.

Distribuição geográfica. Brasil (Rondônia) (Fig. 213).

Comentários. Essa é a única espécie de Acrochaeta que apresenta o gonóstilo bífido apicalmente. Outras quatro espécies descritas aqui-A. balbii sp. nov., A. boliviana sp. nov., A. ruschii sp. nov. e A. rhombostyla sp. nov.—-também apresentam o gonóstilos apicalmente modificado (sinapomorfia do grupo-flaveola), mas nunca bifurcados. Essa 
espécie faz parte de uma politomia com outras quatro espécies (A. mexicana, $A$. flaveola, A. balbii sp. nov. e A. boliviana sp. nov.), sustentada pela sinapomorfia ausência de pilosidade na álula. 


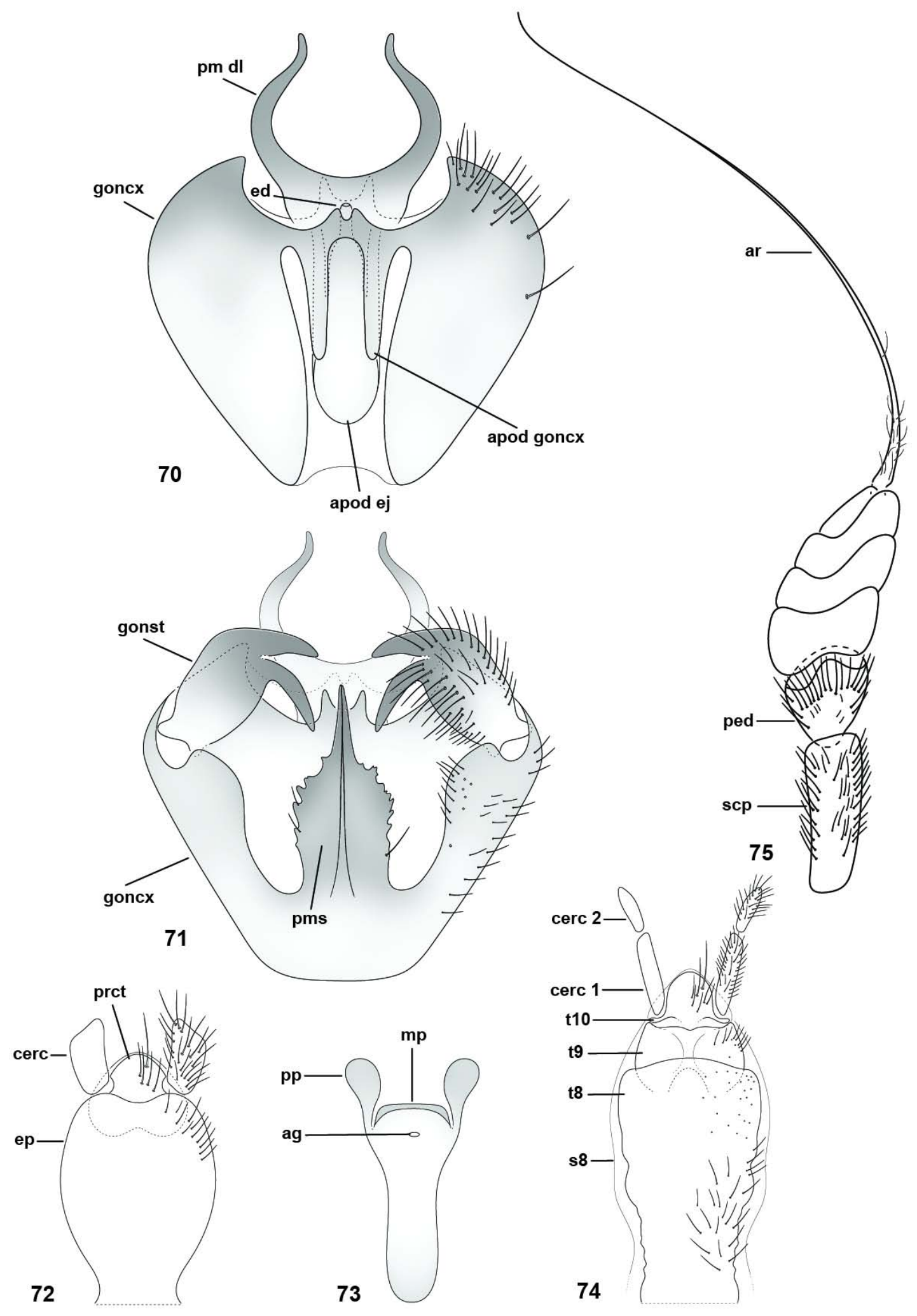

Figuras 70-75. Acrochaeta dichrostyla, sp. nov., (70-72, 75, holótipo macho; 73-74, parátipo fêmea). 70. Cápsula genital, vista dorsal. 71. Cápsula genital, vista ventral. 72. Epândrio, vista dorsal. 73. Furca genital. 74. Genitália feminina, vista dorsal. 75. Antena. 


\section{Acrochaeta mexicana Lindner, 1949}

(Figs. 76-77, 112-113, 131, 146, 161, 183-188)

Acrochaeta mexicana Lindner, 1949: 814. Localidade-tipo: México. Holótipo macho, $[\mathrm{BMNH}]$.

Diagnose. Corpo amarelo a amarelo dourado (Fig. 161), com faixas do tórax distintas (Fig. 146). Área lateral da fronte surgindo anteriormente no vértex (Fig. 113). Mediotergito verde metálico. Processo medial do singonocoxito fusionado à placa medial (Fig. 76); margem distal dos apódemas gonocoxais projetada distalmente em relação ao singonocoxito (Fig. 77). Parâmeros bilobados, margens distais subdivididas e pouco projetadas (Fig. 76).

Material examinado. HOLÓTIPO, 1 \#m, México (BMNH). Material adicional. 1 \#m, ANTÍGUA E BARBUDA, Antigua, 15.x.1976, E.S. Ross. (CAS). 1 \# f, COSTA RICA, Província de Ajaluela, San Pedro de la Tigra, $10^{\circ} 22^{\prime} \mathrm{N}$ 84³4’ W, 200m, xii.1989, Malaise trap, P. Hanson. (USNM). 1 \#f, Cartago, La Suiza, 944’56.1”N 8345’12.3”W, Schild, P. (USNM). 1 \#f, Turrialba, 2000’, 13.vii.1965, H.G. Real. 1 \#m Província de Heredia, La Selva, Est. Biol. La Selva, 10²6’ N 84º1’W, 50m, 9.ii.2003, M. Hauser leg. (CSCA); 1 \#f, La Selva Biol. Station 3 km S. of Puerto Viejo, $10^{\circ} 26^{\prime} \mathrm{N}$ 8401’W, 100m, xi.1992, Malaise, P. Hanson. (USNM). 1 \#m, El Ceibo station, 500m, 10km SE La Virgen, 10²0’N 8405’W, 14.ii.2003, M. Hauser leg. (CSCA). 7 \#m, 5 \#f, Província de Puntarenas, San Vito, Estación Biológica Las Alturas, 1500 meters, 857’N 8250’W, iii.1992, Malaise trap, P. Hanson; 1 \#f, 3 km SW Rincon, 10m, 841’N 83²9’W, viii.1991, Malaise, P. Hanson. (USNM). 1 \#m, 1 \#f, Província de São José, San Antonio de Escazu, 954’N, 8409’W, 1300m, iv.1989, Malaise, W.Eberhard. (USNM). 1 \#m, São José, 956’19.5”N 8405’2.5”W, 10.vi.1974, Harding, W.A \& Donahue, J.F. (USNM); 1 \#f, Turrialba, 1006’34.1”N 8351'31.1”W, 15.vii.1965, Spangler, P.J. (USNM); 1 \#m, EL SALVADOR, 1347’39.1”N 8853’47.5”W, 6.v.ii.1957, Salazar col., N 444-916 (USNM); 1 \#m, Los Chorros, 20.vi.1963 (CAS); 1 \#m, Santa Tecla, 1340’60”N 89¹6’60”W, 11.iii.1955, O.A.B., 602-49 (USNM); 1 \#m, GUATEMALA, Lago Amatitlan, 20.viii.1954, E.S. Ross. (CAS). 1 \#m, MÉXICO, Veracruz, Fortín de las Flores, iv.27.1965, G.P. Waldbauer. (CSCA). 1 \#m, PANAMÁ, Forte Gulick, [Colón], Colón, 9²1’30.9”N 7954’0.10”W, 
v.1980, Harlan, H.J. (USNM); 1 \#f, Canal Zone, Barro Colorado, 8¹2’41.4”N 78¹7’18.9’W, 14.vi.1939, Zetek, J col., N 4458. (USNM).

Redescrição. Macho. Comprimento: corpo, 12.0-14.0; asa, 11.0-14.0. Cabeça (Fig. 113). Vértex amarelo dourado. Parte superior da fronte superior amarelo dourado, fortemente projetada em toda extensão medial, margens mediais paralelas abaixo do tubérculo; área lateral preta, originando-se anteriormente no vértex; parte inferior da fronte e face amarelas. Antenas marrom avermelhadas; escapo mais longo que o pedicelo; complexo flagelar extremamente alongado (3.5:1) (Fig. 81); quarto flagelômero mais largo que a parte basal da arista; arista marrom escura, pubescente, larga basalmente. Tórax (Fig. 146). Amarelo dourado, bandas marrom escuras do escudo claramente delimitadas; escutelo marrom escuro anteriormente; anepisterno anteriormente com uma pequena mancha marrom escura próxima à sutura notopleural; mediotergito marrom a marrom escuro, com coloração verde metálica. Pernas amarelo avermelhadas, exceto pelos tarsômeros anteriores $2-5$, coxas posteriores e parte distal dos fêmures anteriores e medianos, marrom escuros. Asa (Fig. 112). $R_{2+3}$ originando-se muito próximo de $\mathrm{r}-\mathrm{m}$ (frequentemente em $\mathrm{r}-\mathrm{m}$ ); $\mathrm{r}-\mathrm{m}$ tão longa quanto o terceiro setor da célula discal ou bm-cu. Segundo e quarto setores mais longos que o primeiro e quinto, respectivamente (célula discal alongada); $\mathrm{M}_{3}$ completa. Álula nua (Fig. 131). Halteres amarelo avermelhados. Abdômen. Amarelo dourado, com largas bandas marrom escuras; banda do tergito 1 reduzida, pequena faixa proximalmente. Genitália (Figs. 76-78). Cápsula genital quadrangular; processo medial do singonocoxito fusionado à placa medial; margem distal dos apódemas gonocoxais projetada distalmente em relação ao singonocoxito. Parâmeros bilobados com as margens distais subdivididas, pouco projetadas. Gonóstilos largos nos dois terços basais, digitiforme apicalmente. Epândrio retangular, levemente mais longo que largo.

Fêmea. Similar ao macho, exceto no que segue. Comprimento: corpo, 10-13; asa, 8-10. Genitália (Figs. 79-80). Tergito 9 mais largo posteriormente. Furca genital com grande distinção de largura entre as partes posterior e anterior (Fig. 79); porção anterior cilindríca, estreitando-se levemente em direção à base; margem posterior bilobada; processos póstero-laterais paralelos, arrendondados, e fracamente mais largos distalmente; abertura genital circular. Comprimento do cercômero 1 maior que o do cercômero 2. 
Distribuição geográfica. América Central: Antígua e Barbuda (Antigua), Costa Rica (Ajaluela, Cartago, Heredia, Puntarenas, San José), El Salvador, Guatemala, México (Veracruz), Panamá (Colón) (Fig. 216).

Comentários. Essa espécie faz parte de uma politomia que inclui outras quatro espécies. Acrochaeta mexicana e A. flaveola são espécies muito similares no que diz respeito à morfologia externa (e.g., coloração metálica no mediotergito, posição de surgimento de $\mathrm{R}_{2+3}$ ), além de compartilharem uma condição única (área lateral da fronte surgindo anteriormente no vértex, e.g., Fig. 113). Isso sugere a formação de um pequeno clado entre as duas espécies, mas a falta de informação de genitália masculina para A. flaveola, associado a grande quantidade de homoplasias na análise impedem a recuperação desse grupo na árvore mais parcimoniosa. Em princípio, poderia ser considerado também que $A$. mexicana fosse um sinônimo júnior de A. flaveola. (ver comentários em A. flaveola).

O holótipo macho examinado por fotos (Figs. 183-188) encontra-se em boas condições, faltando apenas a antena esquerda, pernas anteriores, medianas e asa direita. 


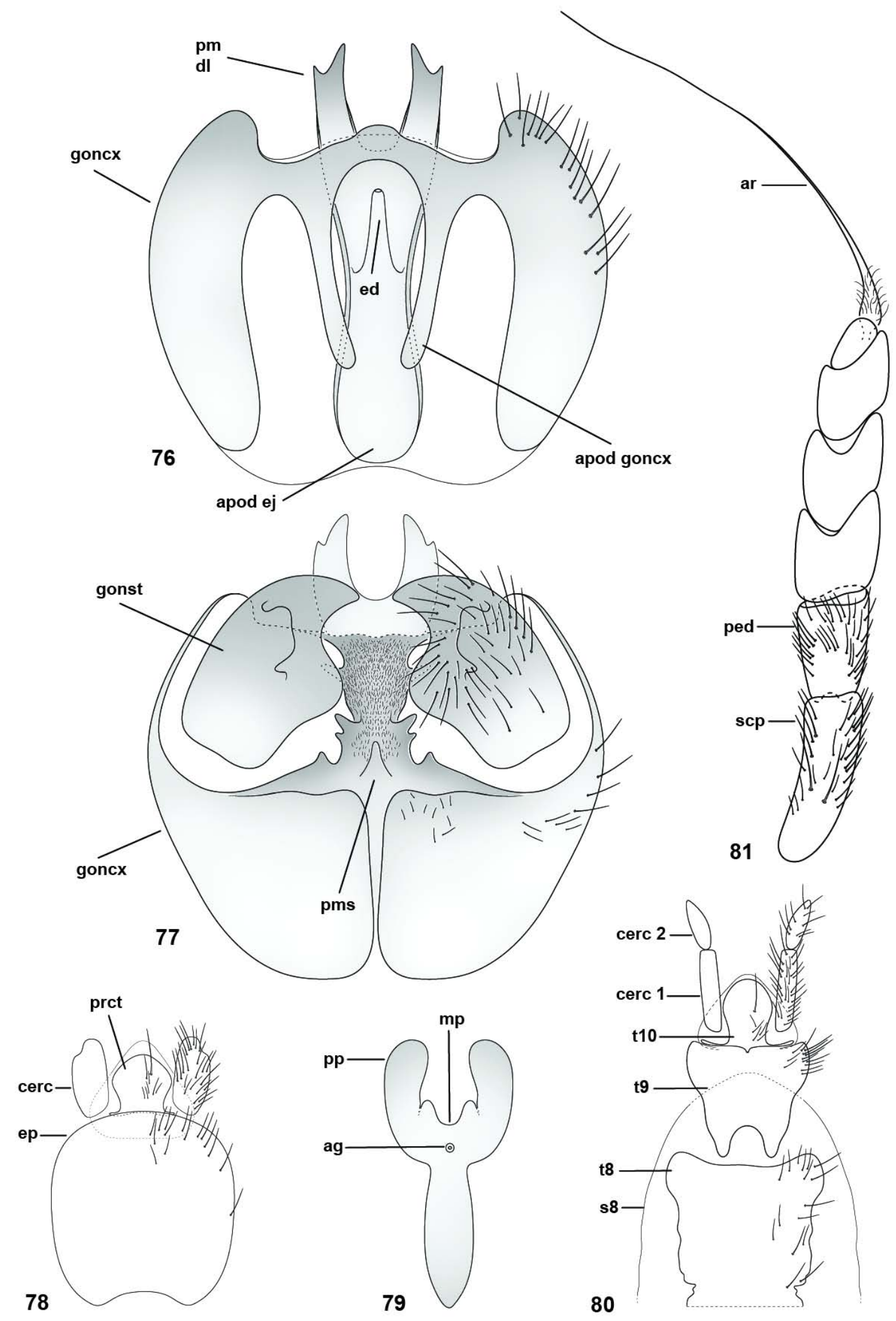

Figuras 76-81. Acrochaeta mexicana, (76-78, 81, macho; 79-80, fêmea). 76. Cápsula genital, vista dorsal. 77. Cápsula genital, vista ventral. 78. Epândrio, vista dorsal. 79. Furca genital. 80. Genitália feminina, vista dorsal. 81. Antena. 


\section{Acrochaeta flaveola Bigot, 1879}

(Figs. 114-115, 132, 147, 189-193)

Acrochaeta flaveola Bigot, 1879: 205-206. Localidade-tipo: México. Holótipo macho (descrito originalmente como fêmea), [BMNH].

Diagnose (macho). Área lateral da fronte originando anteriormente no vértex (Fig. 115); tubérculo ocelar e área medial da fronte bastante projetados. Mediotergito com alguma coloração metálica.

Material examinado. HOLÓTIPO, 1 \#m, MÉXICO, Bigot coll (BMNH).

Distribuição geográfica. México (Fig. 216).

Comentários. Essa espécie é muito semelhante a Acrochaeta mexicana. (e.g., mesmo local de origem da área lateral da fronte, coloração metálica no mediotergito, mesma posição de surgimento de $\mathrm{R}_{2+3}$ ). Isso talvez indique relação de grupo-irmão entre essas espécies ou até mesmo que $A$. mexicana possa ser sinônimo júnior de $A$. flaveola, o que ainda é reforçado pela distribuição geográfica das duas espécies—ambas no México. As demais outras espécies do gênero que compartilham algumas dessas características (e.g., A. balbii sp. nov., A. dichrostyla sp. nov.) são estritamente sul-americanas. Entretanto, apenas o estudo detalhado da genitália masculina dessa espécie, representado até agora apenas pelo holótipo, provavelmente poderia esclarecer essa questão.

O holótipo é um macho (Figs. 189-193), apesar de ter sido descrito originalmente como uma fêmea. Encontra-se em boas condições, mas não tem as antenas (exceto pelo escapo e pedicelo de uma delas) e a asa esquerda e uma parte da costal com $\mathrm{R}_{2+3}$ da asa direita também estão ausentes.

\section{Acrochaeta balbii, sp. nov.}

(Figs. 82-85, 116-117, 133, 148, 162)

Diagnose (macho). Corpo amarelo avermelhado, principalmente abdômen (Fig. 162). $\mathrm{R}_{2+3}$ originando-se em r-m (Fig. 116); $\mathrm{M}_{3}$ completa (Fig. 116). Mediotergito marromescuro a preto, com coloração metálica azul e verde. 
Material examinado. HOLÓTIPO, \#m (lâmina permanente), BRASIL, Rio de Janeiro, Nova Iguaçu, Reserva Biológica do Tinguá, 22³4’32”S 43²6’06.6”W, Malaise, Trilha 3, 08-11.iii.2002, S. T. P. Amarante \& eq. cols. (MZUSP).

Descrição. Macho. Comprimento: corpo, 12.5; asa, 10.5. Cabeça (Fig. 117). Vértex amarelo avermelhado. Parte superior da fronte amarelo avermelhada, fortemente projetada em toda extensão medial; área lateral preta e sinuosa, originando-se posteriormente no vértex; parte inferior da fronte e face amarelas. Antenas amarelo avermelhadas, comprimento do escapo duas vezes o do pedicelo; complexo flagelar alongado (2:1) (Fig. 82); quarto flagelômero mais largo que a arista basalmente; arista larga e pubescente apenas na base. Tórax (Fig. 148). Amarelo avermelhado, faixas longitudinais do escudo marrom escuras a pretas; escutelo preto proximalmente; anespisterno anteriormente e catepisterno amarelos com manchas marrom escuras; mediotergito marrom escuro a preto, com coloração metálica verde e azul. Pernas amarelo avermelhadas, exceto dois terços distais da face ventral dos fêmures anteriores, marrom escuros. Asa. (Fig. 116) $\mathrm{R}_{2+3}$ originando-se quase em $\mathrm{r}-\mathrm{m}$; $\mathrm{r}-\mathrm{m}$ tão longa quanto o terceiro setor da célula discal ou bm-cu. Segundo setor maior que o primeiro, quarto setor tão longo quanto o quinto (célula discal alongada); $\mathrm{M}_{3}$ completa. Álula nua. Halteres amarelo avermelhados. Abdômen. Amarelo avermelhado, com as bandas dos segmentos marrom avermelhadas. Genitália. (Figs. 83-85) Cápsula genital aproximadamente quadrangular, singonocoxito com a margem distal não alcançando a inserção dos gonóstilos, exceto por uma longa projeção medial. Parâmeros largos nos dois terços basais, distalmente projetados em forma de forquilha. Gonóstilos arredondados e mais largos basalmente, afilados apicalmente. Epândrio retangular, muito alongado. Margem posterior do próctiger arredondada, com uma distinta projeção medial.

Fêmea. Desconhecida.

Etimologia. Essa espécie é nomeada em homenagem a Maria Isabel Protti de Andrade Balbi, biologista da Faculdade de Filosofia, Ciências e Letras de Ribeirão Preto, Universidade de São Paulo, pessoa fundamental no andamento das pesquisas do Laboratório de Morfologia e Evolução de Diptera e que sempre tem ajudado os alunos na triagem e identificação de material bem como na preparação de lâminas.

Distribuição geográfica. Brasil (Rio de Janeiro) (Fig. 213).

Comentários. Apesar de, como já comentado, essa espécie apresentar semelhanças com Acrochaeta rhombostyla sp. nov. e principalmente, A. ruschii sp. nov., no que diz 
respeito ao formato dos parâmeros e gonóstilos, essa espécie foi recuperada na análise cladística como sendo irmã de A. boliviana sp. nov. As sinapomorfias desse clado são ambas de venação alar, $\mathrm{R}_{2+3}$ surgindo em $\mathrm{r}-\mathrm{m}$ e comprimento do quarto setor da célula discal equivalente em tamanho ao quinto.
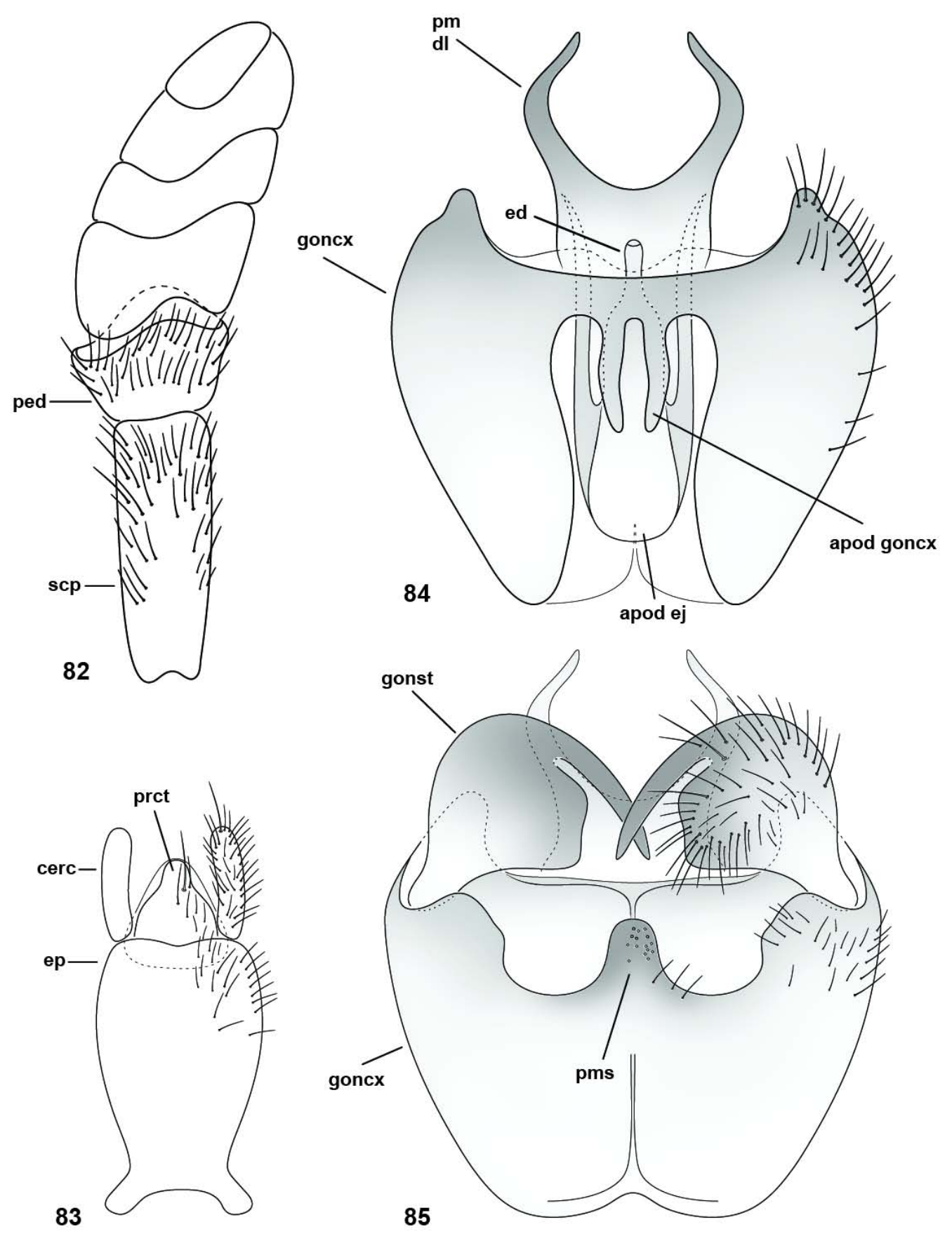

Figuras 82-85. Acrochaeta balbii, sp. nov., holótipo macho. 82. Antena. 83. Epândrio, vista dorsal. 84. Cápsula genital, vista dorsal. 85. Cápsula genital, vista ventral. 


\section{Acrochaeta boliviana, sp. nov.}

(Figs. 86-91, 118-119, 134, 149, 163)

Diagnose. Coloração do corpo amarelo esbranquiçada, exceto pelo abdômen dourado (Fig. 163) e por uma mancha marrom escura mediana que se estende da parte posterior do escudo até a parte proximal do escutelo (Fig. 149). Parâmeros bilobados (Fig. 86).

Material examinado. 1 \#m, HOLÓTIPO, BOLÍVIA, Cochabamba Prov., Villa Tunari, 1654’55”'S 65²2’06”W, Malaise trap, 15.vii.2001, H. Haider leg (CSCA). PARÁTIPO: 1 \#f, BOLÍVIA, Santa Cruz Dist., Potrerillos del Guedo, Reserva Natural, 370m, 1740’S 6327’W, 1-4.x.2007, J. E. Wappes \& R. Morris; ex: BLI/MV (MZUSP).

Descrição. Macho. Comprimento: corpo, 10.0; asa, 11.0. Cabeça (Fig. 119). Vértex amarelo. Parte superior da fronte amarela fortemente projetada em toda extensão medial; área lateral preta, sinuosa. Parte inferior da fronte e face amarelo esbranquiçadas. Antenas amarelo avermelhadas; comprimento do escapo aproximadamente duas vezes o do pedicelo; complexo flagelar alongado (2.0:1) (Fig. 91); quarto flagelômero tão longo quando a arista basalmente; arista amarelo avermelhada na metade basal, marrom escura na metade apical, pubescente, levemente mais larga na base. Tórax (Fig. 149). Amarelo esbranquiçado, exceto pelas faixas longitudinais amarelas no escudo e por uma faixa marrom escura mediana estendendose do pós-escudo ao escutelo anteriormente; pleura esbranquiçada. Pernas amarelas, exceto as anteriores, amarelo avermelhadas. Asa (Fig. 118). $\mathrm{R}_{2+3}$ originando-se praticamente em $\mathrm{r}-\mathrm{m}$; $\mathrm{r}-\mathrm{m}$ mais longa que o terceiro setor da célula discal ou bm-cu. Segundo setor maior que o primeiro, quarto setor tão logo quanto o quinto (célula discal alongada). Álula nua. Halteres amarelados. Abdômen. Amarelo dourado; tergitos 1-2 com bandas brancas proximais reduzidas; tergitos 3-6 totalmente dourados. Genitália (Figs. 86-91). Cápsula genital arredondada distalmente; margem ventral do singonocoxito alcançando a inserção dos gonóstilos, processo medial arredondado, pouco projetado; apódemas gonocoxais quase tão longos quanto dois terços da placa parameral. Parâmeros mais largos no terço distal, fortemente bilobado. Gonóstilos arredondados, largos basalmente, afilados no quinto distal. Epândrio retangular, pouco alongado.

Fêmea. Similar ao macho, exceto no que segue. Comprimento: corpo, 12.0; asa, 12.0. Tórax. Mancha marrom próxima à sutura notopleural; coxas e trocânteres anteriores 
marrom claros. Abdômen. Tergitos com banda branca proximal reduzida. Genitália (Figs. 89-90). Tergito 9 tão largo quanto longo. Furca genital com forte distinção de largura entre partes posterior e anterior (Fig. 89); porção anterior cilindríca, arredondada na base; margem posterior suavemente projetada; processos póstero-laterais paralelos, arrendondados no ápice; abertura genital circular. Comprimento do cercômero 1 maior que o do cercômero 2.

Etimologia. O nome é feminino e o epíteto específico faz referência ao país onde a espécie-tipo foi coletada.

Distribuição geográfica. Bolívia (Fig. 213).

Comentários. Essa espécie é facilmente separada das demais do grupo-flaveola por apresentar a parte posterior do escudo com uma mancha marrom escura mediana que se estende até a parte proximal do escutelo (Fig. 149) e pelos parâmeros bilobados (Fig. 86), condição semelhante que pode ser encontrada apenas em Acrochaeta mexicana (Fig. 76). 


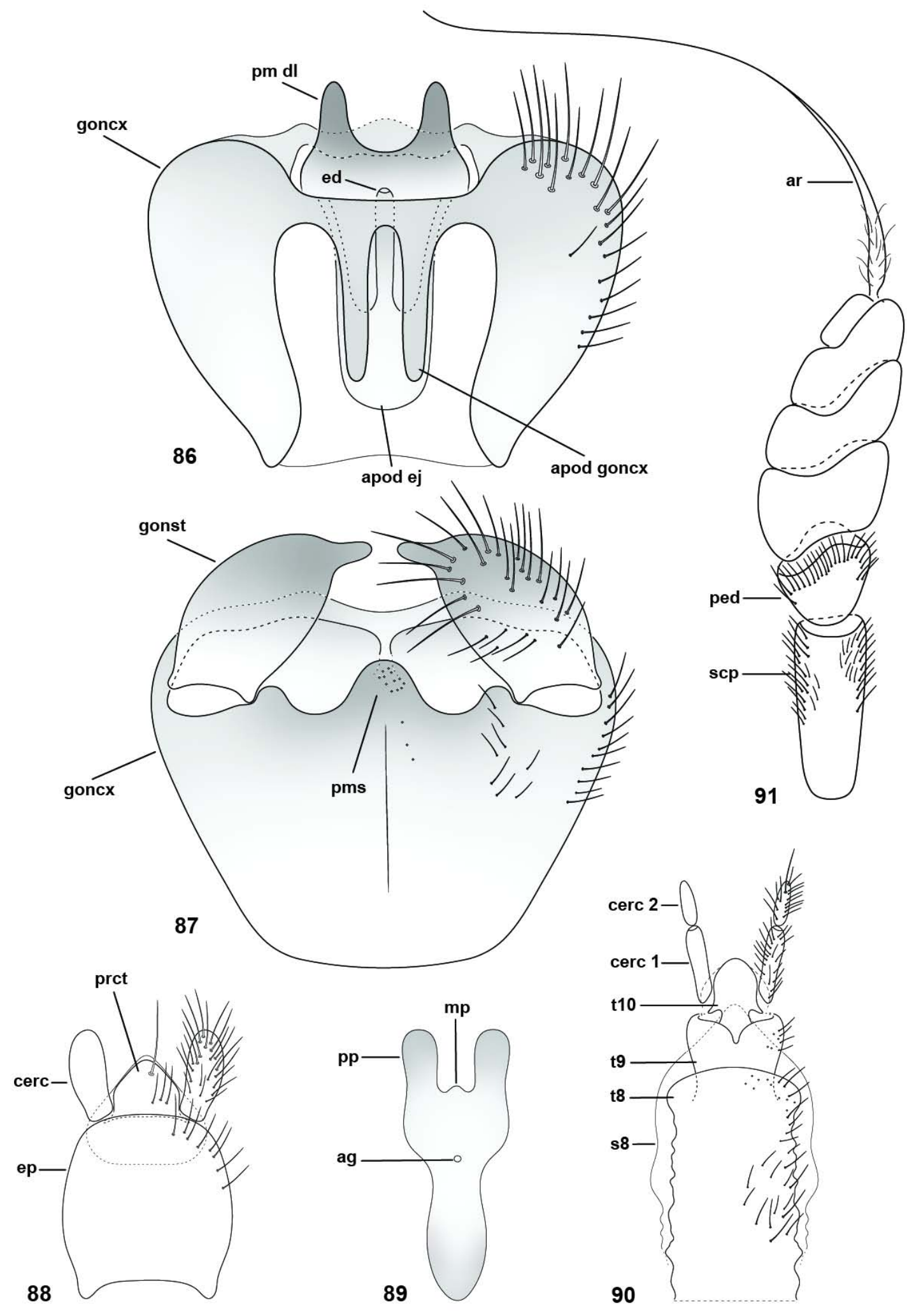

Figuras 86-91. Acrochaeta boliviana, sp. nov., (86-88, 91, holótipo macho; 89-90, parátipo fêmea). 86. Cápsula genital, vista dorsal. 87. Cápsula genital, vista ventral. 88. Epândrio, vista dorsal. 89. Furca genital. 90. Genitália feminina, vista dorsal. 91. Antena. 


\subsection{Novas combinações}

Além de Acrochaeta convexifrons comb. nov., outras quatro novas combinações são feitas aqui, incluindo a mudança de sinonímia de Compsosoma Brauer, 1882 como sinônimo júnior de Acrochaeta para Merosargus. As espécies originalmente descritas para esse gênero e posteriormente sinonimizadas com Acrochaeta, A. chalconota e A. picta são espécies de Merosargus (Fig. 217), na delimitação atual do gênero. Assim, abaixo estão as espécies de Acrochaeta (incluindo A. chalconota e A. picta) sinonimizadas como espécies de Merosargus.

\section{Chysochlorina elegans (Perty, 1833), comb. nov.}

Acrochaeta elegans Perty, 1833: 184, prancha 36, figura 14. Localidade-tipo: Brasil, “Amazon River”. Holótipo macho, [ZSBS].

Material examinado. O holótipo não foi analisado.

Comentários. Em comunicação pessoal, o Dr. Norman E. Woodley indicou que essa espécie não pertence ao gênero Acrochaeta. Trata-se de uma espécie do gênero Chrysochlorina, da subfamília Chrysochlorininae erroneamente descrita em Acrochaeta. Provavelmente, contribuiu para o equívoco a semelhança do padrão de coloração e de comprimento da antena entre os dois gêneros. É proposta aqui uma nova combinação, movendo Acrochaeta elegans para o gênero Chrysochlorina.

Merosargus picta (Brauer, 1882), comb. nov.

(Figs. 194-202, 248, 282, 311, 341, 370, 397, 434, 485)

Acrochaeta picta Brauer, 1882: 80. Localidade-tipo: Venezuela. Síntipos: 1 macho, 2 fêmeas, [NMW].

Diagnose. Espécie facilmente reconhecida pela larga faixa azul metálica no escudo que se estende até o escutelo (Fig. 282), claramente mais larga na metade posterior do escudo; mediotergito azul metálico. $\mathrm{R}_{2+3}$ originando-se próximo de $\mathrm{r}-\mathrm{m}$, a uma distância 
equivalente à metade do comprimento de $\mathrm{r}-\mathrm{m}$, convergindo em direção a $\mathrm{R}_{1}$ (Fig. 311); álula totalmente recoberta por microtríquias (Fig. 341). Tergitos 1-2 e 5 com manchas marrom escuras recobrindo praticamente toda a superfície, tergitos 3-4 claramente amarelos, com manchas marrom escuras frequentemente divididas ou mais estreitas medialmente (Fig. 485).

Material examinado. SÍNTIPOS: 1 \#m, 2 \#f, VENEZUELA (NMW). Material adicional. 1 \#m, VENEZUELA, Aragua, Rancho, Parque Nacional Henry Pittier, 1100m, iii.4.1967, M.E. Irwin.

Distribuição geográfica. Venezuela.

Comentários. Essa espécie não pertence a Acrochaeta, como pode ser visto no cladograma da figura 217, pois não não apresenta as sinapomorfias de Acrochaeta no sentido aqui definido, como por exemplo, a elevação da parte inferior da fronte, o padrão de faixas longitudinais no escudo etc. (para mais detalhes, ver seção Discussão, pág. 124). Além disso, compartilha uma série de características com uma parte das espécies de Merosargus, como por exemplo, edeago bífido. Mesmo considerando essa espécie como pertencente a Merosargus (inserida em um clado com espécies majoritariamente amareladas e de edeago bífido), ainda é difícil estabelecer seu real posicionamento, uma vez que a amostragem das espécies desse gênero foi limitada. É proposta aqui uma nova combinação, movendo Acrochaeta picta para o gênero Merosargus.

O material tipo (Figs. 194-202) foi examinado por fotos e encontra-se em boas condições, faltando somente a antena esquerda em uma das fêmeas e as antenas no macho—presença apenas do escapo e pedicelo da antena esquerda.

Merosargus chalconota (Brauer, 1882), comb. nov.

(Figs. 203-207)

Acrochaeta chalconota Brauer, 1882: 79. Localidade-tipo: Venezuela. Holótipo macho, [NMW].

Diagnose (macho). Essa espécie pode ser claramente reconhecida pela coloração azul metálica na cabeça (i.e., vértex, tubérculo ocelar e parte superior da fronte), escudo, escutelo, mediotergito e tergito 1 em sua totalidade. 


\section{Material examinado. HOLÓTIPO, 1 \#m, VENEZUELA (NMW).}

Distribuição geográfica. Costa Rica e Venezuela.

Comentários. Apesar da falta de informação sobre genitália masculina e feminina dessa espécie, foi possível recuperá-la como parte de Merosargus, em um pequeno clado que inclui espécies inteiramente metálicas (ver Discussão, pág. 124). Da mesma forma que no caso de $M$. picta, ainda não é possível posicionar precisamente essa espécie dentro do sistema do gênero. É proposta aqui uma nova combinação, movendo Acrochaeta chalconota para o gênero Merosargus. Lindner (1936b) indica a presença dessa espécie na Costa Rica, o que ainda carece de confirmação.

O holótipo examinado por fotos (Figs. 203-207) está em boas condições, exceto pela falta dos flagelômeros da antena esquerda, pernas anteriores e pernas medianas e posteriores do lado esquerdo. A asa esquerda está danificada no lóbulo anal.

\section{Merosargus longiventris (Enderlein, 1914), comb. nov.}

(Figs. 208-212, 260, 294, 324, 353, 380, 407, 444, 470, 494)

Acrochaeta longiventris Enderlein, 1914: 595-596, fig. 4. Localidade-tipo: Brasil, Santa Catarina. Holótipo macho (descrito originalmente como fêmea), [PAN].

Diagnose. Corpo marrom avermelhado a marrom escuro (Fig. 494). Calo frontal amarelado, fortemente constrastando com o marrom da parte inferior da fronte e com a face. Tórax totalmente escuro, sem padrão de bandas longitudinais no escudo (Fig. 294). Abdômen não peciolado como em Acrochaeta (Fig. 494); segmentos 1-2 amarelos, com largas bandas marrom escuras cobrindo mais da metade de cada segmento (Fig. 494); segmentos 3-5 totalmente marrom escuros, contrastando com a pilosidade amarela. Lóbulo medial do edeago mais largo que os demais, bruscamente estreitando-se em direção ao ápice (Fig. 380).

Material examinado. HOLÓTIPO, 1 \#m, BRASIL, Santa Catarina, Lüderwaldt (PAN). Material adicional. 1 \#m, BRASIL, Paraná, Colombo, Bairro, Santa Rita, 25²2’45.91”S 4907’56.73”W, Malaise, 913m, ix.2012, Savaris, M. col. 1 \#m, São José dos Pinhais, Br 277- Km 54, 14.i.1985, Luminosa, C.I.I.F; 1 \#m, 21.i.1985; 1 \#m, 26.ii.1985; 1 \#m, 19.iii.1985. (DZUP). 1 \#m, Rio de Janeiro, Itatiaia, Est. Biológica, 1000m, 5.xi.1931, W. Zikan. (MNRJ). 1 \#f, Santa Catarina, Nova Teutônia, i.1972, 
Fritz Plaumann. (MZUSP). 1 \#m, São Paulo, Campos do Jordão, Homem Morto, xii.1945, Barretto col. 1 \#m, Eugênio Lefevre, 12-13.i.1977, F. Val col. (MZUSP). 1 \#f, Serra do Japi, 18.iii.2010, Malaise III. (MZUSP). 1 \#f, PARAGUAI, Pirapó, 3031.xii.1971. 3 \#m, 2 \#f, 1-3.i.1972. (MZUSP).

Distribuição geográfica. Brasil (Paraná, Rio de Janeiro, Santa Catarina, São Paulo), Paraguai.

Comentários. Essa espécie aparece como irmã de todo clado incluindo o gênero Acrochaeta (Fig. 217). Anteriomente considerada como espécie de Acrochaeta, foi excluída do gênero seguindo a atual delimitação aceita aqui, de modo que é proposta uma nova combinação, movendo essa espécie para Merosargus. M. longiventris não apresenta as sinapomorfias de Acrochaeta no sentido aqui definido, como por exemplo, a elevação da parte inferior da fronte, o padrão de faixas longitudinais no escudo etc. (para mais detalhes, ver seção Discussão, pág. 124). Evidentemente, é necessário um estudo mais completo de Merosargus para que seja possível uma confiável organização taxonômica que se permita evitar a formação de um taxon genérico parafilético.

O holótipo macho (Figs. 208-212), embora tenha sido tomado como fêmea na descrição original encontra-se em perfeitas condições.

\subsection{Chave de identificação para as espécies do gênero Acrochaeta}

A chave dicotômica a seguir permite a identificação das 15 espécies do gênero, sendo 8 espécies novas e 7 espécies conhecidas.

1. Área medial da parte superior da fronte não projetada (Fig. 8); apódemas gonocoxais bastante reduzidos (e.g., Fig. 26); edeago trífido (e.g., Fig. 30)

- Área medial da parte superior da fronte fortemente projetada em toda extensão medial (Fig. 9); apódemas gonocoxais muito desenvolvidos (e.g., Fig. 51); edeago simples (e.g., Fig. 67) 8

2. Parte superior da fronte não tão larga quanto a largura do olho (e.g., Fig. 97); $\mathrm{R}_{2+3}$ longa, surgindo depois de r-m (e.g., Fig. 96); célula discal frequentemente alongada (e.g., Fig. 104) 3 
- Parte superior da fronte muito larga, tão larga quanto o olho (Fig. 83); $\mathrm{R}_{2+3}$ curta, surgindo antes de r-m (Fig. 92); célula discal retangular (Fig. 92) (Brasil, SC e MG)

A. degenerata Lindner

3. Antenas alongadas (e.g., Fig. 33); arista larga, pubescente apenas basalmente (e.g., Fig. 33); $\mathrm{R}_{2+3}$ surgindo bem depois de r-m, próximo ao ápice da célula discal (e.g., Fig. 94) 4

- Antenas extremamente alongadas (e.g., Fig. 24); arista gradualmente diminuindo de espessura em direção ao ápice, pubescente pelo menos nos dois terços basais (e.g., Fig. 24); $R_{2+3}$ surgindo pouco depois de $r-m$, a uma distância equivalente ao comprimento de r-m (e.g., Fig. 102)

4. Corpo bem escurecido (Fig. 151); tórax totalmente escuro, difícil visualização do padrão de bandas no escudo (Fig. 136); $\mathbf{M}_{3}$ convexa (Fig. 93); álula nua (Fig. 121) (Brasil, SP) A. asapha, sp. nov.

— Corpo amarelo avermelhado (Fig. 154); padrão de bandas do escudo bastante distinto (e.g., 139); $\mathrm{M}_{3}$ reta (Fig. 98); alúla com pilosidade súpero-distal (Fig. 124) (Brasil, SC) A. dimidiata Lindner

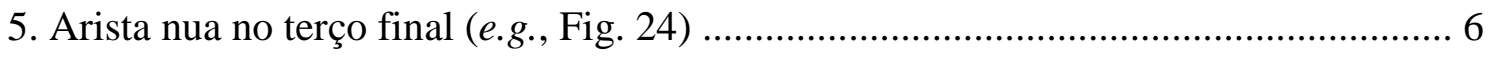

— Arista pilosa no terço final (e.g., Fig. 37) ................................................................ 7

6. Corpo amarelo a amarelo dourado (Fig. 153); padrão de bandas do escudo bem distinto (Fig. 138); tergito 1 do abdômen reduzido a uma mancha marrom escura central (Fig. 153) (Brasil, AP, BA, ES, MS, MG, RJ, SC, SP; Paraguai) A. fasciata Wiedemann - Corpo marrom a marrom escuro (Fig. 152), em alguns casos, bandas do escudo de difícil visualização (Fig. 137); tergito 1 do abdômen com banda marrom escura proximal (Fig. 152) (Brasil, BA, ES, MG, PR, RJ, SC e SP) A. adusta Lindner

7. Corpo amarelo claro (Fig. 156); mediotergito marrom a marrom escuro, contrastando com a coloração amarelada da pleura; terceiro setor de $\mathrm{M}_{1+2}$ claramente mais curto que r-m (Fig. 102) (Brasil, PR, RJ e SP) A. polychaeta, sp. nov. 
- Corpo marrom a marrom escuro (Fig. 155); mediotergito marrom a marrom escuro, não contrastando com a coloração do corpo; terceiro setor de $\mathrm{M}_{1+2}$ tão longo quanto $\mathrm{r}-\mathrm{m}$ (Fig. 100) (Brasil, SP)

A. pseudopolychaeta, sp. nov.

8. Extremo basal de $\mathrm{A}_{1}$ nua até a bifurcação de $\mathrm{A}_{1}$ e $\mathrm{Cu} \mathrm{A}_{2}$ (Fig. 127); tergito 1 do abdômen com duas manchas marrom escuras proximais e uma banda distal marrom escura; parâmeros não projetados (Fig. 51), abertura da furca não reduzida em tamanho (Fig. 53) (Costa Rica, Equador, Guatemala, México) A. convexifrons James — Extremo basal de $A_{1}$ pilosa em metade do comprimento (e.g., Fig 133); tergito 1 do abdômen com uma banda proximal; parâmeros projetados (e.g., Fig. 67); abertura da furca muito reduzida (e.g., Fig. 64)

9. Área lateral da fronte originando anteriormente no vértex (e.g., Fig. 113) ............... 10

— Área lateral da fronte originando posteriormente no vértex (e.g., Fig. 119) ............. 11 10. $R_{2+3}$ surgindo em $r-m$ ou muito perto, a uma distância equivalente a metade do comprimento de r-m (Fig. 112) (Antígua e Barbuda, Costa Rica, El Salvador, Guatemala, México, Panamá) A. mexicana Lindner

- $\mathrm{R}_{2+3}$ surgindo depois de $\mathrm{r}-\mathrm{m}$, a uma distância equivalente ao comprimento de r-m (Fig. 114) (México) A. flaveola Bigot

11. Álula com pilosidade súpero-distal (Fig. 128) 13

— Álula completamente nua (Fig. 133) 12

12. Coloração do corpo amarelo esbranquiçada, exceto pelo abdômen, dourado (Fig. 163); bandas do escudo amarelas (Fig. 149); parte posterior do escudo com uma macha marrom escura mediana, que se estende até a parte proximal do escutelo (Fig. 149); mediotergito não metálico; M3 incompleta (Fig. 118); parâmeros bilobados (Fig. 86) (Bolívia) A. boliviana, sp. nov. — Corpo amarelo avermelhado (principalmente abdômen) (Fig. 162); bandas do escudo marrom escuras (Fig. 148); ausência de mancha mediana próxima ao escutelo; mediotergito metálico; $M_{3}$ completa (Fig. 116); parâmero distintamente em forma de forquilha (Fig. 84) (Brasil, RJ) A. balbii, sp. nov. 
13. Coloração do abdômen escura pelo menos nos três últimos tergitos (Fig. 158); margem dorsal do gonóstilo projetada (e.g., Fig. 58); gonóstilos não bífidos (e.g., Fig. 58)

- Coloração do abdômen amarelo avermelhado, fortemente contrastando com o restante do corpo (Fig. 160); ausência de projeção na margem dorsal dos gonóstilos (Fig. 71); gonóstilos bífidos distalmente (Fig. 71) (Brasil, RO) .. A. dichrostyla, sp. nov.

14. Tergitos 1-2 sem manchas marrom escuras ou com manchas reduzidas (Fig. 160); projeção na margem dorsal dos gonóstilos muito reduzida (Fig. 69) (Brasil, SP) A. ruschii, sp. nov. — Tergitos 1-2 com manchas escuras dispostas em bandas horizontais proximais (Fig. 159); projeção na margem dorsal dos gonóstilos tão longa quanto a parte distal dos gonóstilos (Fig. 64) (Brasil, MS) A. rhombostyla, sp. nov. 


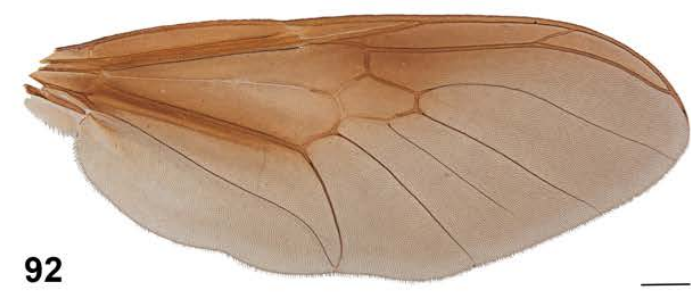

93

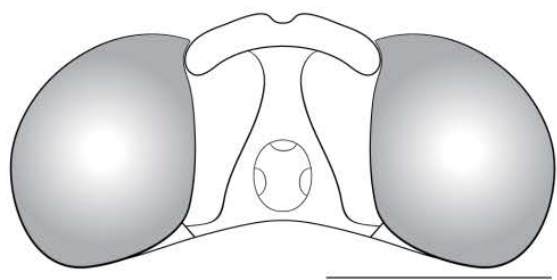

94
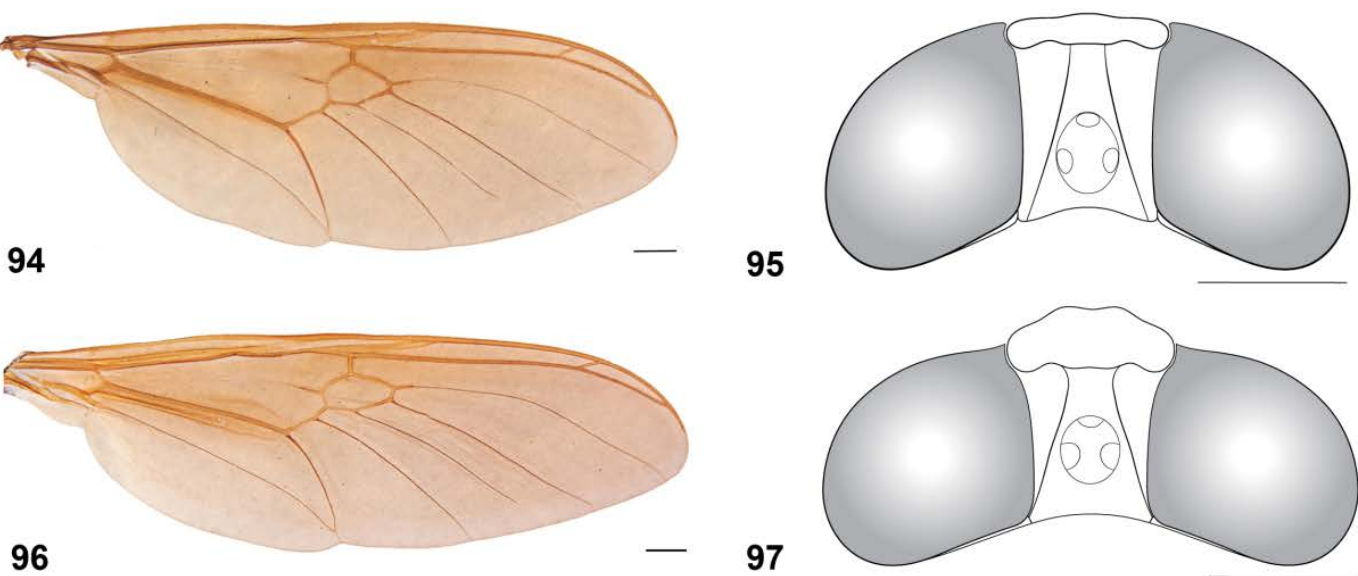

95
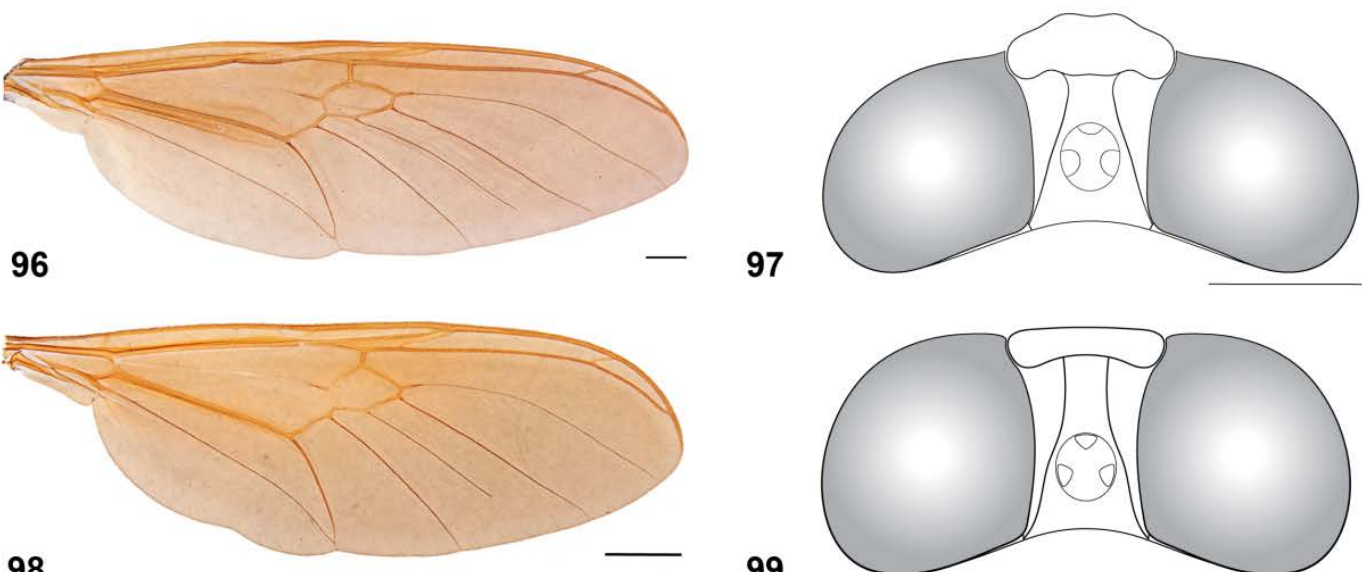

97

98
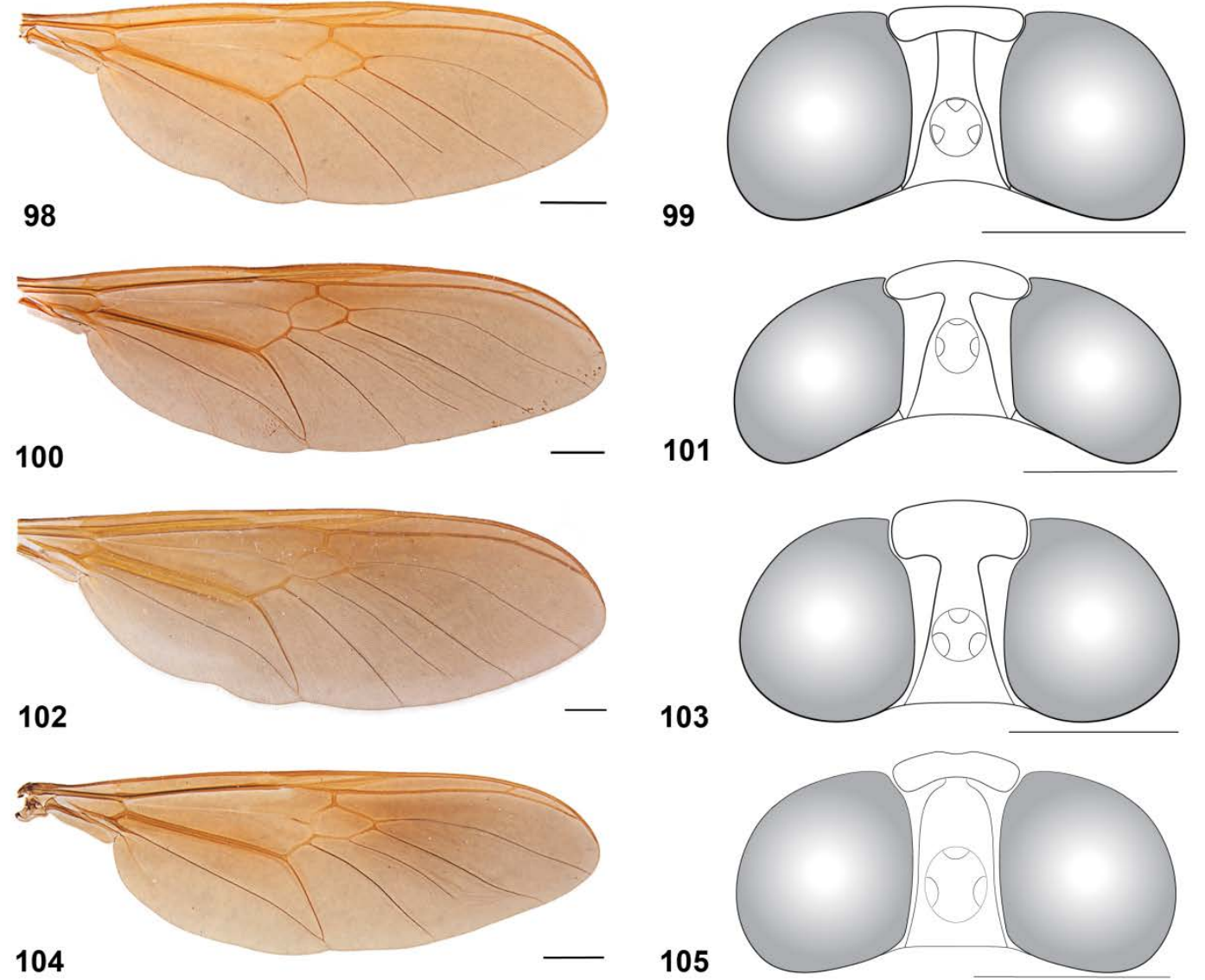

104

105

Figuras 92-105. Acrochaeta spp., asa e cabeça em vista dorsal. 92-93. A. degenerata, fêmea. 94-95. A. asapha, sp. nov., holótipo fêmea. 96-97. A. adusta, macho. 98-99. A. dimidiata, macho. 100-101. A. pseudopolychaeta, sp. nov., holótipo macho. 102-103. A. polychaeta, sp. nov., parátipo macho. 104-105. A. convexifrons, macho. Escala, 1 mm. 


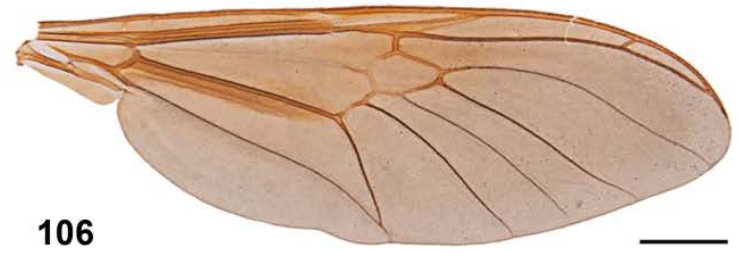

108
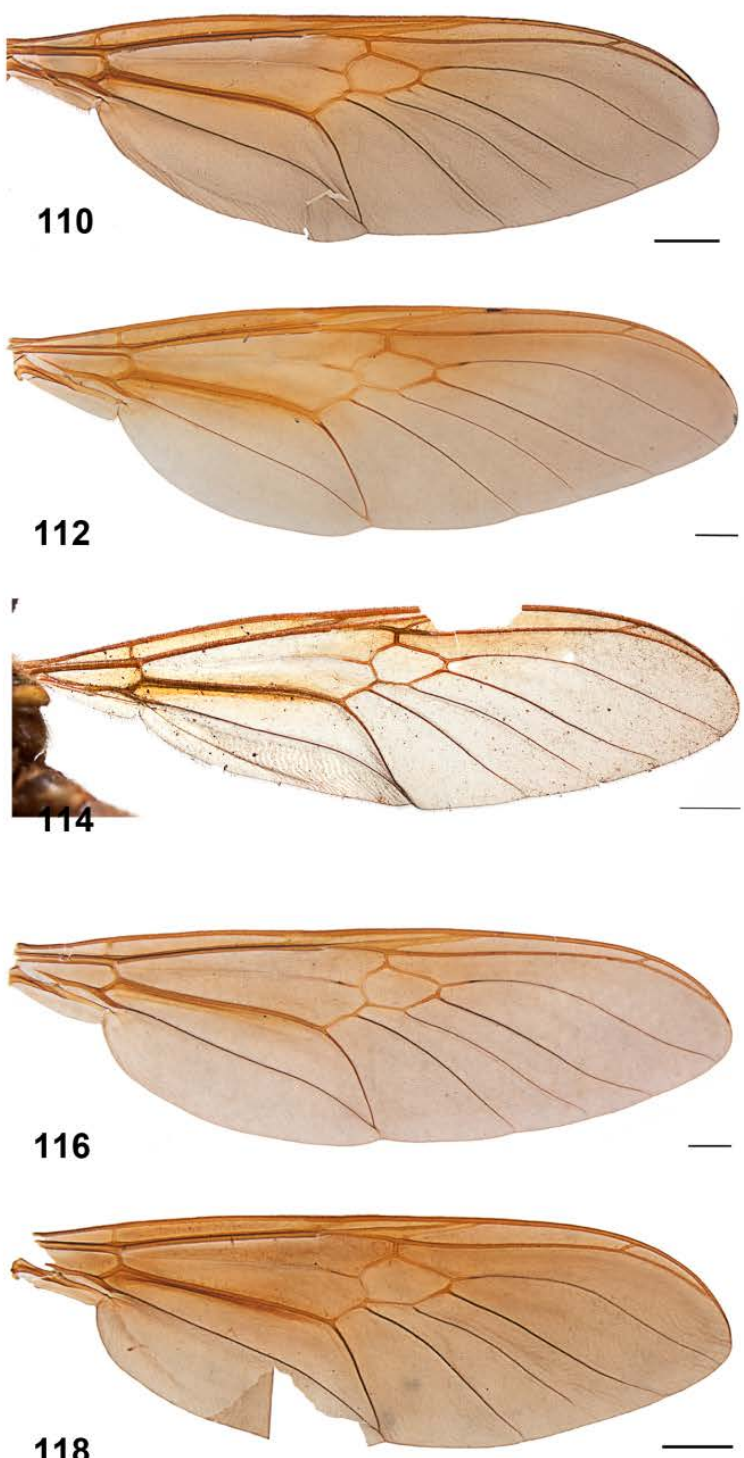

107

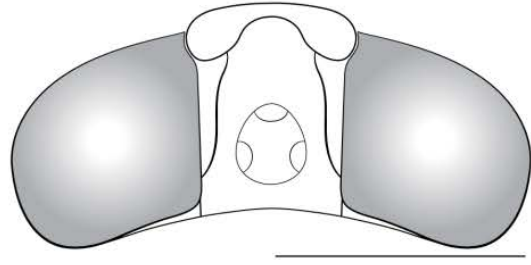

109

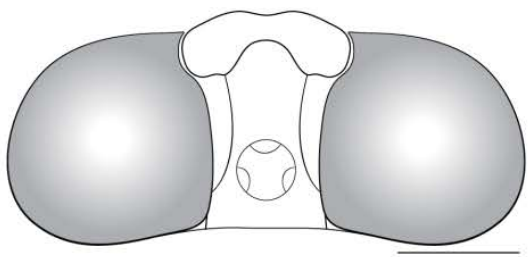

111

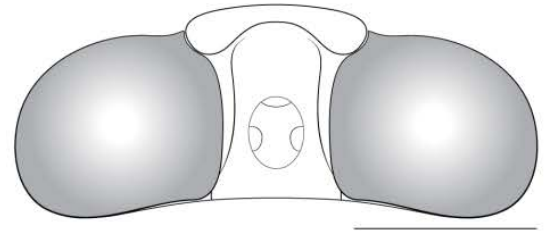

113

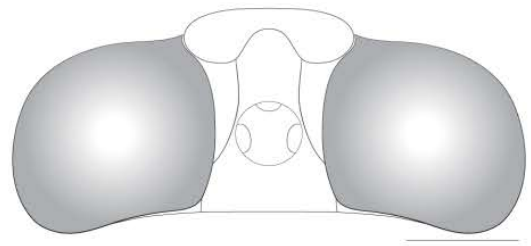

115

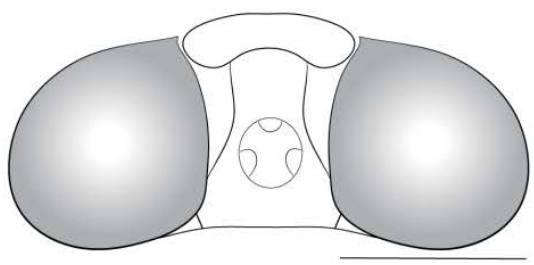

117

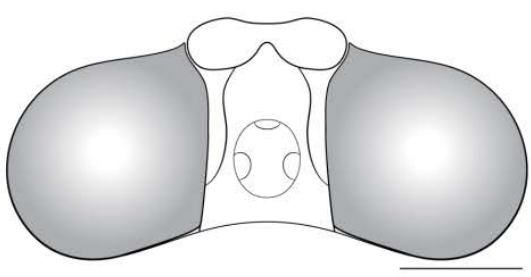

119

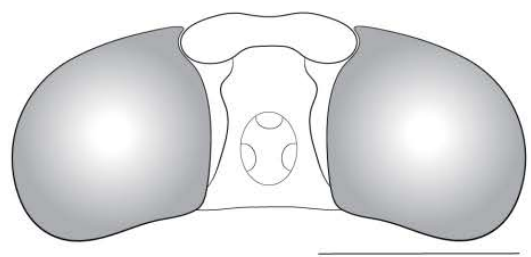

Figuras 106-119. Acrochaeta spp., asa e cabeça em vista dorsal. 106-107. A. rhombostyla, sp. nov., holótipo macho. 108109. A. ruschii, sp. nov., holótipo macho. 110-111. A. dichrostyla, sp. nov, holótipo macho. 112-113. A mexicana, macho. 114-115. A flaveola, holótipo macho. 116-117. A. balbï, sp. nov., holótipo macho. 118-119. A. boliviana, sp. nov., holótipo macho. Escala, $1 \mathrm{~mm}$. 


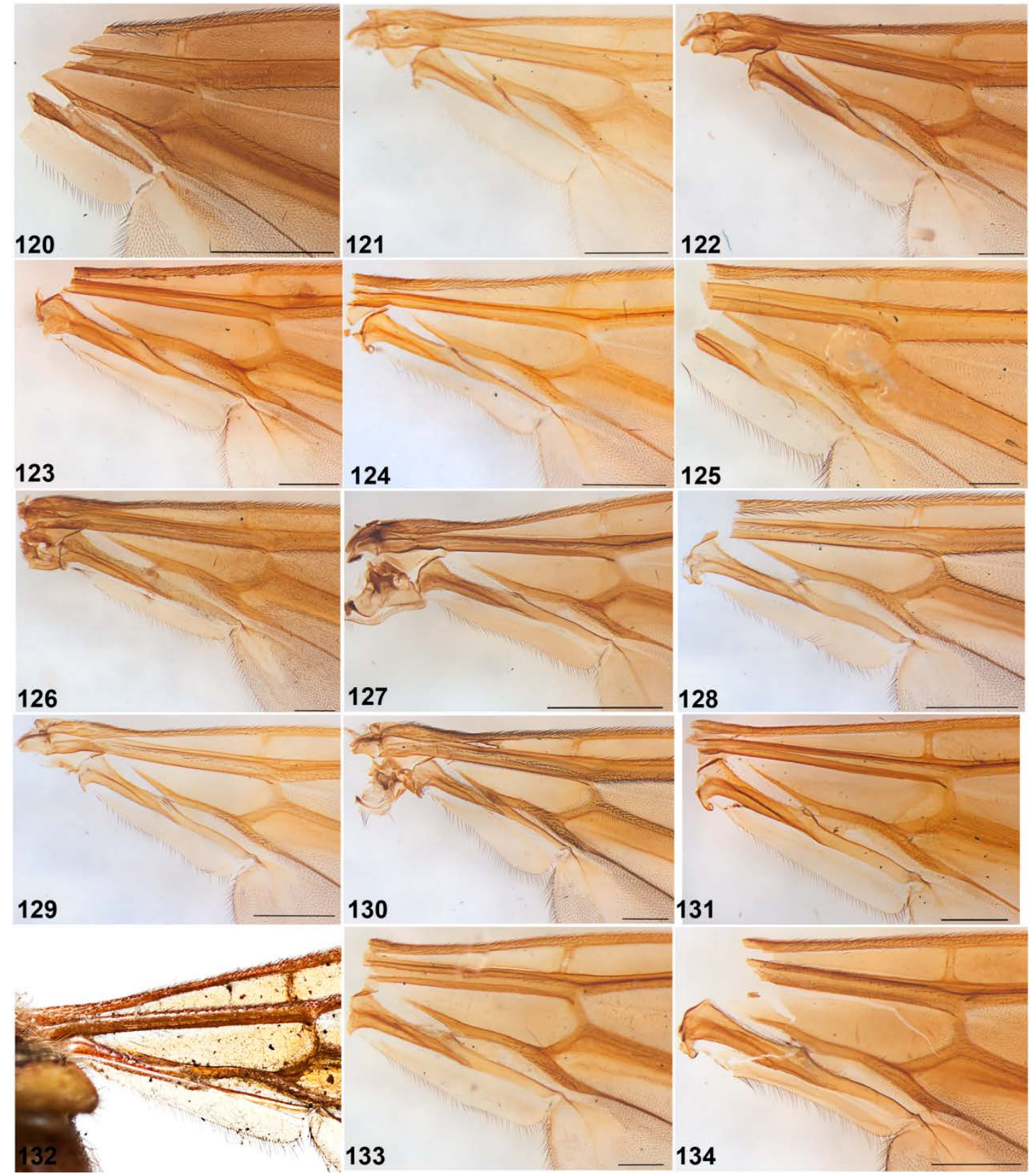

Figuras 120-134. Acrochaeta spp., álula. 120. A. degenerata, fêmea. 121. A. asapha, sp. nov., holótipo fêmea. 122. A. adusta, macho. 123. A. fasciata, macho. 124. A. dimidiata, macho. 125. A. pseudopolychaeta, sp. nov., holótipo macho. 126. A. polychaeta, sp. nov., parátipo macho. 127. A. convexifrons, macho. 128. A. rhombostyla, sp. nov., holótipo macho. 129. A. ruschii, sp. nov., holótipo macho. 130. A. dichrostyla, sp. nov., holótipo macho. 131. A. mexicana, macho. 132. A. flaveola, holótipo macho. 133. A. balbii, sp. nov., holótipo macho. 134. A. boliviana, sp. nov., holótipo macho. Escala, $0.5 \mathrm{~mm}$. 


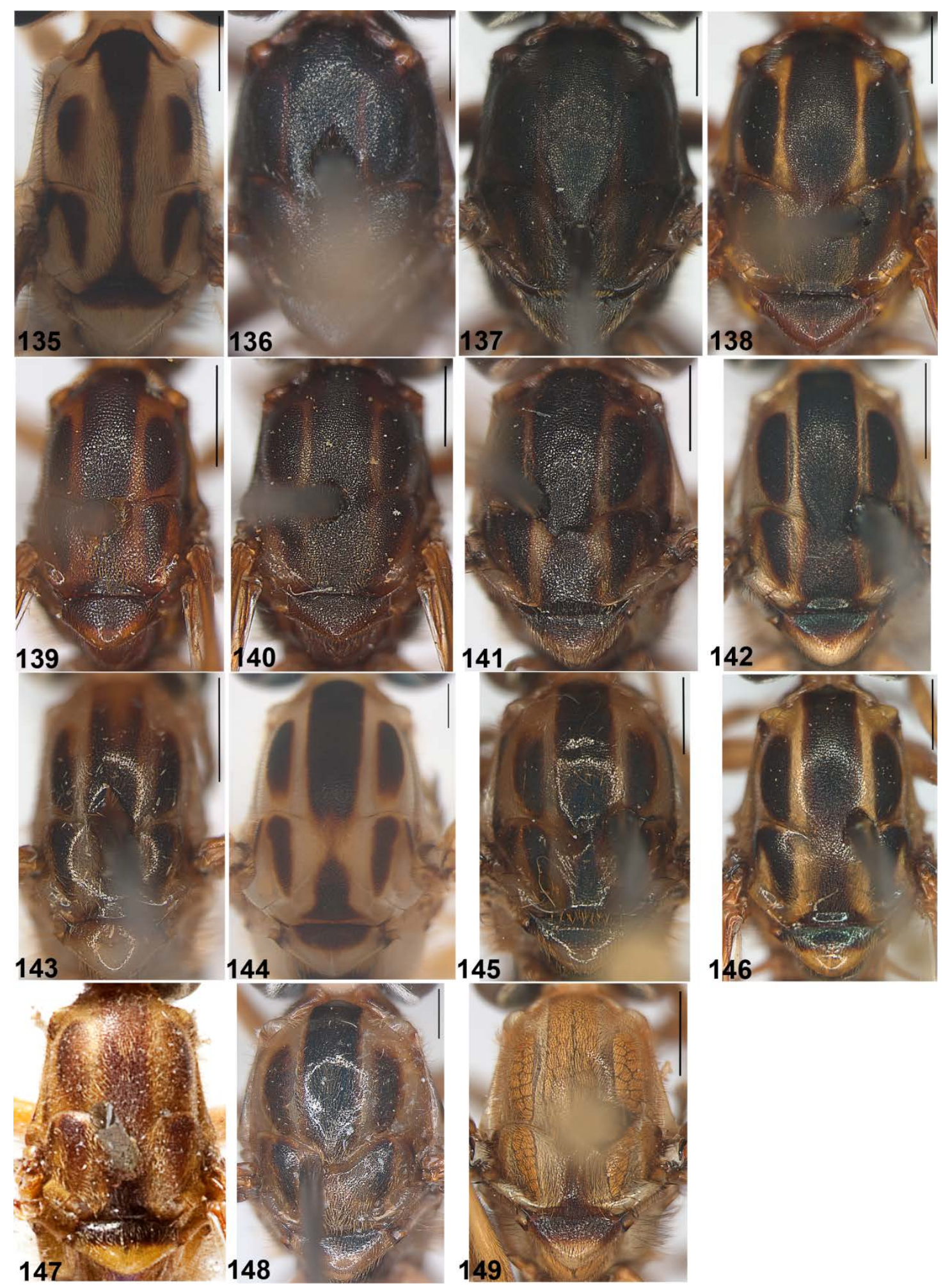

Figuras 135-149. Acrochaeta spp., escudo em vista dorsal. 135. A. degenerata, fêmea. 136. A asapha, sp. nov., holótipo fêmea. 137. A adusta, macho. 138. A fasciata, macho. 139. A dimidiata, macho. 140. A pseudopolychaeta, sp. nov, holótipo macho. 141. A polychaeta, sp. nov., parátipo macho. 142. A convexifrons, macho. 143. A rhombostyla, sp. nov., holótipo macho. 144.A. ruschï, sp. nov., holótipo macho. 145. A dichrostyla, sp.nov., holótipomacho. 146.A. mexicana, macho. 147. A. flaveola, holótipo macho. 148. A. balbii, sp. nov., holótipo macho. 149. A. boliviana, sp. nov., holótipo macho. Escala, $1 \mathrm{~mm}$. 


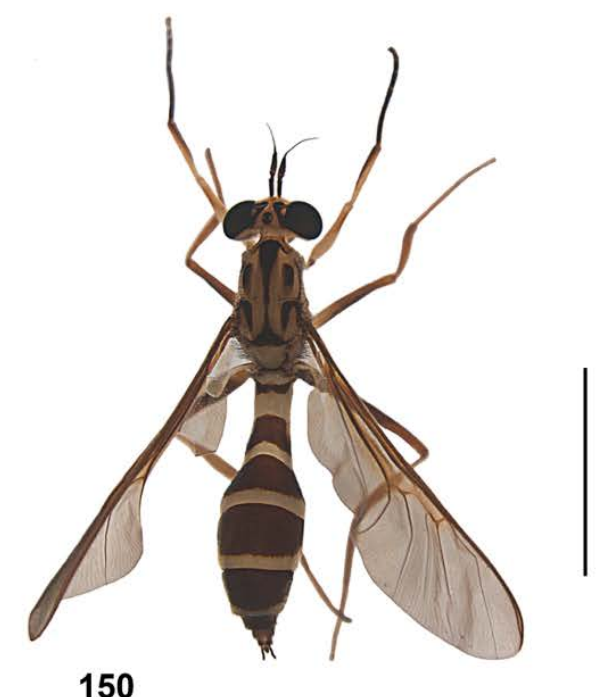

150

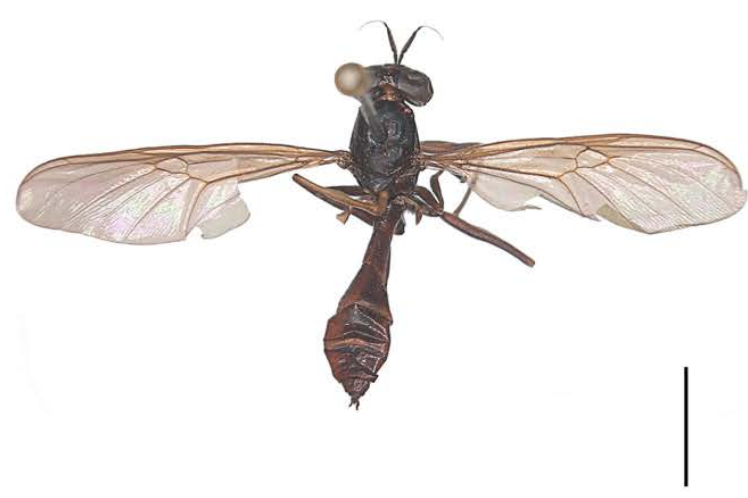

151

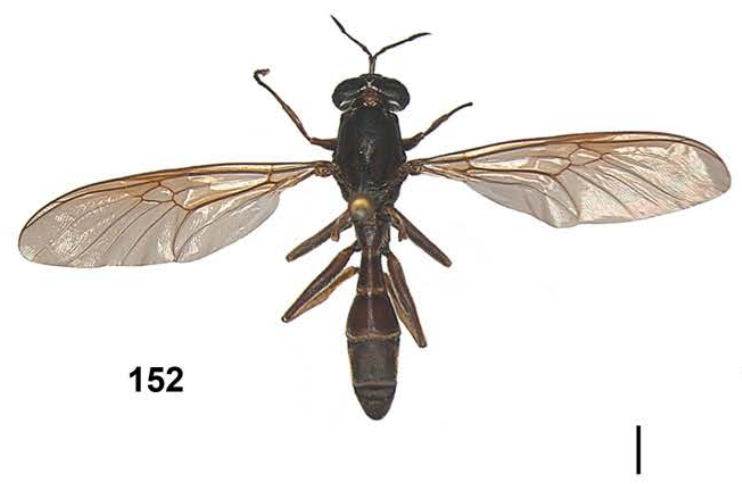

153
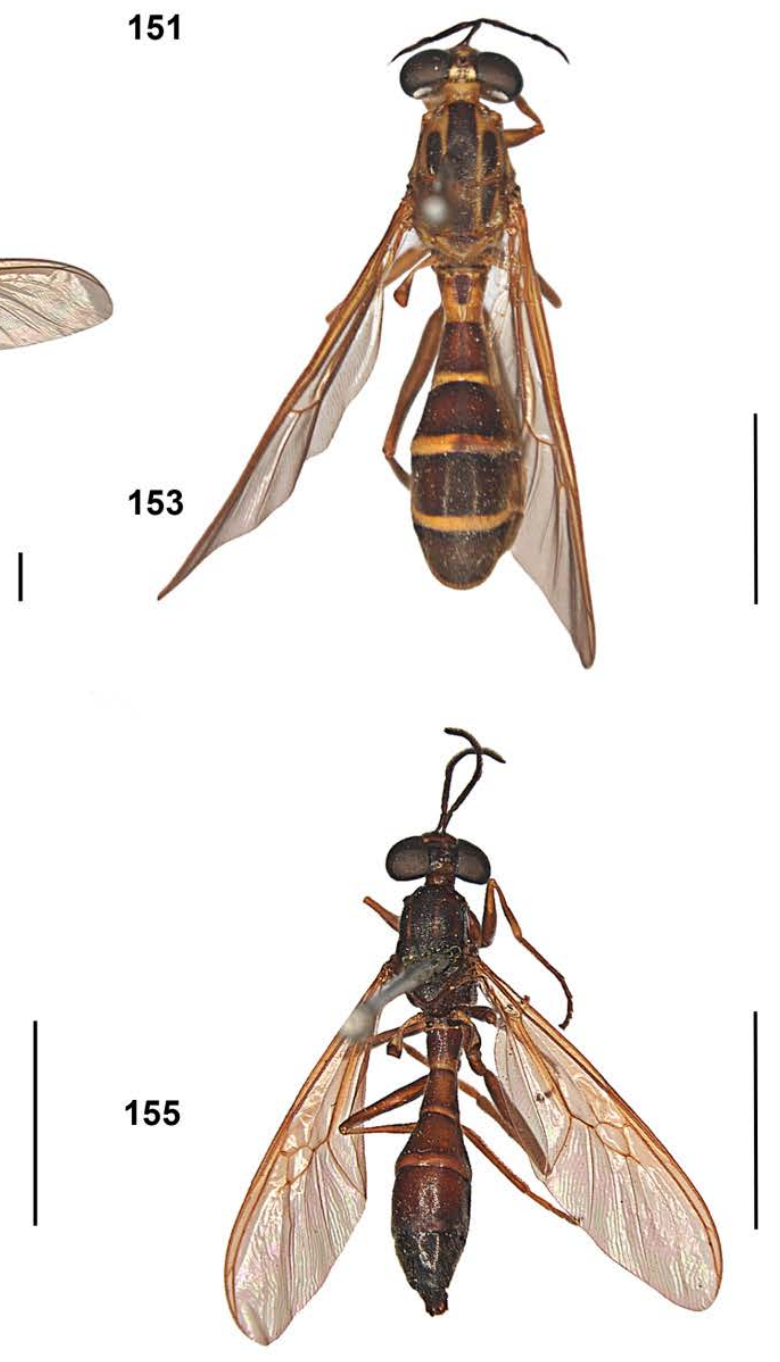

Figuras 150-155. Acrochaeta spp., habitus dorsal. 150. A. degenerata, fêmea. 151. A. asapha, sp. nov., holótipo fêmea. 152. A. adusta, macho. 153. A. fasciata, macho. 154. A. dimidiata, macho. 155. A. pseudopolychaeta, sp. nov., holótipo macho. Escala, 5 mm. 


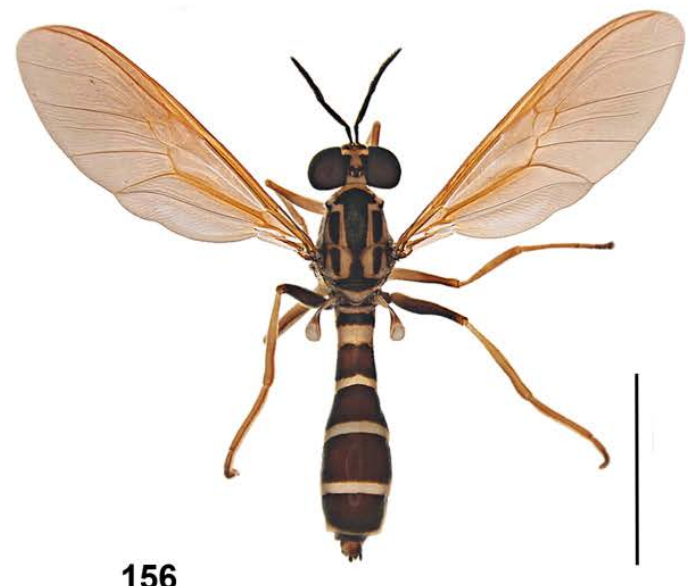

156

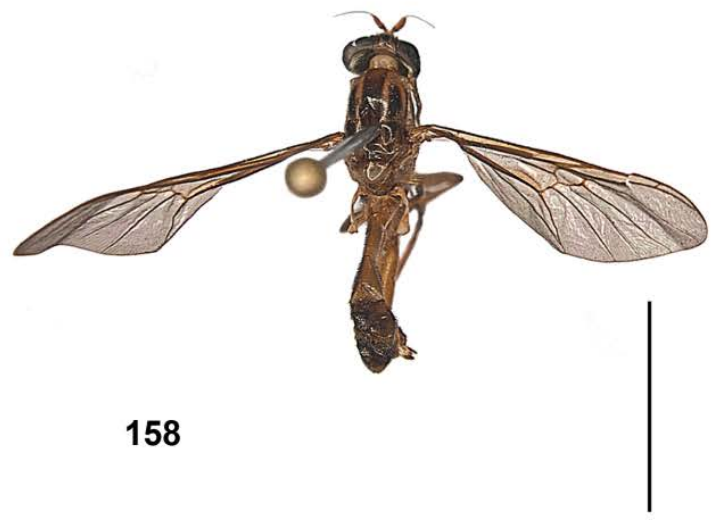

159

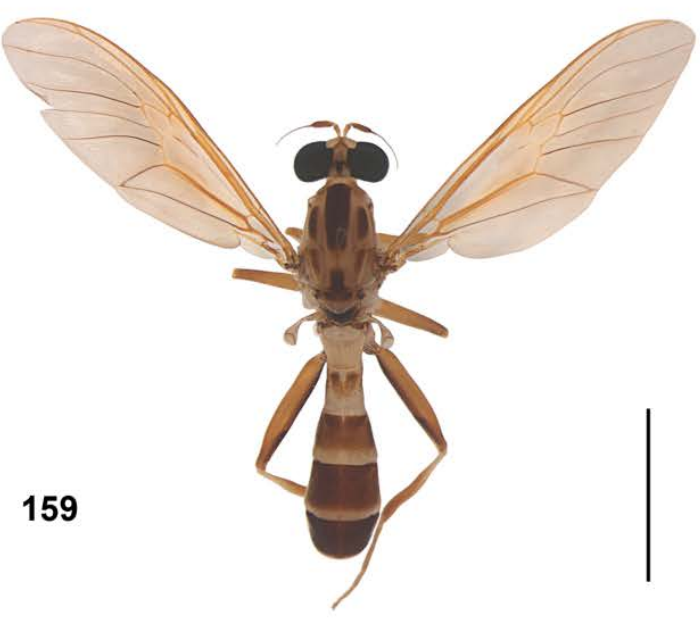

161

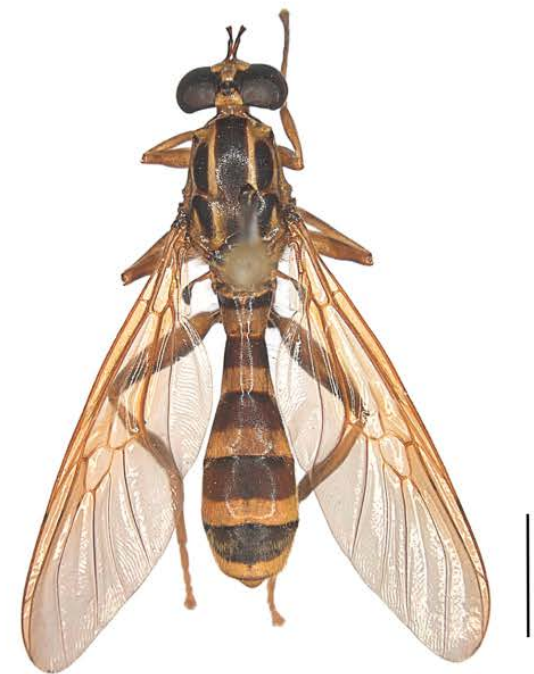

Figuras 156-161. Acrochaeta spp., habitus dorsal. 156. A. polychaeta, sp. nov., parátipo macho. 157. A. convexifrons, comb. nov., macho. 158. A. dichrostyla, sp. nov., holótipo macho. 159. A. ruschii, sp. nov., holótipo macho. 160. A rhombostyla, sp. nov., holótipo macho. 161. A. mexicana, macho. Escala, $5 \mathrm{~mm}$. 

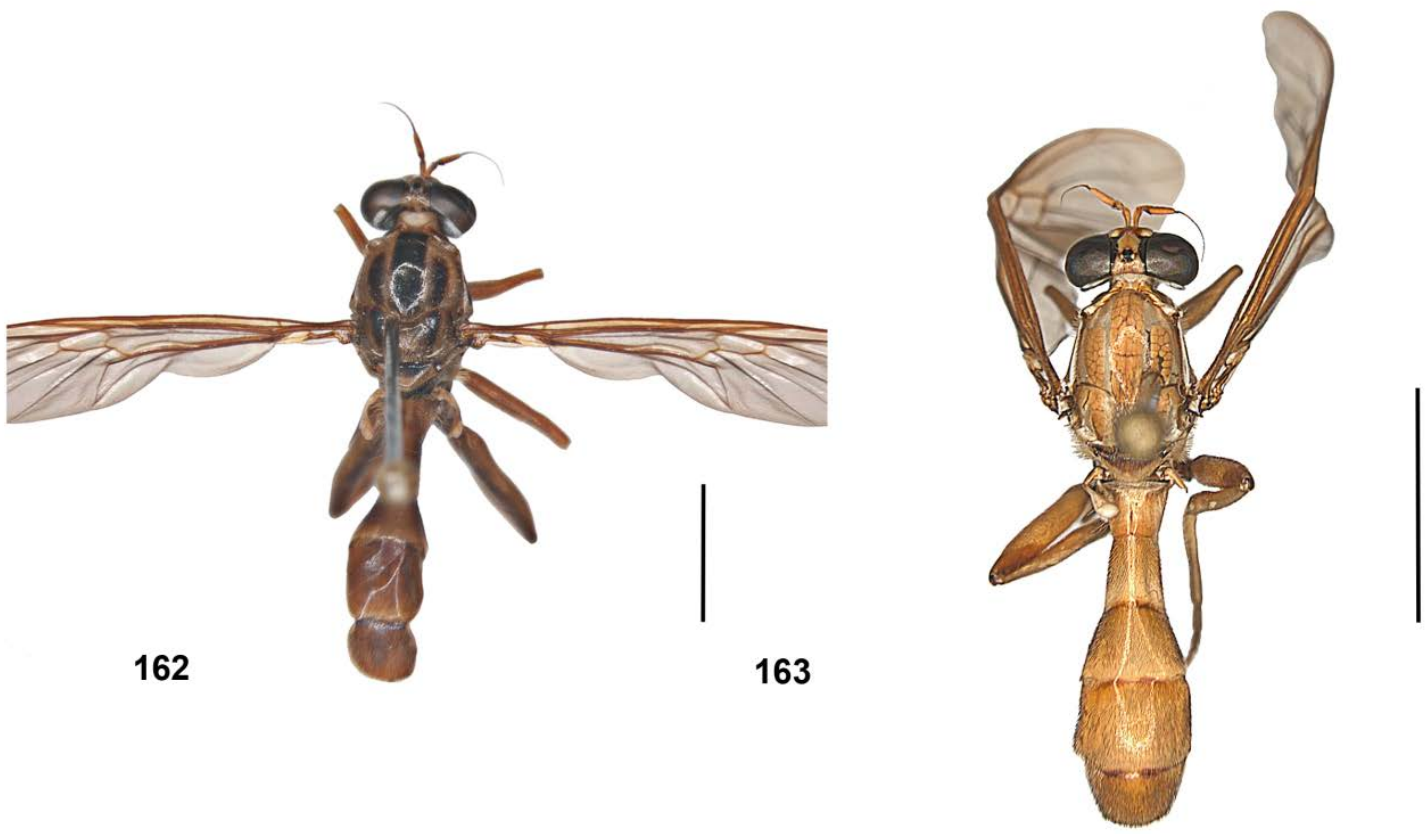

Figuras 162-163. Acrochaeta spp., habitus dorsal. 162. A. balbii, sp. nov., holótipo macho. 163. A. boliviana, sp. nov., holótipo macho. Escala, $5 \mathrm{~mm}$. 

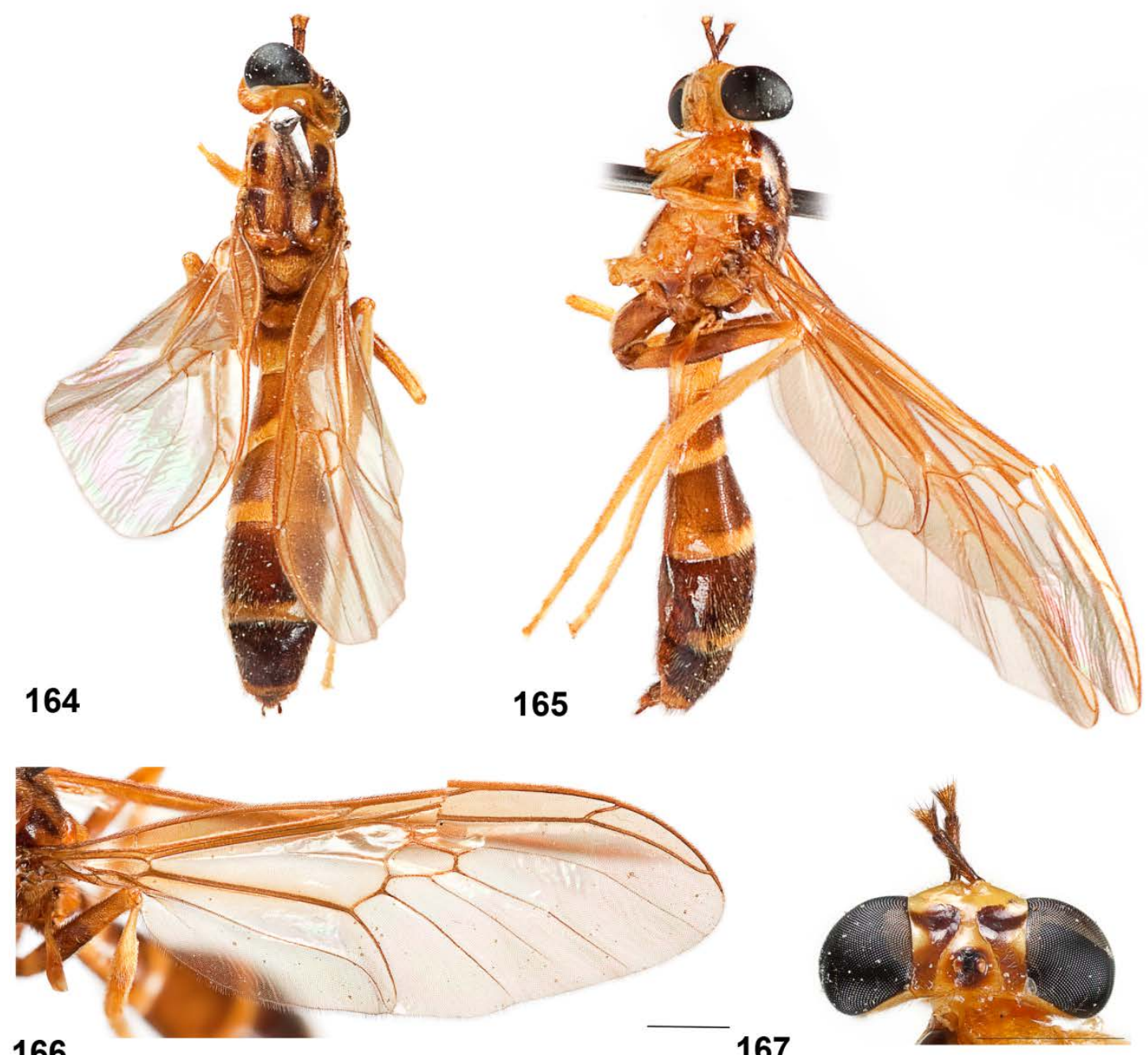

166

\section{7}
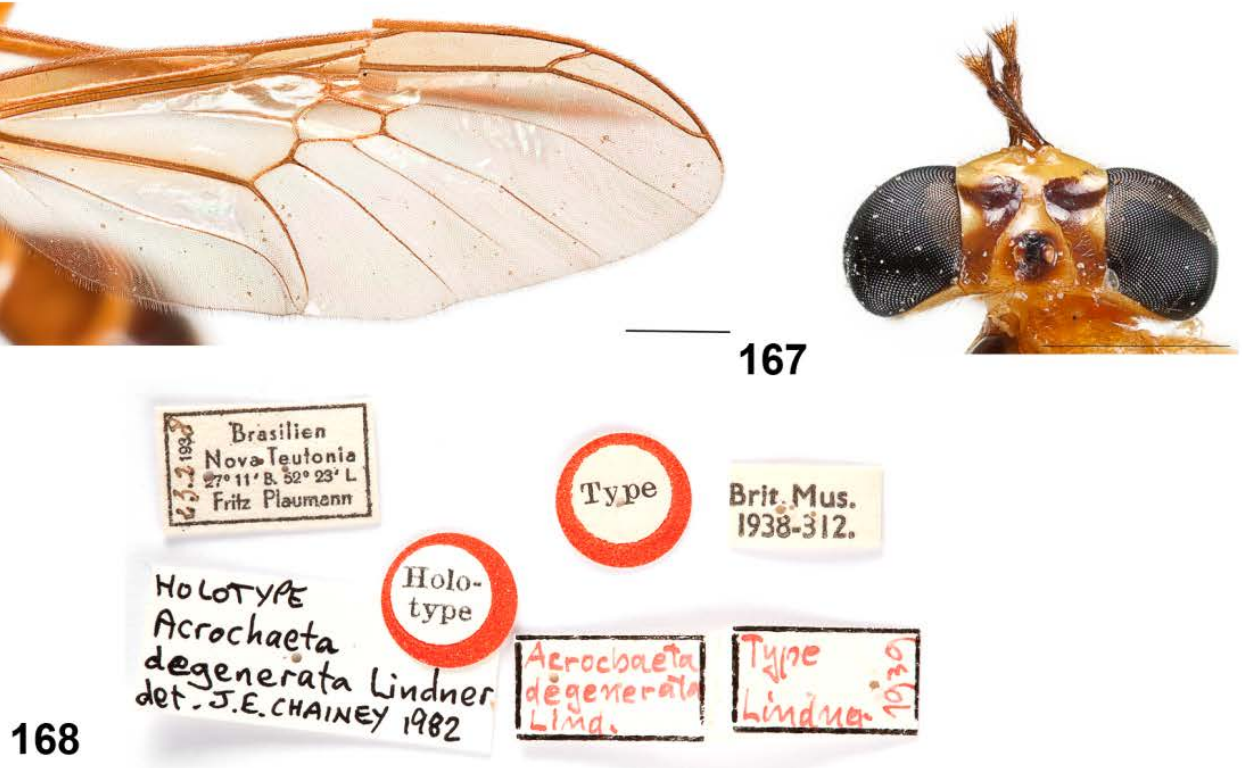

Figuras 164-168. Acrochaeta degenerata, holótipo macho, [BMNH]. 164. Habitus dorsal. 165. Habitus lateral. 166. Asa. 167. Cabeça em vista dorsal. 168. Etiquetas. Escala, 1 mm. 


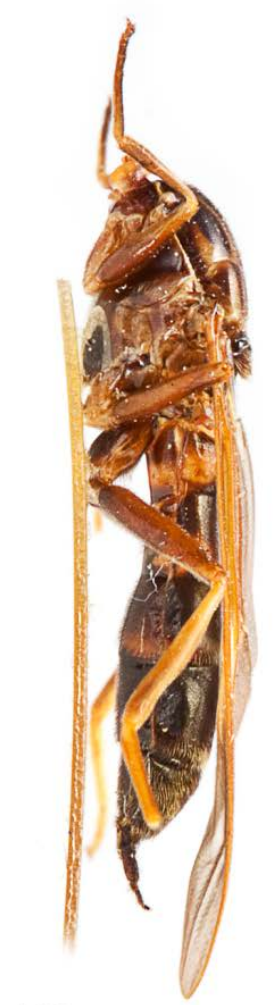

169

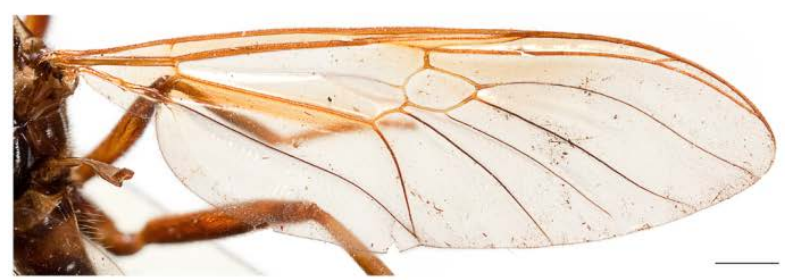

171

170

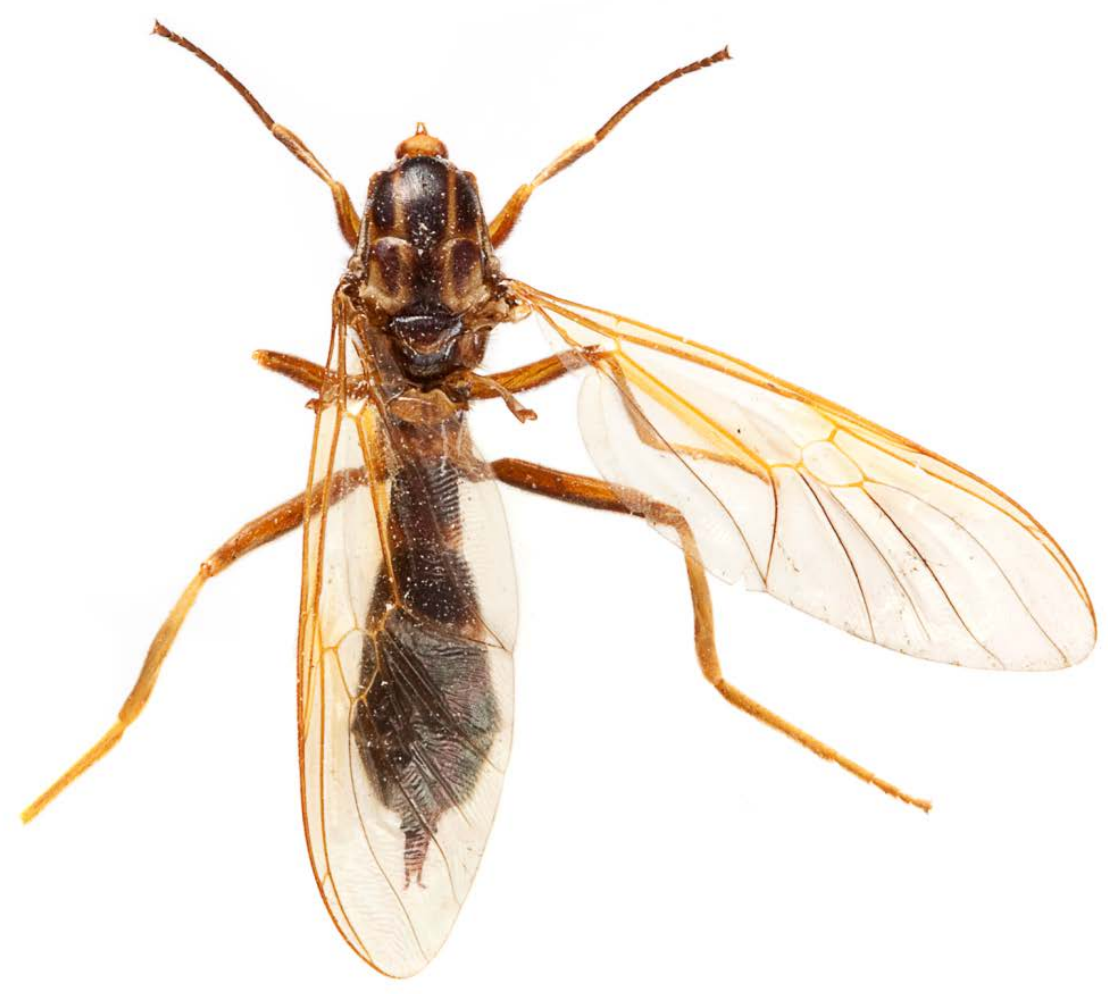

Borasilien

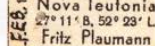

Brit.Mus.
1937-2es.

172

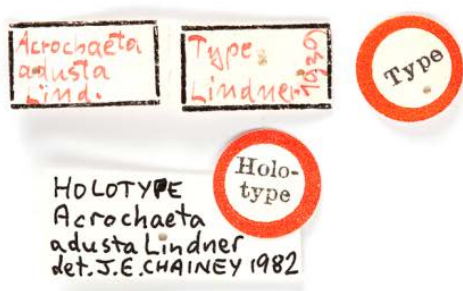

a dusta Lindner
det.J.E.CHAINEY 1982

Figuras 169-172. Acrochaeta adusta, holótipo fêmea, [BMNH]. 169. Habitus lateral. 170. Habitus dorsal. 171. Asa. 172. Etiquetas. Escala, $1 \mathrm{~mm}$. 


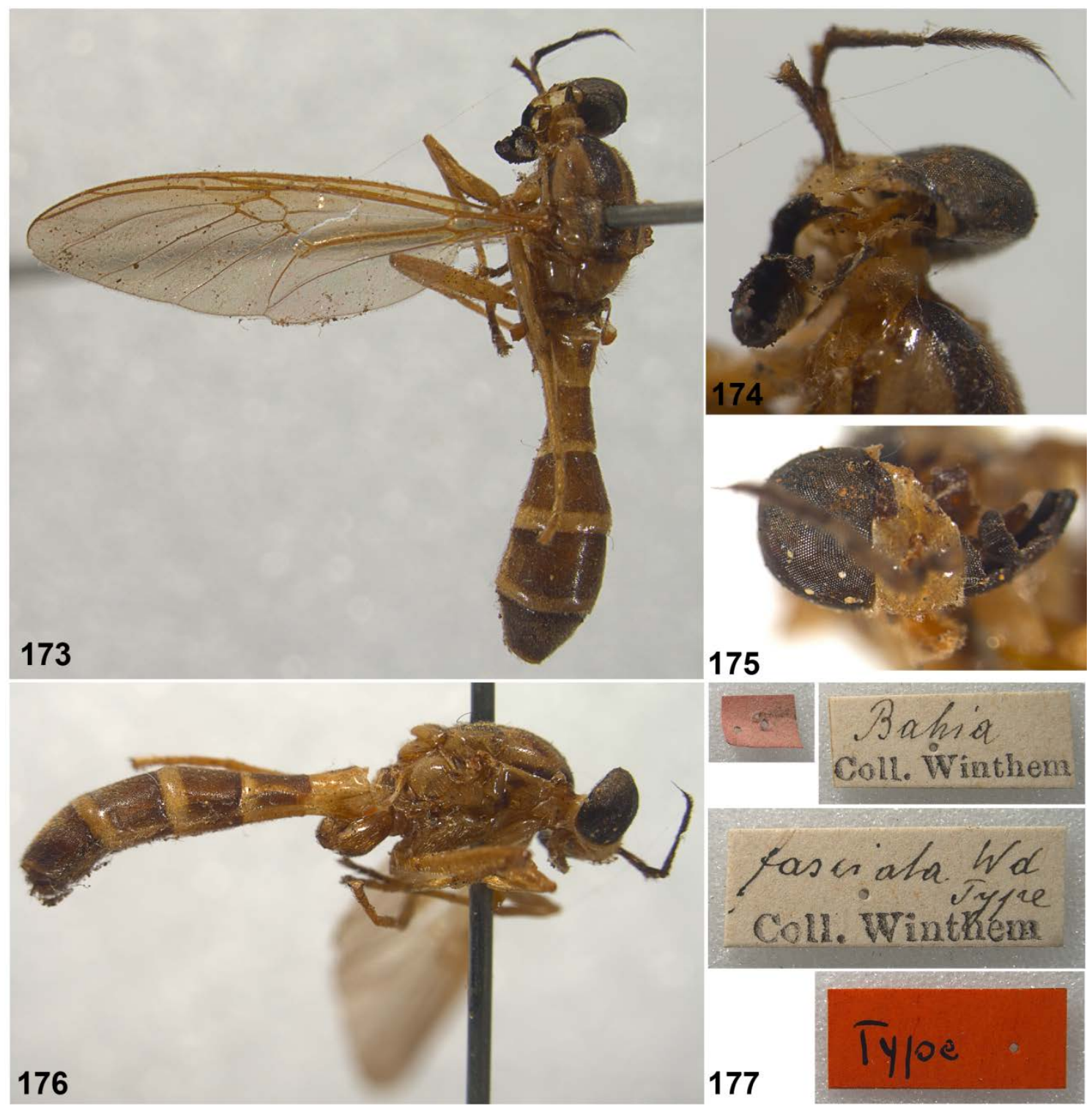

Figuras 173-177. Acrochaeta fasciata, holótipo macho, [NMW]. 173. Habitus dorsal. 174. Cabeça em vista dorsal. 175. Cabeça em vista frontal. 176. Habitus lateral. 177. Etiquetas. 


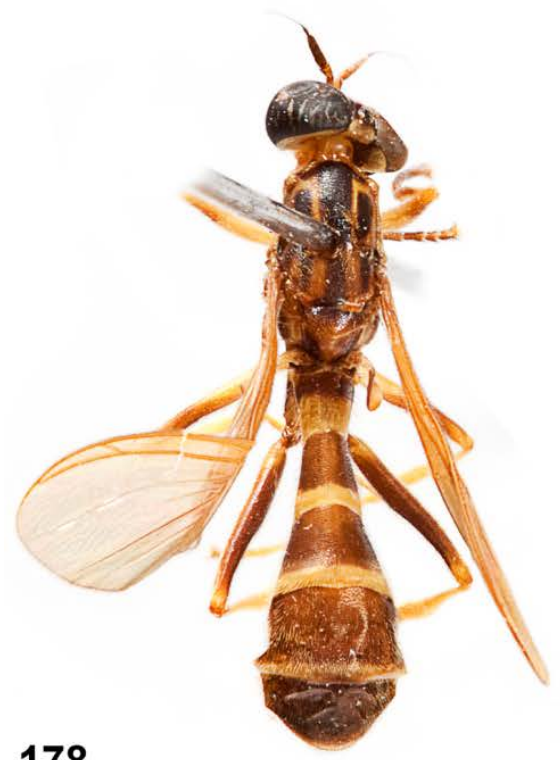

178

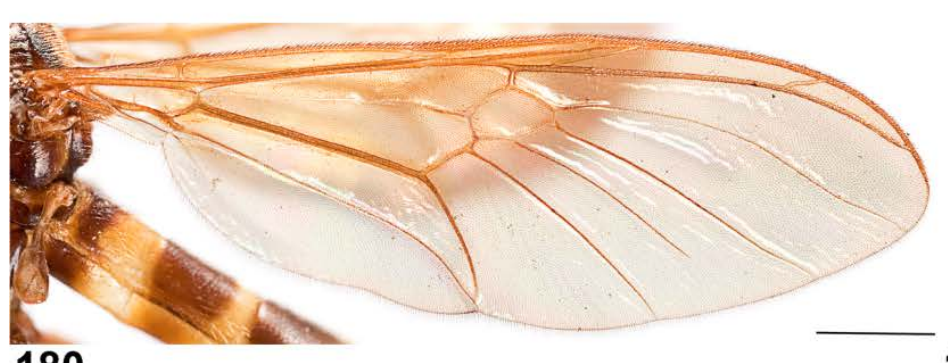

180

182

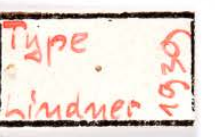

SYN-

TYPE

SYNTYPE

Acrochaeta. dimidiata Linduer det. J.E.CHAINEY 1982

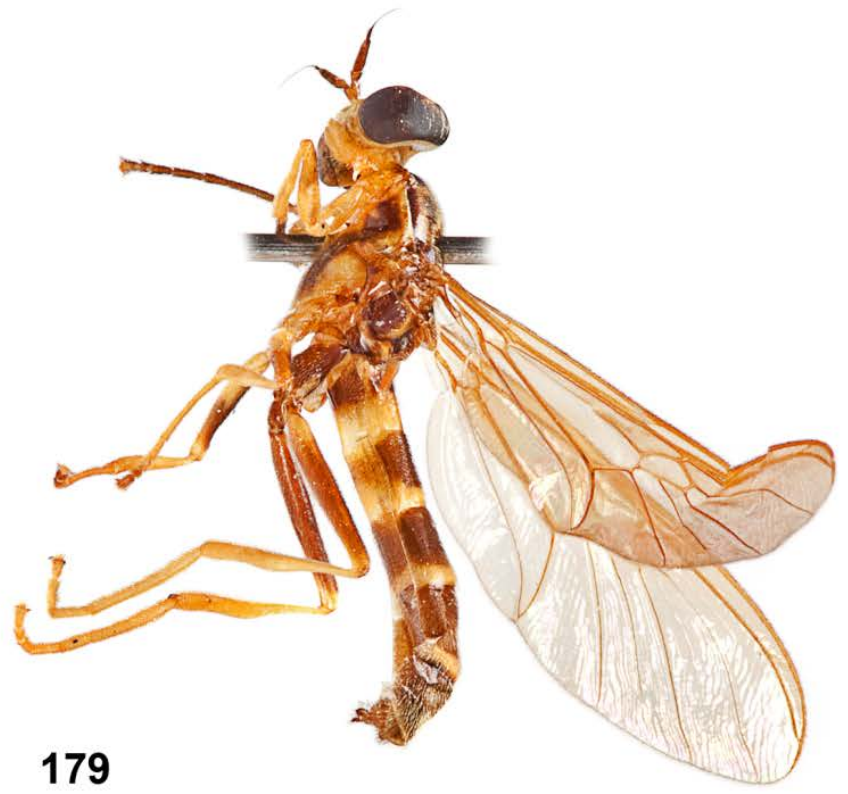

181

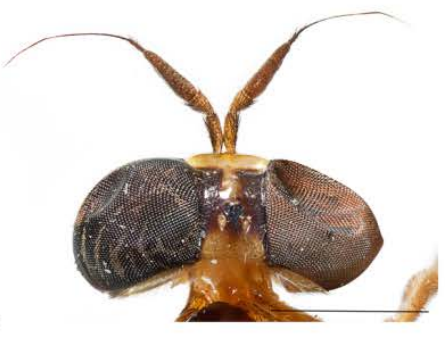

Brit.Mus.

1937.424

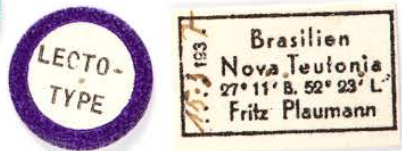

Figuras 178-182. Acrochaeta dimidiata, holótipo macho, [BMNH]. 178. Habitus dorsal. 179. Habitus lateral. 180. Asa. 181. Cabeça em vista dorsal. 182. Etiquetas. Escala, 1 mm. 

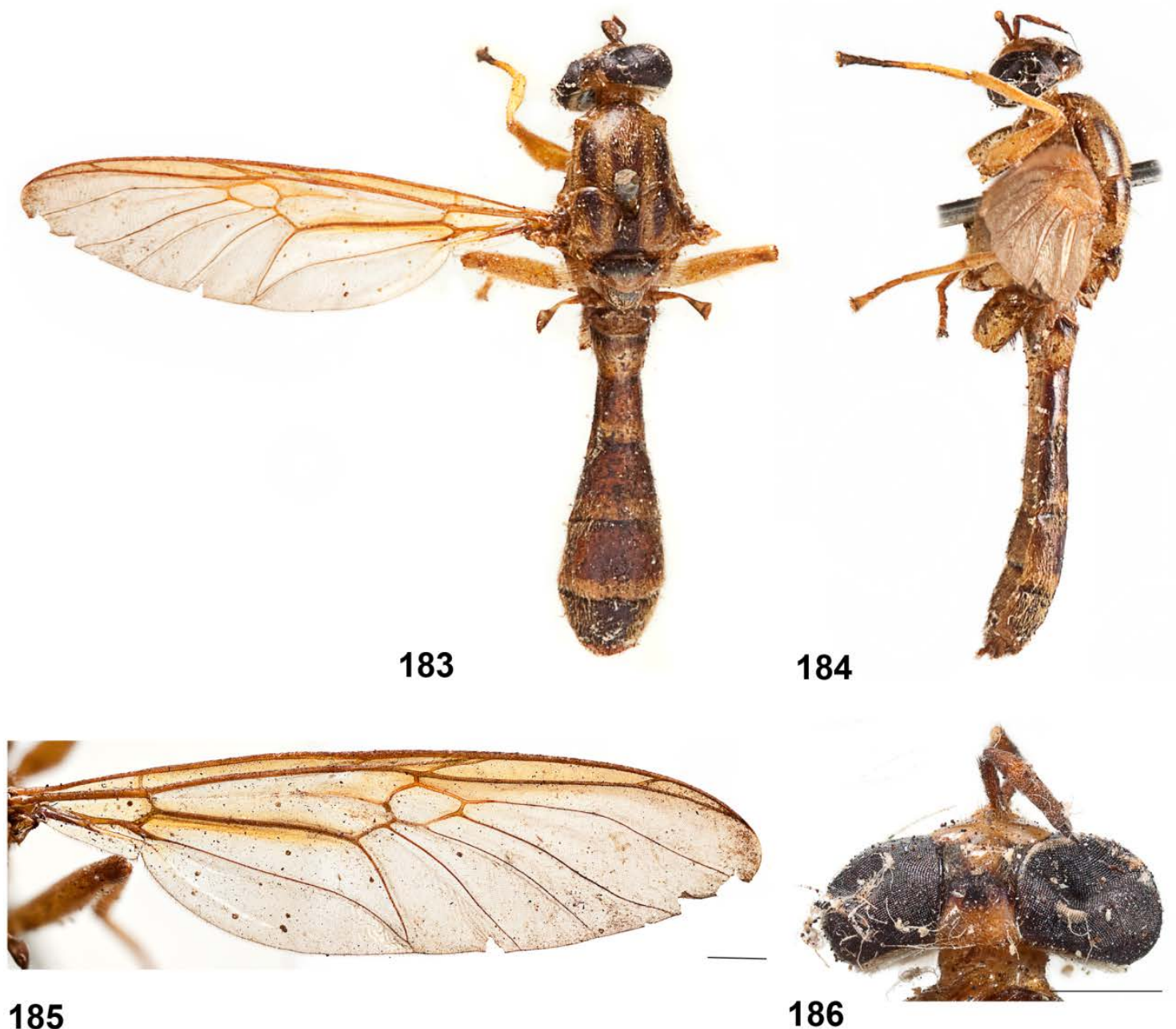

185

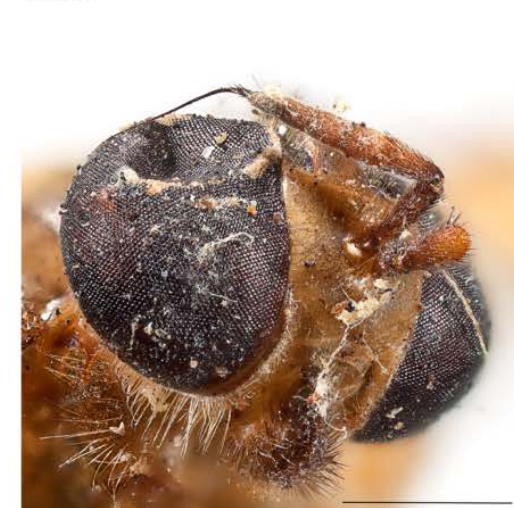

187

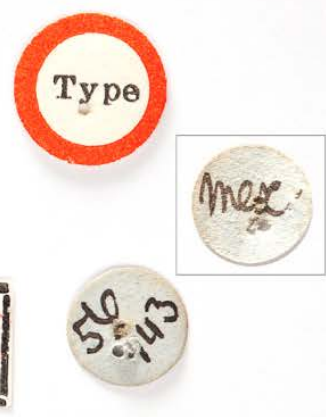

188

Figuras 183-188. Acrochaeta mexicana, holótipo macho, [BMNH]. 183. Habitus dorsal. 184. Habitus lateral. 185. Asa. 186. Cabeça em vista dorsal. 187. Etiquetas. 188. Cabeça em vista frontal. Escala, $1 \mathrm{~mm}$. 

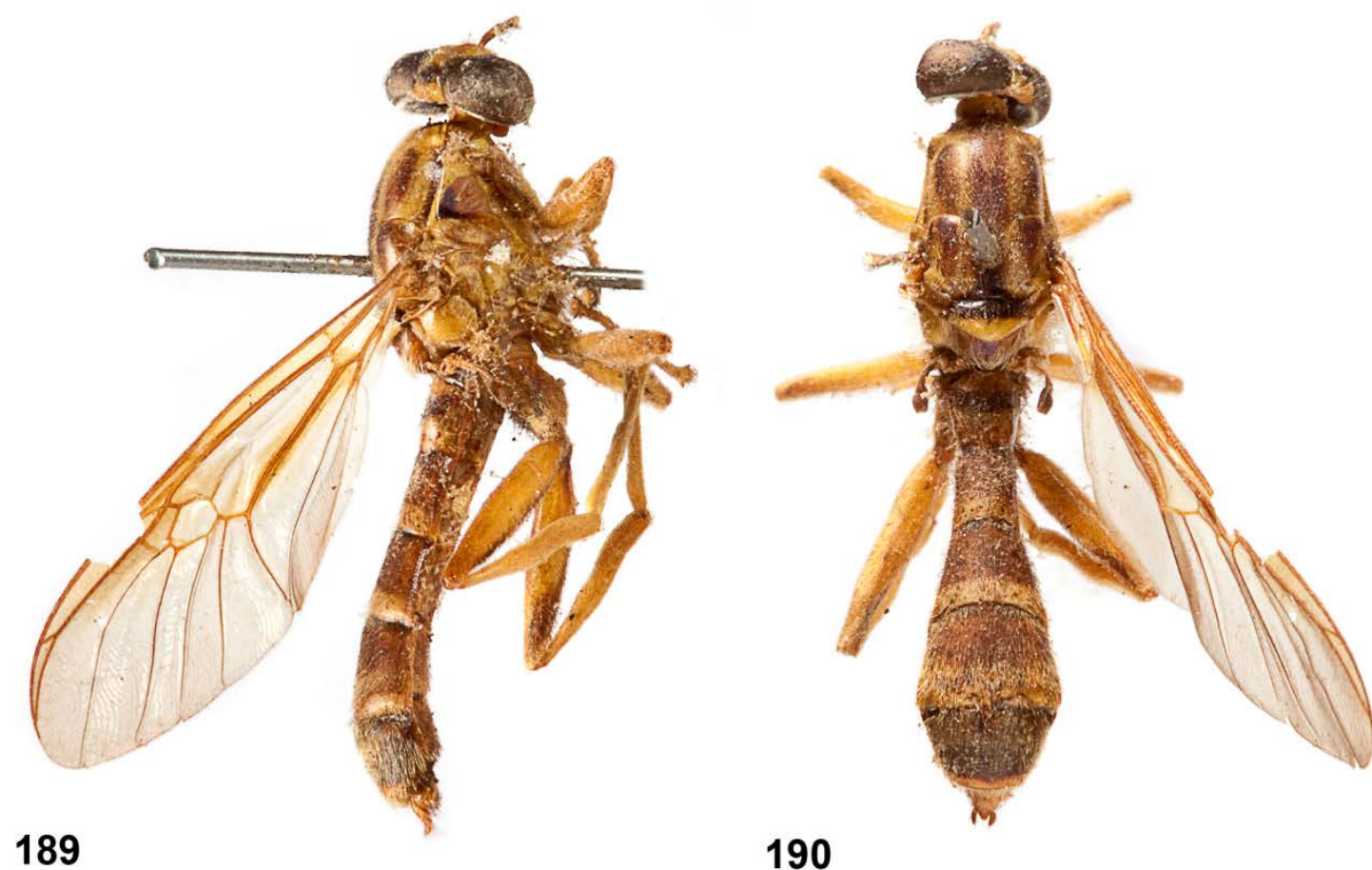

190
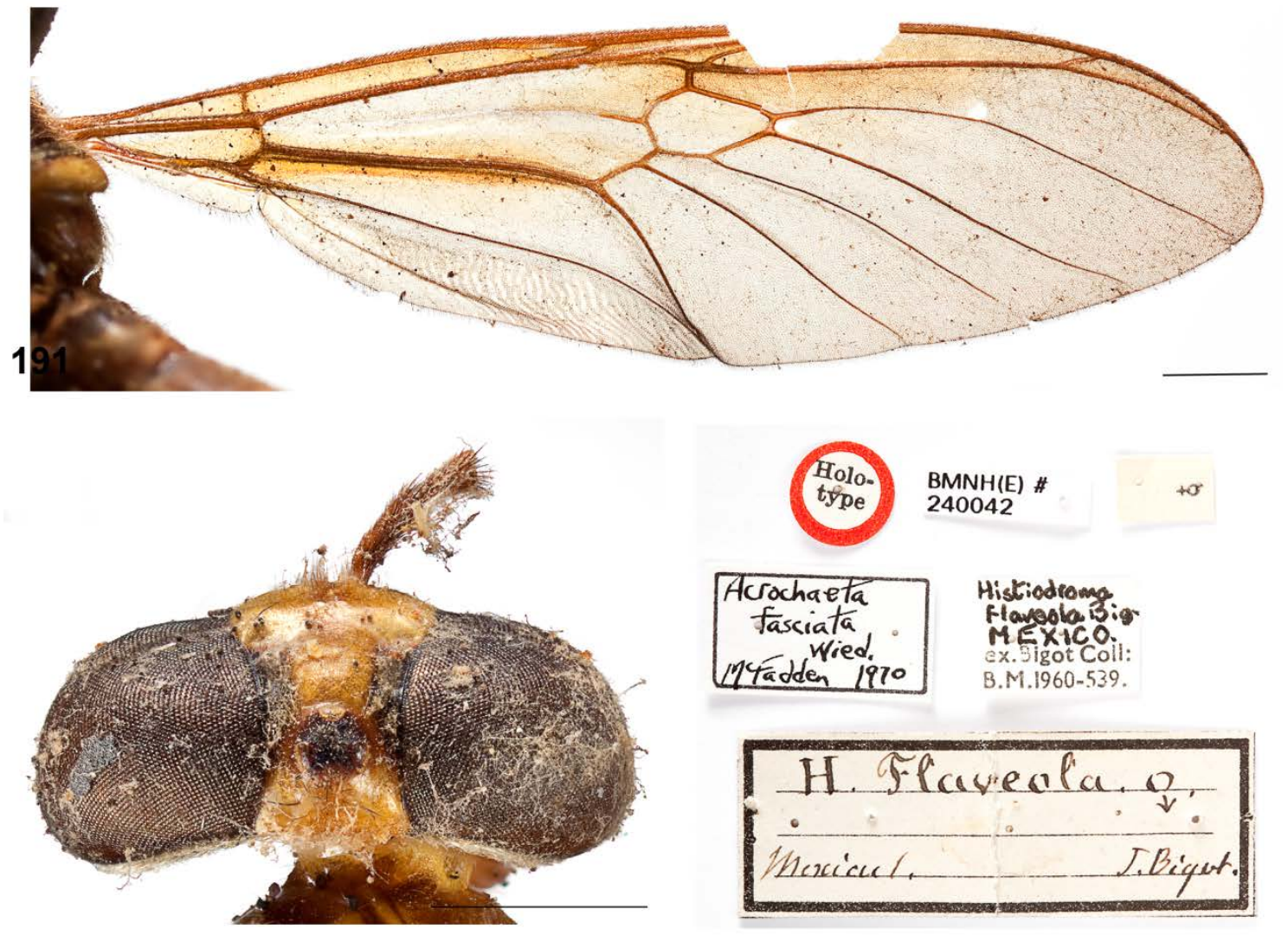

192

193

Figuras 189-193. Acrochaeta flaveola, holótipo macho, [BMNH]. 189. Habitus lateral. 190. Habitus dorsal. 191. Asa. 192. Cabeça em vista dorsal. 193. Etiquetas. Escala, 1 mm. 

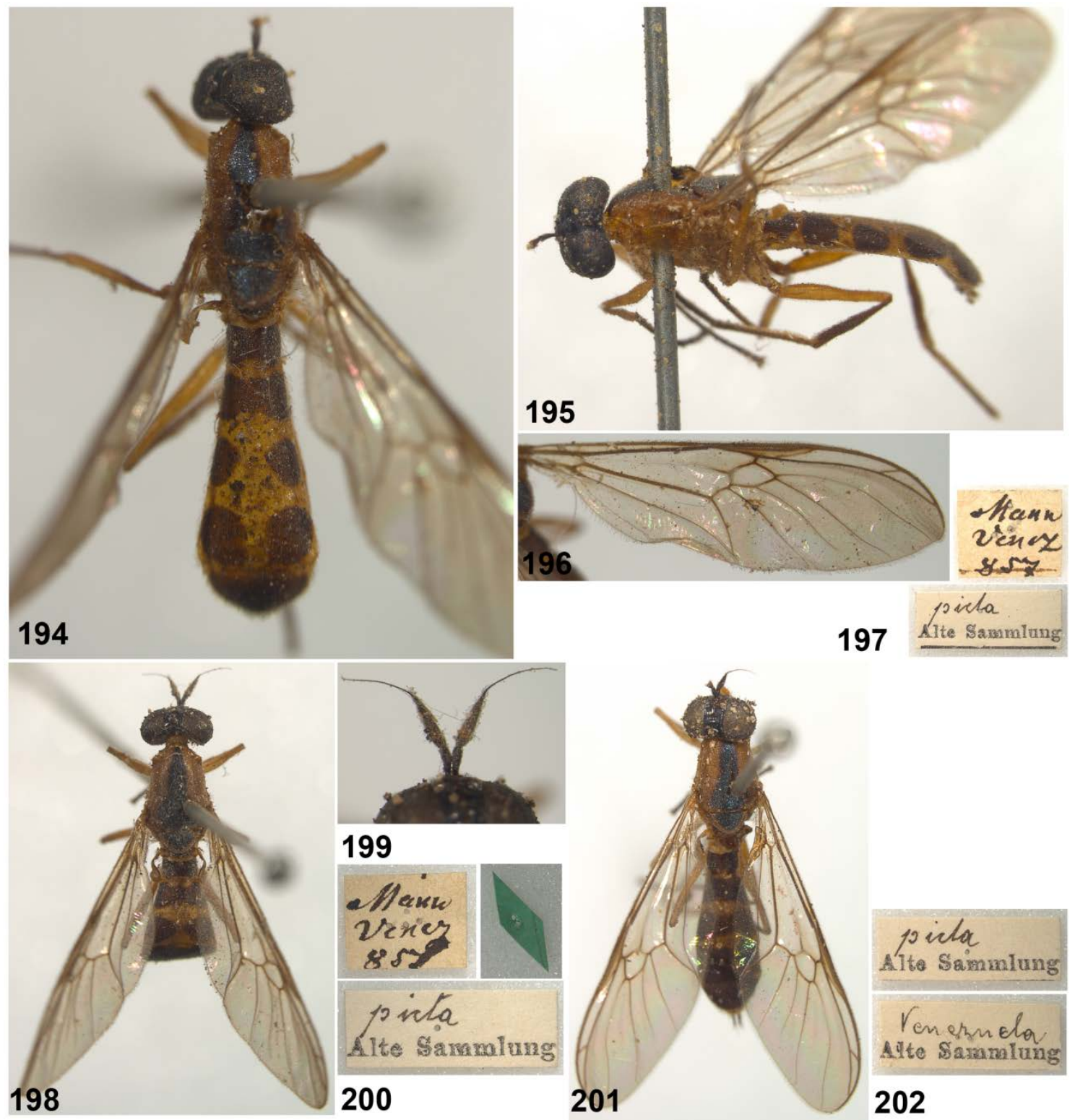

Figuras 194-202. Merosargus picta, comb. nov., [NMW] (194-197, síntipo macho; 198-202, síntipos fêmea). 194. Habitus dorsal. 195. Habitus lateral. 196. Asa. 197. Etiquetas. 198. Habitus dorsal. 199. Antena. 200. Etiquetas. 201. Habitus dorsal. 202. Etiqueta. 


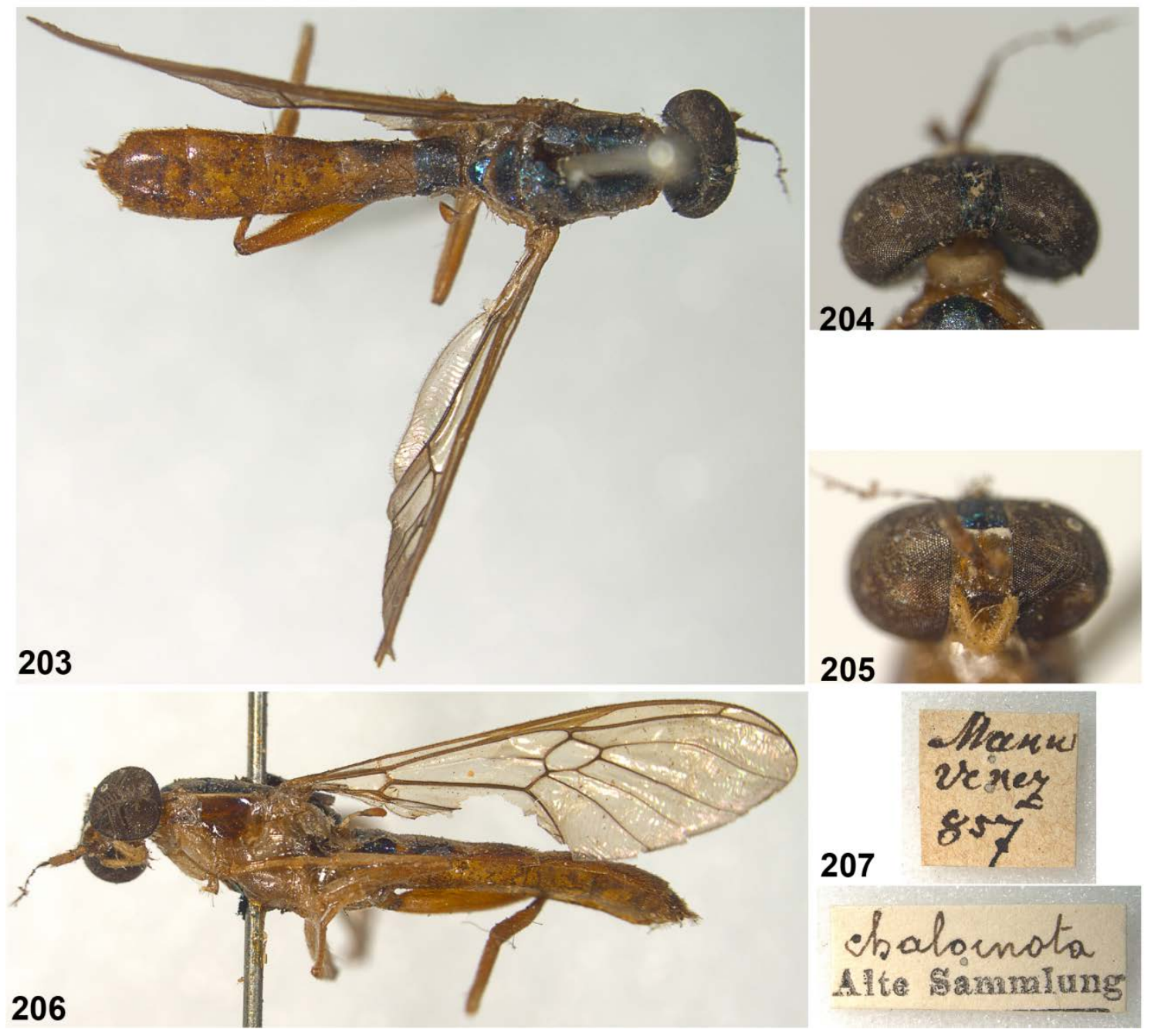

Figuras 203-207. Merosargus chalconota, comb. nov., holótipo macho, [NMW]. 203. Habitus dorsal. 204. Cabeça em vista dorsal. 205. Cabeça em vista dorsal. 206. Habitus lateral. 207. Etiquetas. 


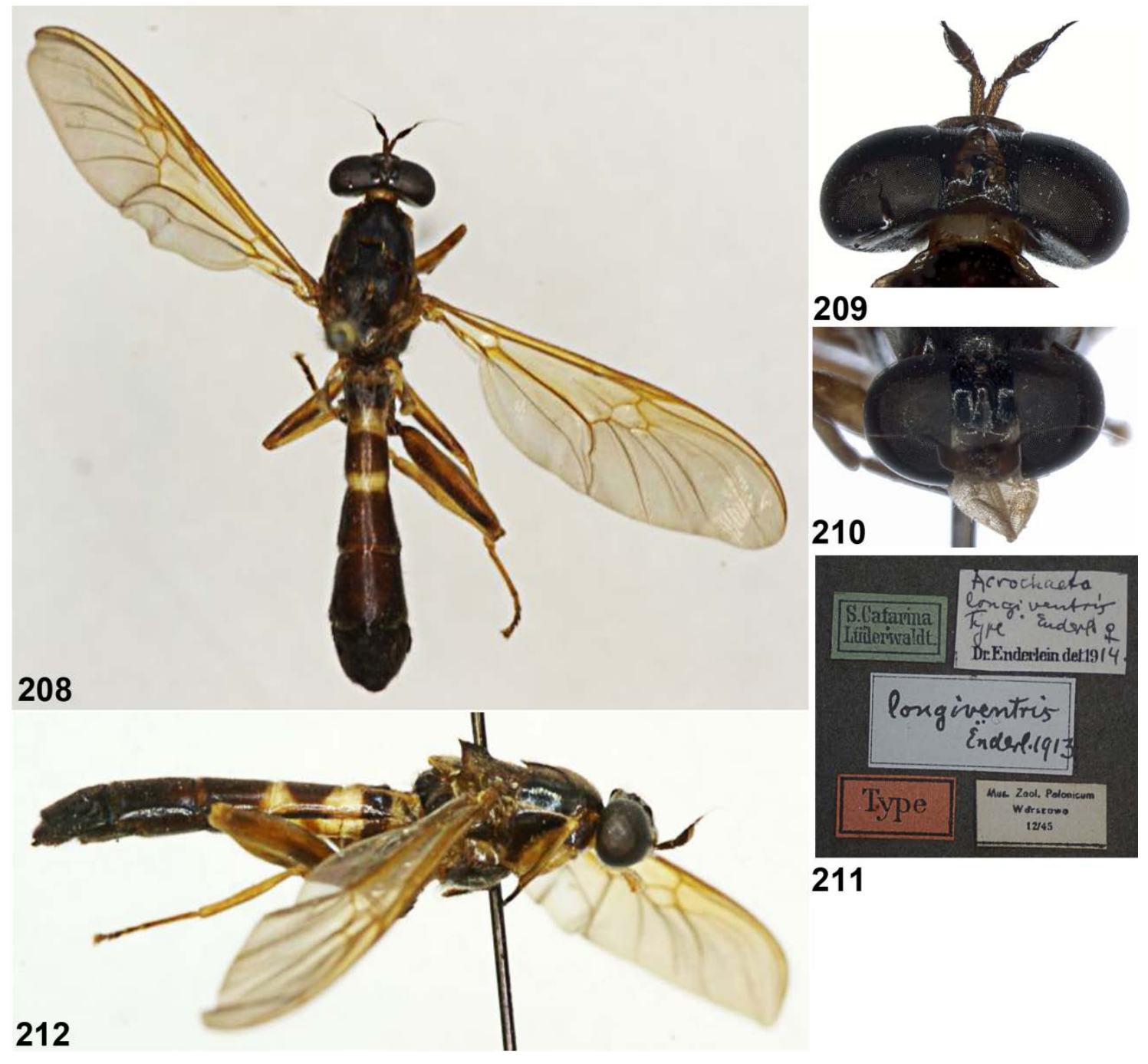

Figuras 208-212. Merosargus longiventris, comb. nov., holótipo macho, [PAN]. 208. Habitus dorsal. 209. Cabeça em vista dorsal. 210. Cabeça em vista frontal. 211. Etiquetas. 212. Habitus lateral. 


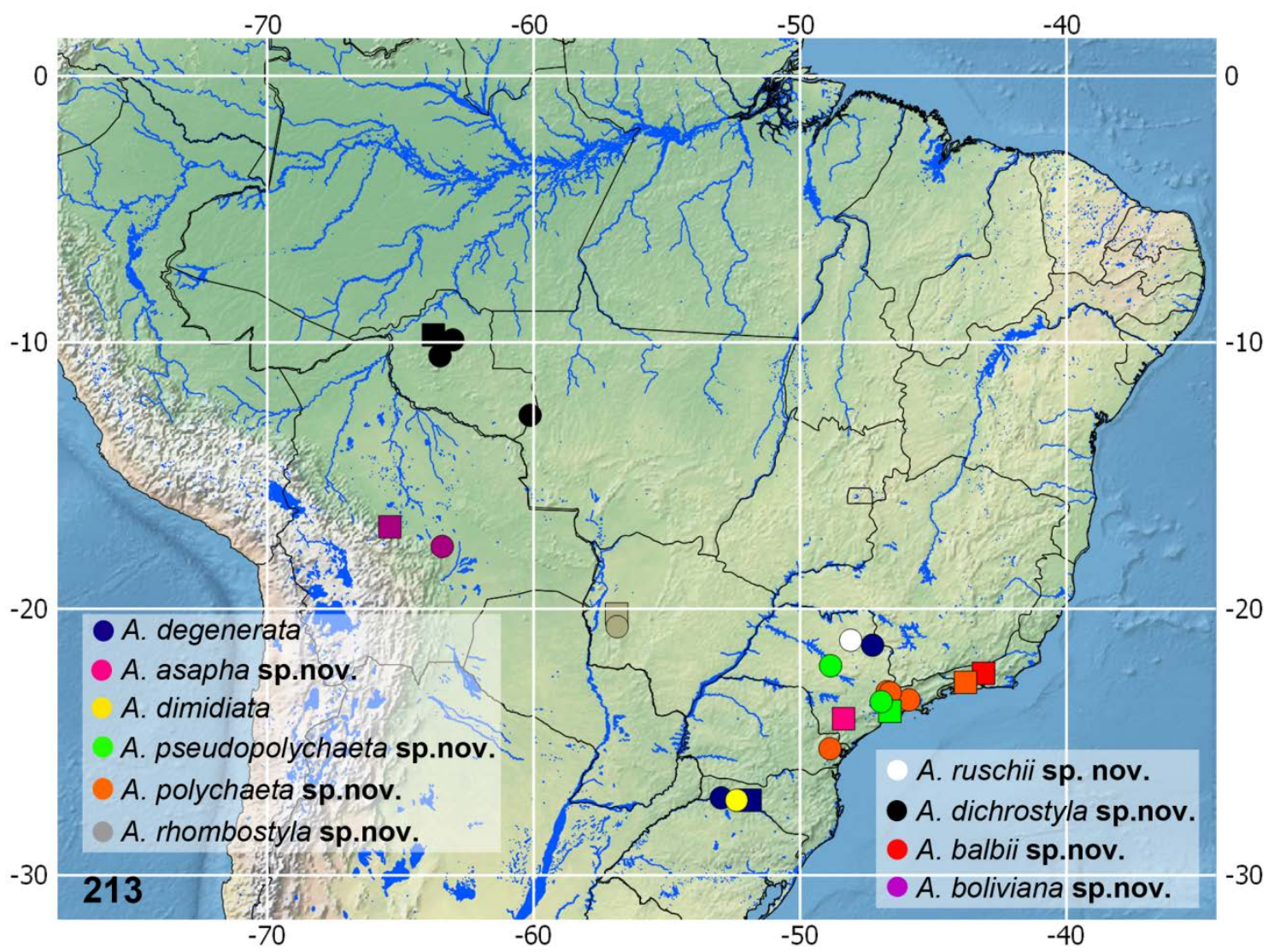

Figura 213. Mapa de distribuição das espécies exclusivamente sul-americanas de Acrochaeta. Quadrados representam holótipos e círculos representam parátipos e material adicional.

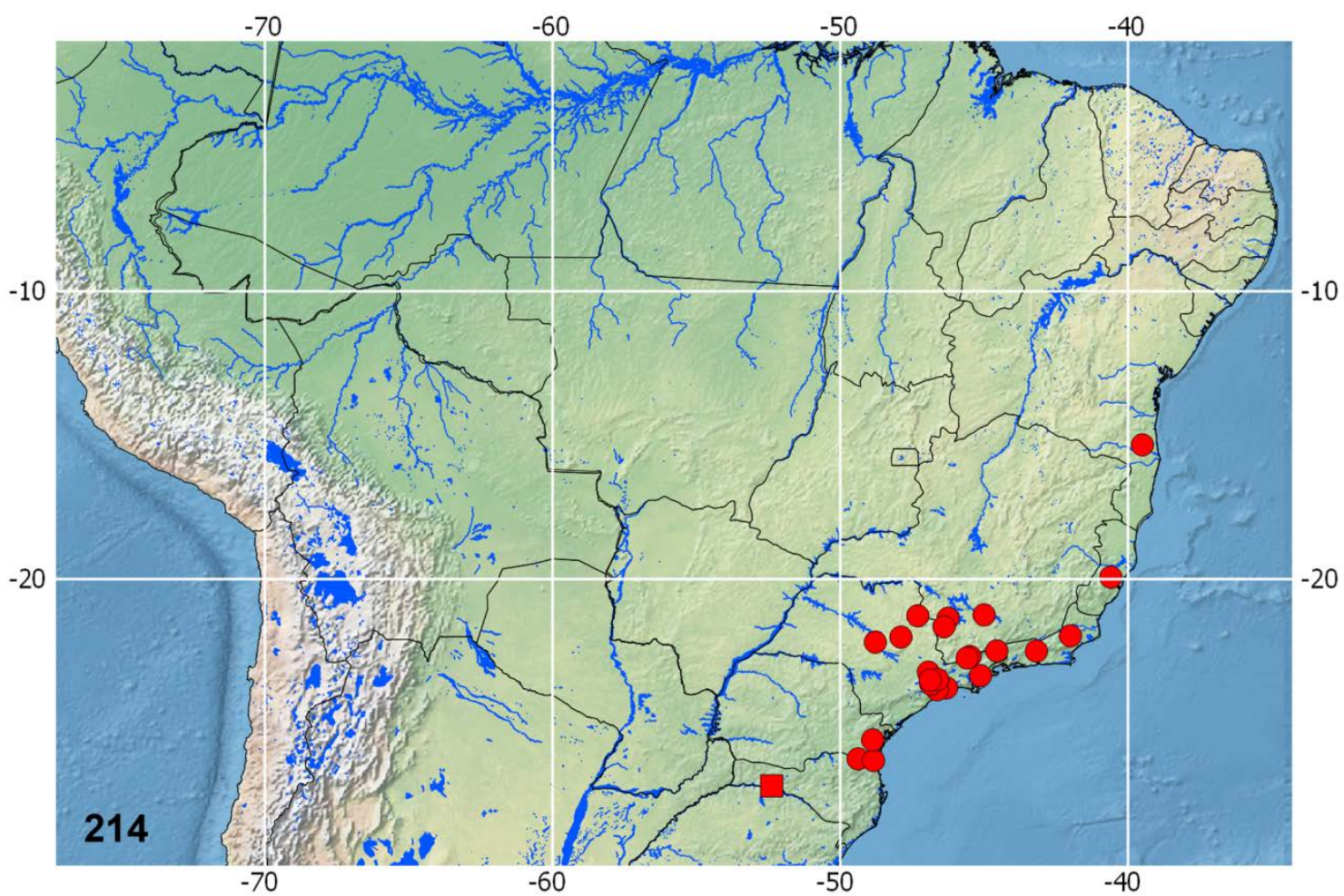

Figura 214. Mapa de distribuição da espécie Acrochaeta adusta. 


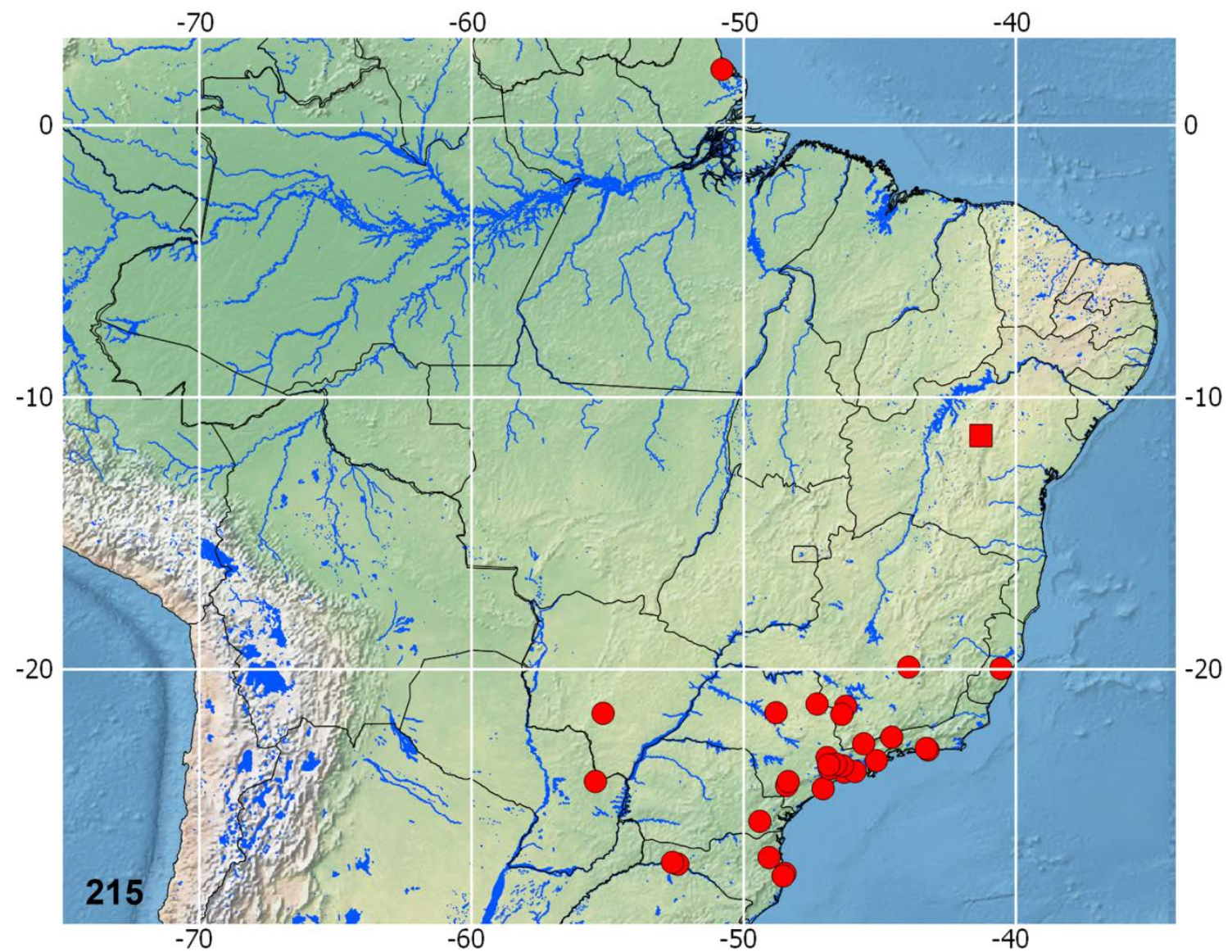

Figura 215. Mapa de distribuição da espécie Acrochaeta fasciata.

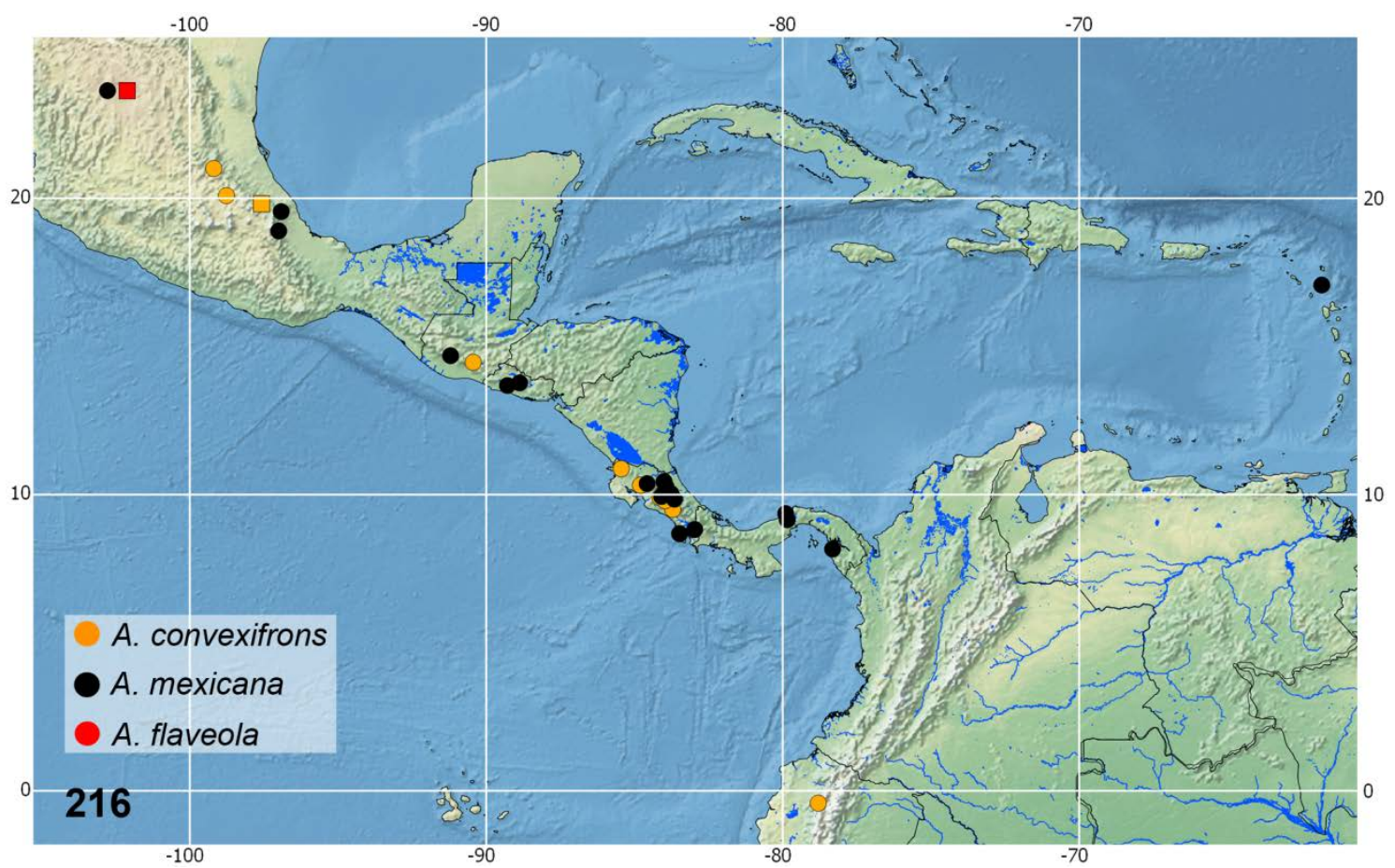

Figura 216. Mapa de distribuição das espécies da América Central e localidades próximas na América do Sul de Acrochaeta. Quadrados representam holótipos e círculos representam parátipos e material adicional. 


\subsection{Lista de caracteres}

Os 63 caracteres utilizados (60 caracteres são novos) são apresentados a seguir. Os três caracteres retirados da literatura são provenientes dos seguintes trabalhos: Woodley (1995) (caracteres 51 e 57) e James \& McFadden (1982) (caráter 37). Os resultados e a discussão abaixo procura discutir as hipóteses de homologia que foram trabalhadas no decorrer da elaboração da matriz, além de interpretar o agrupamento dos táxons e a evolução dos caracteres na árvore obtida.

\section{Cabeça (1-15)}

1. Relação comprimento/largura dos quatro primeiros flagelômeros (I.C. = 20; I.R. = 65; Passos = 10):

(0) levemente achatados, mais largos que longos (e.g., Fig. 232)

(1) globular (1-1,5:1), equivalência entre comprimento/largura (e.g., Fig. 244)

(2) alongados (>1,5), mais longos que largos (e.g., Fig. 15)

2. Espessura do quinto flagelômero antenal (arista) (I.C. = 100; I.R. = 100; Passos = 2):

(0) larga apenas basalmente (e.g., Fig. 15)

(1) larga em dois terços basais (e.g., Fig. 24)

(2) larga em praticamente toda sua extensão (e.g., Fig. 37)

3. Comprimento do quinto flagelômero em relação ao restante da antena (I.C. = 25; I.R. = 83; Passos = 4):

(0) maior (e.g., Fig. 233)

(1) equivalente ou menor (e.g., Fig. 24)

4. Pilosidade do quinto flagelômero antenal (arista) (I.C. = 75; I.R. = 90; Passos = 4):

(0) cerdas esparsas na parte basal (e.g., Fig. 235)

(1) cerdas em toda a parte basal (e.g., Fig. 245)

(2) cerdas em dois terços basais (e.g., Fig. 24)

(3) cerdas em toda a extensão (e.g., Fig. 37) 
5. Projeção da porção anterior interna do pedicelo sobre o complexo flagelar (I.C. = 100; I.R. = 100; Passos = 1):

(0) ausente (e.g., Fig. 235)

(1) presente (e.g., Fig. 237)

Característica tradicionalmente considerada como importante na diagnose do gênero Ptecticus (James \& McFadden 1982, Rozkosný 1994), é também presente em algumas espécies de Merosargus como, por exemplo, M. hansoni James, 1971 (James \& McFadden 1971). No entanto, espécies de Merosargus que apresentam essa condição não foram amostradas aqui.

6. Elevação do tubérculo ocelar em relação à margem distal da cabeça (I.C. = 50;

I.R. = 92; Passos = 2):

(0) no mesmo nível ou levemente ultrapassando (e.g., Fig. 264)

(1) muito acima da margem distal da cabeça, vértex também projetado (e.g., Fig. 9)

7. Coloração metálica na fronte (I.C. = 33; I.R. = 84; Passos = 3):

(0) presente (e.g., Fig. 475)

(1) ausente (e.g., Fig. 476)

8. Formato da margem da fronte nos machos (I.C. = 100; I.R. = 100; Passos = 2):

(0) quase linear, margens estreitando bruscamente em direção ao calo (olhos holópticos) (Fig. 261)

(1) triangular, margens gradualmente estreitando em direção ao calo (Fig. 263)

(2) paralela (e.g., Fig. 7)

Apesar de ser um caráter de machos, em alguns casos foi usado informação de fêmea para algumas espécies de Merosargus e Acrochaeta que não tinham macho disponível, uma vez que não há dimorfismo sexual muito evidente nesses gêneros. Em contrapartida, em Sargus as fêmeas apresentam os olhos separados na parte dorsal, diferentemente da condição holóptica dos machos, ao passo que, nos outros gêneros amostrados, incluindo Merosargus e Acrochaeta, machos e fêmeas apresentam a mesma configuração. Isso se aplica igualmente aos caracteres 9 e 10. 
9. Largura da fronte em relação ao tamanho total da cabeça nos machos (I.C. = 66;

I.R. = 83; Passos = 3):

(0) < que 0,10 (Fig. 261)

(1) entre 0,10 e 0,15 (e.g., Fig. 262)

(2) > que 0,15 (e.g., Fig. 7)

10. Área lateral da fronte nos machos (I.C. = 33; I.R. = 50; Passos = 3):

(0) ausente (e.g., Fig. 263)

(1) presente (e.g., Fig. 262)

11. Posição de origem da área lateral da fronte (I.C. = 50; I.R. = 0; Passos = 2):

(0) posteriormente no vértex, antes do tubérculo ocelar (e.g., Fig. 7)

(1) anteriormente no vértex, final do tubérculo ocelar (e.g., Fig. 115)

12. Formato da margem posterior (abaixo tubérculo ocelar) da área medial da parte superior da fronte (I.C. = 66; I.R. = 91; Passos = 3):

(0) paralela (e.g., Fig. 262)

(1) triangular, convergindo em direção ao calo (e.g., Fig.7)

(2) paralela, com alguma sinuosidade perto fim (e.g., Fig. 119)

13. Área medial da parte superior da fronte em relação à área lateral da fronte (I.C. = 33; I.R. = 66; Passos = 6):

(0) não projetada ou elevada (e.g., Fig. 264)

(1) com um tubérculo medial (Fig. 266)

(2) distintamente elevada em toda a sua extensão (e.g., Fig. 9)

14. Projeção do calo frontal nos machos em relação à parte inferior da fronte (I.C. = 100; I.R. = 100; Passos = 1):

(0) fracamente projetado (e.g., Fig. 264)

(1) fortemente projetado, claramente distinto da parte inferior da fronte (e.g., Fig. 265)

Essa característica também é muito importante na dignose de Ptecticus (James \& McFadden 1982). A interpretação da variação dessa projeção nas espécies de Sarginae amostradas, no entanto, ainda é difícil. Foram considerados apenas os estados extremos, 
de modo a recuperar grandes grupos, havendo estados intermediários que não foram codificados aqui.

15. Elevação da parte inferior da fronte (I.C. = 33; I.R. = 88; Passos = 3):

(0) ausente (e.g., Fig. 266)

(1) presente (e.g., Fig. 8)

\section{$\underline{\text { Tórax (16-19) }}$}

16. Coloração metálica no escudo (I.C. = 16; I.R. = 61; Passos = 6):

(0) presente (e.g., Fig. 267)

(1) ausente (e.g., Fig. 273)

A coloração de algumas estruturas, do mesmo modo que o escudo, também pode ser metálica (fronte, escutelo, mediotergito), de modo que a presença da coloração metálica, por exemplo, no escudo pode estar relacionada a presença dessa colaração em outras regiões (fronte, mediotergito). Isso poderia indicar que há certa dependência entre esses caracteres. Entretanto, nem sempre a presença de coloração metálica em alguma parte do corpo (e.g., fronte e escutelo) está condicionada ao aparecimento das demais (e.g., escudo, mediotergito), como é o caso de Merosargus akrei.

17. Faixas no escudo (I.C. = 33; I.R. = 90; Passos = 3):

(0) ausente (e.g., Fig. 277)

(1) presente (e.g., Fig. 276)

18. Padrão de faixas no escudo (I.C. = 50; I.R. = 66; Passos = 2):

(1) restrito a uma única faixa, mancha mediana e/ou resquícios de faixas laterais (e.g., Fig. 284)

(2) fortemente marcado por três grandes faixas (e.g., Fig. 138)

Apesar de certa incerteza sobre a homologia entre padrões, formatos e posição de manchas no escudo (i.e., no pré-escudo, pós-escudo), esses dois estados foram aqui tratados como homólogos. Entretanto, há necessidade de refinamento com a inclusão de uma maior amostragem de Merosargus, pois esses padrões podem não ser homólogos. 
19. Coloração metálica no mediotergito (I.C. = 14; I.R. = 70; Passos = 7):

(0) presente (e.g., Fig. 275)

(1) ausente (e.g., Fig. 149)

\section{$\underline{\text { Asas (20-37) }}$}

20. Coloração das veias das asas (I.C. $=$ 25; I.R. $=$ 85; Passos $=4)$ :

(0) marrom a marrom escura (e.g., Fig. 310)

(1) amarelo avermelhada (e.g., Fig. 112)

21. Veia M (I.C. = 100; I.R. = 100; Passos = 1):

(0) distinta em toda extensão (e.g., Fig. 295)

(1) distinta apenas apicalmente (e.g., Fig. 302)

22. Posição de r-m em relação à origem de $M_{3}$ na célula discal (I.C. = 14; I.R. = 52;

Passos = 14):

(0) basal, distância equivalente ao comprimento de r-m (e.g., Fig. 296)

(1) basal, distância equivalente à metade do comprimento de r-m (e.g., Fig. 298)

(2) na mesma posição (e.g., Fig. 96)

23. Comprimento de r-m em relação ao terceiro setor da célula discal (I.C. = 9; I.R. $=57 ;$ Passos $=11)$ :

(0) equivalente/menor (e.g., Fig. 296)

(1) 2-3 vezes > (e.g., Fig. 312)

24. Curvaturas de $M_{3}($ I.C. $=33$; I.R. = 55; Passos = 6):

(0) reta (e.g., Fig. 298)

(1) convexa, com curvatura posterior perto do fim (e.g., Fig. 300)

(2) convexa (e.g., Fig. 304)

25. Posição de surgimento de $R_{2+3}(I . C .=21 ;$ I.R. = 52; Passos = 14):

(0) bastante distalmente a r-m, próxima ao ápice da célula discal (e.g., Fig. 296)

(1) em r-m ou apenas um pouco distalmente, distância equivalente à metade de r-m (e.g., Fig. 298) 
(2) basalmente a r-m (e.g., Fig. 300)

(3) distalmente a r-m, distância equivalente ao comprimento de r-m (e.g., Fig. 96)

26. Trajeto do fim de $R_{2+3}$ (I.C. = 25; I.R. = 33; Passos = 8):

(0) paralelo a $\mathrm{R}_{1}$ até a margem da asa (e.g., Fig. 296)

(1) convergindo a $\mathrm{R}_{1}$ no seu último terço (e.g., Fig. 310)

(2) fusionada a $\mathrm{R}_{1}$ nos seus dois últimos terços (e.g., Fig. 312)

27. Curvatura do primeiro setor da célula discal (I.C. = 100; I.R. = 100; Passos = 1):

(0) aproximadamente reta ou reta (e.g., Fig. 307)

(1) sinuosa (e.g., Fig. 301)

28. Comprimento do segundo setor da célula discal em relação ao primeiro setor (I.C. = 25; I.R. = 71; Passos = 8):

(0) maior que duas vezes (e.g., Fig. 295)

(1) tão longo quanto o primeiro setor (e.g., Fig. 299)

(2) entre uma vez e meia e duas vezes (e.g., Fig. 96)

29. Comprimento do quarto setor da célula discal em relação ao quinto setor (I.C. = 25; I.R. = 75; Passos = 4):

(0) maior (e.g., Fig. 295)

(1) equivalente/menor (e.g., Fig. 299)

30. Veia CuP (I.C. = 25; I.R. = 25; Passos = 4):

(0) ausente (e.g., Fig. 295)

(1) presente (e.g., Fig. 102)

31. Comprimento da veia Cup (I.C. = 20; I.R. = 33; Passos = 5):

(0) alcançando a bifurcação entre $\mathrm{CuA}_{1}$ e $\mathrm{CuA}_{2}$ ou bem próxima (e.g., Fig. 102)

(1) não alcançando a bifurcação entre $\mathrm{CuA}_{1}$ e $\mathrm{CuA}_{2}$ (aproximadamente com metade do comprimento), vestigial (e.g., Fig. 319) 
32. Relação entre o comprimento da margem apical do lóbulo anal em relação ao comprimento margem basal posterior da asa (I.C. = 28; I.R. = 64; Passos = 7):

(0) fortemente proeminente, metade posterior da asa claramente mais estreita que a metade anterior (e.g., Fig. 299)

(1) mesmo tamanho, metade anterior e posterior da asa com a mesma largura (e.g., Fig. 100)

(2) retraída, metade anterior da asa menos larga que a metade posterior (e.g., Fig. 311)

33. Pilosidade no extremo basal de $A_{1}$ (I.C. = 28; I.R. = 75; Passos = 7):

(0) nua até a bifurcação com $\mathrm{CuA}_{2}$ (e.g., Fig. 328)

(1) nua até metade do comprimento da veia anterior à bifurcação (e.g., Fig. 330)

(2) pilosa em toda a veia anterior à bifurcação (e.g., Fig. 335)

34. Largura da metade apical da álula em relação ao comprimento da veia humeral (I.C. = 33; I.R. = 63; Passos = 6):

(0) larga, > que uma vez (e.g., Fig. 330)

(1) muito larga, > que duas vezes (e.g., Fig. 329)

(2) estreita, comprimento equivalente (e.g., Fig. 339)

35. Pilosidade na álula (I.C. = 16; I.R. = 16; Passos = 6):

(0) presente (e.g., Fig. 332)

(1) ausente (e.g., Fig. 131)

36. Disposição da pilosidade na álula (I.C. = 33; I.R. = 53; Passos = 9):

(0) parte distal do ápice e parte superior (e.g., Fig. 326)

(1) apenas na parte distal do ápice (e.g., Fig. 331)

(2) apenas na parte superior (e.g., Fig. 126)

(3) metade distal/quase toda superfície (e.g., Fig. 332)

37. Projeção na caliptra (James \& McFadden 1982) (I.C. = 100; I.R. = 100; Passos =1):

(0) presente

(1) ausente 
Característica tradicionalmente utilizada na separação de Sargus e Himantigera, que tem essa projeção, em relação aos gêneros Ptecticus, Merosargus e Acrochaeta, que não apresentam essa projeção (James \& McFadden 1982).

\section{Abdômen (38-40)}

38. Formato do abdômen (I.C. $=$ 30; I.R. = 68; Passos $=10)$ :

(0) mais ou menos retangular, tergitos 2-5 equivalentes em largura (e.g., Fig. 474)

(1) fracamente clavados, tergitos 3-5 gradualmente mais largos que 1-2 (e.g., Fig. 491)

(2) fortemente clavados, tergitos 3-5 bruscamente mais largos que 1-2 (e.g., Fig. 153)

(3) ovalado, tergitos 1 e 5 mais estreitos que 2-4

39. Formato do primeiro segmento abdominal (I.C. = 28; I.R. = 75; Passos = 7):

(0) trapézio isósceles, parte proximal mais estreita (e.g., Fig. 475)

(1) retangular, margens laterais paralelas (e.g., Fig. 485)

(2) trapézio isósceles invertido, parte proximal mais larga (e.g., Fig. 153)

40. Formato do segundo segmento abdominal (I.C. = 14; I.R. = 71; Passos = 7):

(0) retangular, margens laterais paralelas (e.g., Fig. 475)

(1) trapézio isósceles, parte proximal mais estreita (e.g., Fig. 153)

\section{Genitália masculina (41-62)}

41. Gonocoxitos+hipândrio (singonocoxito) (Woodley 1995) (I.C. = 100; I.R. = 100; Passos = 1):

(0) completamente fundidos, estreito espaçamento entre porção ventral e porção dorsal do singonocoxito (e.g., Fig. 381)

(1) parcialmente fundido (linhas de fusão presente), grande espaçamento entre porção ventral e porção dorsal do singonocoxito (e.g., Fig. 403)

42. Relação da porção ventral do singonocoxito a porção dorsal do singonocoxito (I.C. = 50; I.R. = 80; Passos = 2):

(0) fortemente conectado por uma placa medial (e.g., Fig. 407)

(1) fracamente conectado medialmente (e.g., Fig. 63) 
43. Formato da projeção medial do singonocoxito (I.C. = 42; I.R. = 75; Passos = 7):

(0) não projetada ou fracamente projetada (e.g., Fig. 386)

(1) fortemente emarginada, formando um abaulamento profundo (e.g., Fig. 388)

(2) projetada, formando uma estrutura claramente bilobada (e.g., Fig. 394)

(3) projetada, digitiforme (e.g., Fig. 400)

44. Posição de inserção dos gonóstilos no singonocoxito (I.C. = 66; I.R. = 94; Passos = 3):

(0) apical (e.g., Fig. 399)

(1) ventral (e.g., Fig. 404)

(2) inclinada, levemente deslocada para o ventre da placa (e.g., Fig. 63)

45. Formato dos gonóstilos (I.C. = 75; I.R. = 95; Passos = 4):

(0) digitiforme, pouco desenvolvido (e.g., Fig. 399)

(1) mais longo que largo, estreitando gradualmente em direção ao ápice (e.g., Fig. 394)

(2) largos, convexo dorsalmente (e.g., Fig. 404)

(3) largos nos dois primeiros terços basais, muito estreitos no terço apical (e.g., Fig. 58)

46. Projeção na margem dorsal dos gonóstilos (I.C. = 100; I.R. = 100; Passos = 1):

(0) ausente (e.g., Fig. 71)

(1) presente (e.g., Fig. 58)

47. Comprimento dos apódemas gonocoxais em relação ao comprimento dos lóbulos do edeago (I.C. = 25; I.R. = 50; Passos = 8):

(0) comprimento menor que um terço, pouco desenvolvido (e.g., Fig. 355)

(1) comprimento equivalente a um terço ou metade (e.g., Fig. 361)

(2) comprimento maior que a totalidade do lóbulo, muito desenvolvido (e.g., Fig. 70)

48. Posição dos apódemas gonocoxais em relação à margem basal da genitália (I.C. = 50; I.R. = 88; Passos = 4):

(0) muito abaixo (e.g., Fig. 355)

(1) aproximadamente no mesmo nível (e.g., Fig. 361)

(2) muito acima (e.g., Fig. 374) 
49. Extensão horizontal do sulco ligando os apódemas gonocoxais ao singonocoxito (I.C. = 50; I.R. = 80; Passos = 2):

(0) muito pronunciado (e.g., Fig. 355)

(1) pouco pronunciado (e.g., Fig. 368)

50. Extensão longitudinal do sulco ligando os apódemas gonocoxais ao singonocoxito (I.C. = 50; I.R. = 91; Passos = 2):

(0) muito pronunciada, atingindo ou ultrapassando a metade do gonocoxito (e.g., Fig. 355)

(1) pouco pronunciada, não alcançando a metade do gonocoxito (e.g., Fig. 356)

51. Ponte gonocoxal (I.C. = 100; I.R. = 100; Passos = 1):

(0) basal (e.g., Fig. 374)

(1) distal (e.g., Fig. 70)

52. Apódema ejaculatório (I.C. = 40; I.R. = 83; Passos $=5$ ):

(0) ultrapassando em muito os limites dos gonocoxitos (e.g., Fig. 355)

(1) muito próximo do limite dos gonocoxitos (e.g., Fig. 357)

(2) muito acima do limite dos gonocoxitos (e.g., Fig. 377)

53. Porção dorsal dos parâmeros (I.C. = 66; I.R. = 85; Passos = 3):

(0) pouco desenvolvido, não ultrapassando a base do edeago (e.g., Fig. 413)

(1) desenvolvido, ultrapassando a base do edeago (e.g., Fig. 409)

(2) muito desenvolvido, ultrapassando o ápice do edeago (e.g., Fig. 65)

54. Formato da porção dorsal dos parâmeros (I.C. = 66; I.R. = 85; Passos = 3):

(0) achatados (e.g., Fig. 413)

(1) largo, gradualmente estreitando em direção ao ápice (e.g., Fig. 409)

(2) largo nos dois primeiros terço, em forma de forquilha na terço distal (e.g., Fig. 67)

55. Porção ventral dos parâmeros (I.C. = 50; I.R. = 0; Passos = 2):

(0) não projetado, fundido ao edeago (e.g., Fig. 414)

(1) projetado, ultrapassando a base do edeago (e.g., Fig. 412) 
56. Número de lóbulos do edeago (I.C. = 40; I.R. = 81; Passos = 5):

(0) trífido (e.g., Fig. 413)

(1) bífido (e.g., Fig. 410)

(2) simples, um único tubo (e.g., Fig. 67)

57. Lóbulo medial do edeago (Woodley 1995) (I.C. = 33; I.R. = 75; Passos = 3):

(0) presente (e.g., Fig. 413)

(1) ausente (e.g., Fig. 410)

58. Comprimento do edeago (I.C. = 25; I.R. = 80; Passos $=4)$ :

(0) curto, não ultrapassando ou atingindo o limite distal dos gonocoxitos (e.g., Fig. 355)

(1) longo, ultrapassando o limite distal dos gonocoxitos (e.g., Fig. 360)

59. Proctiger (I.C. = 100; I.R. = 100; Passos = 1):

(0) bem desenvolvido, largura equivalente ao comprimento dos cercos (e.g., Fig. 419)

(1) pouco desenvolvido, largura equivalente a um terço do comprimento dos cercos (e.g., Fig. 427)

60. Proctiger+epândrio (I.C. = 100; I.R. = 100; Passos = 1):

(0) não fusionados (e.g., Fig. 425)

(1) fusionados (e.g., Fig. 421)

61. Relação comprimento/largura do epândrio (I.C. = 3; I.R. = 66; Passos = 88):

(0) distintamente mais largos que longos, formato em V (e.g., Fig. 419)

(1) equivalente, aproximadamente com formato retangular ou quadrado (e.g., Fig. 429)

(2) distintamente mais longos que largos (e.g., Fig. 420)

62. Margem distal do epândrio (I.C. = 100; I.R. = 100; Passos = 1):

(0) não projetada (e.g., Fig. 429)

(1) projetada (e.g., Fig. 424)

\section{Genitália feminina (63)}


63. Formato da porção anterior da furca genital (I.C. = 100; I.R. = 100; Passos = 1):

(0) triangular, estreitando fortemente em direção à base (e.g., Fig. 452)

(1) aproximadamente cilíndrica, estreitamento não aparente (e.g., Fig. 73)

\subsection{Análise cladística}

Utilizando a análise da matriz de caracteres (Tabela 4) com pesagem igual construída a partir dos caracteres listados acima, foram obtidas quatro árvores mais parcimoniosas, com 267 passos—com um índice de consistência de 0,36 e índice de retenção de 0,75. O consenso estrito dessas quatro árvores-com 273 passos, índice de consistência (I.C.) de 0,35 e índice de retenção (I.R.) de 0,74—foi utilizado como árvore de referência para a discussão (Fig. 217).

Tabela 4. Matriz de dados com 63 caracteres e 45 táxons terminais utilizados na análise.

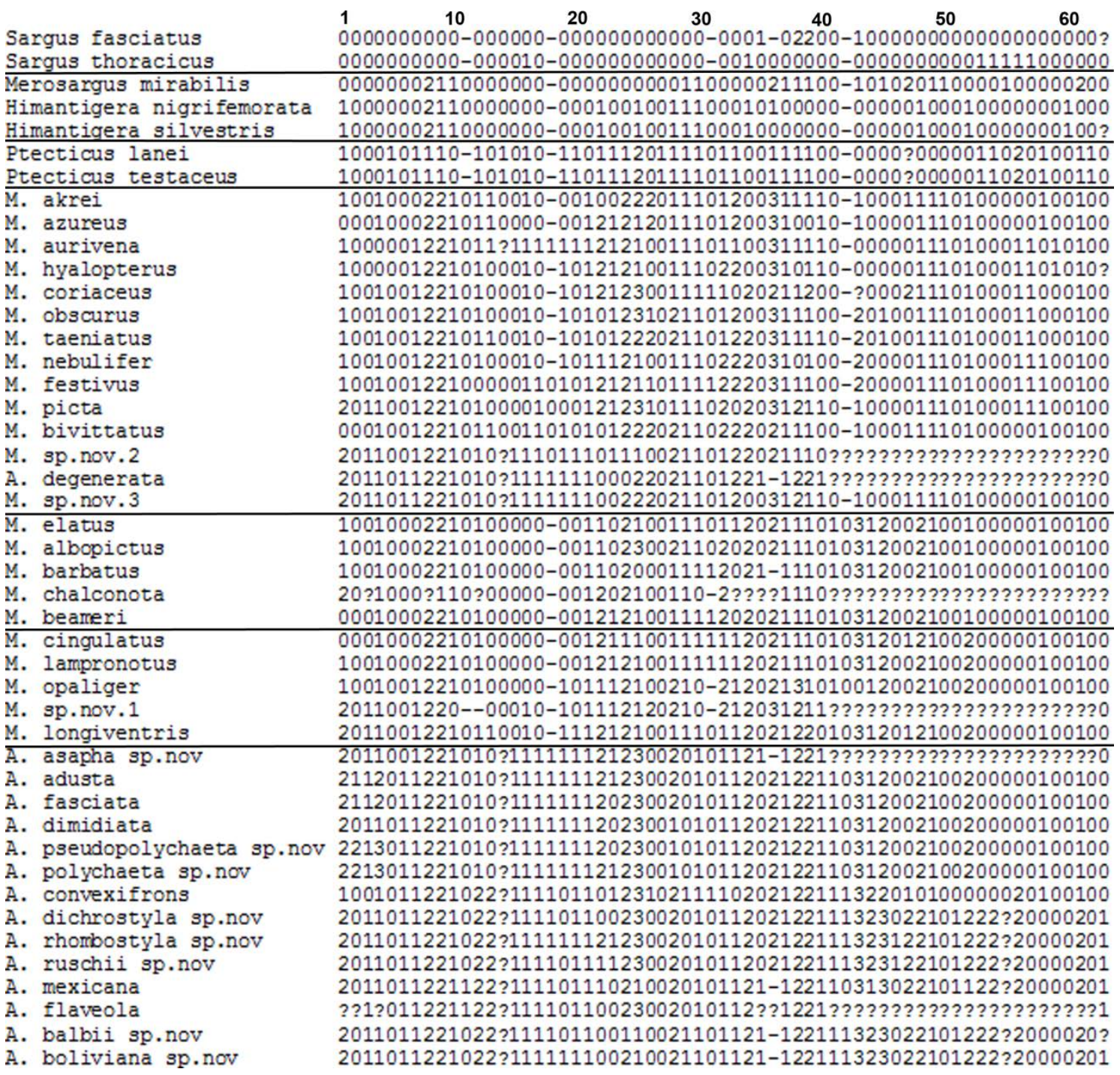


A árvore consenso da figura 218 é resultado de uma análise sem as espécies representadas apenas por fêmeas, obtida a partir de 16 árvores mais parcimoniosas com 246 passos, I.C. de 0,39 e I.R. de 0,76. Essa árvore tem 263 passos (I.C. de 0,36 e I.R. de 0,73) e uma topologia bastante semelhante àquela obtida com todas as espécies. Dentre as poucas diferenças relevantes, destaque para a completa resolução do grupoflaveola e para exclusão de A. dimidiata do clado com A. adusta, A. fasciata, A. pseudopolychaeta sp. nov. e A. polychaeta sp. nov. A. dimidiata passa para uma politomia com o clado (A. pseudopolychaeta sp. nov. + A. polychaeta sp. nov.) e com o restante do gênero. Em Merosargus, foi recuperado o clado que inclui apenas as espécies de edeago bífido, além do estabelecimento de uma grande politomia no grupo das espécies metálicas. Em síntese, para Merosargus há alguma perda de informação e alteração na sequência de clados.

Com a pesagem implícita, foi feita a análise com $k=7.8125$ (Fig. 219) e $k$ com os valores $1,2,3,5,6,8,9,10,11,12$ e 13, correspondente ao intervalo de teste de estabilidade da árvore obtida com o valor de $k=7.8125$. A tabela 6 compara o número de passos, o I.C. e o I.R. dos diferentes valores de $k$ testados para a matriz de dados. Apenas para os valores de $k=1$ e $k=2$ foram obtidas mais do que uma árvore igualmente mais parcimoniosa, nove e três, respectivamente. Dessa forma, para esses valores de $k$, foram plotados na tabela 5 os valores das árvores de consenso.

A igualdade referente aos mesmos resultados que àqueles obtidos pelo $k=$ 7.8125 em termos de número de passos, I.C. e I.R. é alcançando no intervalo de $\mathrm{k}=3$ até 10 (Tabela 5). Apenas os valores $k=8$ e 9 apresentam igualdade de topologia (não há variação entre o posicionamento dos clados) com $k=7.8125$. De modo geral, as relações entre as espécies de Acrochaeta basicamente se mantêm (Figs. 218-221), sendo que as variações de posicionamento, quando ocorrem, dizem respeito ao clado ( $A$. adusta + A. fasciata). As principais variações entre os cladogramas ocorrem nos clados contendo as espécies de Merosargus (que sempre aparece como parafilético). 
Tabela 5. Comparação entre número de passos, I.C. e I.R. para diferentes valores de $k$ para a matriz de dados.

\begin{tabular}{|l|l|l|l|}
\hline Valores de $\boldsymbol{k}$ & Número de passos & I.C. & I.R. \\
\hline 1 (Fig. 218) & 285 & 0,34 & 0,72 \\
\hline 2 (Fig. 219) & 276 & 0,35 & 0,74 \\
\hline 3 (Fig. 220) & 271 & 0,35 & 0,74 \\
\hline 4 (Fig. 221) & 271 & 0,35 & 0,74 \\
\hline 5 (Fig. 222) & 271 & 0,35 & 0,74 \\
\hline 6 (Fig. 223) & 271 & 0,35 & 0,74 \\
\hline 7.8125 (Fig. 217) & 271 & 0,35 & 0,74 \\
\hline 8 (Fig. 224) & 271 & 0,35 & 0,74 \\
\hline 9 (Fig. 225) & 271 & 0,35 & 0,74 \\
\hline 10 (Fig. 226) & 271 & 0,35 & 0,74 \\
\hline 11 (Fig. 227) & 268 & 0,36 & 0,75 \\
\hline 12 (Fig. 228) & 268 & 0,36 & 0,75 \\
\hline 13 (Fig. 229) & 268 & 0,36 & 0,75 \\
\hline
\end{tabular}




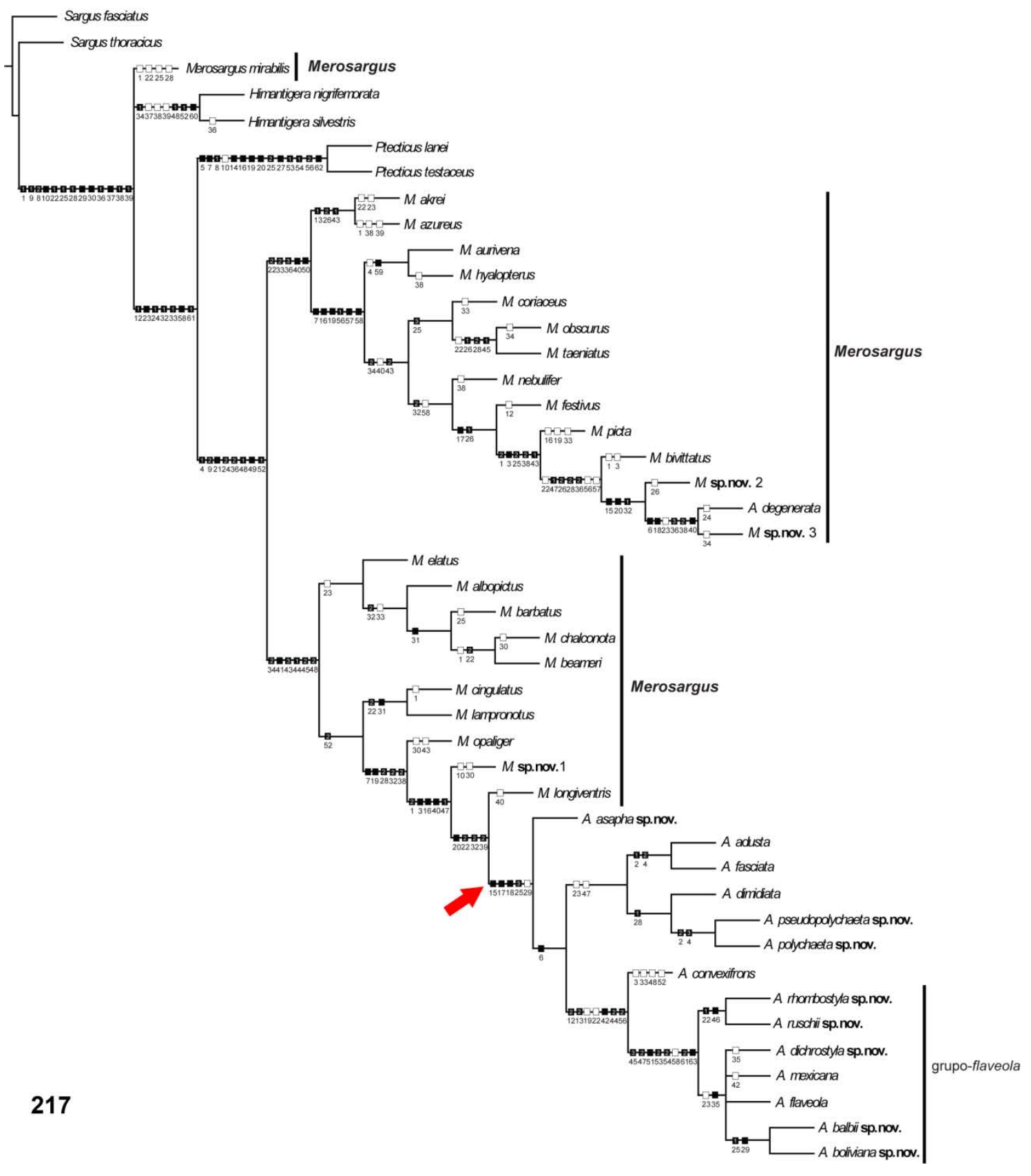

Figura 217. Consenso estrito das quatro árvores mais parcimoniosas obtidas na análise cladística de Acrochaeta. Apenas as condições sinapomórficas (mesmo homoplásticas) foram plotadas. Quadrados pretos mudanças para o estado apomórfico em relação ao grupo mais externo (Sargus fasciatus) e quadrados brancos reversões. A seta vermelha indica o clado Acrochaeta. 


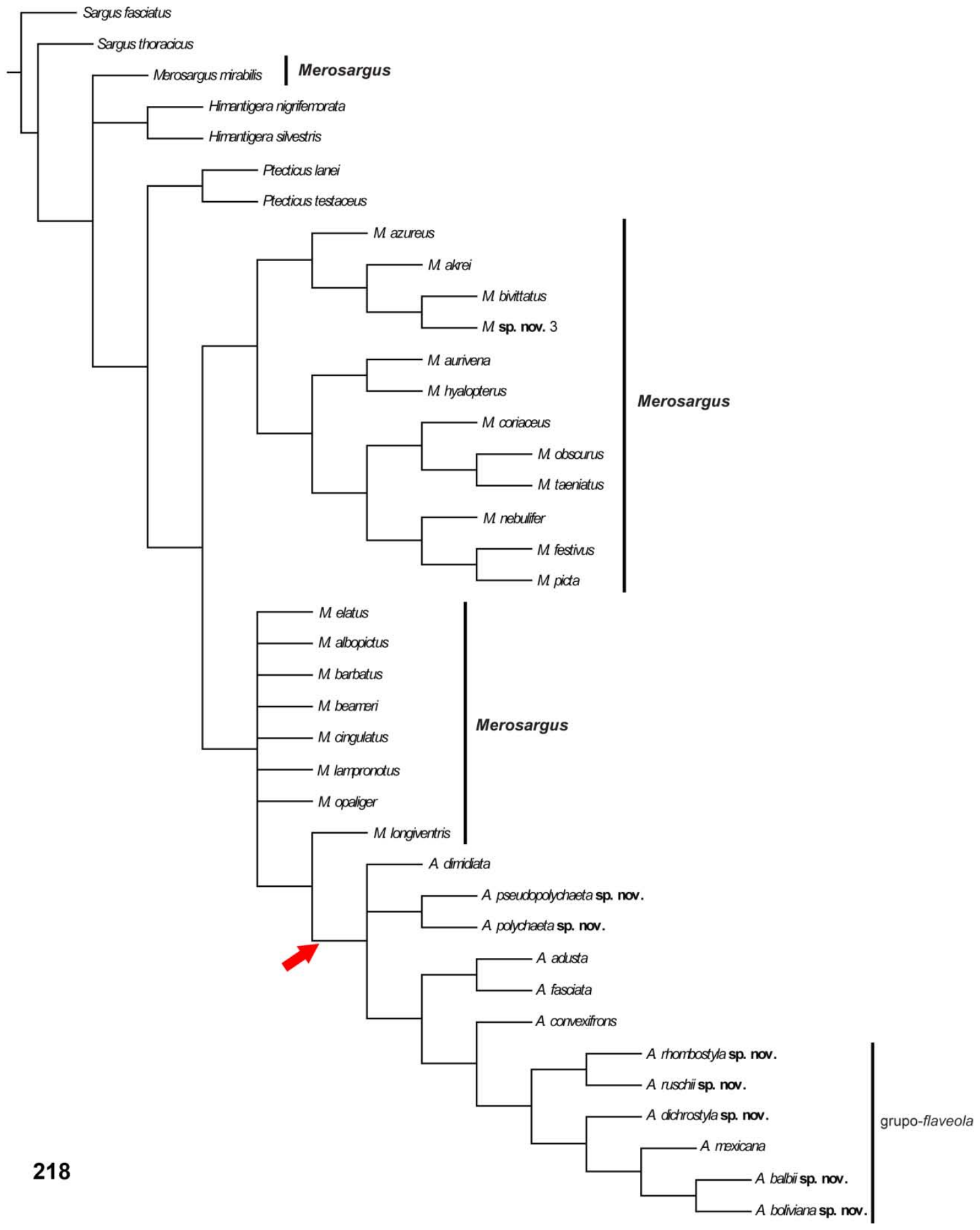

Figura 218. Consenso estrito das dezesseis árvores mais parcimoniosas obtidas na análise cladística de Acrochaeta desconsiderando os táxons com apenas fêmeas. A seta vermelha indica o clado Acrochaeta. 


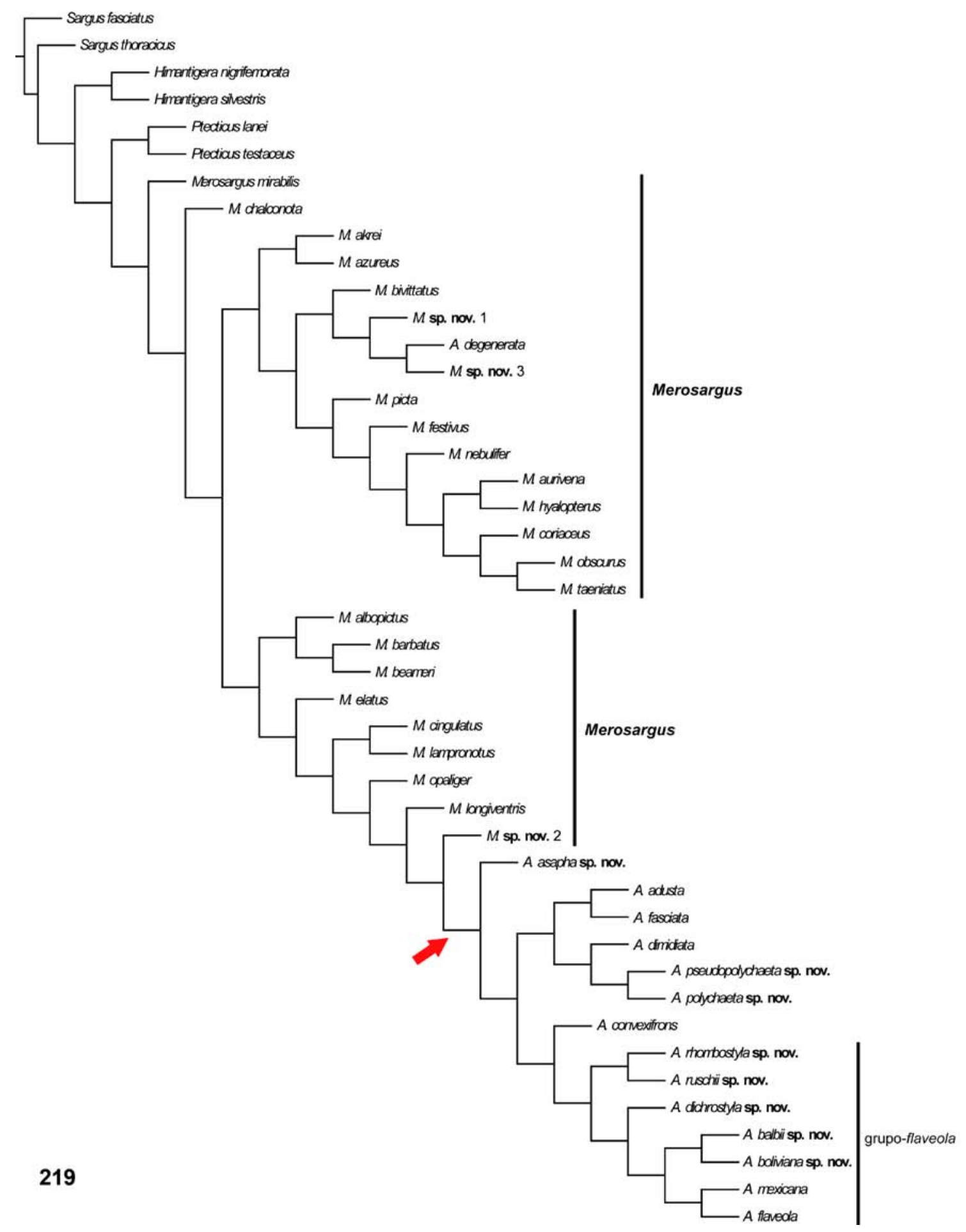

Figura 219. Árvore mais parcimoniosa da análise cladística de Acrochaeta, obtida por meio de pesagem implícita com valor de $k=7.8125$. A seta vermelha indica o clado Acrochaeta. 


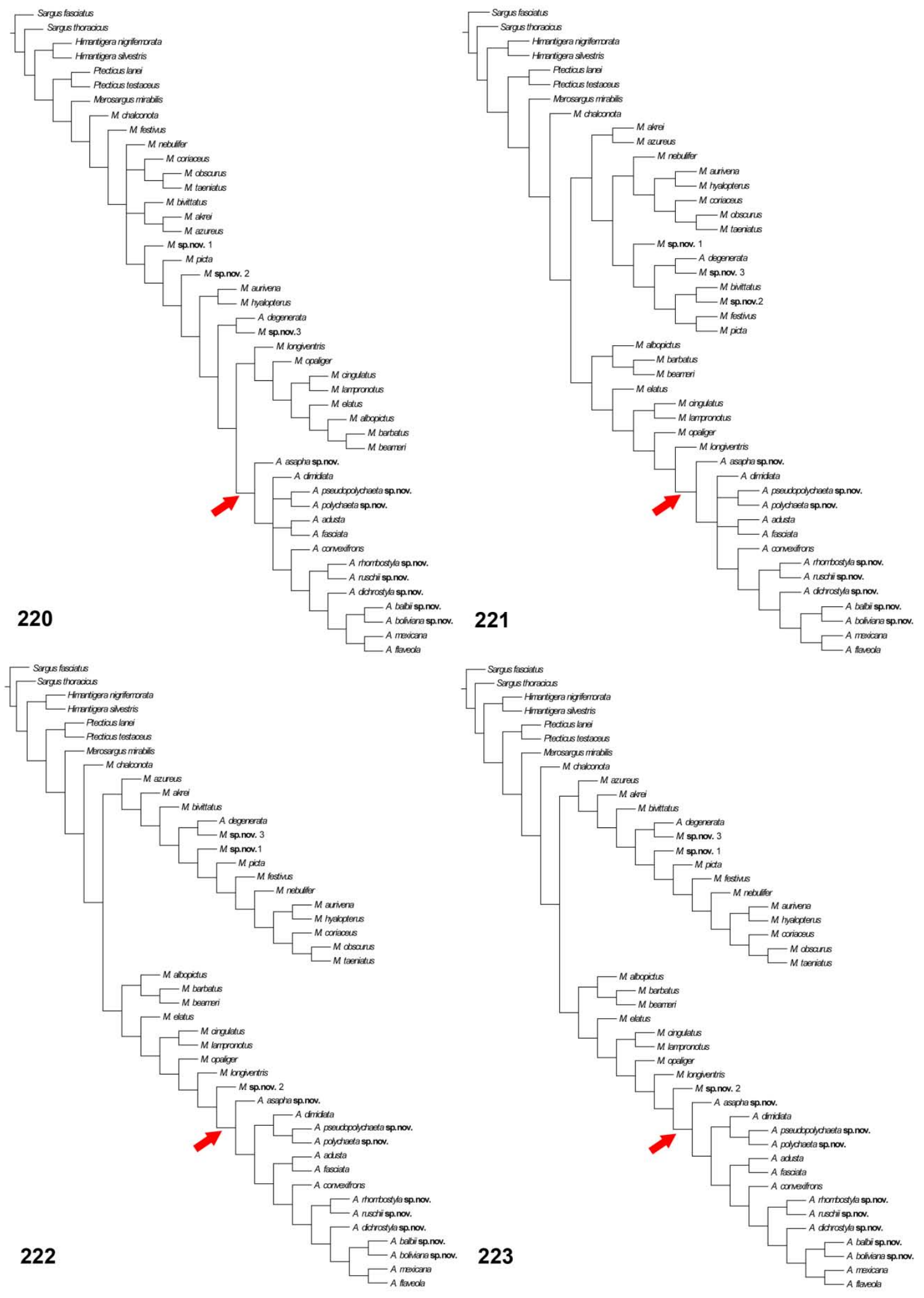

Figuras 220-223. Árvores mais parcimoniosas da análise cladística de Acrochaeta, obtidas por meio de pesagem implícita com diferentes valores de $k .220 . k=1.221 . k=2.222 . k=3.223 . k$ $=4$. A seta vermelha indica o clado Acrochaeta. 

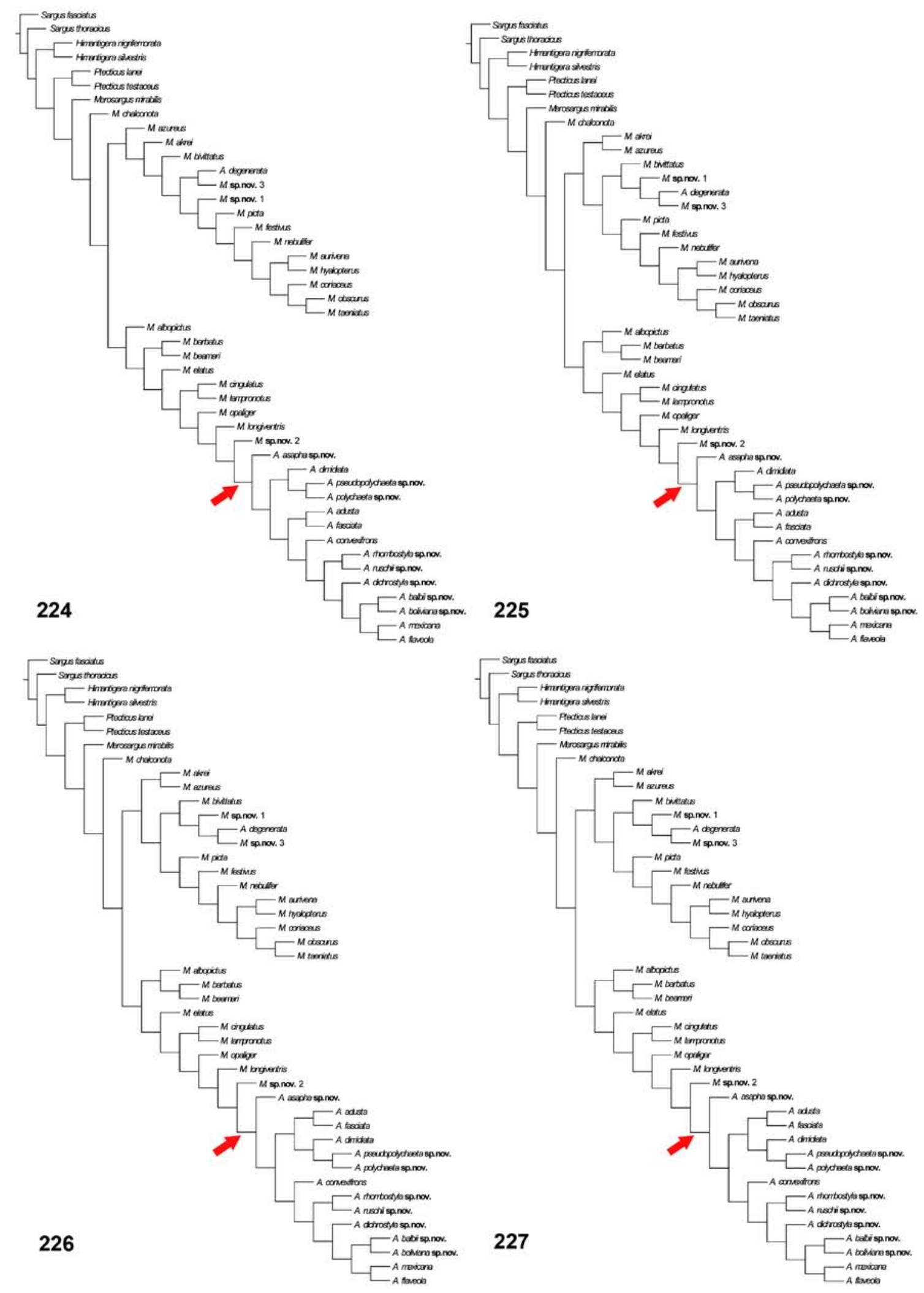

Figuras 224-227. Árvores mais parcimoniosas da análise cladística de Acrochaeta, obtidas por meio de pesagem implícita com diferentes valores de $k .224 . k=5.225 . k=6.226 . k=8.227 . k$ $=9$. A seta vermelha indica o clado Acrochaeta . 

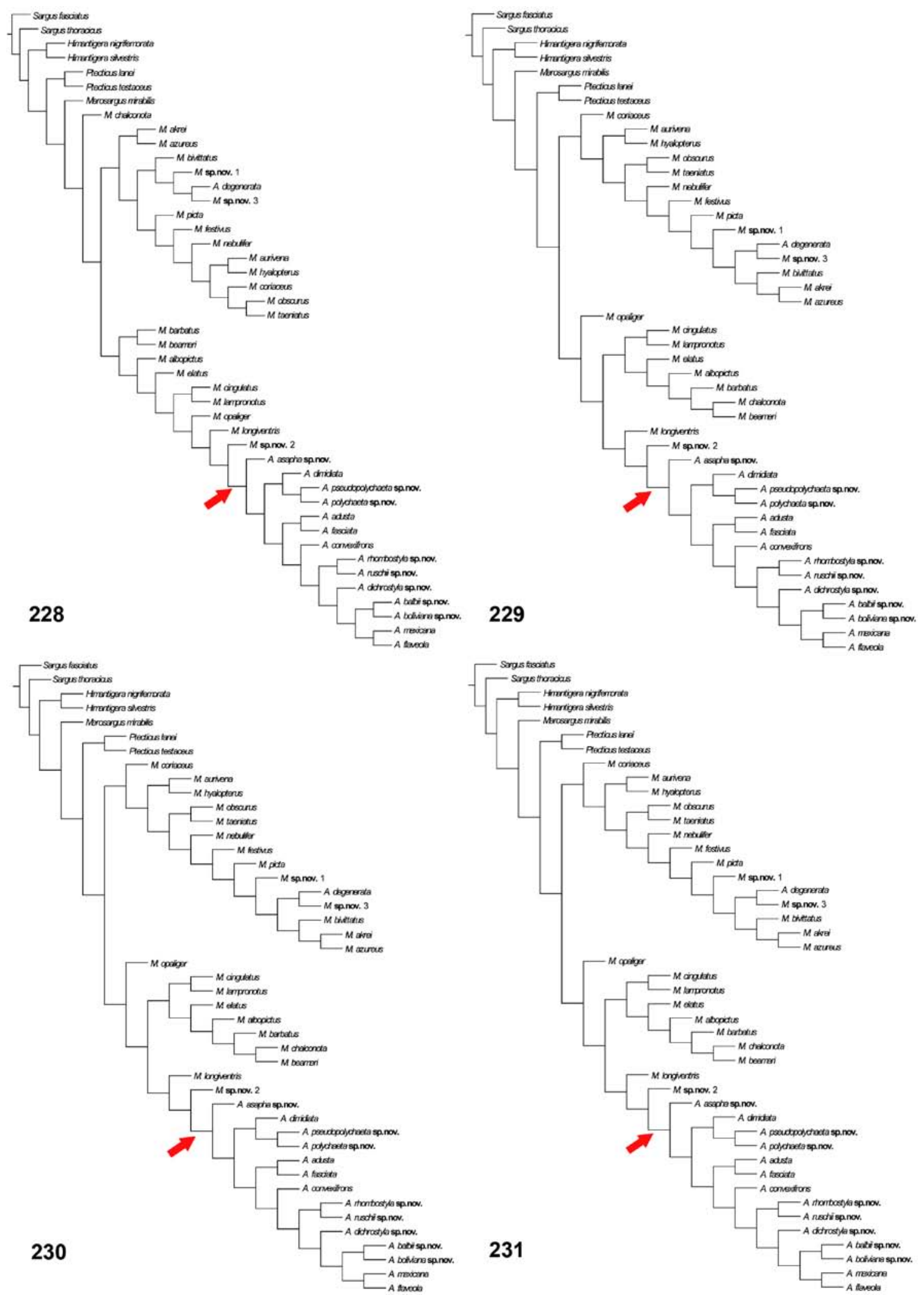

Figuras 228-231. Árvores mais parcimoniosas da análise cladística de Acrochaeta, obtidas por meio de pesagem implícita com diferentes valores de $k .228 . k=10.229 . k=11.230 . k=12$. 231. $k=13$. A seta vermelha indica o clado Acrochaeta. 


\section{DISCUSSÃO}

\subsection{Relacionamento de Acrochaeta e Merosargus}

Tradicionalmente, Acrochaeta tem sido delimitado quase que exclusivamente pela presença de longas antenas (i.e., flagelômeros mais longos que largos) (James \& McFadden 1982; Woodley 2009), como mencionado anteriormente. A presença de antenas longas, no entanto, não é uma condição exclusiva de Acrochaeta. A análise realizada aqui mostra que essa condição (caráter 1, estado 2) também está presente em um pequeno clado de Merosargus e em duas outras espécies de Merosargus (M. sp. nov. 1 e M. longiventris) proximamente relacionadas a Acrochaeta. Isso corrobora as indicações anteriores na literatura (Woodley 2009) de que o alongamento das antenas não seja exclusivo de Acrochaeta.

Desse modo, essa condição não é sinapomórfica para Acrochaeta, mas para um nível um pouco mais abrangente que inclui Acrochaeta e parte das espécies de Merosargus (Fig. 217). Assim, Merosargus é parafilético em relação a Acrochaeta, ou seja, Acrochaeta é um clado que se insere dentro de Merosargus.

A análise, por outro lado, recuperou Acrochaeta como um grupo monofilético, sendo sinapomorfias desse clado:

(1) elevação da parte superior da fronte (caráter 15, estado 1);

(2) escudo fortemente marcado por três grandes faixas longitudinais (carateres 17 e 18, estado 1$)$;

(3) $\mathrm{R}_{2+3}$ surgindo distalmente a r-m com a distância equivalente ao comprimento de r-m (exceto em A. degenerata, A. mexicana, A. balbii sp. nov. e A. boliviana sp. nov.) (caráter 25, estado 3);

(4) comprimento maior do quarto setor da célula discal em relação ao quinto (exceto em A. convexifrons, A. balbii sp. nov. e A. boliviana sp. nov.) (caráter 29);

(5) abdômen peciolado com $1^{\circ}$ segmento abdominal com parte proximal mais larga e $2^{\circ}$ segmento abdominal com parte proximal mais estreita (caracteres 39, estado 2 e 40, estado 1).

\subsection{Novas combinações: Merosargus picta, M. chalconota, M. longiventris e Acrochaeta convexifrons}

Essas características sinapomórficas de Acrochaeta permitem o reexame da lista de espécies incluídas taxonomicamente no gênero. $M$. picta e $M$. chalconota foram 
propostas inicialmente como espécies do gênero Compsosoma, posteriormente sinonimizado a Acrochaeta por James (1973) sem uma justificativa. Nesta análise, essas duas espécies não aparecem formando um mesmo clado e também não foram recuperadas como espécies de Acrochaeta.

Apesar da presença de alguma coloração metálica (plesiomorfia) no escudo e no mediotergito, $M$. picta aparece em um clado com espécies de coloração geral amarela (i.e., sem coloração metálica) em Merosargus. A presença de edeago bifído e o lóbulo medial do edeago ausente são outras duas sinapomorfias que sustentam esse grupo de Merosargus do qual $M$. picta faz parte. O relacionamento de $M$. picta com as outras quatro espécies nesse clado ainda é um pouco controverso. A amostragem de espécies de Merosargus neste estudo é em particular para enraizar a análise de Acrochaeta e não há um levantamento extensivo de caracteres para resolver a relação dentro de Merosargus. Além disso, há uma espécie nominalmente incluída em Acrochaeta nesse grupo.

M. chalconota, por sua vez, faz parte do clado das espécies metálicas de Merosargus, ainda que nominalmente estivesse em Acrochaeta. Esse agrupamento, incluindo a relação de espécies-irmãs entre $M$. chalconota e $M$. beameri James, 1941, é sustentado em sua maioria por reversões homoplásticas (e.g., caráter 23, estado 0). Ainda é necessário um esforço na delimitação desse agrupamento para que o posicionamento de $M$. chalconota seja apoiado por mais caracteres. A inferência de que M. chalconota não faz parte de Acrochaeta, no entanto, parece ser bem segura uma vez que essa espécie não apresenta as sinapomorfias definidas aqui para Acrochaeta.

M. longiventris, tradicionalmente incluída em Acrochaeta, aparece como irmã do gênero. Isso é indicado por caracteres de asas (20, estado 1; 22, estado 2 e 32, estado 2) e abdômen (caráter 39, estado 2) —apenas o primeiro segmento abdominal tem a mesma conformação de Acrochaeta. Desse modo, M. longiventris não apresenta as sinapomorfias (e.g., elevação do tubérculo ocelar, padrão de faixas no escudo, abdômen verdadeiramente peciolado) do clado que foi escolhido aqui para associar o nome genérico de Acrochaeta. Essa delimitação, desse modo, não inclui $M$. longiventris, sendo a espécie transferida para Merosargus.

Uma única espécie originalmente incluída em Merosargus foi recuperada em Acrochaeta-A. convexifrons. Essa espécie aparece como irmã do grupo-flaveola (ver discussão abaixo) possuindo como sinapomorfias: área medial da fronte paralela posteriormente (caráter 12, estado 2), área medial da fronte distintamente elevada 
(caráter 13, estado 2), porção ventral do singonocoxito fracamente conectada com a porção dorsal (caráter 42, estado 1), gonóstilos inseridos inclinadamente na porção ventral do singonocoxito (caráter 44, estado 2) e edeago simples (caráter 56, estado 2). É bem provável, no entanto, que outras espécies de Merosargus não incluídas nesta análise, como M. brunnipes, M. flavissimus, M. pictithorax (Fig. 3), espécies que se assemelham ao padrão de coloração de Acrochaeta, também venham a ser pertencentes a Acrochaeta.

\subsection{O posicionamento de Acrochaeta degenerata}

O posicionamento de $A$. degenerata obtido na análise realizada aqui ainda é discutível, uma vez que essa espécie não foi recuperada como parte de Acrochaeta. Na análise, ela aparece como irmã de $M$. sp. nov. 3, tendo como sinapomorfias: elevação do tubérculo ocelar muito acima da margem dos olhos (caráter 6, estado 1)—sinapomorfia de Acrochaeta exceto A. asapha sp. nov.; escudo fortemente marcado por três faixas longitudinais (caráter 18, estado 1) — sinapomorfia de Acrochaeta; pilosidade em toda a superfície da álula (caráter 36, estado 3); abdômen fortemente clavado (caráter 38, estado 2)—condição presente em Acrochaeta, e segundo segmento abdominal com a parte proximal mais estreita (caráter 40, estado 1)—condição presente em Acrochaeta. Além disso, compartilha com Acrochaeta o primeiro segmento abdominal com a parte proximal mais larga (caráter 39, estado 1). A. degenerata apresenta todas as sinapomorfias que definem Acrochaeta exceto $\mathrm{R}_{2+3}$ surgindo antes de r-m. A falta de informação de genitália masculina para a espécie e algumas modificações compartilhadas com subgrupos de Merosargus (e.g., $\mathrm{R}_{2+3}$ surgindo antes de r-m, extremo basal de $A_{1}$ pilosa em toda extensão) resulta em uma topologia possivelmente incorreta nesse aspecto. O mais provável é que essa espécie pertença ao clado de Acrochaeta.

Situação semelhante ocorre com a espécie-irmã de $A$. degenerata na análise, $M$. sp. nov. 3. Essa espécie também apresenta as condições apomórficas de Acrochaeta, mas não tem algumas das sinapomorfias de genitália masculina (caracteres 41, estado 1; 43, estado 3; 44, estado 1; 45, estado 2 e 48, estado 2) que provavelmente implicam na sua exclusão do clado Acrochaeta. Desse modo, essas condições apomórficas compartilhadas com Acrochaeta são interpretadas como surgimentos independentes. Por outro lado, para $A$. degenerata a suspeita é de que ela seja uma espécie altamente modificada de Acrochaeta, possivelmente com reversões em caracteres de asa (e.g., 
$\mathrm{R}_{2+3}$ surgindo antes de r-m e fusionada nos seus dois últimos terços à $\mathrm{R}_{1}$, pilosidade em toda a extensão do extremo basal de $\mathrm{A}_{1}$ ) que, na análise númerica, a aproxime do clado com as espécies amareladas de Merosargus. Entretanto, apenas o estudo da genitália masculina poderá trazer conclusões mais robustas a essa questão.

\subsection{Grandes clados em Acrochaeta}

A. asapha foi recuperada como irmã de todas as outras espécies de Acrochaeta, tanto na análise com pesos iguais (Fig. 217), quanto com pesagem implícita (Fig. 219). As demais espécies do gênero formam um grupo monofilético sustentado pela elevação do tubérculo ocelar muito acima da margem dos olhos (caráter 6, estado 1), característica compartilhada também com $A$. degenerata.

O cladograma (Fig. 217), como é comum, tem um número de sinapomorfias diferente para distintos clados. Destaque foi dado ao grupo de espécies flaveola que é sustentado pelas sinapomorfias: gonóstilos largos nos primeiros terços basais e estreito no terço apical (caráter 45, estado 3), apódema gonocoxal muito desenvolvido, maior que a totalidade do lóbulo do edeago (caráter 47, estado 2), ponte gonocoxal distal (caráter 51, estado 1), parâmeros ultrapassando o ápice do edeago (caráter 53, estado 2) e em forma de forquilha (caráter 54, estado 2), epândrio distintamente mais longos que largos (caráter 61, estado 2) e porção anterior da furca aproximadamente cilíndrica (caráter 63, estado 1).

Outro clado importante é o das espécies que apresentam a arista extremamente pilosa e larga da base até o ápice (exceto A. dimidiata). Esse clado é recuperado por uma reversão homoplástica (caráter 23, estado 0) e por uma reversão (caráter 47, estado 0). Em contrapartida, o relacionamento de grupos-irmãos (entre A. adusta e A. fasciata, e entre A. pseudopolychaeta sp. nov. e A. polychaeta sp. nov.) é bem sustentado por condições únicas, caracteres 2 e 4.

\subsection{O relacionamento dentro do grupo-flaveola}

Como já comentado logo acima, o grupo-flaveola é sustentado por um número importante de sinapomorfias, tendo como clado-irmão a espécie Acrochaeta convexifrons. Dentro do grupo-flaveola, dois subgrupos podem ser reconhecidos: (1) um deles formado por A. rhombostyla sp. nov. e A. ruschii sp. nov. que apresenta como sinapomorfias, a posição de r-m anterior a $\mathrm{M}_{3}$ na célula discal (caráter 22, estado 1) e presença de uma projeção na margem dorsal dos gonóstilos (caráter 46, estado 1); (2) o 
outro subgrupo inclui, em uma politomia, A. dichrostyla sp.nov., A. mexicana, A. flaveola e o clado A. balbii sp. nov. + A. boliviana sp. nov. Esse clado tem como sinapomorfia a ausência de pilosidade na álula (perda secundária em A. dichrostyla sp.nov.) (caráter 35, estado 1). O clado com A. balbii sp. nov. e A. boliviana sp. nov. tem como sinapomorfias: $\mathrm{R}_{2+3}$ surgindo em $\mathrm{r}-\mathrm{m}$ ou muito pouco depois (caráter 25, estado 1) e comprimento do quarto setor da célula discal menor que o quinto (caráter 29, estado 1).

O clado com essas cinco espécies é o que apresenta maior instabilidade em Acrochaeta, ou seja, a relação entre as espécies dentro desse clado varia entre as árvores mais parcimoniosas. A relação de espécies-irmãs entre A. balbii sp. nov. e A. boliviana sp. nov. é a única informação que se mantém constante nas quatro árvores mais parcimoniosas, ainda que $A$. boliviana sp. nov. seja bastante semelhante a A. mexicana no que diz respeito ao formato geral dos parâmeros (i.e., bilobados). A condição apomórfica do caráter 11 (estado 1) poderia sustentar o relacionamento entre $A$. mexicana e A. flaveola, mas por conta da falta de informação (principalmente de genitália masculina) em A. flaveola talvez implique que esse clado não tenha sido recuperado na árvore de consenso.

\subsection{A não-monofilia de Merosargus}

Como foi mencionado acima, Merosargus tem sido referido como um gênero próximo a Acrochaeta (James \& McFadden 1971), o que é particularmente evidente quando notamos que algumas espécies de Merosargus compartilham características (e.g., antena alongada, padrão de coloração do escudo) com algumas espécies de Acrochaeta. Essas semelhanças têm acarretado dificuldades em separar algumas espécies de ambos os gêneros, de modo que tem ocorrido na literatura a proposta de que Merosargus pudesse ser parafilético em relação à Acrochaeta (Woodley 2001) ou ainda, que Acrochaeta pudesse ser polifilético dentro de Merosargus (Woodley 2009).

Além do problema da delimitação de Merosargus, baseado principalmente em simplesiomorfias (e.g., projeção do pedicelo ausente, veia $\mathrm{M}$ distinta apenas apicalmente), é grande a dificuldade em determinar quais espécies pertecem ao gênero. Em alguns casos, as espécies são identificadas como pertencendo a Merosargus com base na aparência geral do gênero, i.e., antenas frequentemente globosas, presença de um calo frontal distinto do restante da fronte, $\mathrm{R}_{2+3}$ surgindo antes ou pouco depois de $\mathrm{r}$ m, presença de alguma coloração metálica etc. Essas características também estão 
presentes em espécies de Himantigera, Ptecticus e Acrochaeta, de modo que não há características únicas ou sinapomórficas que estabeleçam a inclusão dessas espécies em Merosargus. Isso demonstra o quão fraca é a delimitação atual de Merosargus, indicando que talvez o gênero reúna clados que sejam mais próximos a mais de um gênero em Sarginae (ou seja, polifilético e não apenas parafilético em relação a Acrochaeta), como comentado por James \& McFadden (1971).

A compreensão mais ampla das relações entre as espécies de Sarginae feita nesta análise (ainda que um pouco além do escopo deste trabalho) confirma com um grau bastante razoável de confiança o que havia sido indicado na literatura, ou seja, Merosargus não monofilético. Os resultados mostram que há espécies mais próximas de Acrochaeta e Himantigera que da espécie-tipo do gênero, Merosargus obscurus. Embora falte uma amostragem mais ampla das espécies de Merosargus, é possível destacar três grupos principais: (1) conjunto de espécies de Merosargus que inclui a espécie-tipo do gênero, Merosargus obscurus Wiedemann, 1830; (2) um clado que inclui espécies referidas a Merosargus e o próprio clado de Acrochaeta; (3) M. mirabilis James, 1971, que aparece fora do clado que inclui (Ptecticus + Merosargus + Acrochaeta). Talvez mereçam destaque também o clado formado pelas espécies amareladas e de edeago bifído de Merosargus (exceto $M$. bivittatus e $M$. sp. nov. 3) e os clados que incluem as espécies de Merosargus proximamente relacionadas a Acrochaeta, incluindo as espécies, M. opaliger Lindner, 1931, M. sp. nov. 1 e $M$. longiventris.

O clado que inclui a espécie-tipo do gênero (maioria espécies amareladas) tem como sinapomorfias: $\mathrm{r}-\mathrm{m}$ na mesma posição que $\mathrm{M}_{3}$ na célula discal (caráter 22, estado 2), extremo basal de $A_{1}$ pilosa em toda a sua extensão (caráter 33, estado 2), álula pilosa em quase toda a sua superfície (caráter 36, estado 3), segundo segmento abdominal estreito na sua parte proximal (caráter 40, estado 1) e extensão do sulco longitudinal pouco pronunciado, não alcançando a metade do singonocoxito (caráter 50, estado 1). Esse clado é majoritariamente, composto por espécies não metálicas de Merosargus, além disso, diferentemente do clado irmão (i.e., espécies de Merosargus + Acrochaeta) apresenta os gonocoxitos completamente fundidos (e.g., Fig. 389), com gonóstilos apicais e pouco desenvolvidos (e.g., Fig. 391), condições que são plesiomórficas dentro de Sarginae. O reconhecimento desse clado coloca alguma luz sobre o problema taxonômico de Merosargus. Com uma ampliação na amostragem de espécies, esse clado deve corresponder a Merosargus no futuro, pois inclui a espécie-tipo do gênero. 
Sua linhagem irmã, com uma redefinição, corresponderia a Acrochaeta, incluindo espécies que atualmente estão em Merosargus.

A presença de espécies de Merosargus no clado que inclui Acrochaeta corrobora o que foi comentado antes, ou seja, que Acrochaeta filogeneticamente corresponde a um grupo especializado do que atualmente se denomina Merosargus. Esse grande grupo é suportado por uma série de sinapomorfias únicas de genitália masculina (caracteres 41, estado 1; 43, estado 3; 44, estado 1; 45, estado 2 e 48, estado 2). A relação entre essas espécies que nominalmente pertecem a Merosargus, no entanto, ainda é um pouco incerta.

O posicionamento de $M$. mirabilis não chega ser uma surpresa. Essa espécie, como já comentado por Woodley (2009), compartilha muitas plesiomorfias com as espécies de outros gêneros de Sarginae (Sargus e Himantigera), além de uma genitália masculina bastante modificada. Provavelmente foi incorretamente descrita para Merosargus, mas estava além do escopo deste trabalho solucionar o problema de sua posição.

A inferência de que Merosargus não é monofilético parece ser independente da decisão sobre onde é feita a delimitação de Acrochaeta. Não apenas a presença de espécies pertencentes à Merosargus no clado que também inclui Acrochaeta tem mantido Merosargus como não-monofilético, mas também o posicionamento de $M$. mirabilis - espécie claramente excluída do clado que inclui Ptecticus, Merosargus, Acrochaeta, estando próximo da base de Sarginae.

\subsection{O posicionamento de Merosargus mirabilis}

Merosargus mirabilis é uma espécie de Merosargus bastante peculiar, sendo uma das peças chave no questionamento da monofilia e identidade de Merosargus. Provavelmente essa espécie foi descrita como Merosargus pela aparência geral (e.g., antena supostamente globosa). Essa espécie tem uma combinação distinta de características (e.g., $\mathrm{M}$ distinta em toda sua extensão, $\mathrm{R}_{2+3}$ surgindo próximo ao ápice da célula discal, projeção da caliptra ausente, porção ventral dos parâmeros fortemente projetada), o que certamente poderia garantir a criação de um novo gênero mesmo sob uma visão não filogenética. Além disso, diferentemente das espécies de Merosargus (exceto M. albifacies James \& McFadden, 1971), M. mirabilis tem um número importante de condições plesiomórficas (e.g., área medial paralela posteriormente, $\mathrm{M}_{3}$ reta, M distinta em toda a sua extensão), além algumas apormorfias (e.g., parâmero 
ventral projetado além da base do edeago) que tem sustentado essa espécie, mesmo que pelo compartilhamento dessas plesiomorfias, mais próximo de Himantigera e Sargus (i.e., externo ao clado Ptecticus + Merosargus + Acrochaeta) do que da espécie-tipo de Merosargus, corroborando o que já tinha sido comentando por Woodley (2009). Na análise com pesagem implícita (e.g., Fig. 219), no entanto, M. mirabilis aparece como irmã de um clado com todas as espécies de Merosargus e Acrochaeta.

A posição de M. mirabilis em relação a Himantigera e (Ptecticus + Merosargus + Acrochaeta) ainda não está esclarecida. Em algumas das topologias obtidas, o clado irmão de (Ptecticus + Merosargus + Acrochaeta) é Himantigera, enquanto que em outras é M. mirabilis. Na topologia gerada pela análise com pesagem implícita, a questão taxonômica fica facilitada, ainda que Merosargus continue parafilético em relação a Acrochaeta.

\subsection{Evolução do comprimento complexo flagelar}

O alongamento característico do complexo flagelar das espécies de Acrochaeta tem sido condição tradicionalmente usada como diagnóstico do gênero. A análise feita aqui mostra formalmente que essa apomorfia não é exclusiva desse táxon, sendo compartilhado por algumas espécies de Merosargus. Dois grandes clados, além de $M$. chalconota, apresentam as antenas alongadas, provavelmente modificadas a partir da condição apomórfica globular (i.e., complexo flagelar tão largo quanto longo). No primeiro grupo (M. sp. nov. $1+(M$. longiventris + Acrochaeta)), apenas em $A$. convexifrons tem a condição de antena globular. No agrupamento $(M$. picta $+(M$. bivittatus $+(M$. sp. nov. $2+($ A. degenerata $+M$. sp. nov. 3)))), há uma reversão desse caráter apenas em $M$. bivittatus, entretanto, o próprio posicionamento de $M$. bivittatus nesse clado é duvidoso. Essa espécie tem a genitália masculina e a furca genital muito semelhante a M. azureus Enderlein, 1914 e, principalmente, a M. akrei, o que poderia indicar a formação de um clado com essas três espécies.

É interessante notar que, de alguma forma, o alongamento da arista (quinto flagelômero) parece estar relacionado com o alongamento da antena como um todo. Assim, nos dois grupos com “antenas longas”, a arista é tão longa ou mais curta que o comprimento restante da antena. Nas outras espécies, a arista é, frequentemente, muito maior que o comprimento restante da antena. Ainda é difícil dizer se existe uma relação de dependência entre essas características, mas poderíamos inferir que, antenas 
alongadas (flagelômeros mais longos que largos) têm arista mais curta e antenas achatadas ou globulares (flagelômeros mais largos que longos) têm arista mais longa.

\subsection{Evolução do padrão de coloração e características associadas}

Há duas linhagens de Merosargus-M. aurivena e $M$. sp. nov. 3-que apresentam padrão de coloração do escudo similar ao das espécies de Acrochaeta. O aparecimento desse padrão de coloração nessas espécies ocorreu independemente de Acrochaeta, pois elas não integram o mesmo clado.

Esse padrão de coloração pode estar associado à evolução de mimetismo, pois a maioria das espécies de Acrochaeta são claramente miméticas as vespas da subfamília Polistinae. Isso poderia explicar porque linhagens diferentes têm padrões de coloração tão semelhantes. A evolução de outras características parece estar de alguma forma associadas com o surgimento dessa coloração nesses três grupos: elevação da parte superior da fronte (caráter 6, estado 1), coloração amarelo avermelhada das asas (caráter 20, estado 1) e algum grau de estrangulamento dos dois primeiros segmentos abdominais. Essas condições podem aparecer nessas diferentes linhagens pelo comportamento mimético dessas espécies, mas isso é ainda algo que precisa ser melhor investigado sob o ponto de vista comportamental.

\subsection{Evolução dos singonocoxitos}

Em Stratiomyidae, como foi discutido, há fusão entre os gonocoxitos e desses com o S9, formando uma estrutura denominada singonocoxito, de modo que não é possível distinguir essas placas separadamente. Entretanto, no clado das espécies de Merosargus que também inclui Acrochaeta há a presença de uma condição sinapomórfica (caráter 41, estado 1), na qual é possível notar uma linha de fusão entre o que seria originalmente os gonocoxitos (e.g., Fig. 403). Paralelamente, há a formação de uma placa medial (e.g., Fig. 27), que pode ser mais ou menos desenvolvida, entre a porção dorsal e a porção ventral do singonocoxito, resultando em uma maior separação entre essas placas, diferentemente do que é visto nos grupos externos (e.g., Fig. 381). Nas espécies de Merosargus desse clado e em parte das espécies de Acrochaeta ( $A$. adusta, A. fasciata, A. dimidiata, A. pseudopolychaeta sp. nov. e A. polychaeta sp. nov.) essa placa medial é bem desenvolvida (e.g., Fig. 27). Entretanto, em A. convexifrons e nas espécies do grupo-flaveola (com uma reversão em A. mexicana) a placa medial é 
reduzida a uma estrutura tênue (caráter 42, estado 1) (e.g., Fig. 63) responsável por manter a conexão entre a porção dorsal e ventral do singonocoxito.

O processo medial do singonocoxito (caráter 43), a porção mais distal da face ventral do singonocoxito, também tem uma evolução interessante. A distribuição do processo digitiforme (e.g., Fig. 27) no cladograma parece estar diretamente associada à presença da linha de fusão entre os gonocoxitos (exceto por uma reversão em $M$. opaliger).

A face dorsal do singonocoxito, internamente na genitália, tem duas configurações possíveis. Em uma delas (sinapomorfia do grupo-flaveola), a ponte gonocoxal é distal (e.g., Fig. 62), conectando os gonocoxitos ao longo da sua margem distal, com o par de apódemas gonocoxais fortemente desenvolvidos e projetados ventralmente. Na outra (plesiomorfia), a ponte gonocoxal ocupa uma posição mais basal na genitália (e.g., Fig. 26).

\subsection{Evolução do número de lóbulos do edeago}

Na análise aqui realizada foi observada uma variação bastante grande no número de lóbulos do edeago, condição esperada para a família (Nagatomi 1984). Em Acrochaeta, o edeago é trífido no plano-básico (e.g., Fig. 26) (assim como nas espécies de Merosargus do clado que inclui Acrochaeta), mas há uma importante modificação (redução) para edeago simples (i.e., um lóbulo) (e.g., Fig. 69) no clado (A. convexifrons + grupo-flaveola). O surgimento de edeago simples (um único lóbulo) também aconteceu independentemente em Ptecticus (e.g., Fig. 416).

A passagem de edeago trífido para edeago bifído aconteceu, pelo menos, duas vezes independentemente: uma vez em Sargus (e.g., Fig. 408) e uma vez em Merosargus (e.g., Fig. 363).

\subsection{Evolução do formato da parte anterior e do tamanho da abertura genital na furca genital}

O formato cilíndrico da parte anterior da furca genital (caráter 63, estado 1) (e.g., Fig. 73) é uma condição única do grupo-flaveola, característica que talvez possa estar relacionada com o tamanho da abertura genital.

A evolução do tamanho da abertura genital feminina não foi formalmente abordado na análise. Diferentes espécies não proximamente relacionadas apresentam condição bastante semelhante (e.g., Merosargus elatus Curran, 1932, Fig. 462; M. 
longiventris, Fig. 470), o que poderia gerar um ruído desnecessário na análise. A condição no grupo-flaveola (i.e., formato circular e extremamente reduzido, quando comparado com a abertura da furca em outras espécies) (e.g. 73), no entanto, aparenta ser única no grupo. É possível que essa estrutura, assim como o formato cilíndrico da parte anterior da furca, seja uma apomorfia para o grupo-flaveola,

\subsection{Considerações sobre as árvores obtidas com pesagem implícita}

As análises com pesagem implícita recuperaram árvores bem semelhantes àquela obtida por meio da pesagem igual. Dentre as diferenças, destacam-se: a resolução da politomia entre M. mirabilis, Himantigera e o restante de Sarginae (e.g., Fig. 219), o posicionamento de $M$. chalconota (na maioria das vezes como irmã de todas as outras espécies de Merosargus + Acrochaeta, exceto M. mirabilis) (e.g., Fig. 219) e a resolução entre as espécies que compõem o grupo-flaveola (e.g., Fig. 219). Acrochaeta, assim como o grupo-flaveola, é monofilético em todas as hipóteses (Figs. 219-231).

O grupo-irmão de Acrochaeta varia bastante entre as diferentes hipóteses. Em boa parte delas, $M$. sp. nov. 2 é irmã de Acrochaeta e $M$. longiventris é irmã desse clado (e.g., Fig. 219). A situação do cladograma da figura 217 (pesagem igual), com $M$. longiventris como irmã de Acrochaeta, aparece em duas das hipóteses com pesagem implícita (e.g., Fig. 222). Em outra (e.g., Fig. 220), Acrochaeta é recuperada como um grupo-irmã de todas as espécies de Merosargus anteriormente proximamente relacionadas ao gênero. Ainda que exista algum nível de incerteza com relação ao clado ou a espécie mais proximamente relacionada à Acrochaeta, a opção por delimitar Acrochaeta a partir de A. asapha sp. nov., neste momento, parece a escolha mais adequada, pois esse clado corresponde a um grupo recuperado em todas as árvores.

Por fim, merece destaque o possível impacto da informação faltante em espécies conhecidas apenas por fêmeas. Em linhas gerais, todos essas espécies (M. chalconota, M. sp. nov. 1, M. sp. nov. 2 e A. flaveola) sofreram modificações de posicionamento quando comparado com o cladograma da figura 218 (e.g., Fig. 219), exceção feita a $A$. degenerata e A. asapha sp.nov. Mesmo entre as árvores com pesagem implícita, houve modificações de posicionamento entre algumas dessas espécies, com destaque para $M$. chalconota, $M$. sp. nov. 1 e M. sp. nov. 2.

\section{CONSIDERAÇÕES FINAIS}


O presente trabalho contribuiu em diversos aspectos para a taxonomia e sistemática de Acrochaeta, além de avançar na compreensão das relações entre as espécies de Merosargus e dessas com Acrochaeta. Alguns desses pontos são destacados abaixo.

(1) Redescrição de Acrochaeta e revisão das espécies que compõem o gênero, incluindo as novas, de modo que agora o gênero Acrochaeta é composto por 15 espécies. Todas as descrições foram padronizadas, com o uso sistematizado de características de importância filogenética.

(2) Grande quantidade de ilustrações (e.g., antenas, genitálias masculinas e femininas), incluindo fotografias de habitus, tórax em vista dorsal, asa e álula é adicionada a todas as espécies de Acrochaeta, e também para todas as espécies utilizadas da análise como terminais.

(3) Preparação de uma chave dicotômica para todas as espécies de Acrochaeta.

(4) Definições de novas combinações a partir do estabelecimento dos limites de Acrochaeta, transferindo algumas espécies para o gênero e transferindo algumas espécies para Merosargus. O estudo detalhado da mofologia da genitália masculina foi ponto fundamental nesse processo.

(5) Uma matriz com 63 caracteres e 45 táxons terminais, permitindo a primeira análise cladística do gênero Acrochaeta, incluindo um esforço formal em posicionar o gênero entre os Sarginae sob o ponto de vista filogenético.

(6) Corroboração da monofilia de Acrochaeta com a formulação de uma primeira hipótese filogenética de relacionamento entre as espécies do gênero.

(7) Acrochaeta como um subgupo de Merosargus, também demonstrando que Merosargus é parafilético em relação a Acrochaeta. 
(8) Estudo da evolução de algumas características importantes em Sarginae, especialmente em Merosargus e Acrochaeta. 


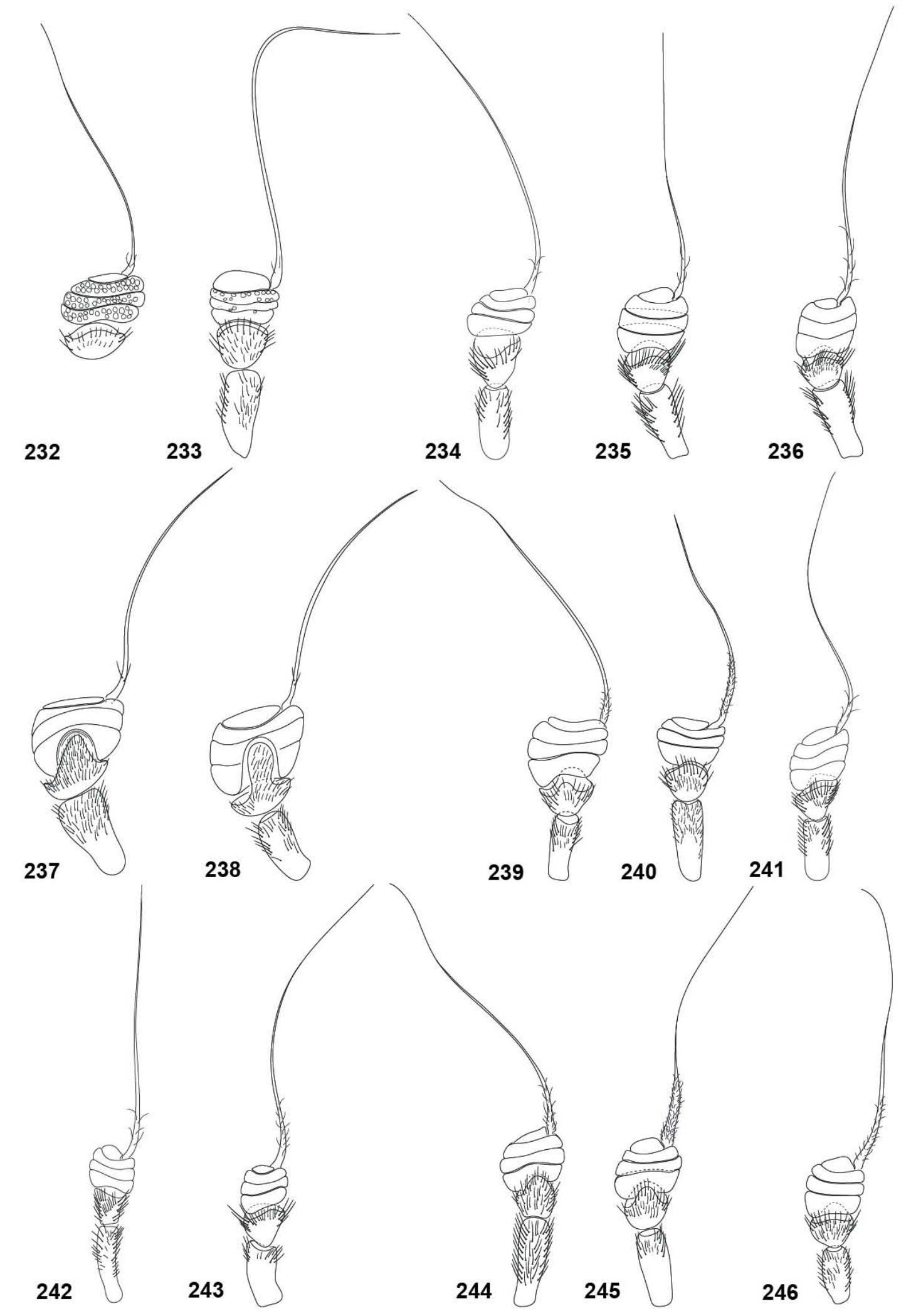

Figuras 232-246. Antenas dos grupos extemos. 232. Sargus fasciatus. 233. S. thoracicus. 234. Merosargus mirabilis. 235. Himantigera nigrifemorata. 236. H. silvestris. 237. Ptecticus lanei. 238. P. testaceus. 239. M. akrei. 240. M. azureus. 241. M. aurivena. 242. M. hyalopterus. 243. M. coriaceus. 244. M. obsaurus. 245. M. taeniatus. 246. M. nebulifer. 


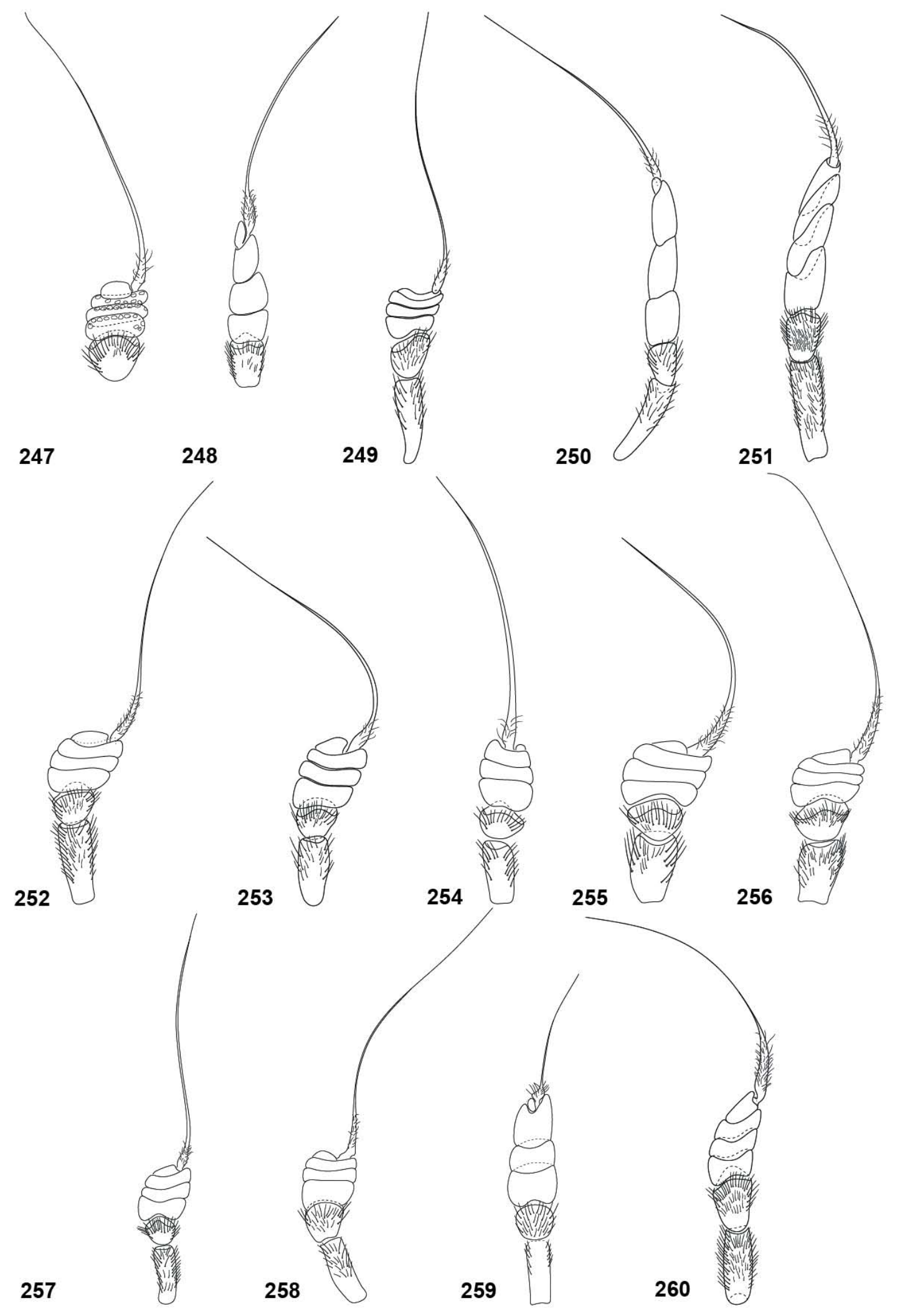

Figuras 247-260. Antenas dos grupos externos. 247. Merosargus festivus. 248. M. picta, comb. nov. 249. M. bivittatus. 250. M. sp. nov. 2. 251. M. sp. nov. 3. 252. M. elatus. 253. M. albopictus. 254. M. barbatus. 255. M. beameri. 256. M. cingulatus. 257. M. lampronotus. 258. M. opaliger. 259. M. sp. nov. 1. 260. M. longiventris, comb. nov. 

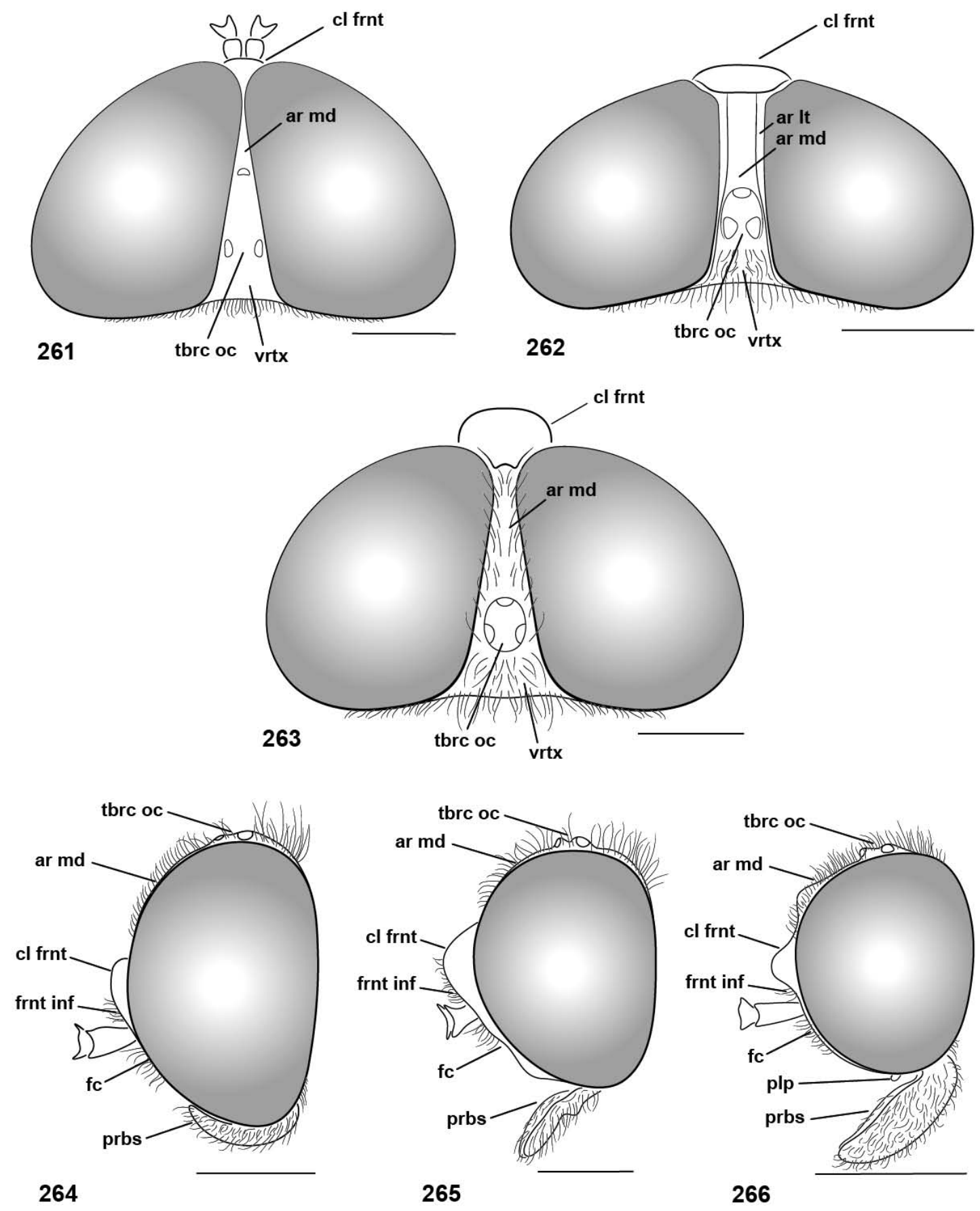

Figuras 259-266. Cabeça dos grupos externos (261, 262, 263, em vista dorsal; 264, 265, 266, em vista lateral). 261. Sargus fasciatus. 262, 264. Himantigera silvestris. 263, 265. Ptecticus testaceus. 266. Merosargus azureus. Escala, $1 \mathrm{~mm}$. 


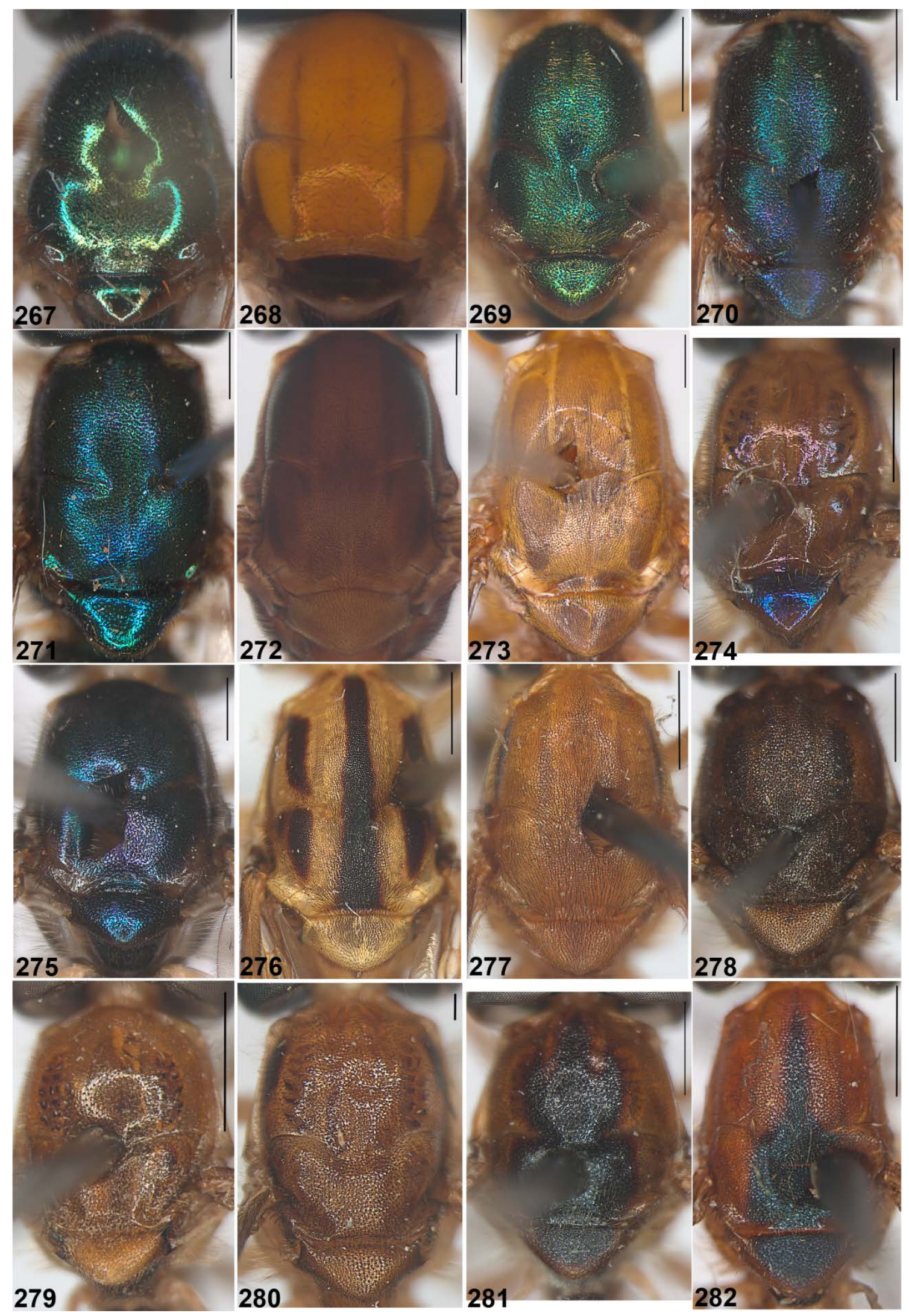

Figuras 267-282 Escudo em vista dorsal dos grupos extemos. 267. Sargus fasciatus. 268. S. thoracicus. 269. Merosargus mirabilis. 270. Himantigera nigrifemorata. 271. H. silvestris. 272. Ptecticus lanei. 273. P. testaceus. 274. M. akrei. 275. M. azureus. 276. M. aurivena. 277. M. hyalopterus. 278. M. obscurus. 279. M. taeniatus. 280. M. nebulifer. 281. M. festivus. 282. M. picta, comb. nov.Escala, $1 \mathrm{~mm}$. 


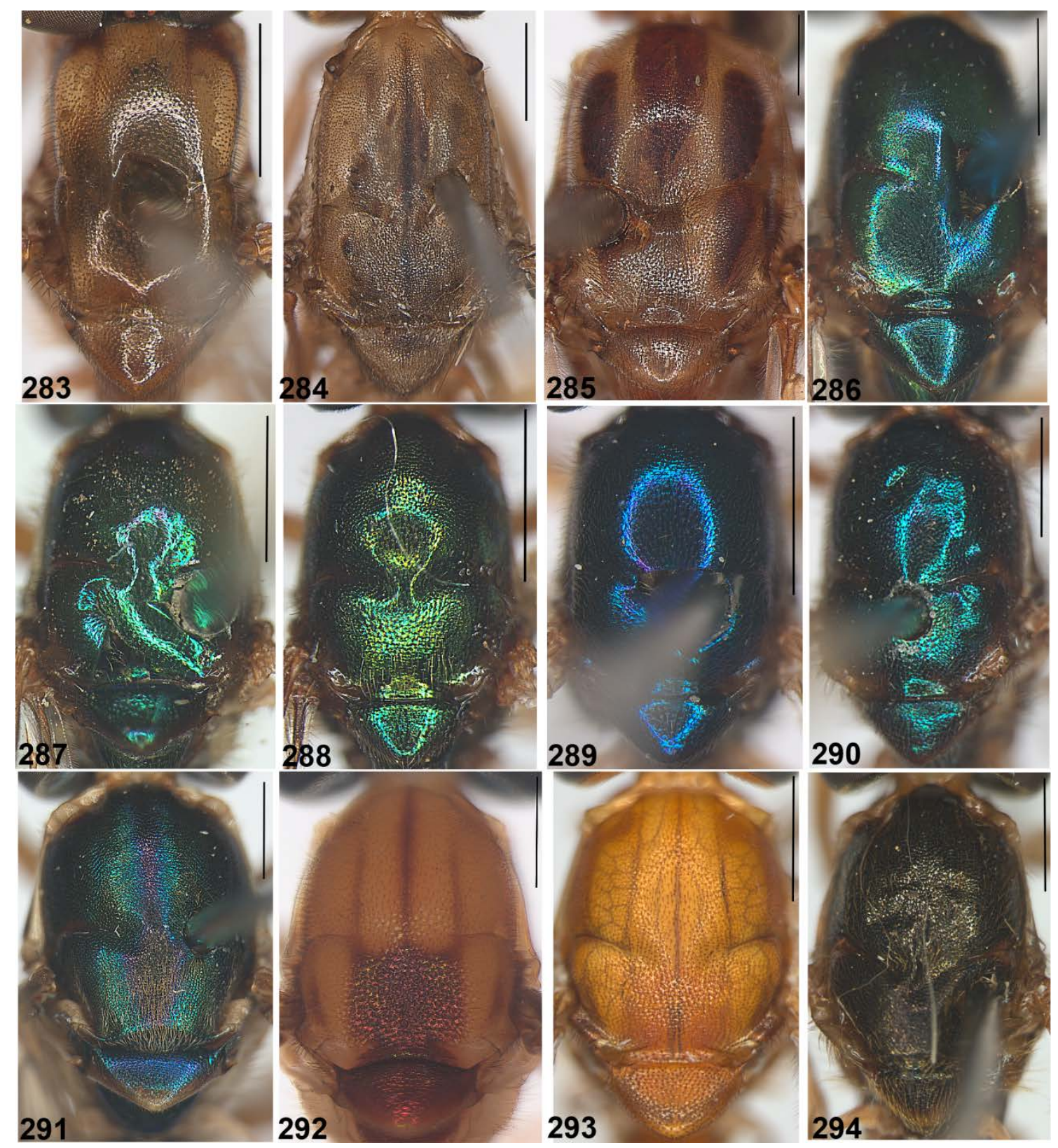

Figuras 283-294. Escudo em vista dorsal dos grupos externos. 283. Merosargus bivittatus. 284. M. sp. nov. 2. 285. M. sp. nov. 3. 286. M. elatus. 287. M. albopictus. 288. M. barbatus. 289. M. beameri. 290. M. cingulatus. 291. M. lampronotus. 292. M. opaliger. 293. M. sp. nov. 1. 294. M. longiventris, comb. nov. Escala, $1 \mathrm{~mm}$. 


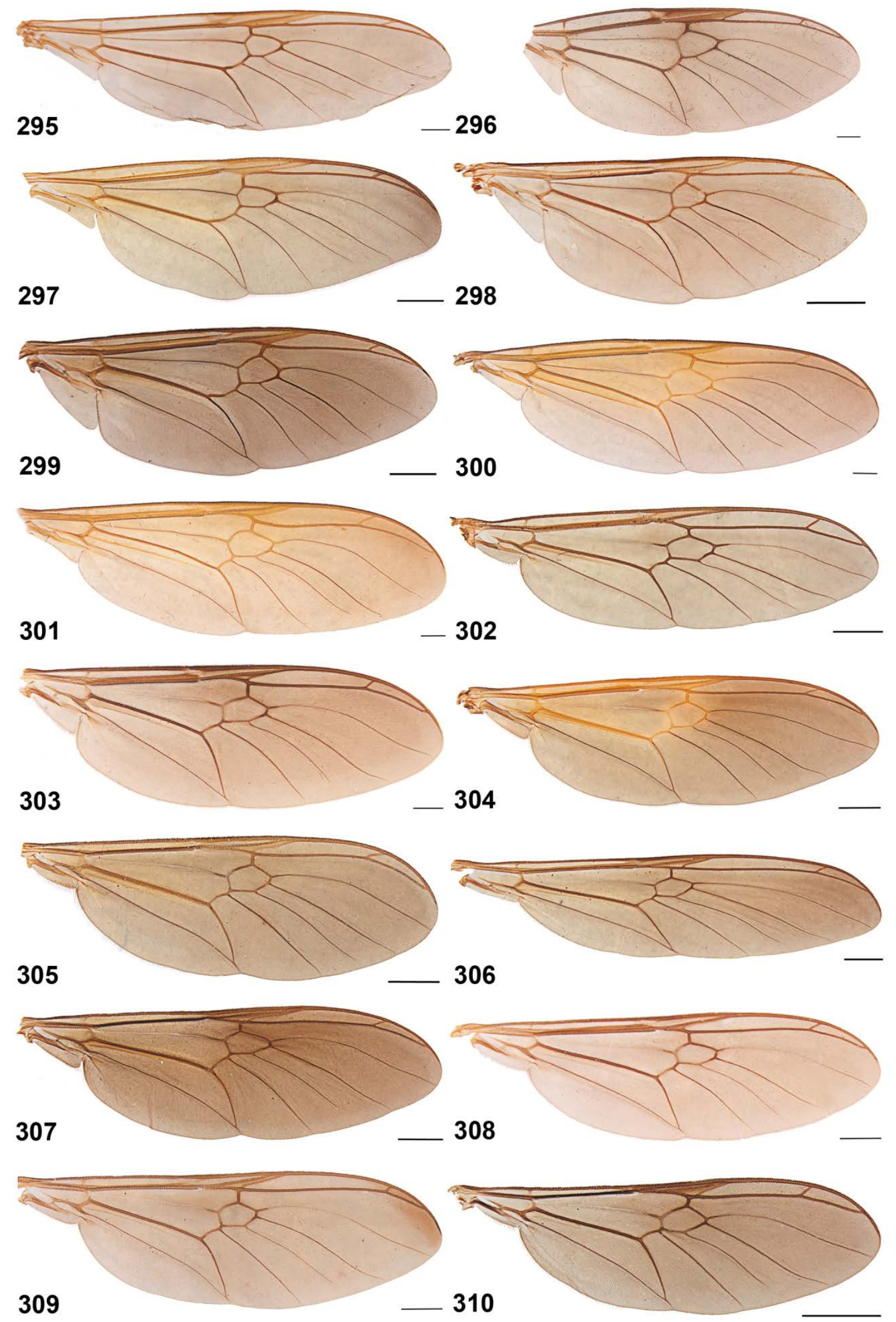

Figuras 295-310. Asas dos gnupos extemos. 295. S. fasciatus. 296. S. thoracicus. 297. M. mirabilis. 298. H. nigrifemorata.

299. H. silvestris. 300. P. lanei. 301. P. testaceus. 302. M. akrei. 303. M. azureus. 304. M. aurivena. 305. M. hyalopterus. 306. M. coriaceus. 307. M. obscurus. 308. M. taeniatus. 309. M. nebulifer. 310. M. festivus. Escala, $1 \mathrm{~mm}$. 

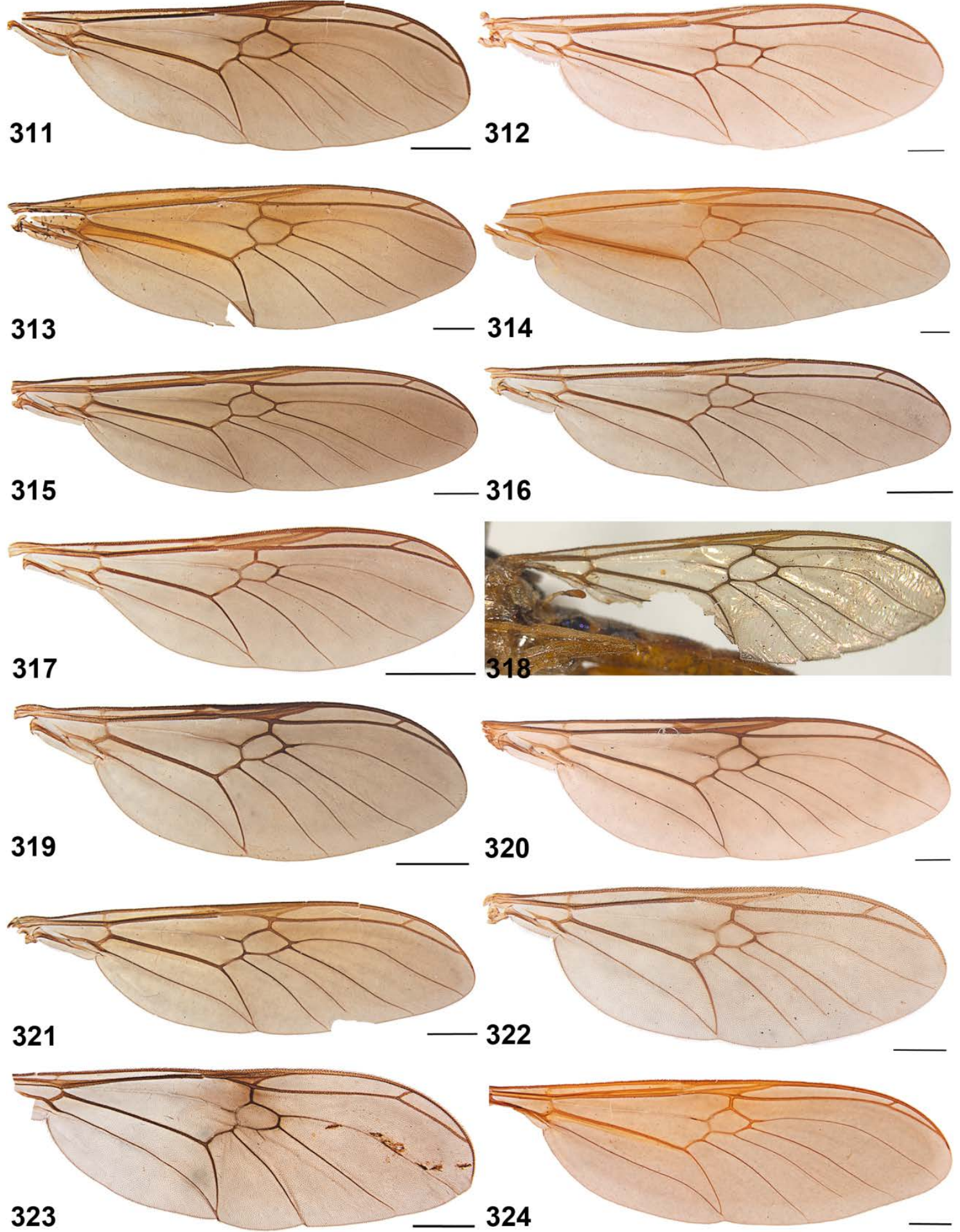

Figuras 311-324. Asas dos grupos externos. 311. Merosargus picta, comb. nov. 312. M. bivittatus. 313. M. sp. nov. 2. 314. M. sp. nov. 3. 315. M. elatus. 316. M. albopictus. 317. M. barbatus. 318. M. chalconota, comb. nov. 319. M. beameri. 320. M. cingulatus. 321. M. lampronotus. 322. M. opaliger. 323. M. sp. nov. 1. 324. M. longiventris, comb. nov. Escala, 1 $\mathrm{mm}$. 


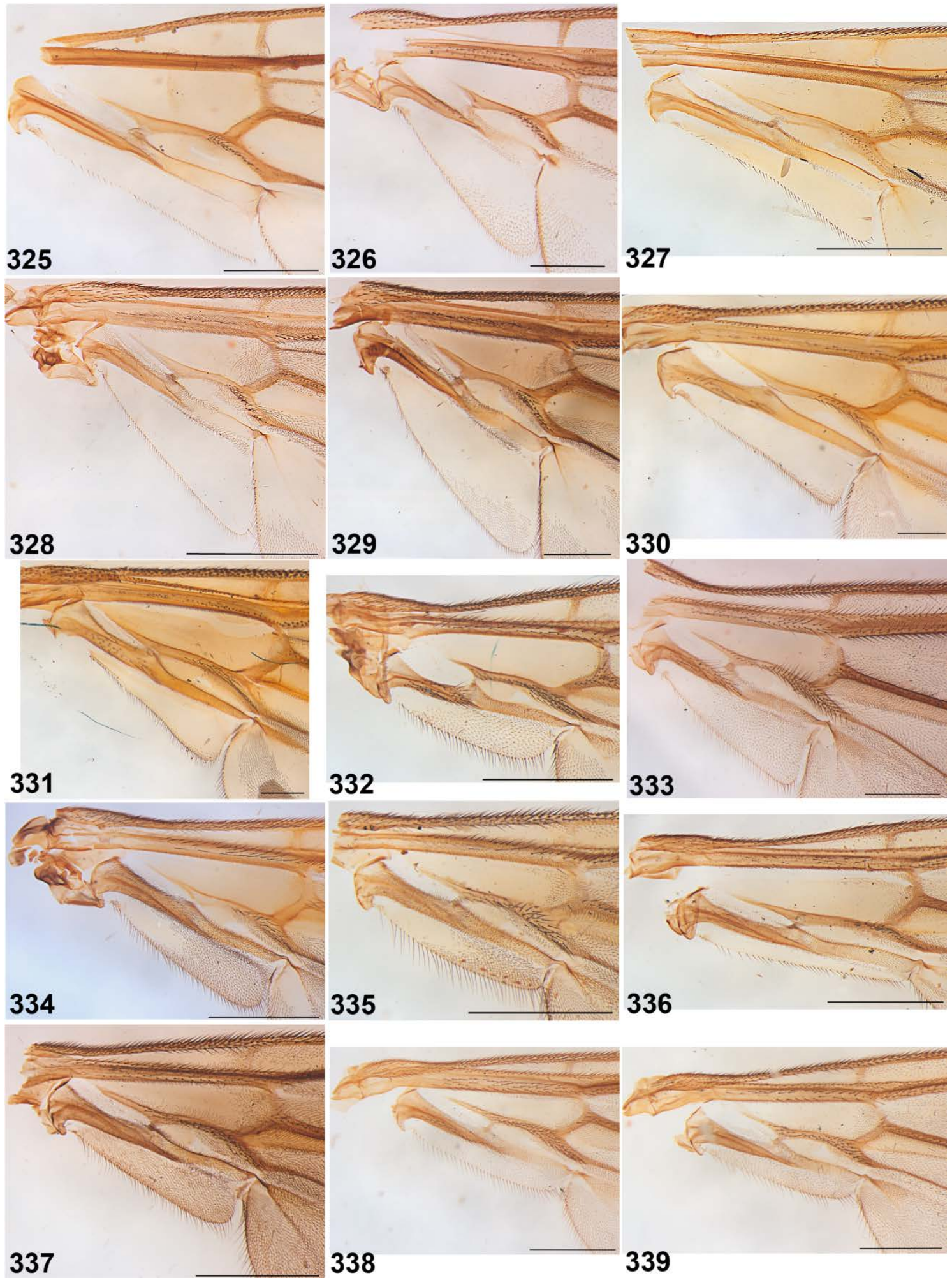

Figuras 325-339. Álulas dos grupos externos. 325. Sargus fasciatus. 326. S. thoracicus. 327. Merosargus mirabilis. 328. Himantigera nigrifemorata. 329. H. silvestris. 330. Ptecticus lanei. 331. P. testaceus. 332. M. akrei. 333. M. azureus. 334. M. aurivena. 335. M. hyalopterus. 336. M. coriaceus. 337. M. obscurus. 338. M. taeniatus. 339. M. nebulifer. Escala, 0.5 mm. 


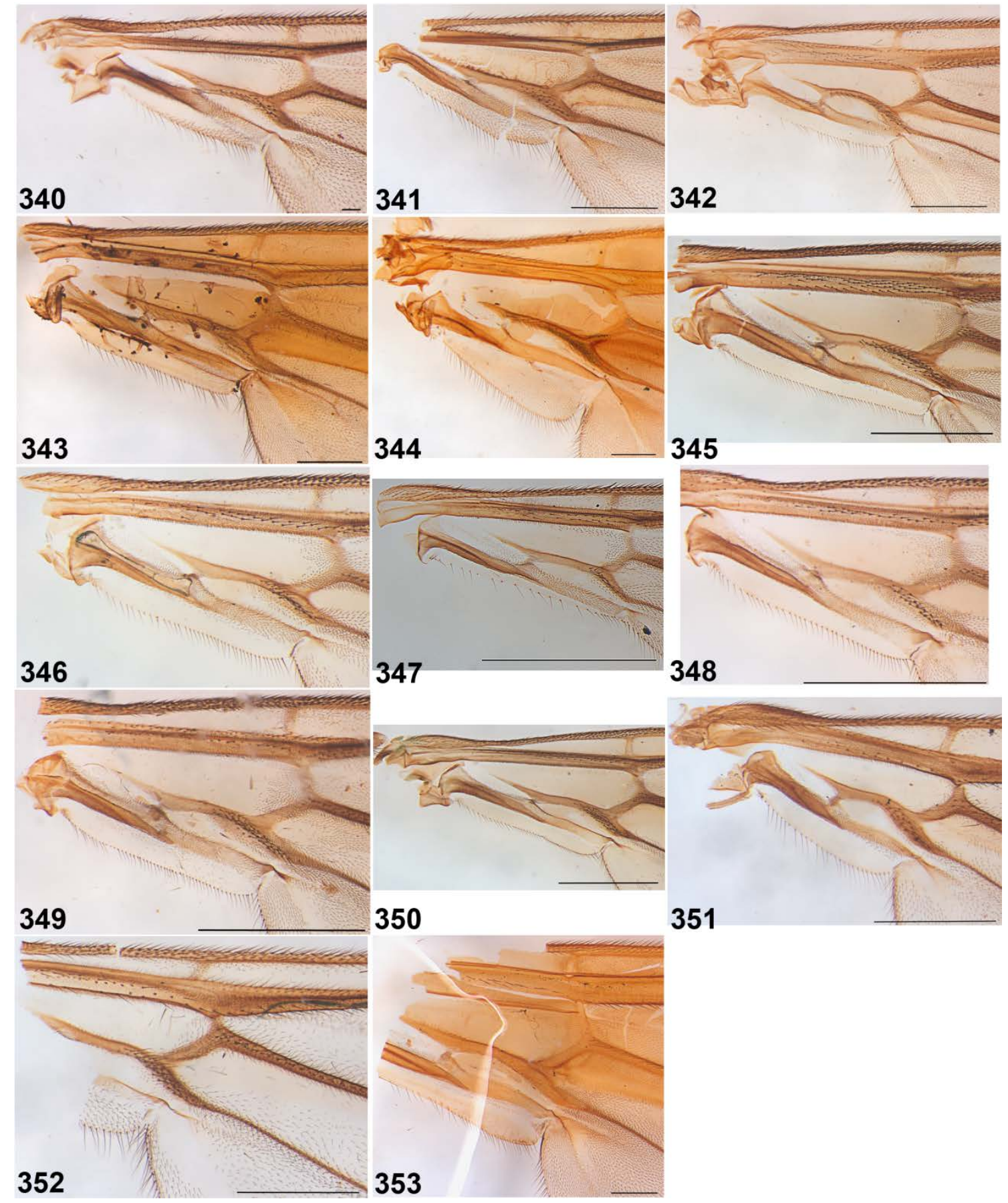

Figuras 340-353. Álulas dos grupos externos. 340. Merosargus festivus. 341. M. picta, comb. nov. 342. M. bivittatus. 343. M. sp. nov. 2. 344. M. sp. nov. 3. 345. M. elatus. 346. $M$. albopictus. 347. M. barbatus. 348. M. beameri. 349. M. cingulatus. 350. M. lampronotus. 351. M. opaliger. 352. M. sp. nov. 1. 353. M. longiventris, comb. nov. Escala, $0.5 \mathrm{~mm}$. 

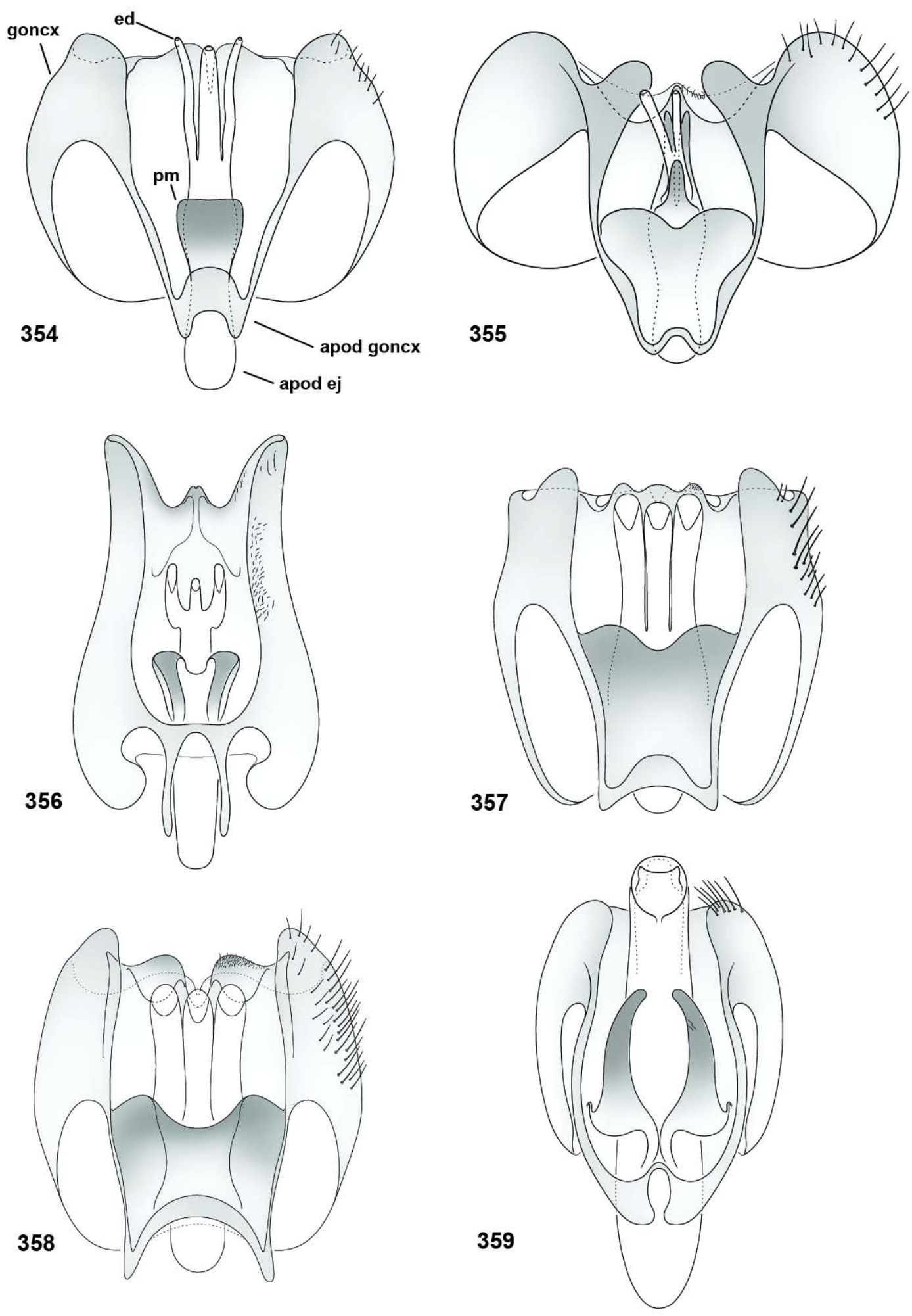

Figuras 354-359. Genitálias masculinas dos grupos externos em vista dorsal. 354. Sargus fasciatus. 355. S. thoracicus. 356. Merosargus mirabilis. 357. Himantigera nigrifemorata. 358. H. silvestris. 359. Ptecticus lanei. 

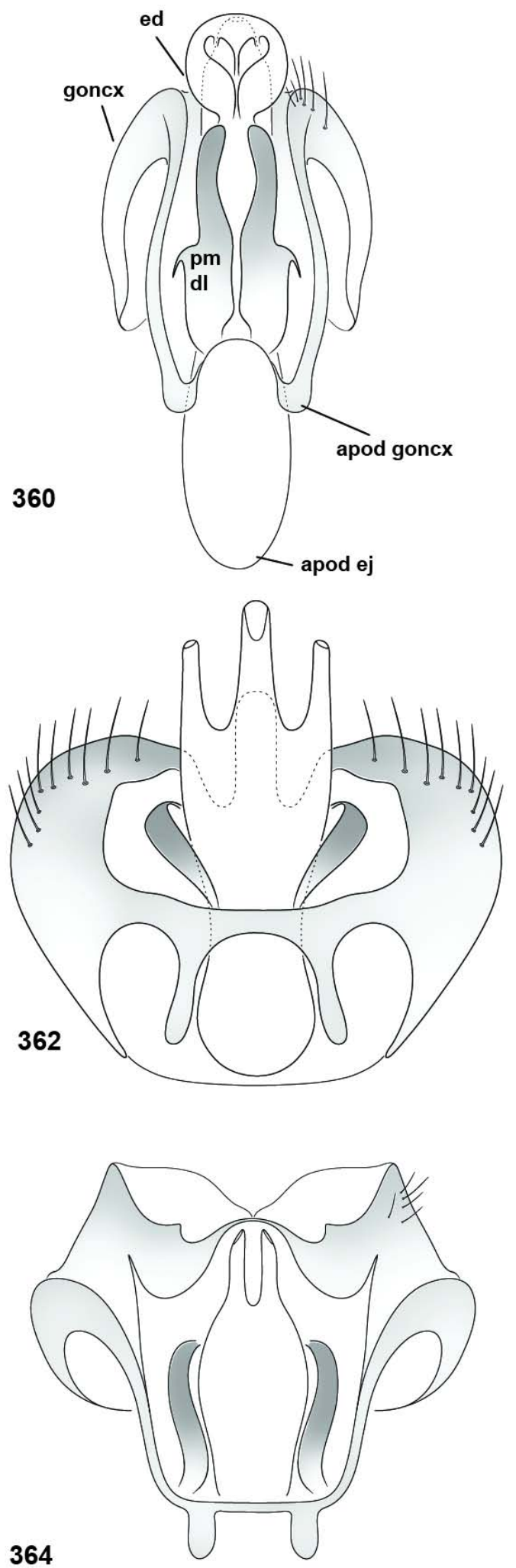
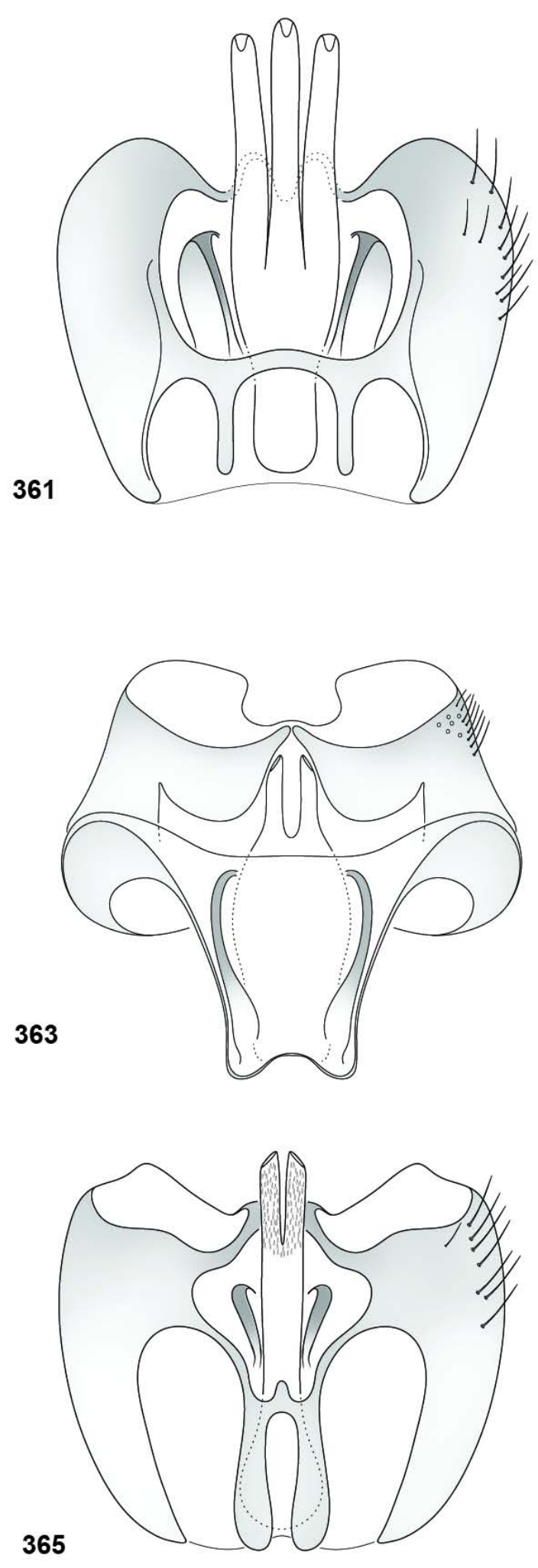

Figuras 360-365. Genitálias masculinas dos grupos externos em vista dorsal. 360. Ptecticus testaceus. 361. Merosargus akrei. 362. M. azureus. 363. M. aurivena. 364. M. hyalopterus. 365. M. coriaceus. 

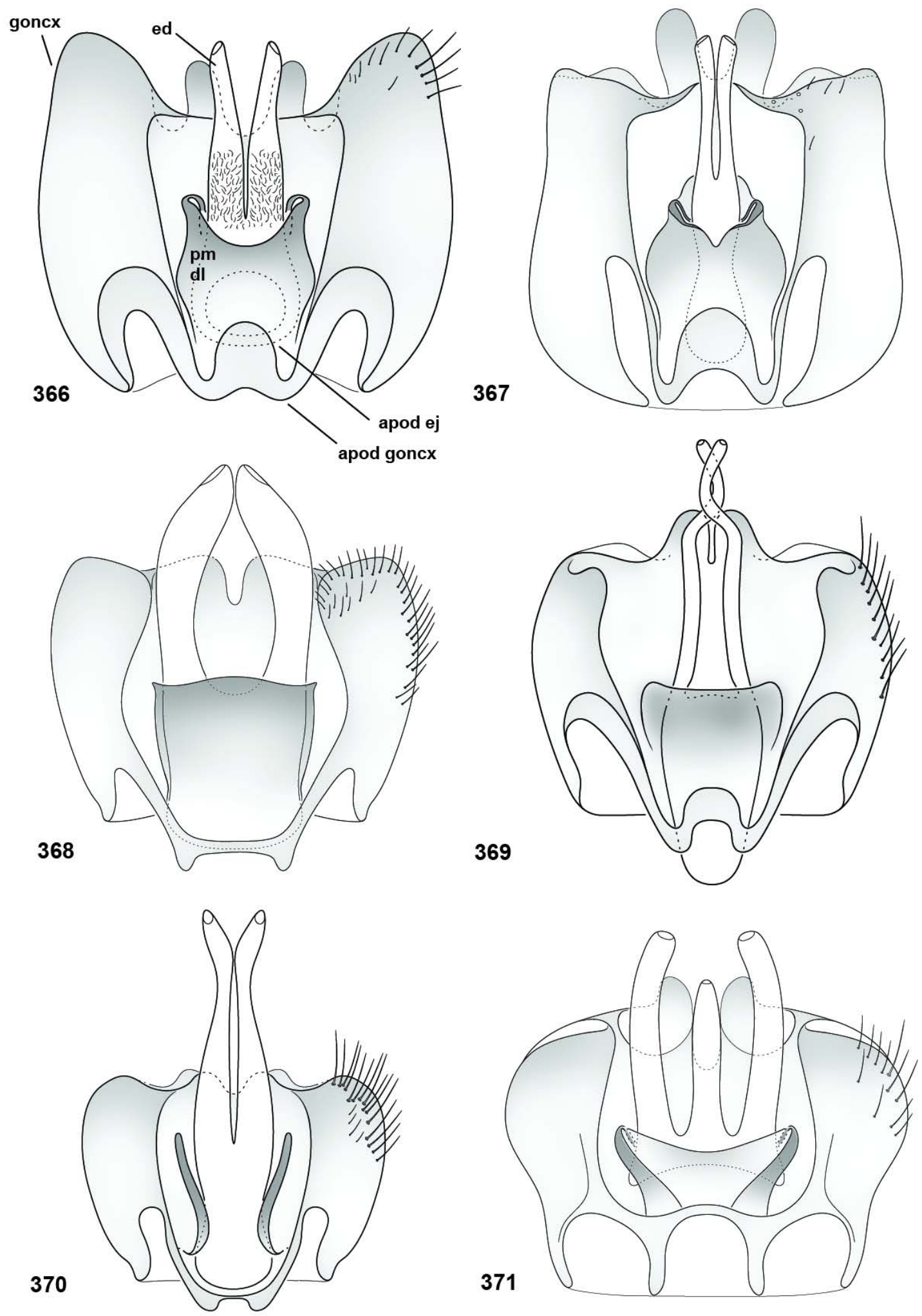

Figuras 366-371. Genitálias masculinas dos grupos externos em vista dorsal. 366. Merosargus obscurus. 367. M. taeniatus. 368. M. nebulifer. 369. M. festivus. 370. M. picta, comb. nov. 371. M. bivittatus. 

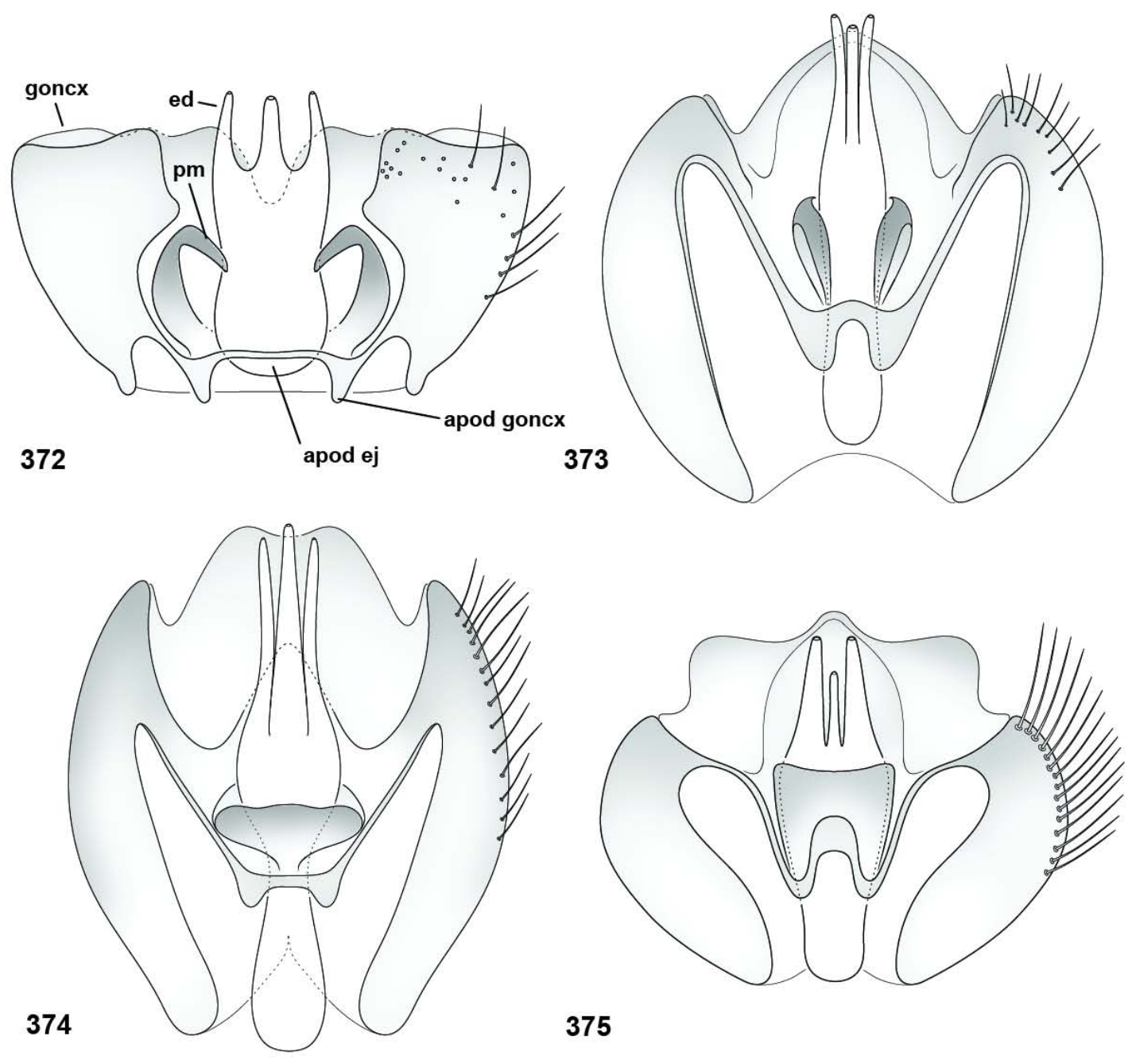

375
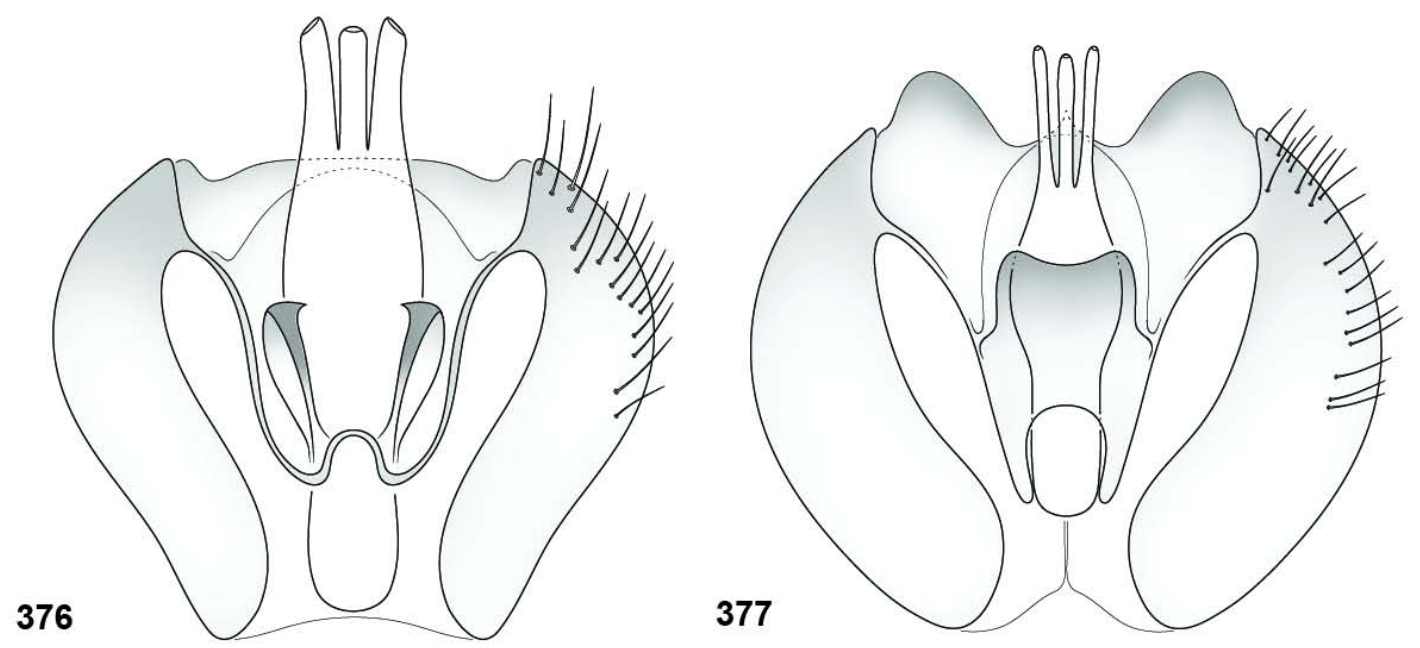

Figuras 372-377. Genitálias masculinas dos grupos externos em vista dorsal. 372. Merosargus sp. nov. 3. 373. M. elatus. 374. M. albopictus. 375. M. barbatus. 376. M. beameri. 377. M. cingulatus. 

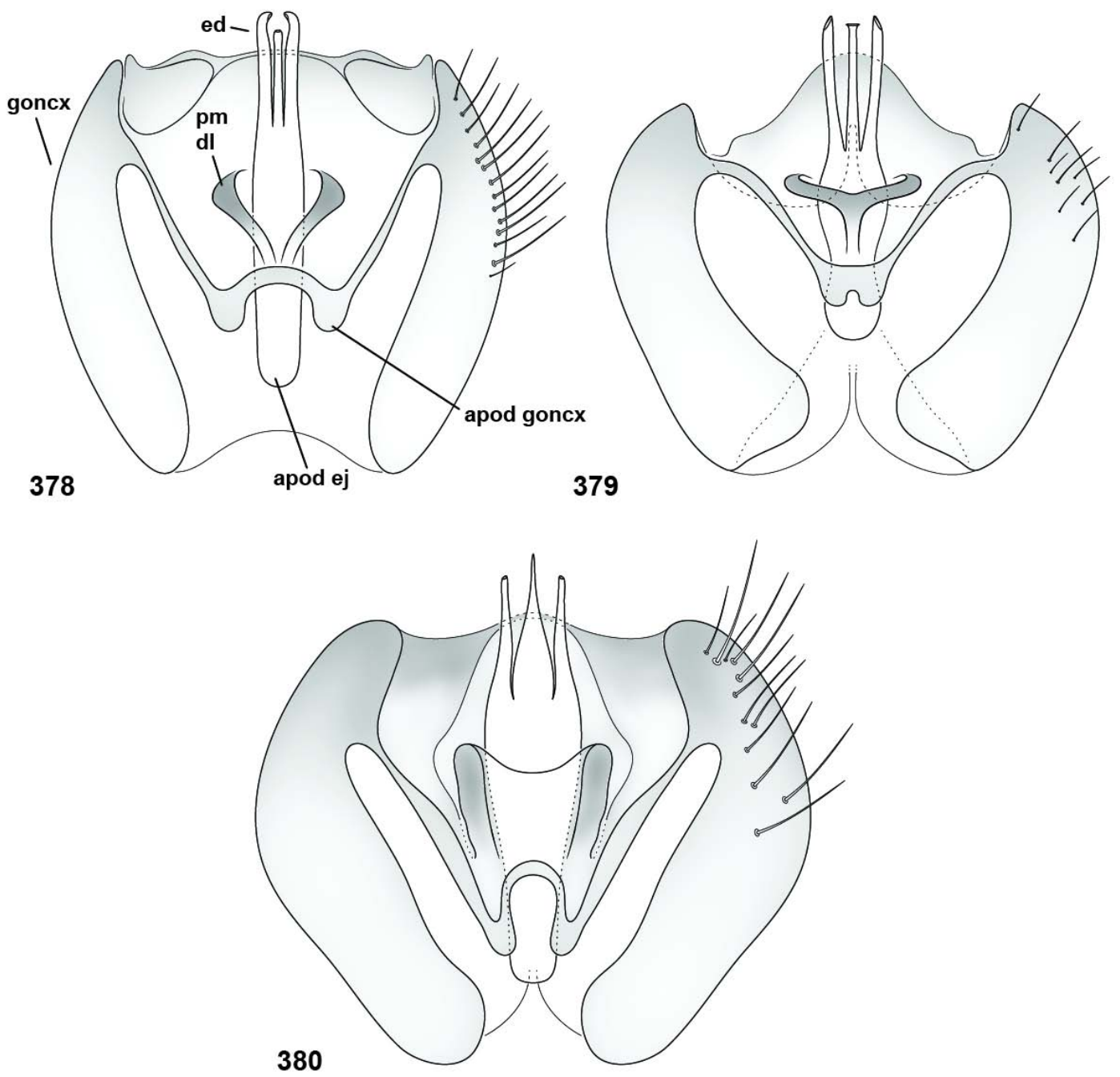

Figuras 378-380. Genitálias masculinas dos grupos externos em vista dorsal. 378. Merosargus lampronotus. 379. M. opaliger. 380. M. longiventris, comb. nov. 

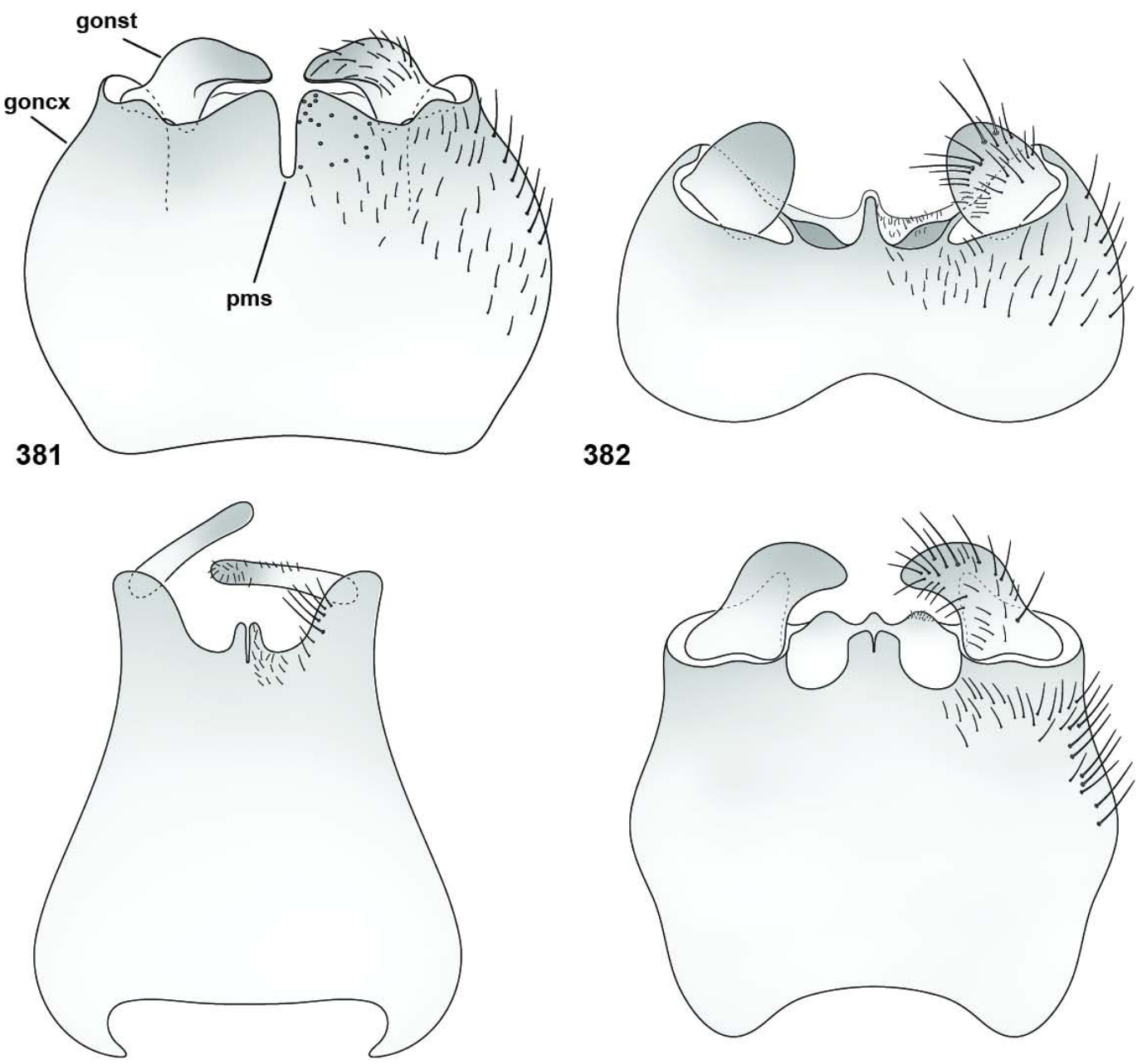

382

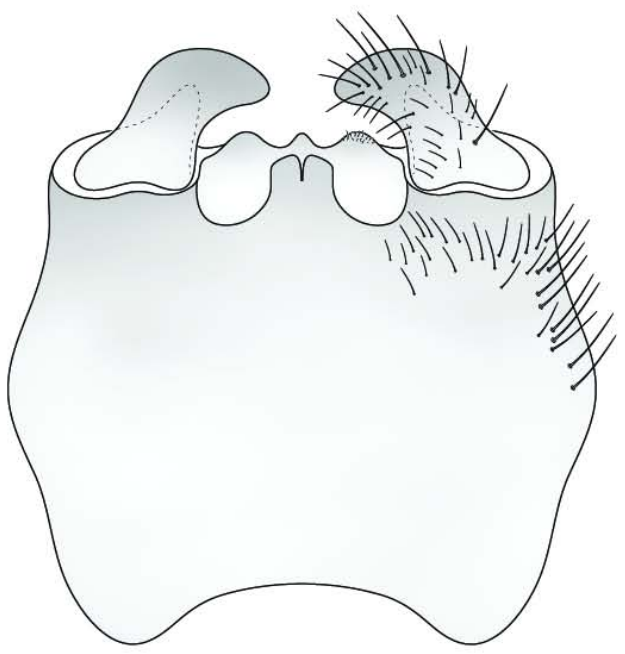

383

384
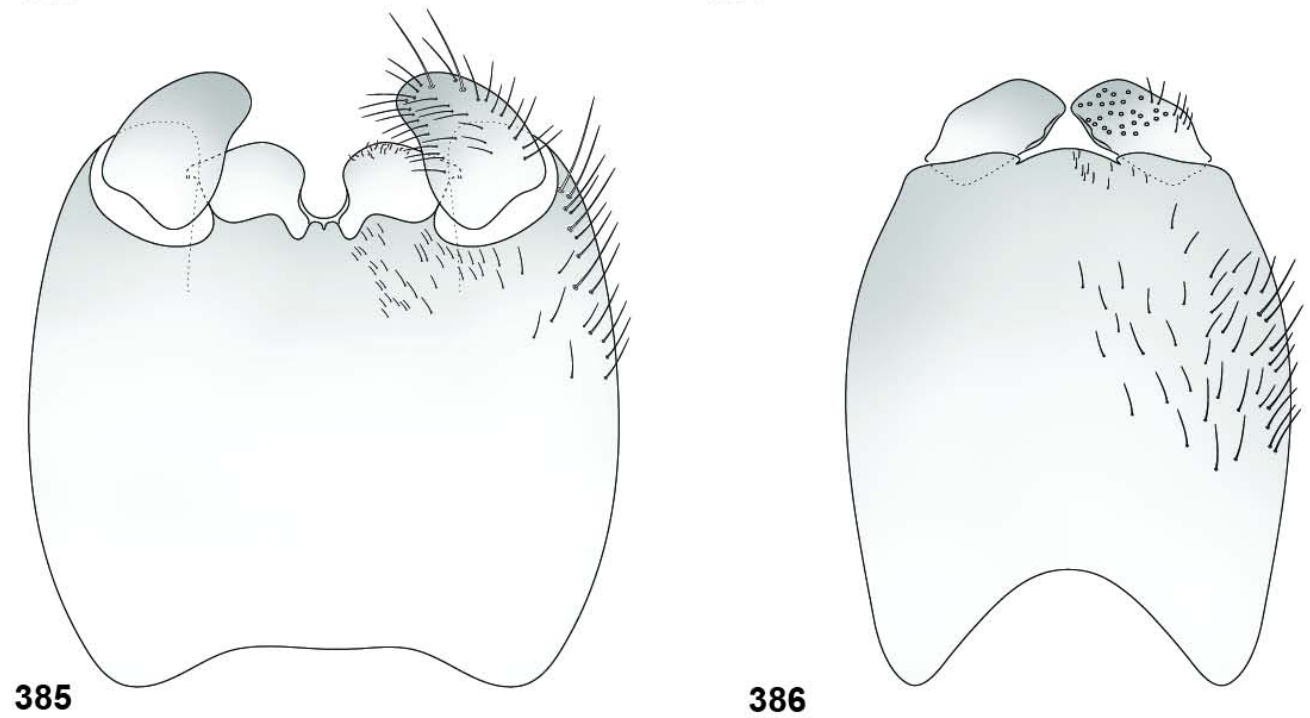

Figuras 381-386. Genitálias masculinas dos grupos externos em vista ventral. 381. Sargus fasciatus. 382. S. thoracicus. 383. Merosargus mirabilis. 384. Himantigera nigrifemorata. 385. H. silvestris. 386. Ptecticus lanei. 


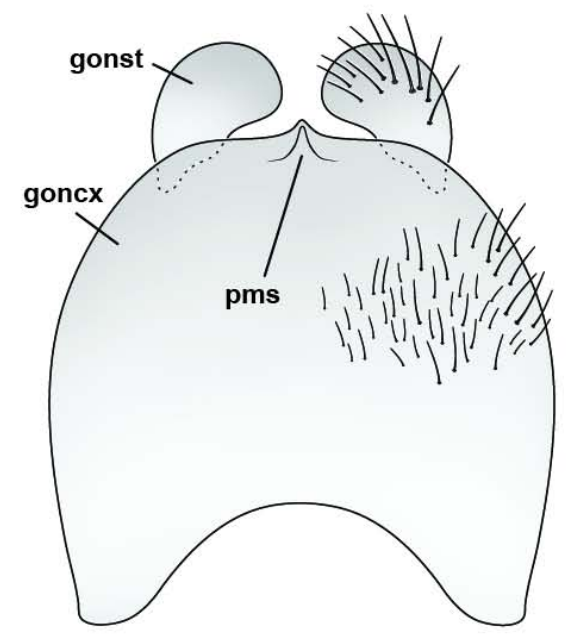

387

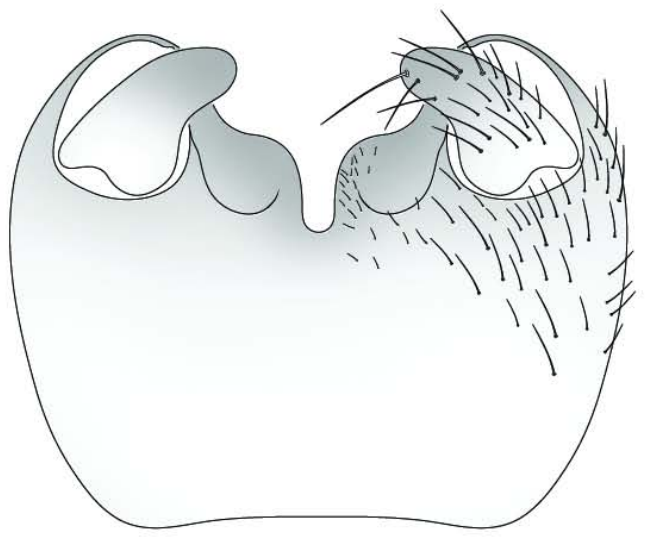

389
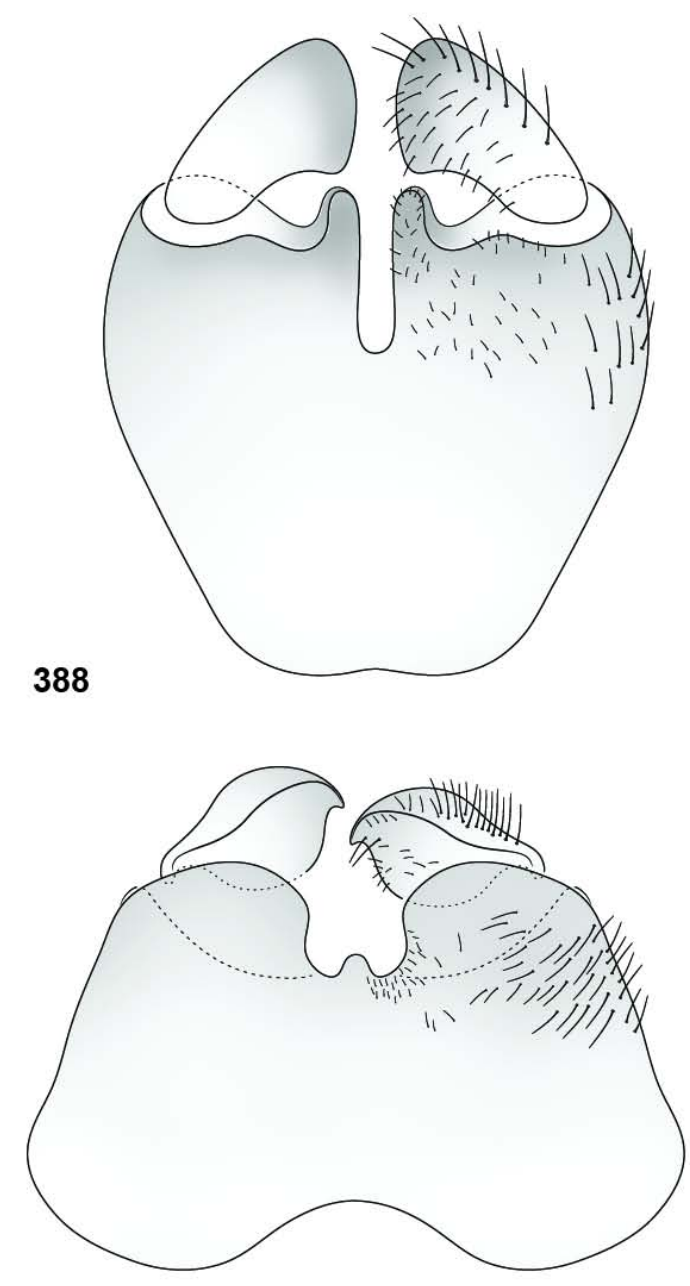

390

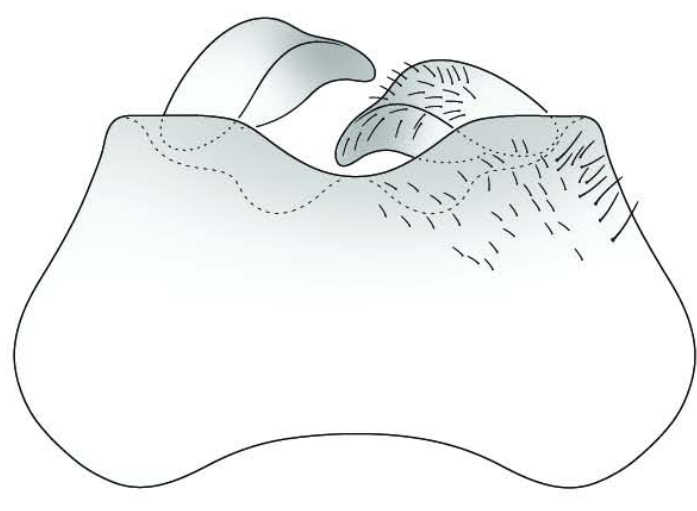

391

392

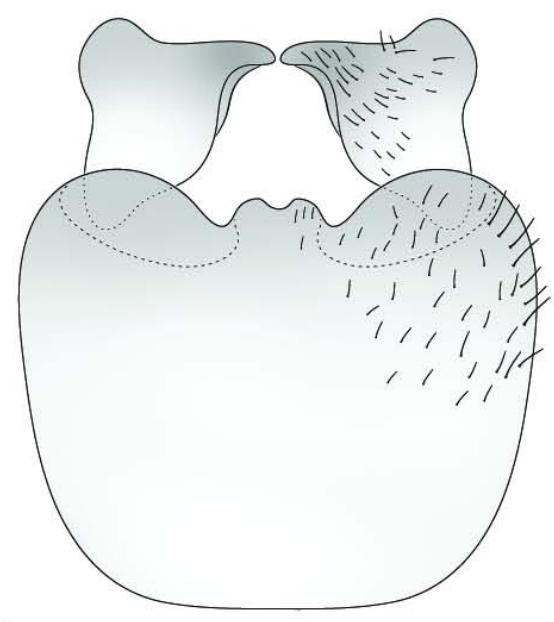

Figuras 387-392. Genitálias masculinas dos grupos externos em vista ventral. 387. Ptecticus testaceus. 388. Merosargus akrei. 389. M. azureus. 390. M. aurivena. 391. M. hyalopterus. 392. M. coriaceus. 

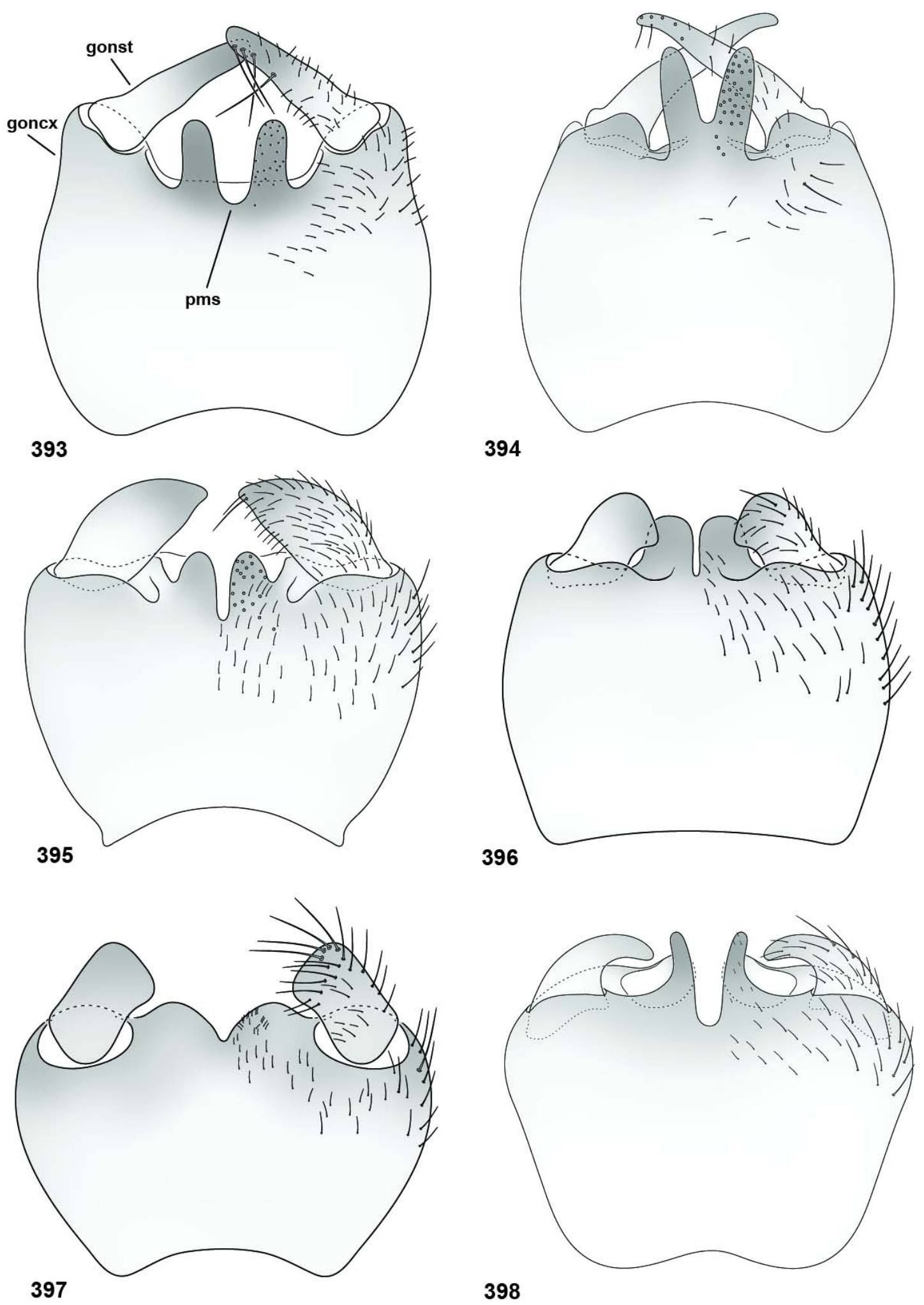

Figuras 393-398. Genitálias masculinas dos grupos externos em vista ventral. 393. Merosargus obscurus. 394. M. taeniatus. 395. M. nebulifer. 396. M. festivus. 397. M. picta, comb. nov. 398. M. bivittatus. 

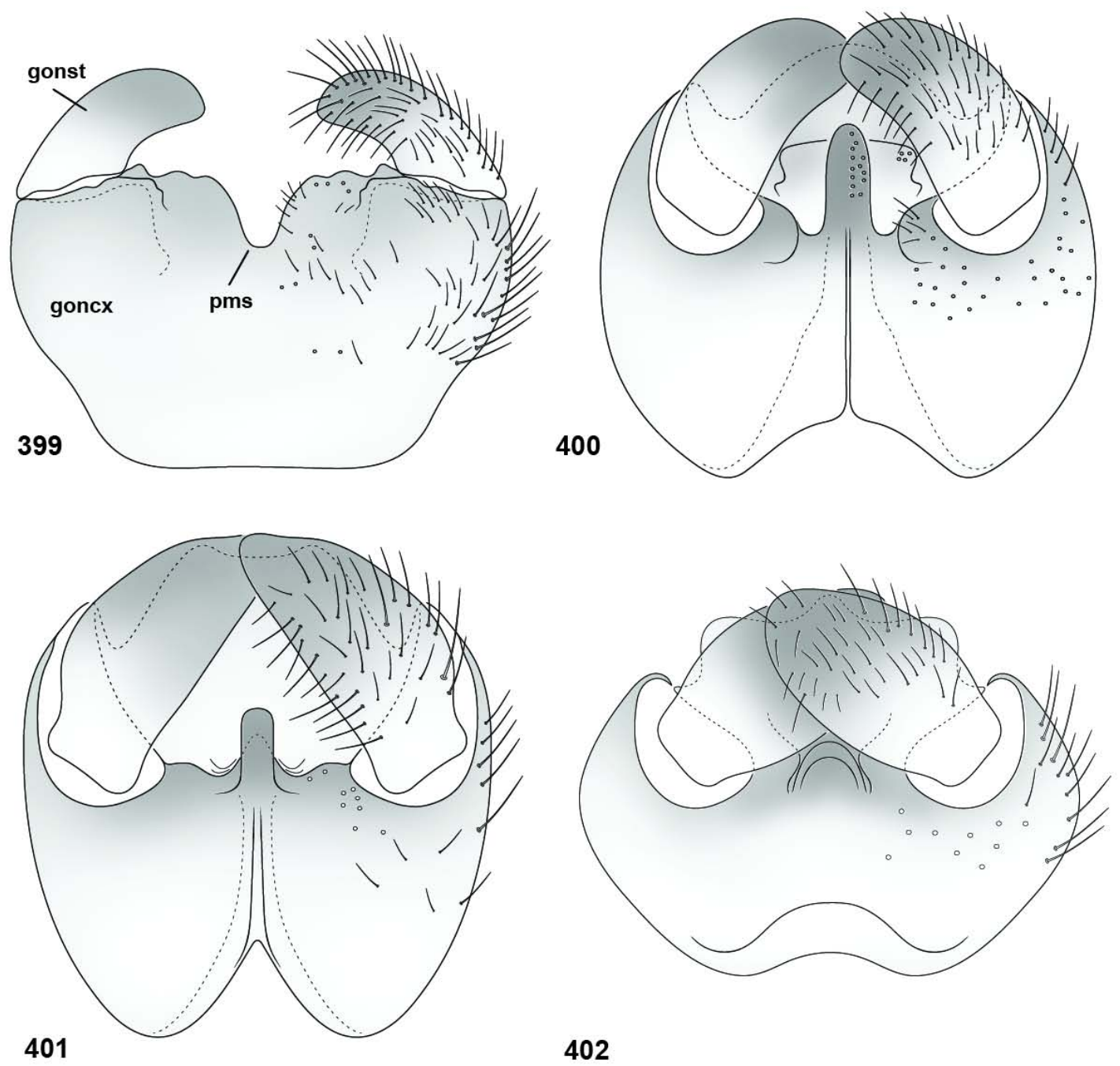

401

402
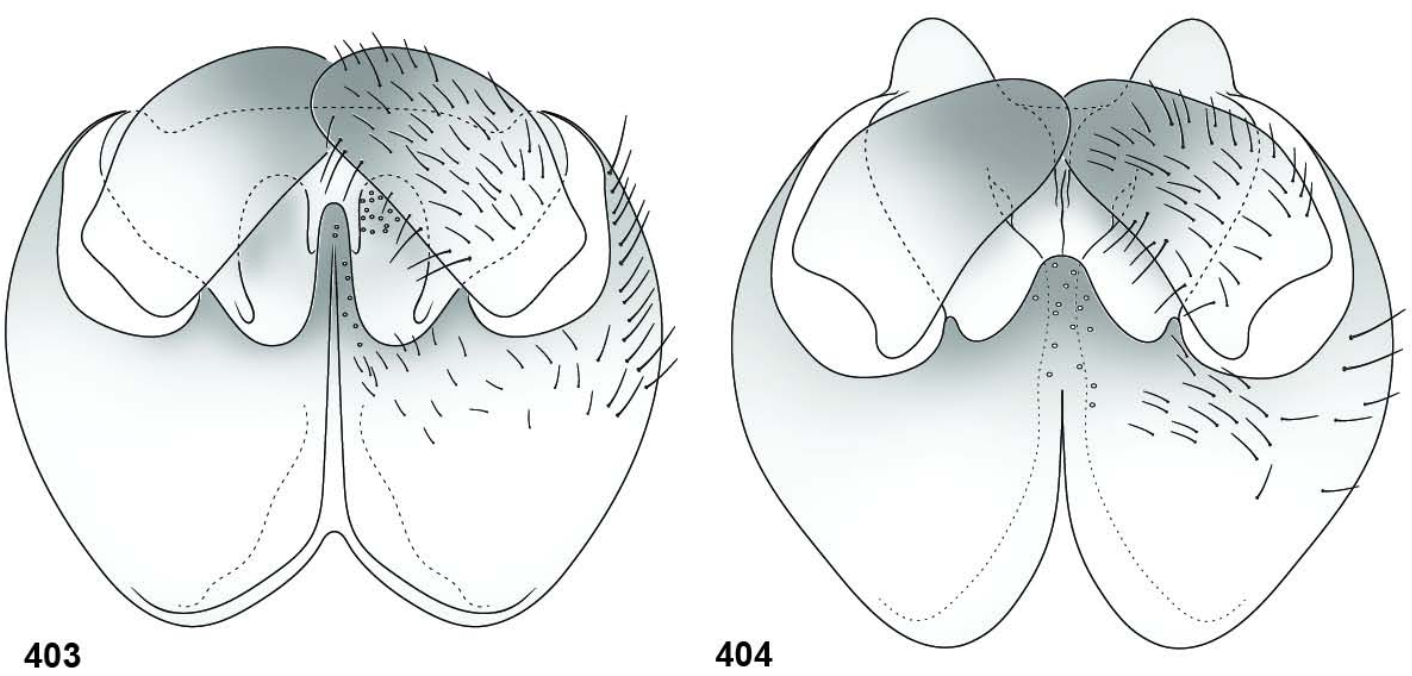

Figuras 399-404. Genitálias masculinas dos grupos externos em vista ventral. 399. Merosargus sp. nov. 3. 400. M. elatus. 401. M. albopictus. 402. M. barbatus. 403. M. beameri. 404. M. cingulatus. 

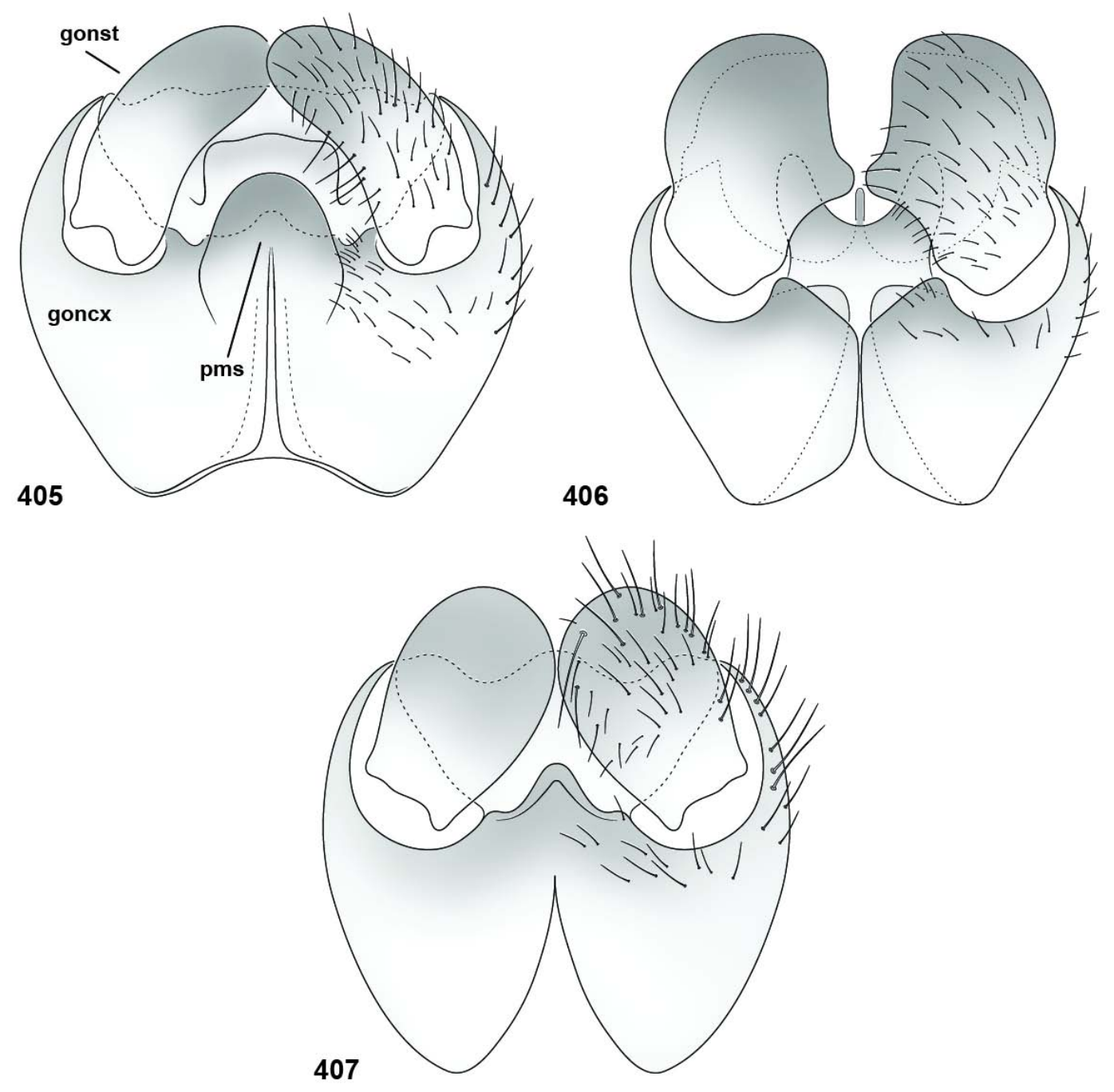

Figuras 405-407. Genitálias masculinas dos grupos externos em vista ventral. 405. Merosargus lampronotus. 406. M. opaliger. 407. M. longiventris, comb. nov. 

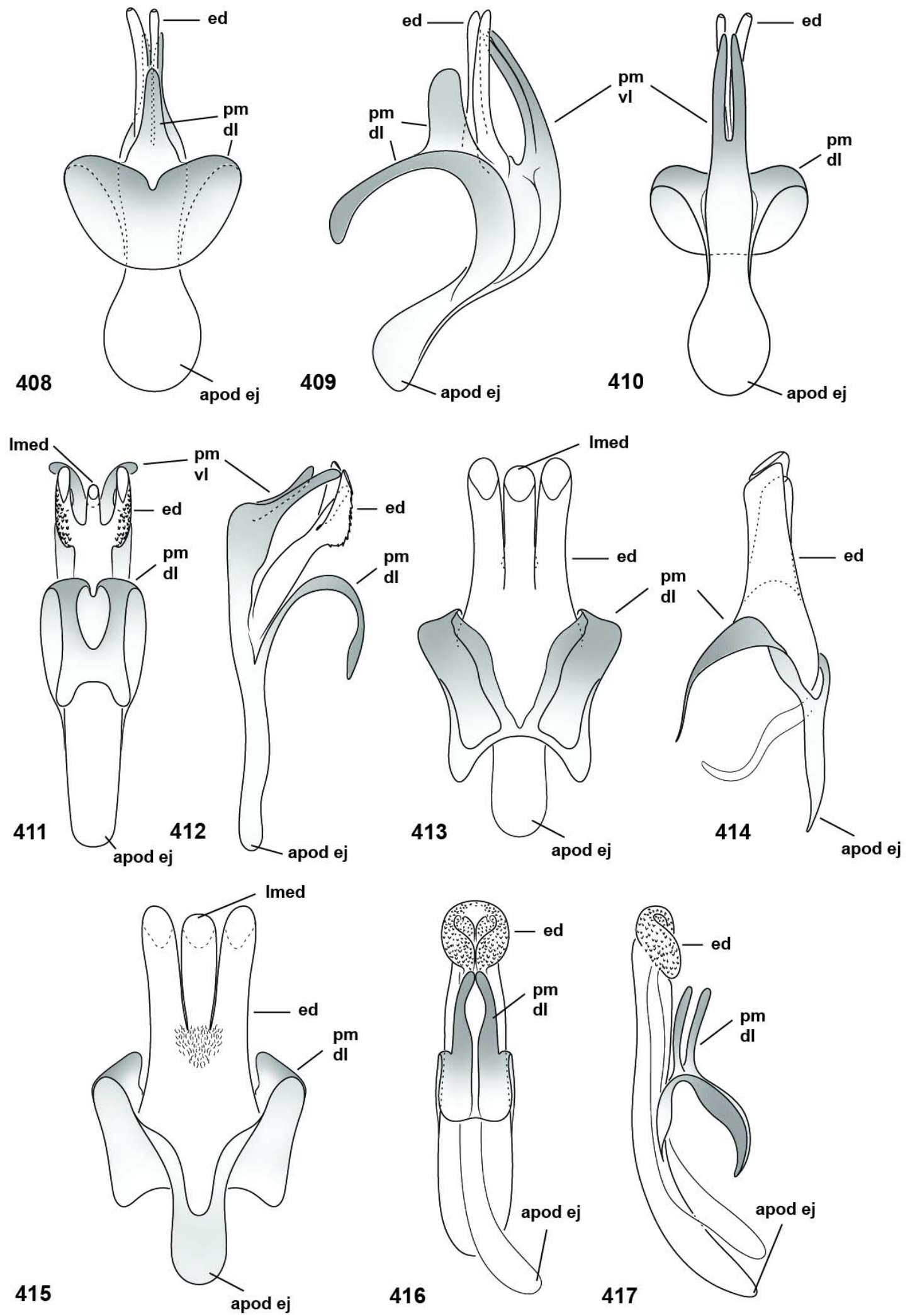

Figuras 408-417. Edeago+parâmeros dos grupos externos (408, 411, 413, 416, vista dorsal; 409, 412, 414, 417, vista lateral; 410, 415, vista ventral). 408-410. Sargus thoracicus. 411-412. Merosargus mirabilis. 413-415. Himantigera silvestris. 416-417. Ptecticus testaceus. 


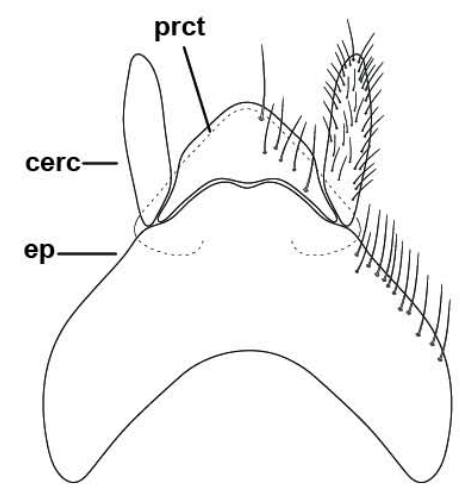

418

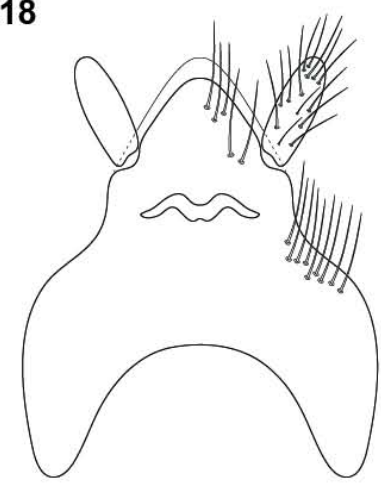

421

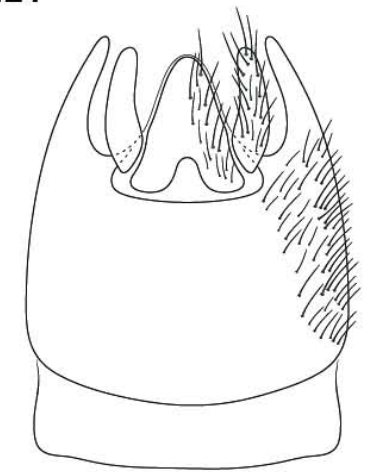

424

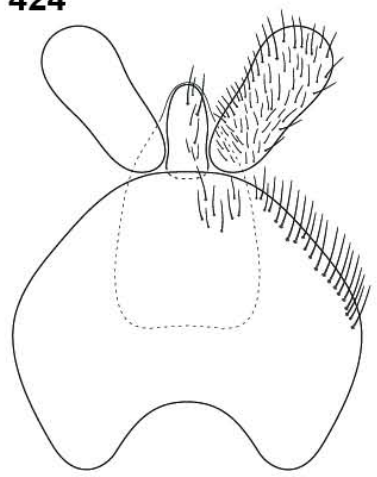

427

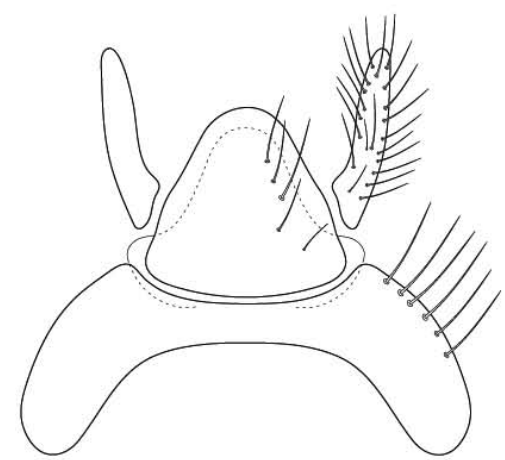

419

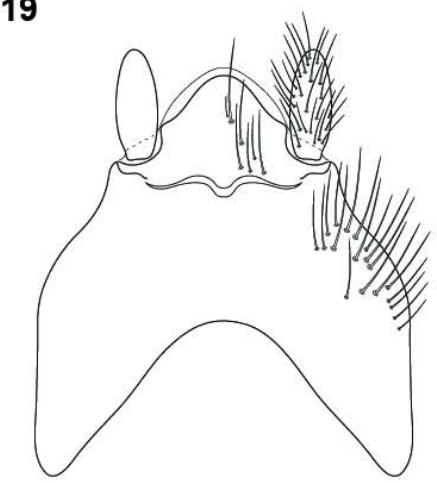

422

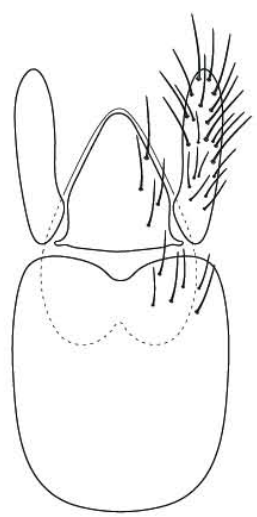

425

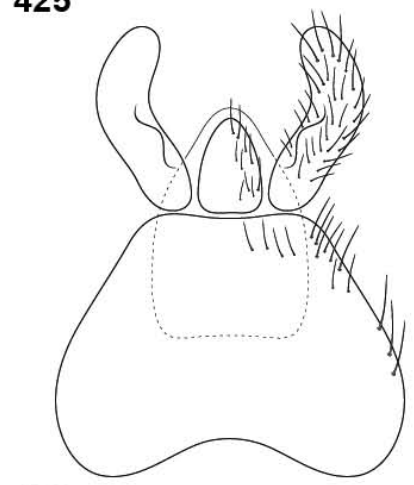

428

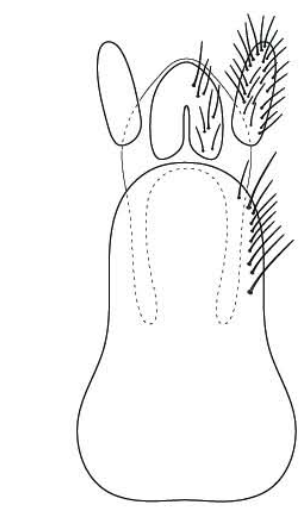

420

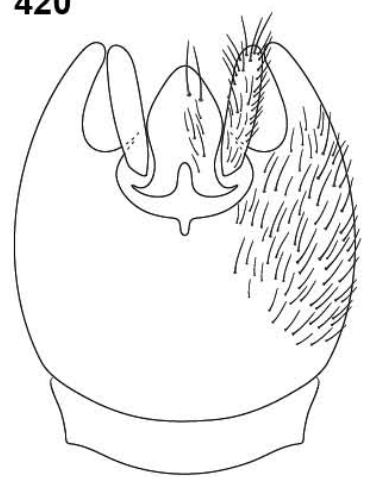

423

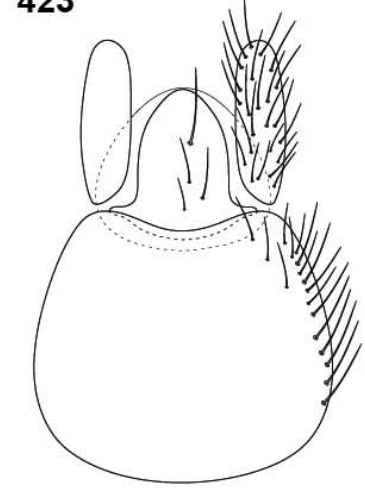

426

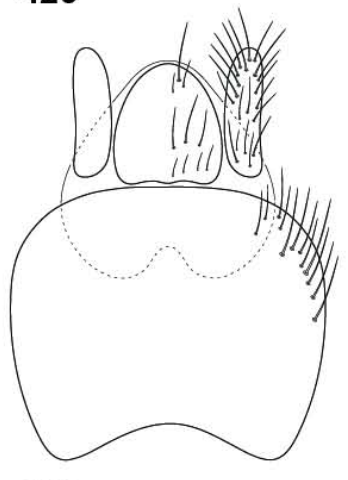

429

Figuras 418-429. Epândrio, cercômeros e proctiger dos grupos externos. 418. Sargus fasciatus. 419. S. thoracicus. 420. Merosargus mirabilis. 421. Himantigera nigrifemorata. 422. $\mathrm{H}$. silvestris. 423. Ptecticus lanei. 424. P. testaceus. 425. M. akrei. 426. M. azureus. 427. M. aurivena. 428. M. hyalopterus. 429. M. coriaceus. 


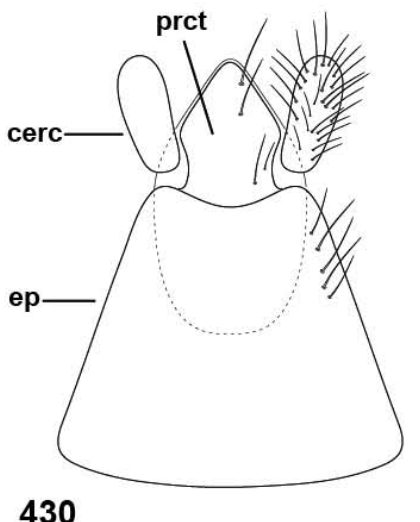

430

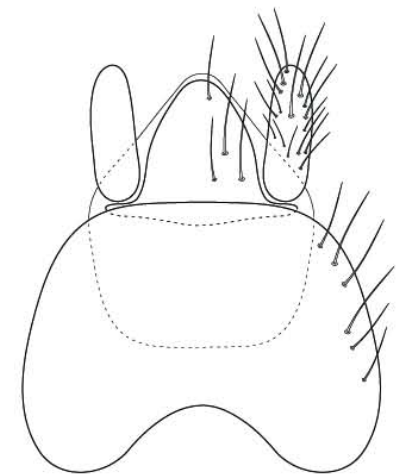

433

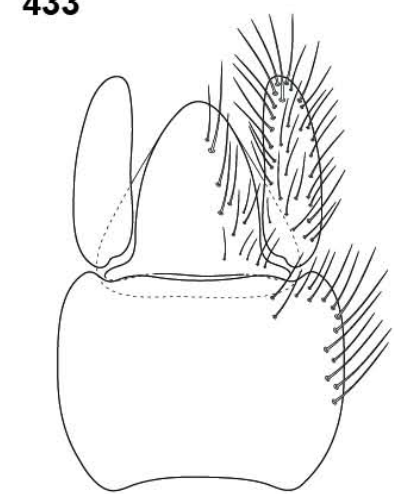

436

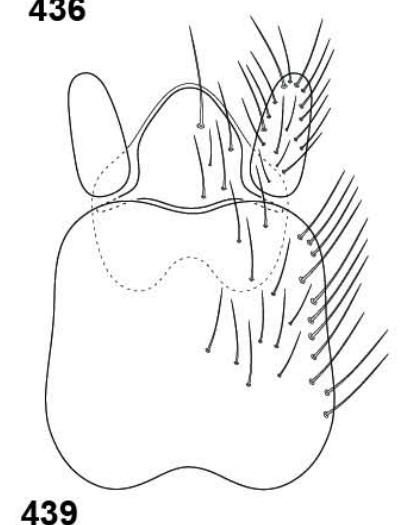

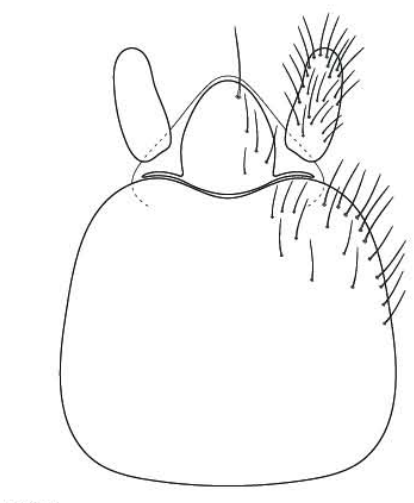

431

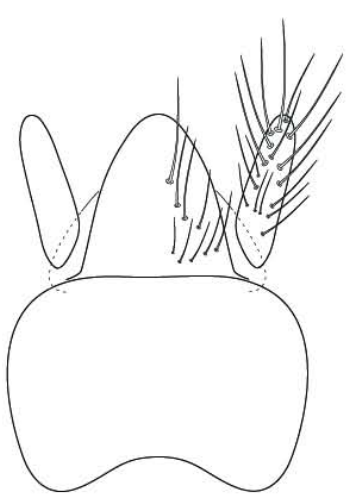

434

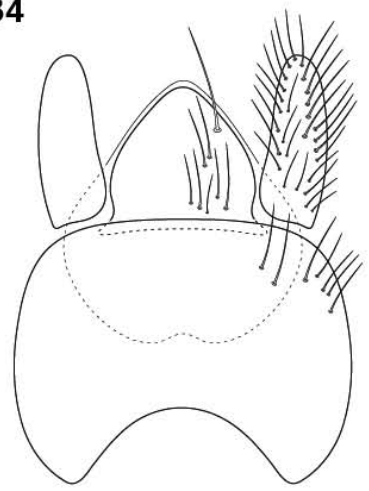

437

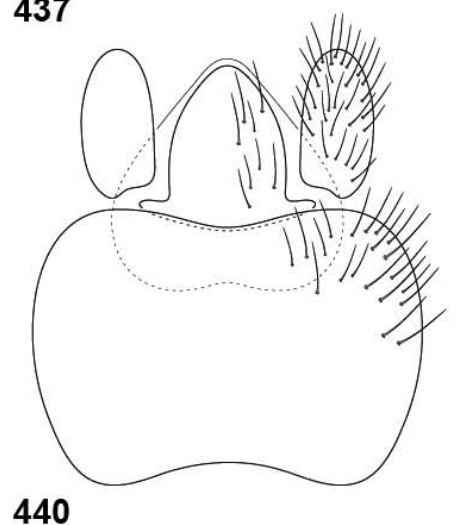

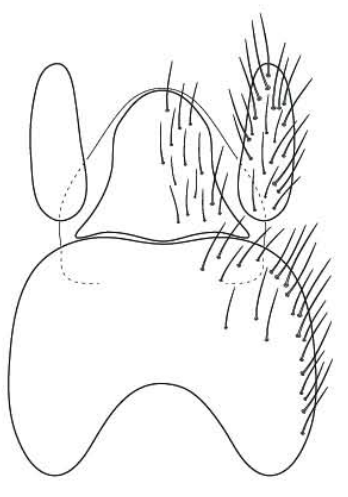

432

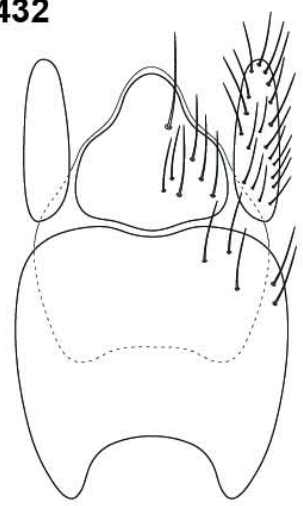

435

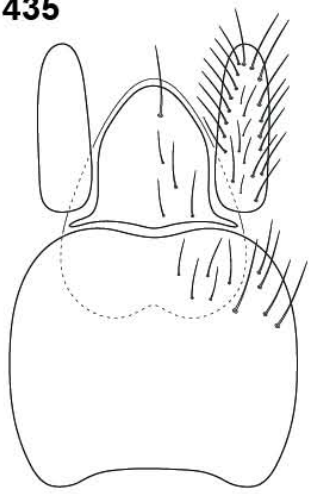

438

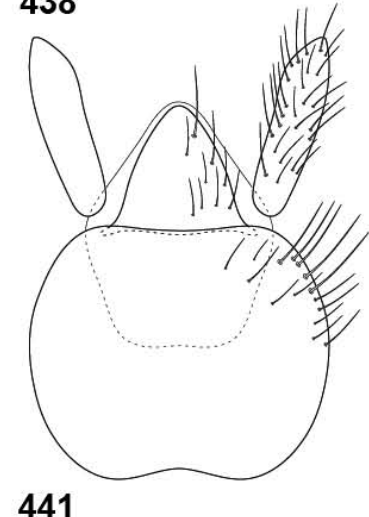

Figuras 430-441. Epândrio, cercômeros e proctiger dos grupos externos. 430. Merosargus obscurus. 431. M. taeniatus. 432. M. nebulifer. 433. M. festivus. 434. M. picta, comb. nov. 435. M. bivittatus. 436. M. sp. nov. 3. 437. M. elatus. 438. M. albopictus. 439. M. barbatus. 440. M. beameri. 441. M. cingulatus. 


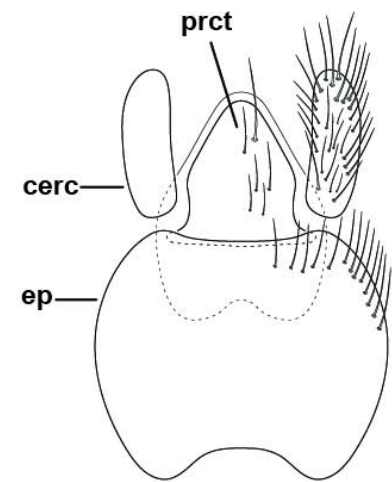

442

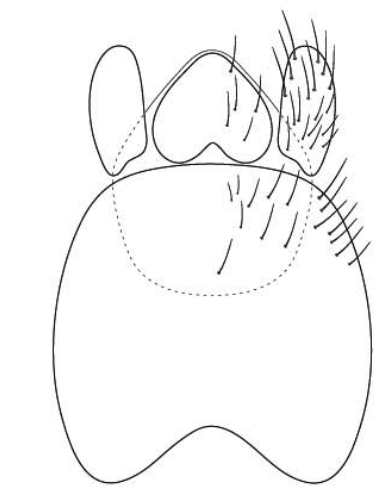

443

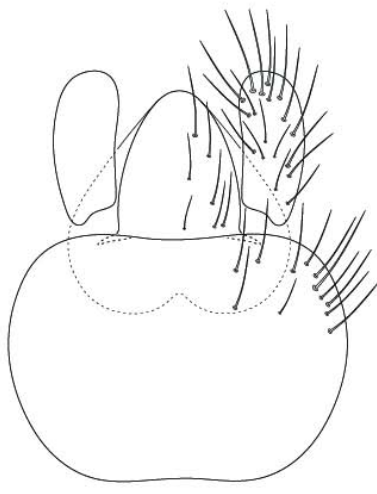

444

Figuras 442-444. Epândrio, cercômeros e proctiger dos grupos externos. 442. Merosargus lampronotus. 443. M. opaliger. 444. M. longiventris, comb. nov. 

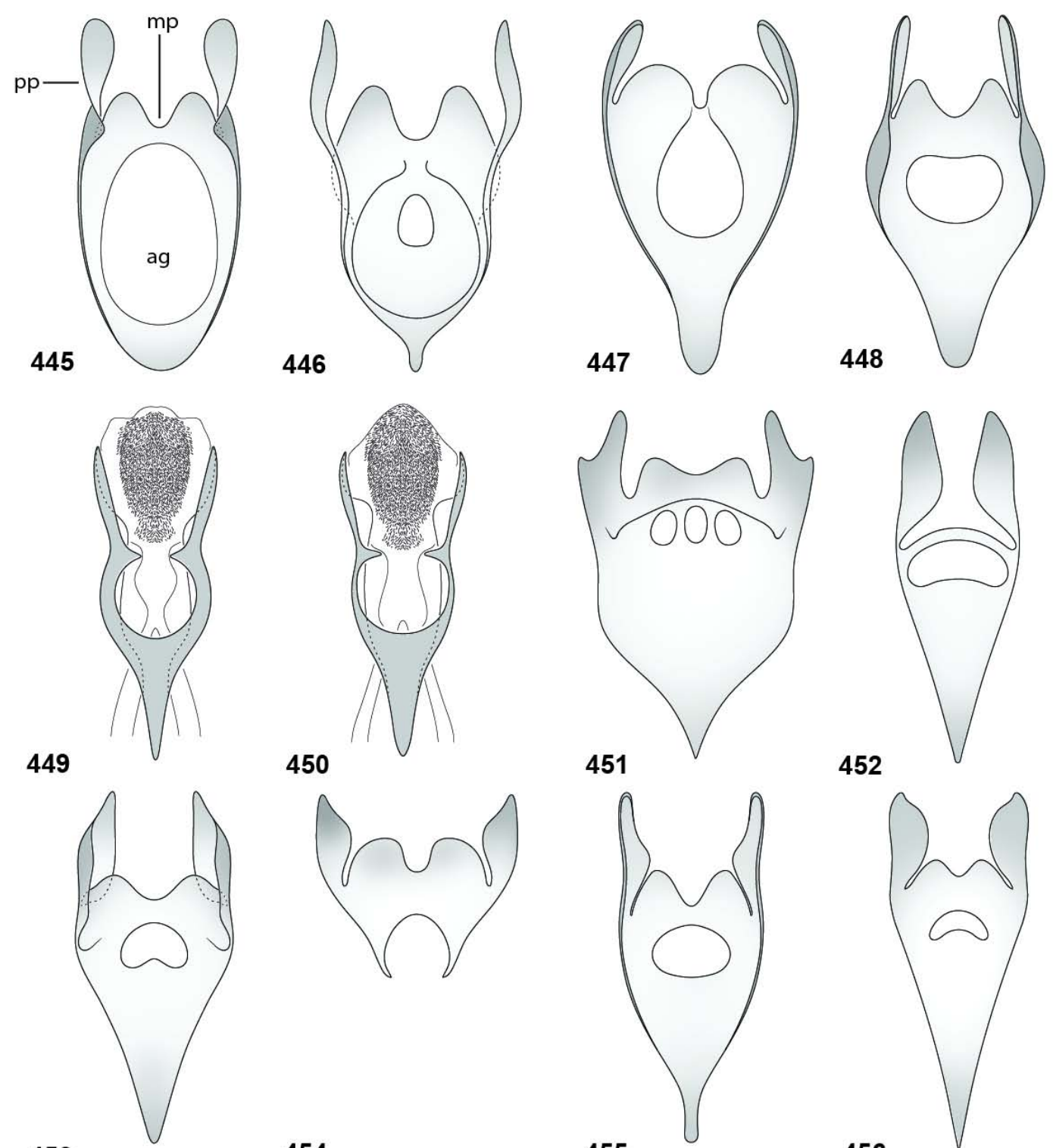

453

454
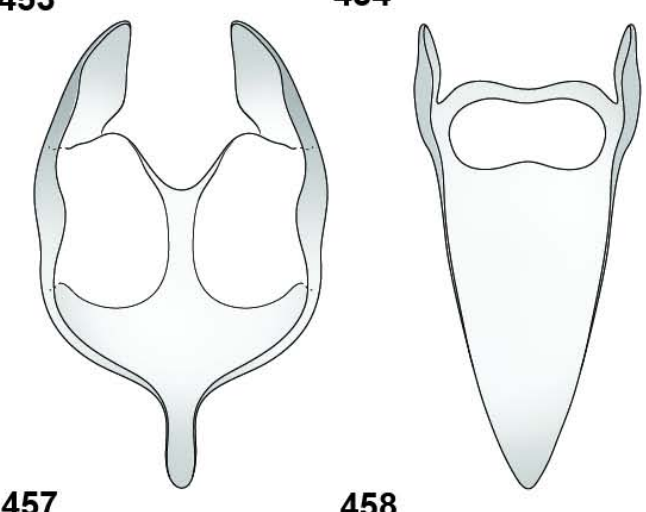

455

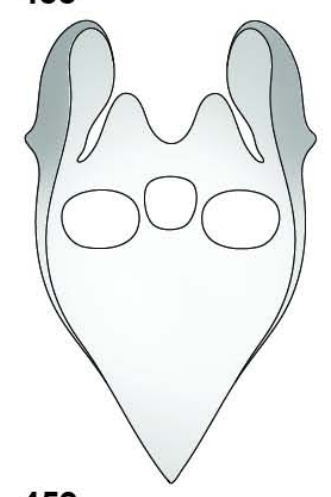

456
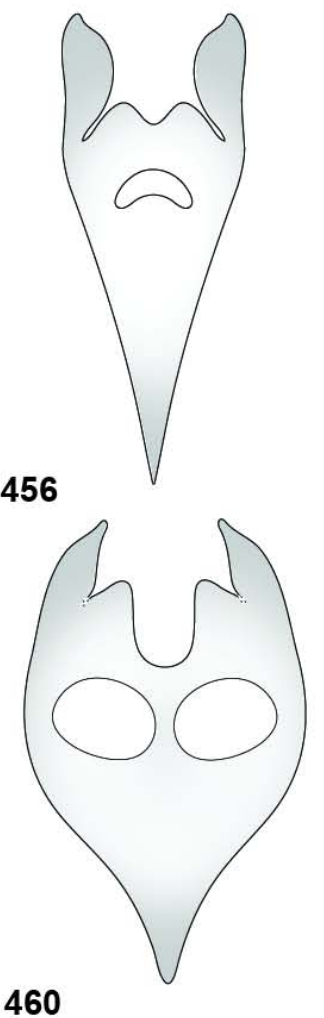

459

460

Figuras 445-460. Furca genital (estemito 9) dos grupos externos. 445. Sargus fasciatus. 446. S. thoracicus. 447. Merosargus mirabilis. 448. Himantigera nigrifemorata. 449. Ptecticus lanei. 450. P. testaceus. 451. M. akrei. 452. M. azureus. 453. M. aurivena. 454. M. coriaceus. 455. M. obscurus. 456. M. taeniatus. 457. M. nebulifer. 458. M. festivus. 459. M. bivittatus. 460.M.sp.nov.2. 

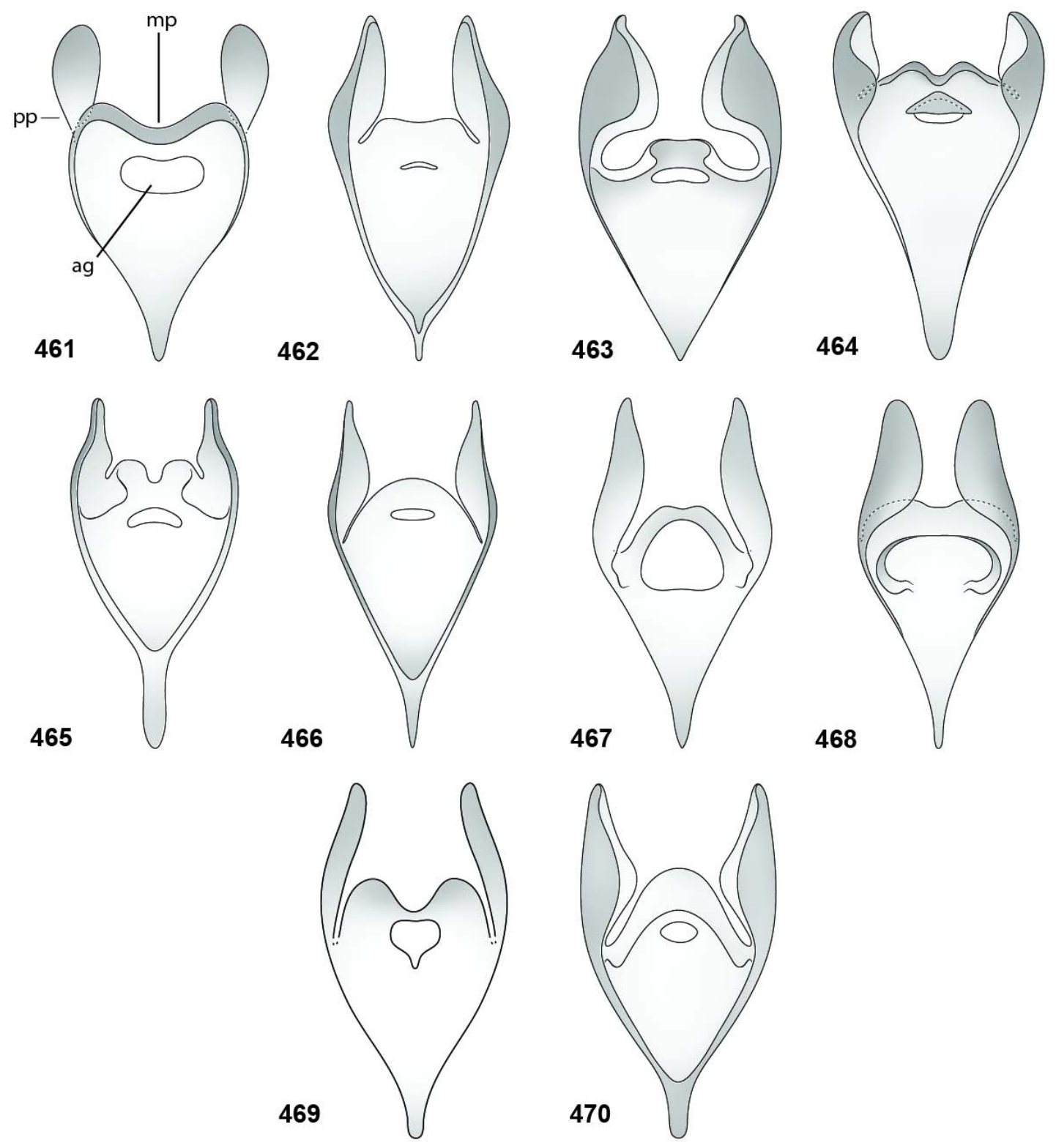

468

Figuras 461-470. Furca genital (esternito 9) dos grupos externos. 461. Merosargus sp. nov. 3. 462. M. elatus. 463. M. albopictus. 464. M. barbatus. 465. M. beameri. 466. M. cingulatus. 467. M. lampronotus. 468. M. opaliger. 469. M. sp. nov. 1. 470. M. longiventris, comb. nov. 

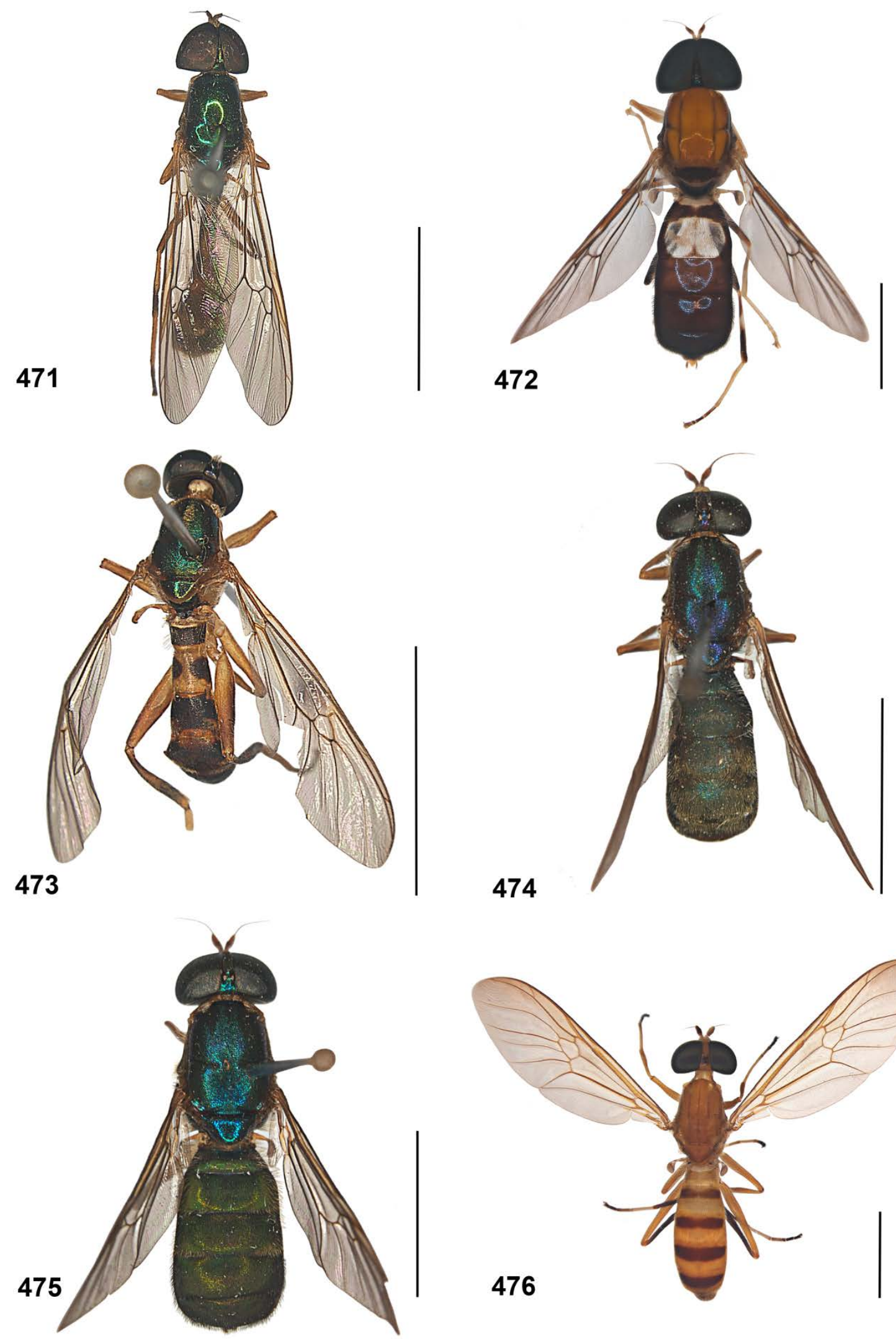

474
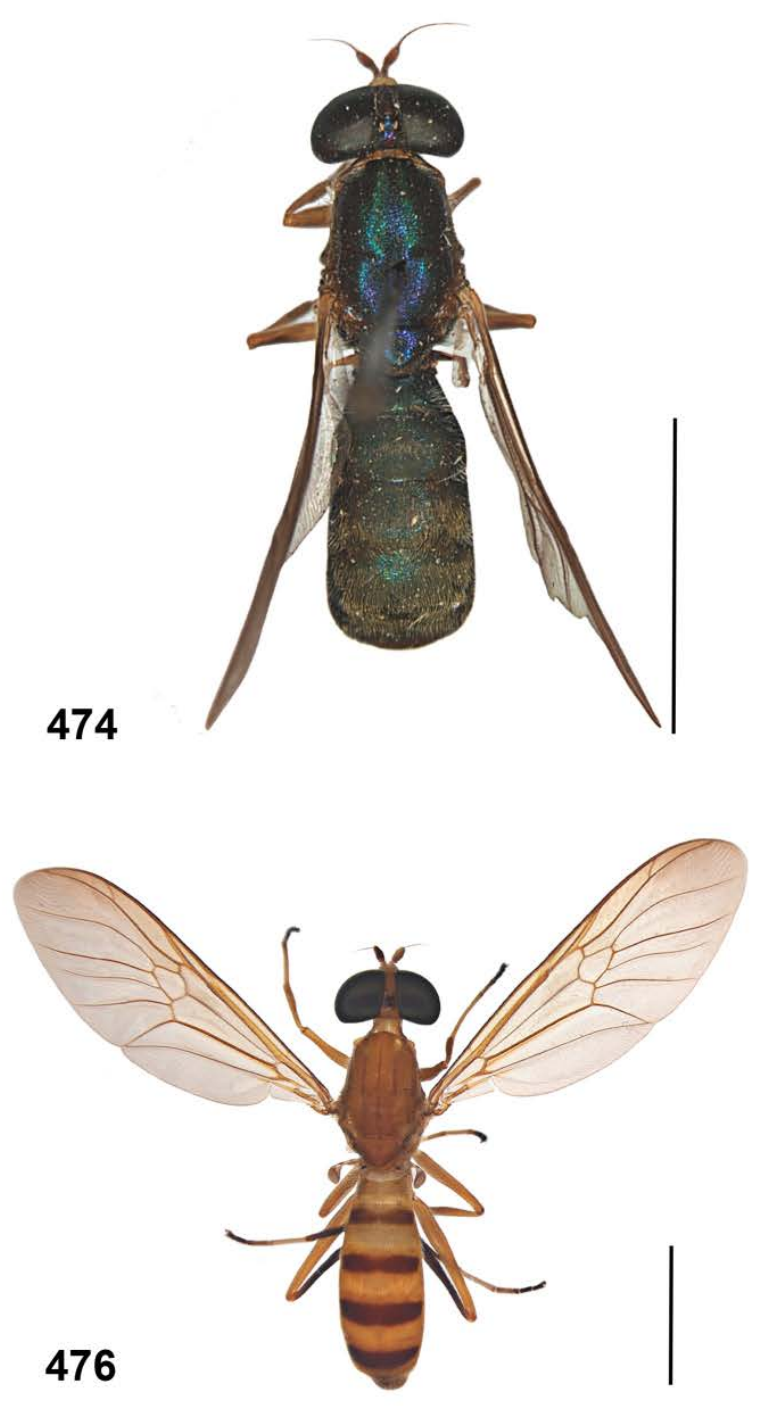

Figuras 471-476. Grupos externos em habitus dorsal. 471. Sargus fasciatus. 472. S. thoracicus. 473. Merosargus mirabilis. 474. Himantigera nigrifemorata. 475. H. silvestris. 476. Ptecticus testaceus (fêmea). Escala, 5 mm. 

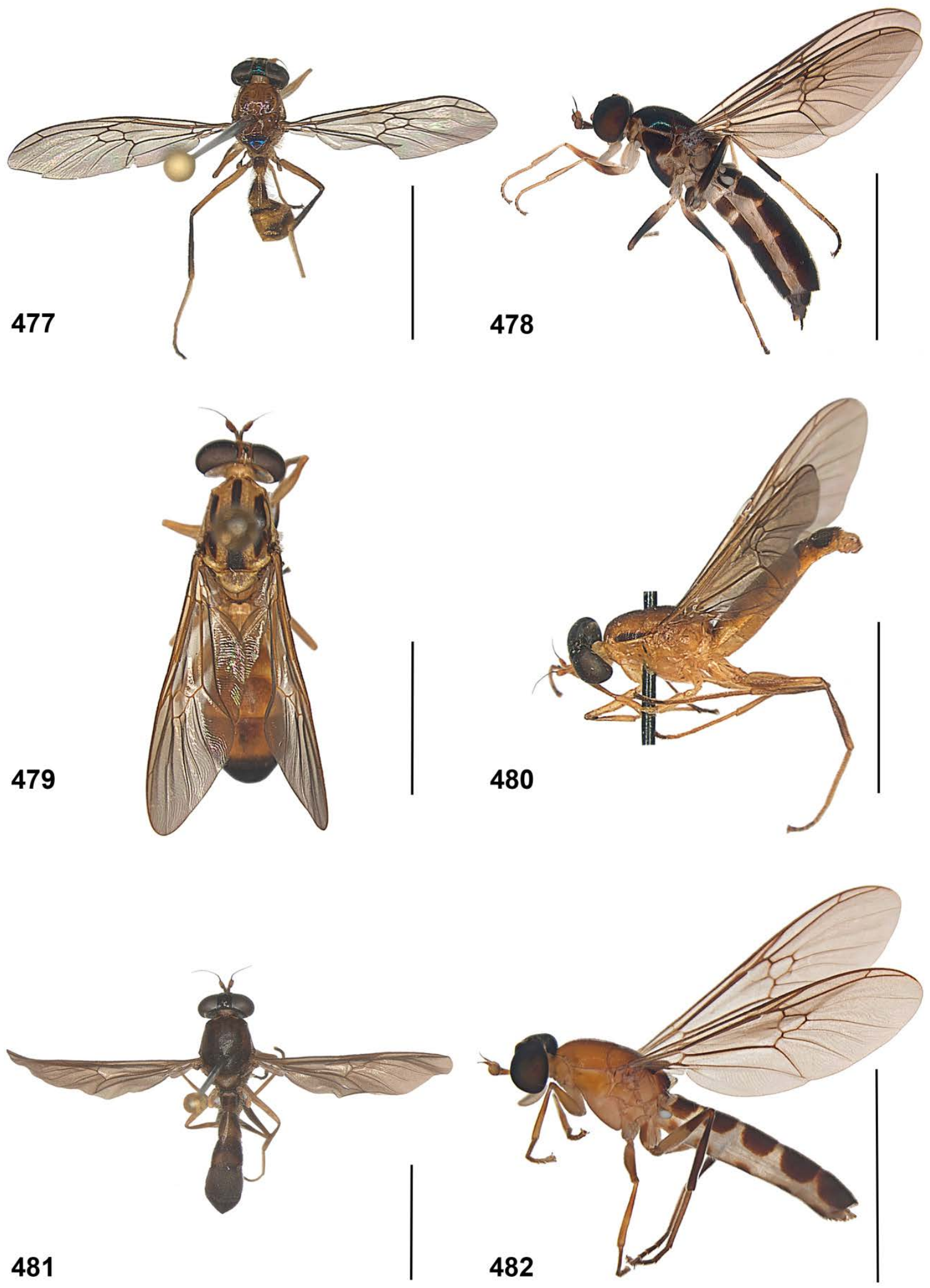

Figuras 477-482. Grupos externos em habitus dorsal e lateral (477, 479, 481, dorsal; 478, 479, 482, lateral). 477. Merosargus akrei. 478. M. azureus (fêmea). 479. M. aurivena. 480. M. hyalopterus. 481. M. obscurus. 482. M. taeniatus. Escala, $5 \mathrm{~mm}$. 

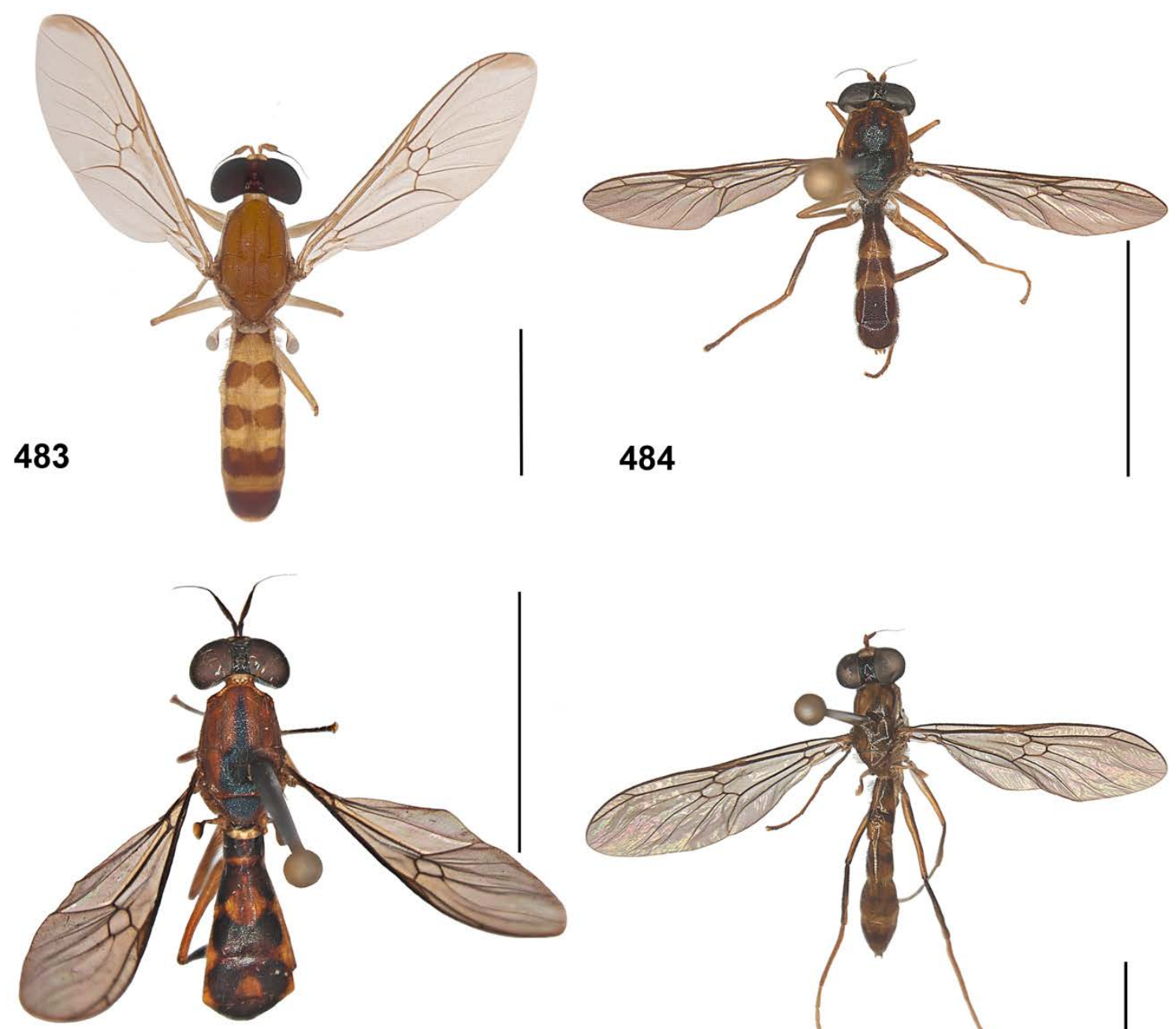

485
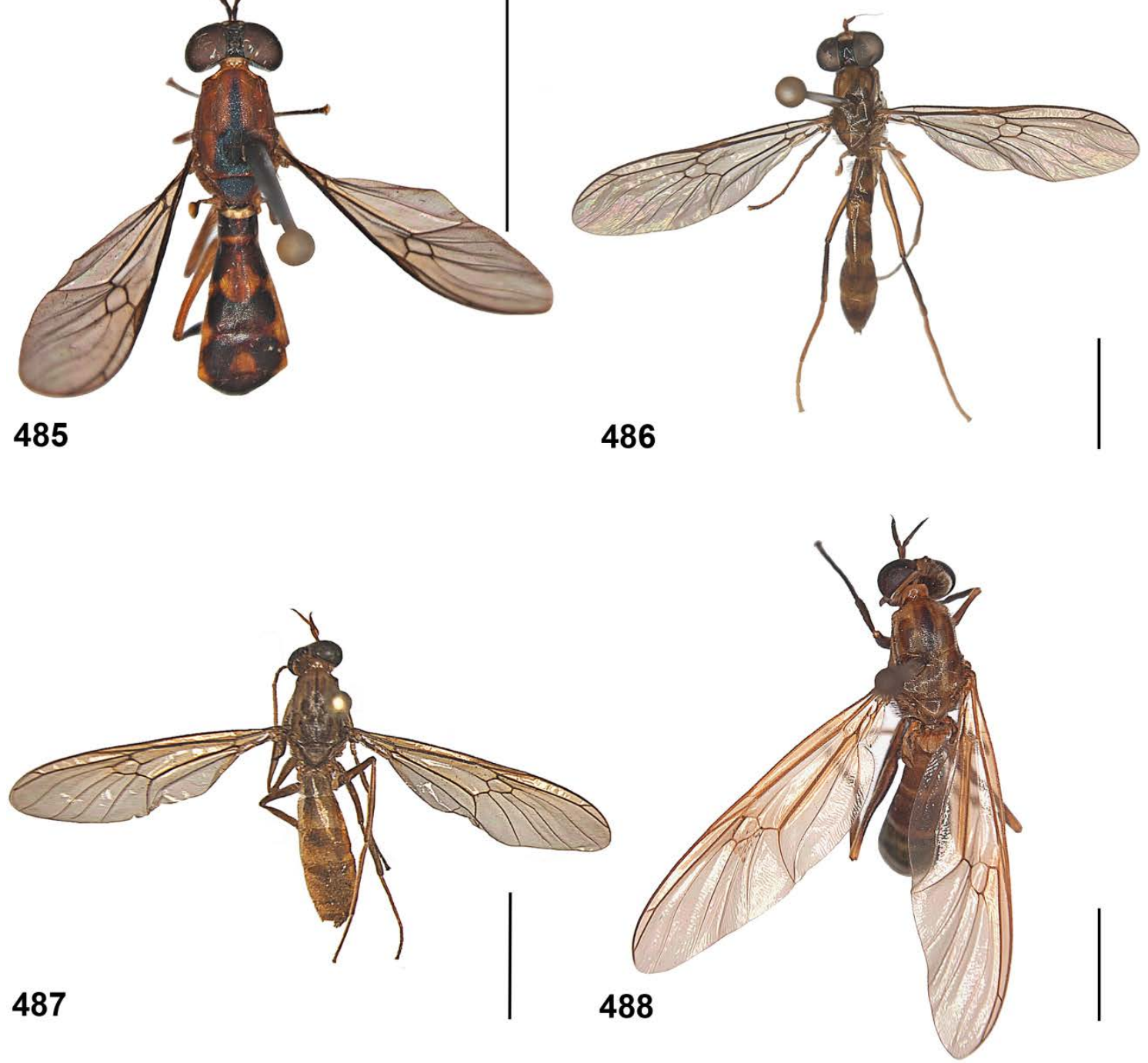

Figuras 483-488. Grupos externos em habitus dorsal. 483. Merosargus nebulifer. 484. M. festivus. 485. M. picta, comb. nov. 486. M. bivittatus. 487. M. sp. nov. 2. 488. M. sp. nov. 3. Escala, $5 \mathrm{~mm}$. 

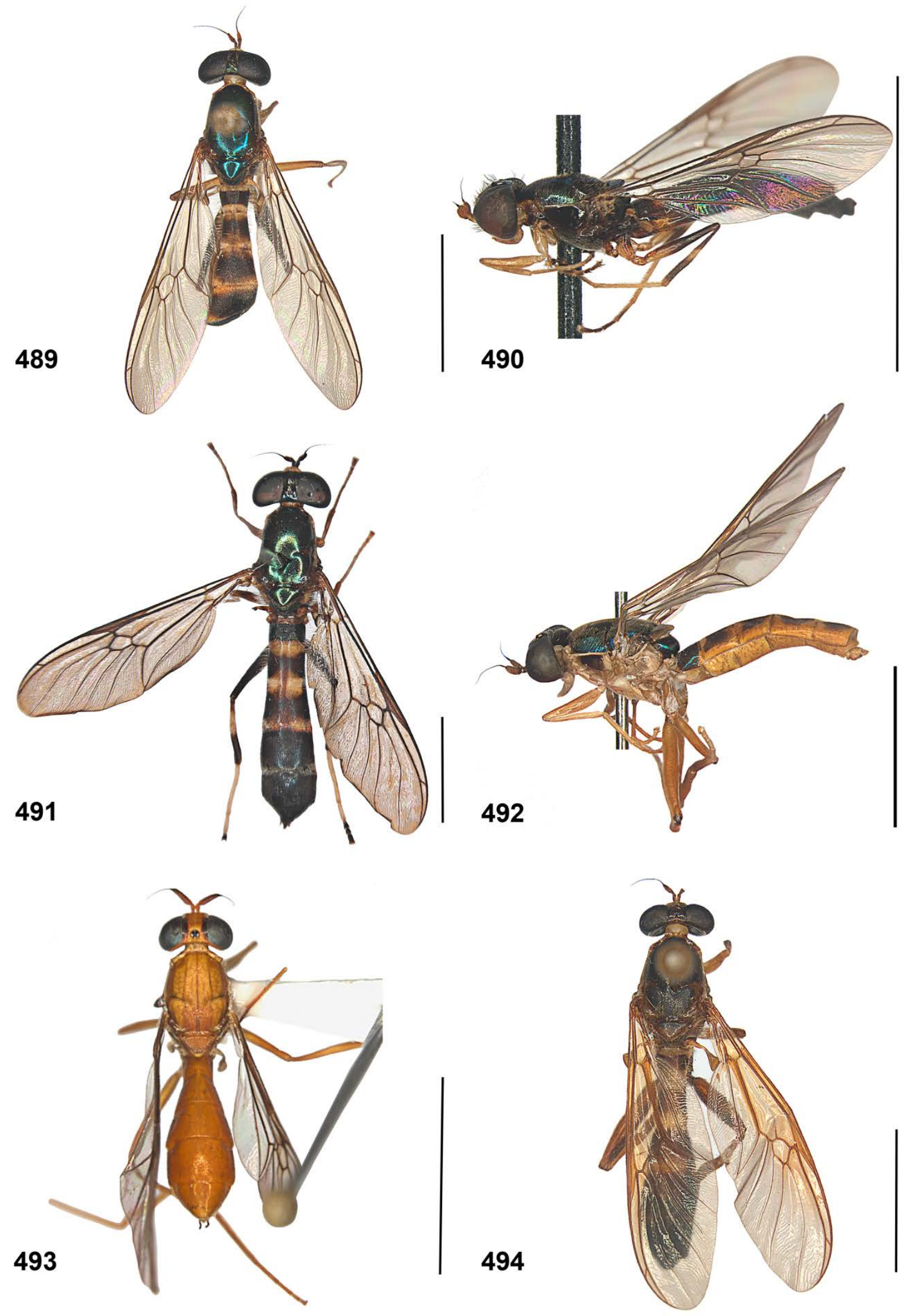

Figuras 489-494. Grupos externos em habitus dorsal e lateral (489, 491, 493, 494, dorsal; 490, 492, lateral). 489. Merosargus elatus. 490. M. barbatus. 491. M. cingulatus. 492. M. lampronotus. 493. M. sp. nov. 1. 494. M. longiventris, comb. nov. Escala, 5 mm. 


\section{REFERÊNCIAS BIBLIOGRÁFICAS}

Adisoemarto, S. 1974. A new genus of soldier flies from Indonesia (Diptera: Stratiomyidae). Treubia 28(3): 69-71.

Amorim, D.S. 2002. Fundamentos de Sistemática Filogenética. Holos Editora. Ribeirão Preto.

Bigot, J.M.F. 1879. Diptères nouveaux ou peu connus. 11e partie. XVI. Curiae Xylophagidarum et Stratiomydarum (Bigot) [part]. Annales de la Société Entomologique de France, Cinquième série 9: 183-208.

Brammer, C.A. \& von Dohlen, C.D. 2010. Morphological phylogeny of the variable fly Family Stratiomyidae (Insecta, Diptera). Zoologica Scripta, 39: 363-377.

Brauer, F. 1882. Zweiflügler des Kaiserlichen Museums zu Wien. II. Denkschriften der Kaiserlichen Akademie Wissenschaften Mathematisch-Naturwissenschaftliche Classe. Wien. 44(1): 59-110.

Brunetti, E. 1926. New Belgian Congo Stratiomyidae, with a species from British East Africa. Revue Zoologique Africaine 14(1): 123-136.

Carvalho, C.J.C., Rafael, J.A., Couri, M.S. \& Silva, V.C. 2012. Diptera. In: Insetos do Brasil-Diversidade e Taxonomia (Rafael, J.A., Melo, G.A.R., Carvalho, C.J.B, Casari, S.A \& Constantino, R. eds). Holos Editora, p.702-744.

Cumming, J.W. \& Wood, D.M. 2009. Chapter 2: Adult morphology and Terminology, p. 9-50. In: Brown, B.V.; Borkent, A.; Cumming, J.M.; Wood, D.M.; Woodley, N.E. \& Zumbado, M.A. (eds.), Manual of Central American Diptera: Volume 1. NCR Research Press, Ottawa, Ontario, Canada.

Curran, C. H. 1932b. New American Diptera. American Museum Novitates 534: 1-15.

Curran, C.H. 1933. Two news Diptera from Guatemala. American Museum Novitates 643: $1-2$.

de Pinna, M.G.G. 1991. Concepts and tests of homology in the cladistics paradigm. Cladistics, 7: 367-394.

Duncan, J. 1837. Characters and descriptions of the dipterous insects indigenous to Britain. Magazine of Zoology and Botany 1(2): 145-167.

Enderlein, G. 1914. Dipterologische Studien. IX. Zur Kenntnis der Stratiomyiiden mit 3ästiger Media und ihre Gruppierung. A. Formen, bei denen der 1. Cubitalast mit der Discoidalzelle durch Querader verbunden ist oder sie nur in einem 
Punkte berührt (Subfamilien: Geosarginae, Analcocerinae, Stratiomyiinae). Zoologischen Anzeiger 43(13): 577-615.

Fabricius, J. C. 1794. Entomologia systematica emendata et aucta. Secundum classes, ordines, genera, species adjectis synonimis, locis, observationibus, descriptionibus. Tom IV. C. G. Proft, Fil. et Soc., Hafniae [= Copenhagen]. [8], $1-472,[6]$.

Fabricius, J. C. 1798. Supplementum entomologiae systematicae. Proft et Storch, Hafniae [=Copenhagen]. [4], 1-572.

Fabricius, J. C. 1805. Systema antliatorum secundum ordines, genera, species adiectis synonymis, locis, observationibus, descriptionibus. Carolum Reichard, Brunsvigae. I-XIV, 15-172, [4], 1-30.

Fontenelle, J.C.R.,Viana-Silva, F.E.C \& Martins, R.P. 2012. Use of Plant Resources by Merosargus (Diptera, Stratiomyidae, Sarginae) Larvae. Psyche. Volume 2012, Article ID 690203, p.10.

Forey P.L. \& Kitching I.J. 2000. Experiments in coding multistate characters. In: Scotland R.W. Pennington R.T. (eds.). Homology and systematics: coding characters for phylogenetic analysis. London: Taylor and Francis, p. 54-80.

Giglio-Tos, E. 1891. Nuove specie di Ditteri del Museo Zoologico di Torino. V. Bollettino dei Musei di Zoologia ed Anatomia comparata della R. Università di Torino 6(102): 1-4.

Giglio-Tos, E. 1893. Ditteri del Messico. Parte I. Stratiomyidae - Syrphidae. Carlo Clausen, Torino. 1-72.

Goloboff, P.A., 1993. Estimating character weights during tree search. Cladistics 9, 8391.

Goloboff, P.A., Carpenter, J.M., Arias, J.S., Esquivel, D.R.M., 2008a. Weighting against homoplasy improves phylogenetic analysis of morphological data sets. Cladistics 24, 758-773.

Goloboff, P. A., Farris, J. S. \& Nixon, K.C. TNT, 2008b. A free program for phylogenetic analysis. Cladistics, 15, 415-428.

Grünberg, K. 1915. Zoologische Ergebnisse der Expedition des Herrn G. Tessmann nach Südkamerun un Spanisch-Guinea. Diptera. I. Stratiomyidae. Mitteilungen aus dem Zoologischen Museum in Berlin 8(1): 41-70. 
Huber, F. \& Reis, F.H. 2011. Técnica alternativa para montagem de insetos em lâminas permanentes para visualização em microscópia óptica. EntomoBrasilis, 4(1), 1319.

Iide, P. 1966. Estudo sôbre as Espécies Brasileiras do gênero Chrysochlorina James, 1939 (Diptera, Stratiomyidae). Arquivos de Zoologia, Vol. XIV, fasc. 2: 69-112.

James, M. T. 1939a. Studies in Neotropical Stratiomyidae (Diptera). I. The American species formerly referred to Chrysochlora Latreille. Journal of the Kansas Entomological Society 12(1): 32-36.

James, M. T. 1939b. New Formosan Stratiomyidae in the collection of the Deutsches Entomologisches Institut. Arbeiten über morphologische und taxonomische Entomologie aus Berlin-Dahlem 6(1): 31-37.

James, M.T. 1941. A preliminary study of the New World Geosarginae (Diptera: Stratiomyidae). Lloydia 4: 300-309.

James, M.T. 1973a. Family Stratiomyidae. In: A catalogue of the Diptera of the Americas south of the United States (N. Papavero, ed.). São Paulo, Departamento de Zoologia, Secretaria de Agricultura, v. 26, p1-95.

James, M.T. 1973b. A preliminary review of the Stratiomyidae of Chile. Part I. Rev. Chil. Entomol. 7: 11-23.

James, M.T. 1974. The genus Nemotelus in South America (Diptera, Stratiomyidae). Melanderia 14: [2,] 1-22.

James, M.T. 1975. A preliminary review of the Stratiomyidae of Chile. Part II. Melanderia 20: i-iv, 1-28.

James, M.T. \& M.W. McFadden. 1971. The Genus Merosargus in Middle America and the Andean Subregion (Diptera: Stratiomyidae). Melanderia 7: [2], 1-76.

James, M.T. \& McFadden, M.W. 1979. The Stratiomyinae (Diptera, Stratiomyidae) of Middle America. Melanderia 32: 1-40.

James, M.T. \& M.W. McFadden. 1982. The Sarginae (Diptera: Stratiomyidae) of Middle America. Melanderia 40: vii-x, 1-50.

Kertész, K. 1912. The Percy Sladen Trust Expedition to the Indian Ocean in 1905, under the leadership of Mr J. Stanley Gardiner, M. A. Volume IV. No. VI.Diptera, Stratiomyiidae. The Transactions of the Linnean Society of London 2nd Series, Zoology 15(1): 95-99. 
Leal, M. do C.A. \& Oliveira, M.H.C.C. 1979. Revisão das espécies brasileiras do gênero Ptecticus Loew, 1855 (Diptera: Stratiomyidae). An. Univ. Fed. Rural PE., Recife, 4: 37-102.

Lindner, E. 1931. Beitrag zur Kenntnis der südamerikanischen Stratiomyidenfauna (Dipt.). Revista de Entomologia (Rio de Janeiro) 1(3): 304-312.

Lindner, E. 1936a. Stratiomyiiden von Madagaskar (Dipt.). Konowia 15(1): 33-50.

Lindner, E. 1936b. Stratiomyiiden von Costa Rica (Dipt.). Stettiner Entomologische Zeitung 97(1): 153-158.

Lindner, E. 1938. Stratiomyiiden aus dem Kongo-Gebeit. (Diptera). Bulletin du Musée royal d'Histoire naturelle de Belgique 14(54): 1-35.

Lindner, E. 1949. Neotropische Stratiomyiiden des Britischen Museums in London. Annals and Magazine of Natural History. Vol. 1. Stuttgart. Lindner, 1958

Lindner, E. 1958. Äthiopische stratiomyiiden (Diptera). IV. Journal of the entomological Society of Southern Africa 21(1): 121-128.

Lindner, E. 1959. Stratiomyiidae de Madagascar [Diptera]. Le Naturaliste Malgache 10: 87-91.

Lindner, E. 1968. Madagassische Stratiomyiden aus dem Muséum National d'Histoire Naturelle de Paris (Diptera). Stuttgarter Beiträge zur Naturkunde 190: 1-18.

Loew, H. 1855. Einige Bemerkungen über die Gattung Sargus. Verhandlungen des zoologisch-botanischen Vereins in Wien 5(2): 131-148.

Macquart, P. J. M. 1834. Histoire naturelle des Insectes. Diptères. Tome Premier. Librairie Encyclopédique de Roret, Paris. [4], 1-578, 1-8.

Macquart, P. J. M. 1847. Diptères exotiques nouveaux ou peu connus. 2.e Supplément. Roret, Paris. 5-104.

Mason, F. \& Rozkosný, R. 2008. A new species of Sargus Fabricius, 1798 from Europe (Diptera, Stratiomyidae). Dtsch. Entomol. Z. 55 (2): 303-309.

Nagatomi, A. 1984. Male genitalia of the lower Brachycera (Diptera). Beitr. Ent. 34: 99-157.

Nixon, K. C. 2002. WinClada ver. 1.00.08. Ithaca, NY. Publicado pelo autor, disponível em http://taxonomy.zoology.gla.ac.uk/rod

Nixon, C.K. \& Carpenter, J.M. 1993. On outgroups. Cladistics, vol. 9, p. 413-426.

Perty, M. 1833a. Plates 25-40, in Delectus animalium articulatorum, quae in itinere per Brasiliam annis MDCCCXVII - MDCCCXX jussu et auspiciis Maximiliani Josephi I. Bavariae regis augustissimi peracto collegerunt Dr. J. B. de Spix, et 
Dr. C. F. Ph. de Martius. The Editors, Monachii [=Munich]; Müller et Soc., Amstelodami [=Amsterdam]; Perthes et Besser, Hamburgi [=Hamburg]; Fr. Fleischer, Lipsiae [=Leipzig]; Treuttel, Würtz et Richter, Londini [=London]; Artaria et Fontaine, Manhemii [=Mannheim]; Renouard and Treuttel et Würtz, Parisiis [=Paris]; and Rohrmann et Schweigerd, Vindobonae [=Vienna]. [8], IIV, 1-44, 1-224.

Perty, M. 1833b. Pp. 125-224, in Delectus animalium articulatorum, quae in itinere per Brasiliam annis MDCCCXVII - MDCCCXX jussu et auspiciis Maximiliani Josephi I. Bavariae regis augustissimi peracto collegerunt Dr. J. B. de Spix, et Dr. C. F. Ph. de Martius. The Editors, Monachii [=Munich]; Müller et Soc., Amstelodami [=Amsterdam]; Perthes et Besser, Hamburgi [=Hamburg]; Fr. Fleischer, Lipsiae [=Leipzig]; Treuttel, Würtz et Richter, Londini [=London]; Artaria et Fontaine, Manhemii [=Mannheim]; Renouard and Treuttel et Würtz, Parisiis [=Paris]; and Rohrmann et Schweigerd, Vindobonae [=Vienna]. [8], IIV, 1-44, 1-224.

Pleske, T. 1926. Études sur les Stratiomyidae de la région paléarctique (Dipt.). Revue des espèces paléarctiques des sousfamilles Sarginae et Berinae. Eos 2(4): 385420.

Pleske, T. 1930. Résultats scientifiques des expéditions entomologiques du Musée Zoologique dans la région de l’Oussouri. II. Diptera: Les Stratiomyiidae, Erinnidae, Coenomyiidae et Oestridae. Annuaire du Musée Zoologique de l’Académie des Sciences de l’URSS 31(2): 181-206.

Rozkosný, R. 1982. A biosytematic study of the European Stratiomyidae (Diptera). Volume 1. Introduction, Beridinae, Sarginae and Stratiomyinae. Series Entomologica 21: 1-401.

Rozkošný, R. \& Kovac, D. 2000. A revision of the Pteticus tenebrifer species group (Insecta: Diptera: Stratiomyidae). The Raffles Bulletin of Zoology 48: 103-110.

Sinclair, B.J., Cumming, J.M. \& Wood, D.M. 1993. Homology and phylogenetic implications of male genitalia in Diptera-Lower Brachycera, Entomol. scand. 24: 407-432.

Schiner, J. R. 1868b. Diptera. In Reise der österreichischen Fregatte Novara um die Erde inden Jahren 1857, 1858, 1859, unter den Befehlen des Commodore B. von Wüllerstorf-Urbair. Zoologischer Theil 2, 1 (B). Kaiserlich-königlichen Hofund Staatsdruckeriin comission bei Karl Gerold's Sohn, Wien. I-VI, 1-388. 
Schuh, R.T. \& Brower, A.V.Z. 2009. Biological Systematics - Principles and Applications. Second edition. Cornell University Press. Ithaca, New York.

Wiedemann, C.R.W. 1830. Aussereuropäische zweiflügelige Insekten. Zweiter Theil. Schulzischen Buchhandlung, Hamm. I-XII, 1-684.

Williston, S.W. 1888. Diptera Brasiliana, ab H.H. Smith collecta. Part I- Stratiomyidae, Syrphidae. Transactions of the American Entomological Society 15: 243-292.

Williston, S. W. 1896b. Manual of the families and genera of North American Diptera. Second Edition. James T. Hathaway, New Haven. I-LIV, [2], 1-167.

Wood, D.M. 1991. Homology and phylogenetic implications of male genitalia in Diptera. The ground plan. 255-284. In: Weismann, L.; Országh, I. \& Pont, A.C. (eds). Proceedings of the Second International Congress of Dipterology, Bratislava, Czechoslovakia, 367 pp.

Woodley, N.E. 1981. A revision of the Neartic Beridinae (Diptera: Stratiomyidae). Bulletin of Museum of Comparative Zoology, 149(6): 319-369.

Woodley, N.E. 1995. The genera of Beridinae (Diptera: Stratiomyidae). Memoirs of the Entomological Society of Washington 16: 1-231.

Woodley. N.E. 1989. Phylogeny and classification of the "orthorrhaphous” Brachycera. In: Manual of Nearctic Diptera (J.F. McAlpine \& D.M. Wood, eds.). Monograph/Agriculture Canada, Ottawa, Volume 3, p.1371-1395.

Woodley, N.E. 2001. A World Catalog of the Stratiomyidae (Insecta: Diptera). Backhuys Publishers, Leiden.

Woodley, N.E. 2009. Chapter 38: Stratiomyidae, p. 521-550. In: Brown, B.V.; Borkent, A.; Cumming, J.M.; Wood, D.M.; Woodley, N.E. \& Zumbado, M.A. (eds), Manual of Central American Diptera: Volume 1. NCR Research Press, Ottawa, Ontario, Canada.

Woodley, N.E. 2011. A World Catalog of the Stratiomyidae (Insecta: Diptera): A Supplement with Revisionary Notes and Errata. In: Contributions to the Biosystematic Database of World Diptera. Myia (F.C. Thompson, I. Brake \& O. Lonsdale, eds.). Myia, v. 12, p.443-484.

Woodley, N.E., Borkent, A. \& Wheeler, T.A. 2009. Phylogeny of the Diptera, In: Manual of Central American Diptera (B.V. Brown, A. Borkent, J.M. Cumming, D.M. Wood, N.E. Woodley \& M.A. Zumbado, eds.). NCR Research Press, Boca Raton, v. 1, p.79-94. 


\section{APÊNDICES}

\section{1. Apêndice 1}

Tabela 6. Lista detalhada do material dissecado e analisado.

1. Acrochaeta adusta. 1 \#m. Brasil, São Paulo, Jundiaí, Serra do Japí, Trilha da Cachoeira do Paraíso-Riacho Paraíso, 2314”S 465”W, 25.ii-12.iii.2008, Malaise trap, Lecci, L.S., Moretto, R.A. \& Nascimento, E.A. (MZUSP).

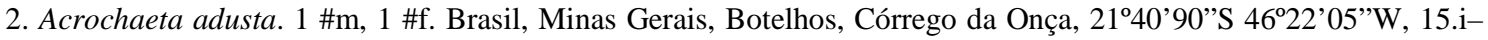
21.ii.2007, Malaise trap, Basso, J. col. (MZUSP).

3. Acrochaeta adusta. 1 \#m. Brasil, Rio de Janeiro, Rio de Janeiro, Parque Estadual do Desengano, Trilha, Refugo, Malaise trap 2, 17-20.iv.2002. (MZUSP).

4. Acrochaeta degenerata. 1 \#f. Brasil, Minas Gerais, Arcelurgo, F. Fortaleza, xii.1946, Barretto col. (MZUSP).

5. Acrochaeta degenerata. 1 \#f. Brasil, Santa Catarina, Chapecó. Linha Montebelo, 27²’11.74”S 52³2’20.22”W, 580m., 1-30.xi.2012, M. Savaris, S. Lampert cols. (MZUSP).

6. Acrochaeta dimidiata. 1 \#m, Brasil, Santa Catarina, Nova Teutônia, x.1967, F. Plaumann col. (MZUSP).

7. Acrochaeta fasciata. 1 \#m. Brasil, Mato Grosso do Sul, Maracajú, Serviço Febre Amarela, M.E.S., Bras. (MZUSP).

8. Acrochaeta fasciata. 1 \#m. Brasil, São Paulo, Ferraz de Vasconcelhos, 23³2’32,1”S 46²2’8,3”W, iv.1954, Barreto Reyes. (MZUSP).

9. Acrochaeta fasciata. 1 \#m. Brasil, São Paulo, Jundiaí, Serra do Japí, Trilha da Cachoeira do Paraíso-Riacho Paraíso, Malaise trap, 2314”S 4657”W, 25.ii-12.iii.2008, Lecci, L.S., Moretto, R.A. \& Nascimento, E.A. (MZUSP). 10. Acrochaeta fasciata. 1 \#m. Brasil, São Paulo, Ribeirão Grande, Pq. Est. Intervales - Barra Grande $24^{\circ} 15^{\prime} S$ 48¹0’W, Malaise - Ponto B1, 13-16.xii.2000, M.T. Tavares \& eq. col. (MZUSP).

11. Acrochaeta fasciata. 1 \#m. Brasil. São Luís do Paraitinga, P.E.S.M. - Núcleo Sta. Virgínia, 23¹9’27.1”S 4505’38.4” O, 21.i.2011, Malaise - Ponto 6 (teste), N.W. Perioto e eq. cols. (MZUSP).

12. Acrochaeta fasciata. 1 \#f. Brasil, Santa Catarina, Florianópolis, Ratones, sobre o afluente do Rio Ratones, Malaise trap I, 27³0’66”S, 48²9’22”W, 05.i-07.iii.2010, Pinho, L.C. leg. (MZUSP).

13. Acrochaeta longiventris. 1 \#m. Brasil, Rio de Janeiro, Itatiaia, Est. Biológica, 1000m, 5.xi.1931, W. Zikan. (MNRJ).

14. Acrochaeta longiventris. 1 \#m. Brasil, São Paulo, Campos do Jordão, Homem Morto, xii.1945, Barretto col. (MZUSP).

15. Acrochaeta longiventris. 1 \#f. Brasil, Santa Catarina, Nova Teutônia, i.1972, Fritz Plaumann. (MZUSP).

16. Acrochaeta longiventris. 1 \#f. Paraguai, Pirapó, 1-3.i.1972. (MZUSP).

17. Acrochaeta mexicana. 1 \#m. El Salvador, 1347’39,1”N 8853’47,5”W, 6.v.ii.1957, Salazar col., No 444-916. (USNM).

18. Acrochaeta mexicana. 1 \#m. Antígua e Barbuda, Antigua, 15.x.1976, E.S. Ross. (CAS).

19. Acrochaeta mexicana. 1 \#f. Costa Rica, Turrialba, 1006’34,1”N 8351’31,1”W, 15.vii.1965, Spangler, P.J. (USNM).

20. Acrochaeta picta. 1 \#m. Venezuela, Aragua Rancho, Parque Nacional Henry Pittier, 1100m, iii.4.1967, M.E. Irwin (CAS). 
21. Acrochaeta asapha sp.nov. Holótipo \#f (lâmina permanente). Brasil, São Paulo, Ribeirão Grande, Parque Estadual Intervales-Barra Grande, Malaise, 2405’52,5”S 48²2’17,5’W, 13-16.xii.2000, M. T. Tavares \& eq. cols. (MZUSP).

22. Acrochaeta balbii sp.nov. Holótipo \#m (lâmina permanente). Brasil, Rio de Janeiro, Nova Iguaçu, Reserva Biológica do Tinguá, 22³4’32”S 46²6’07”W, Malaise, 08-11.iii.2002, S. T. P. Amarante \& eq. cols. (MZUSP).

23. Acrochaeta boliviana sp.nov. Holótipo \#m. Bolívia, Cochabamba Prov., Villa Tunari, 1654’55”S 65²2’06”W, Malaise trap, 15.vii.2001, H. Haider leg. (CSCA).

24. Acrochaeta boliviana sp.nov. Parátipo \#f. Bolívia, Santa Cruz Dist., Potrerillos del Guedo, Preserva Natural, 370m, 17²40’S 6327’W, 1-4.x.2007, J. E. Wappes \& R. Morris; ex: BLI/MV. (CSCA).

25. Acrochaeta dichrostyla sp.nov. Holótipo \#m. Brasil, Rondônia, Monte Negro, Linha C25, Setor Chacareiro, 10¹6’21,4”S 63²0’45,4”W, Malaise trap 29, 10.ii-05.iv.2012, Lamas, Nihei \& eq. cols. (MZUSP).

26. Acrochaeta dichrostyla sp.nov. Parátipo \#f. Brasil, Rondônia, Campo Novo, Fazenda Amorim, 1040’6”S 63²9’0”W, Malaise trap 6 m, 06-10.xii.2011, Amorim, Ament \& Riccardi col. (MZUSP).

27. Acrochaeta polychaeta sp.nov. Holótipo \#m, Brasil, Rio de Janeiro, Nova Iguaçu, Reserva Biológica do Tinguá, 22³4’32”S 46²6’06, 6”W, 05-08.iii.2002, Malaise trap, Amarante, S. T. P. \& eq. cols. (MZUSP).

28. Acrochaeta polychaeta sp.nov. Parátipos: \#m, \#f. Brasil, São Paulo, Trilha dos Pilões, 23³9”S 4553’W, 611.xi.2010, 30.iii-02.iv.2001, Malaise trap, Amorim e Riccardi col. (MZUSP).

29. Acrochaeta pseudopolychaeta sp.nov. Holótipo \#m. Brasil, São Paulo, Salesópolis, Estação Biológica de Boracéia, 11.xi.1960, Lenko, K. col. (MZUSP).

30. Acrochaeta pseudopolychaeta sp.nov. Parátipo \#f. Brasil, São Paulo, Bocaina, iv.1924, Luedw. col. (MZUSP).

31. Acrochaeta rhombostyla sp.nov. Holótipo \#m. Brasil, Mato Grosso do Sul, Bodoquena, Serra da Bodoquena, Fazenda Califórnia, 2041’55,4”S 5652’49,4”W, Malaise trap 6, 06-21.ix.2011, Lamas, Nihei \& eq. col. (MZUSP).

32. Acrochaeta rhombostyla sp.nov. Parátipo \#f. BRASIL, Mato Grosso do Sul, Bodoquena, Fazenda Califórnia, 2041’49,9”S 5652’54,0”W, Malaise trap 4, 06-21.ix.2011, Lamas eq. col. (MZUSP).

33. Acrochaeta ruschii sp.nov. Parátipo \#m. Brasil, São Paulo, Sertãozinho, Reserva Biológica Augusto Ruschi, Fragmento 1 (interior), 21¹0,520’S 485,47’W, 529 m, Malaise trap, 27.x.-10.xi.2010, Silva, V. C., Donda, P. F. \& Ignácio. (MZUSP).

34. Acrochaeta ruschii sp.nov. Parátipo \#m. Brasil, São Paulo, Sertãozinho, Reserva Biológica Augusto Ruschi, Fragmento 1 (borda), 21¹0,520’S 485,47’W, 529 m, Malaise trap, 24.xi-08.xii.2010, Silva, V. C., Donda, P. F. \& Ignácio. (MZUSP).

35. Acrochaeta ruschii sp.nov. Parátipo \#f. Brasil, São Paulo, Sertãozinho, Reserva Biológica Augusto Ruschi, Fragmento 1 (interior), 21²10,520’S 485,47’W, 529 m, Malaise trap, 13-27.x.2010, Silva, V. C., Donda, P. F. \& Ignácio. (MZUSP).

36. Himantigera silvetris. Parátipo 2 \#m. México, Veracruz, 1100 ft. Catemaco, 16-18.vi.1969, W.R.M. Mason. (CNC).

37. Himantigera nigrifemorata. 1 \#m. México, Morelos, 12 Mi. E. Cuernavaca, 4300’, 14-viii.1954, J.G. Chillcott. (CNC).

38. Himantigera nigrifemorata. 1 \#f. México, Sinaloa, 15 Mi. W. El Palmito, 5000', 30.vii.1964, W.R.M. Mason. (CNC).

39. Merosargus akrei. 1 \#m. Panamá, Canal Zone, Barro Colorado Isl. 8.vi.1978, N.E. Woodley. (USNM).

40. Merosargus akrei. 1 \#f. Brasil, Rondônia, Cacaulândia, Trilha Cachoeira Jamari, 10¹3’26.8”S 63¹3’49”W, Malaise 27, 10.ii-20.v.2012, Lamas, Nihei \& eq. col. (MZUSP).

41. Merosargus albopictus. 1 \#m, 1 \#f. Perú, Madre de Dios, Rio Manu, 250 m, Pakitza, 127’S 7058’W, 923.ix.1988, Wayne N. Mathis, Malaise trap. (USNM).

42. Merosargus aurivena. 2 \#m. Panamá, Cerro Campana, 19.viii.1978, N.E. Woodley. (USNM). 
43. Merosargus aurivena. 1 \#f. Costa Rica, Limon 16 km W Guapiles, 400m, 1009’N 8355’W, vi-ix.1991, Malaise, P. Hanson (USNM).

44. Merosargus azureus. 2 \#m, 1 \#f. Brasil, Salesópolis, Boracéia, malaise 6, 6-11.xi.2010, D. Ament, D. Amorim, P. Riccardi col. (MZUSP).

45. Merosargus barbatus. 1 \#m. Panamá, Canal Zone, Barro Colorado Isl. 21.viii.1978, N.E. Woodley. (USNM).

46. Merosargus barbatus. 1 \#m. Costa Rica, Prov. Heredia, F. La Selva 3 km S Pto. Viejo, $10^{\circ} 26^{\prime} N^{\circ} 84^{\circ} 01^{\prime} W$, 15.iii.1980, H.A. Hespenheide. (USNM).

47. Merosargus barbatus. 1 \#f. Costa Rica, Alajuela, Prov., Penas Blancas, 7.vi.1987, Malaise trap, E. Cruz. (USNM) 48. Merosargus beameri. 1 \#m. Estados Unidos, Arizona, Cochise Co. Miller Canyon, 31²4’40”N 110¹6’52”W, 5600-6000 ft., 16.vii.2001, N.E.Woodley. (USNM).

49. Merosargus beameri. 1 \#m. Estados Unidos, Arizona, Cochise Co. Miller Canyon, 31²4’40”N 110¹6’52”W, 5600-6000 ft., 17.vii.2001, N.E.Woodley. (USNM).

50. Merosargus beameri. 1 \#f. Estados Unidos, Arizona, Cochise Co. Huachuca mts., 5354 Ash Cyn. Rd., 0.5 mi W Hwy 92 el 5100 ft., at UV light, N. McFarland, 20.vi.1992. (USNM).

51. Merosargus bivittatus. 1 \#m. Brasil, Bahia, Porto Seguro, Est. Ecol. Pau Brasil, 107m., 16²3’17,6”W 39¹0’55,6”W, 20.v.2002, Malaise, Bosque 1, C.O. Azevedo \& eq. col. (MZUSP).

52. Merosargus bivittatus. 1 \#m. Brasil, Bahia, Ilheús, Mata Esperança, Malaise - Beira do Rio, 15-21.v.2002. (MZUSP).

53. Merosargus bivittatus. 1 \#f. Brasil, Rio de Janeiro, Rio de Janeiro, Reserva Biológica do Tinguá, Moericke Bosque 1, 9-12.iii.2002, S.T.P. Amarante e eq. col. (MZUSP).

54. Merosargus cingulatus. 2 \# m, 1 \# f. Brasil, São Paulo, Matão, Mata Semidecídua, 21³7’40”S 48³2’15”W, Shannon, 26-30.xii.2008, V.C. Silva \& D.S. Amorim cols. (MZUSP).

55. Merosargus coriaceus. 1 \#m, 1 \#f. Guatemala, La Providencia. (USNM).

56. Merosargus convexifrons. 1 \#m. Costa Rica, Puntarenas, San Vito, Estación Biológica Las Alturas, 1500 meters, 857’N 8250’W, iv.1992, Malaise trap, P. Hanson. (USNM).

57. Merosargus convexifrons. 1 \#f. Costa Rica, Puntarenas, San Vito, Las Alturas, 857’ N 8250’W, 1500m, v.1992, Malaise trap, P. Hanson. (USNM).

58. Merosargus elatus. 1 \#m. Panamá, Canal Zone, Barro Colorado Isl. 7.vi.1978, N.E. Woodley. (USNM).

59. Merosargus elatus. 1 \#f. Panamá, Canal Zone, Barro Colorado Isl. 19.vi.1978, N.E. Woodley. (USNM).

60. Merosargus festivus. 1 \#m. Brasil, São Paulo, Salesópolis, Reserva Biológica Boracéia, Trilha dos Pilões, 23³9’05.1”S 4553’51.8”W, Malaise, 23-24.ii.2005 (18h00-06h00), L.K. Nogueira \& A.P. Aguiar. (MZUSP).

61. Merosargus festivus. 1 \#f, Brasil, São Paulo, Salesópolis, Reserva Biológica Trilha dos Pilões, 23³9’05.8”S 4553’44.6”W, 02-05.iv.2001, Malaise - Trilha 4, S.T.P. Amarante \& eq. col. (MZUSP).

62. Merosargus hyalopterus. 1 \#m. México, Veracruz, Fortin de las Flores, 2.v.1985, 952 m, A. Freidberg. (USNM). 63. Merosargus lampronotus. 1 \#m. Costa Rica, Puntarenas, 5 km W Piedras Blancas, 846’ N, 83¹7’W, 100 m, v.1992, Malaise, P.Hanson. (USNM).

64. Merosargus lampronotus. 1 \#f. Costa Rica, Puntarenas, 24 km W Pedras Blancas, 8²45’ $83^{\circ} 24^{\prime}$ W, 200m, ivv.1991, Malaise trap, P. Hanson. (USNM).

65. Merosargus mirabilis. 1 \#m, 1 \#f. México, Chiapas, El Triunfo (49 km S. Yaltenango), 13-15.v.1985, 1500 m, A. Freidberg. (USNM).

66. Merosargus nebulifer. 1 \#m. Brasil, Rio de Janeiro, Rio de Janeiro, Parque Estadual do Desengano, $3^{\text {a }}$ Malaise Bosque, 17-20.iv.2002 - Refugo. (MZUSP).

67. Merosargus nebulifer. 1 \#f. Brasil, Rondônia, Porto Velho, Rio Madeira, 9³8’5.6”S 65²7’11.2”W, Malaise 5a camp. T9 e T11, 05-17.i.2011, Silva \& Probst col. (MZUSP). 
68. Merosargus opaliger. 1 \#m. Brasil, Santa Catarina, Florianópolis (Ratones), (sobre afluente do Rio Ratones), 27³0’66”S 48²9’22”W, 05.i-07.iii.2010, Malaise I, L.C. Pinho leg. (MZUSP).

69. Merosargus opaliger. 1 \#m. Brasil, Minas Gerais, Botelhos, Córrego da Onça, 2140’50”S 46²2’05”W, Malaise - mata, 07.xii.2008-06.i.2009, João Basso col. (MZUSP).

70. Merosargus opaliger. 1 \#f. Brasil, Minas Gerais, Cabo Verde, Fazenda da Cata, 598m, 21²7’11.04”S 46²0’52.8”W, Malaise trap 1, 01-04.xi.2010, D.S. Amorim col. (MZUSP).

71. Merosargus obscurus. 1 \#m. Brasil, São Paulo, Salesópolis, Reserva Biológica Boracéia, Trilha dos Pilões, 23³9’02.9”S 4553’39”W, Malaise - Ponto 2 - trilha, 30.iii-02.iv.2001, S.T.P. Amarante \& eq. col. (MZUSP).

72. Merosargus obscurus. 1 \#f. Brasil, São Paulo, Salesópolis, Reserva Biológica Boracéia, Trilha dos Pilões, 23³9’05.1”S 4553’51.8”W, Malaise, 22.ii.2005 (17h00-18h00), L.K. Nogueira \& A.P. Aguiar. (MZUSP).

73. Merosargus taeniatus. 1 \#m, Brasil, Pernambuco, Recife, Parque dos Dois Irmãos, Malaise - Trilha Ponto 5, 2023.vii.2002, S.T.P. Amarante \& eq. col. (MZUSP).

74. Merosargus taeniatus, 1 \#f. Brasil, São Paulo, Peruíbe, Estação Ecol. Juréia-Itatins, 24³1’06”S 47¹2’06”W, Malaise 8 - Bosque, 3.v.2002, N.W. Perioto \& eq. col. (MZUSP).

75. Merosargus sp.nov. 1. Holótipo \#f, Bolívia, Province La Paz, Cumbre Alto Beni, Vicinity of Caranavi, 1685m, 1540’19”S 67²9’35”W, Malaise trap, 15-21.iv.2004, S. D. Gaimari \& M. Hauser. (CSCA).

76. Merosargus sp.nov. 2. Holótipo \#f. Brasil, Rondônia, Cacaulândia, Sítio do Cabeça, 10¹7’56,5”S 63¹4’12”W, Malaise trap 25, 10.ii-05.iv.2012, Lamas, Nihei \& eq. cols. (MZUSP).

77. Merosargus sp.nov. 3. Parátipos 1 \#m, 1 \#f, Brasil, Goiás, Corumbá, F. Monjolinho, xi.1945, Barretto col. (MZUSP).

78. Ptecticus lanei. 1 \#m. Brasil, Minas Gerais, Botelhos, Córrego da Onça, 2140’50”S 46²2’05”W, Malaise mata, 07.xii.2008-06.i.2009, João Basso col. (MZUSP).

79. Ptecticus lanei. 1 \#m. Brasil, Espírito Santo, Santa Teresa, Est. Biol. Santa Lucia, 867m, 1958’37.3”S 40³2’22.5”W, 06-09.iv.2001, Malaise - Ponto 1 Bosque, C.O. Azevedo \& equipe col. (MZUSP).

80. Ptecticus lanei. 1 \#f. Brasil, Minas Gerais, Cabo Verde, Fazenda da Cata, 598m, 21²7’11.04”S 46²0’52.8”W, Malaise - Barranco, 14.vii.2011-04.i.2012, Amorim \& Oliveira col. (MZUSP).

81. Ptecticus testaceus. 1 \#m. Brasil, Minas Gerais, Presidente Olegário, Fazenda Gigante, 18³1’S 468’W, 1000m, Shannon, 02-09.i.2010, Ribeiro, Amorim, Silva e Berbert. (MZUSP).

82. Ptecticus testaceus. 1 \#m. Brasil, Espírito Santo, Santa Teresa, Est. Biol. Santa Lucia, 867m, 1958’37.3”S 40³2’22.5’W, 06-09.iv.2001, Malaise - Ponto 1 Bosque, C.O. Azevedo \& equipe col. (MZUSP).

83. Ptecticus testaceus. 1 \#f, Brasil, São Paulo, Descalvado, Fazenda Itaúna, Moericke - citrus A3, 26.ii.2007, Periotto, N. (MZUSP).

84. Ptecticus testaceus. 1 \#f, Brasil, Bahia, Porto Seguro, Est. Ecol. Pau Brasil - 107m, 16²3’17.6”S 39¹0’55.6”W, 20.v.2002, Malaise - Bosque 1, C.O. Azevedo \& eq. col. (MZUSP).

85. Sargus fasciatus. 1 \#m, Brasil, Mato Grosso, Nova Mutum, Fazenda Buriti, 17.i.2000, H.F. Menezes col. (MZUSP).

86. Sargus fasciatus. 1 \#f, Brasil, São Paulo, Ribeirão Preto, 19.x.1995, Oliveira, A. (MZUSP).

87. Sargus thoracicus. 1 \#m. Brasil, São Paulo, Sertãozinho, Res. Biol. Augusto Ruschi, Malaise, Fragmento 2 (interior), 09-22.xi.2010, V.C. Silva, P.F. Donda \& G. Ignácio. (MZUSP).

88. Sargus thoracicus. 1 \#f, Brasil, Rio de Janeiro, Rio de Janeiro, Parque Estadual do Desengano, $21^{\circ} 50^{\prime} \mathrm{S} 41^{\circ} 40^{\prime} \mathrm{W}$, $1^{\text {a }}$ Malaise - Bosque, 17-20.iv.2002 - Refugo. (MZUSP). 